\title{
Conversion to Evangelical Christianity during College: An Interpretative Phenomenological Analysis
}

\author{
Meagan Alicia Brunson
}

Follow this and additional works at: https://researchrepository.wvu.edu/etd

\section{Recommended Citation}

Brunson, Meagan Alicia, "Conversion to Evangelical Christianity during College: An Interpretative Phenomenological Analysis" (2016). Graduate Theses, Dissertations, and Problem Reports. 5274.

https://researchrepository.wvu.edu/etd/5274

This Dissertation is protected by copyright and/or related rights. It has been brought to you by the The Research Repository @ WVU with permission from the rights-holder(s). You are free to use this Dissertation in any way that is permitted by the copyright and related rights legislation that applies to your use. For other uses you must obtain permission from the rights-holder(s) directly, unless additional rights are indicated by a Creative Commons license in the record and/ or on the work itself. This Dissertation has been accepted for inclusion in WVU Graduate Theses, Dissertations, and Problem Reports collection by an authorized administrator of The Research Repository @ WVU.

For more information, please contact researchrepository@mail.wvu.edu. 


\title{
Conversion to Evangelical Christianity during College: An Interpretative
} Phenomenological Analysis

\author{
Meagan Alicia Brunson \\ Dissertation submitted to the \\ College of Education and Human Services \\ at West Virginia University \\ in partial fulfillment of the requirements for the degree of
}

Doctor of Philosophy in

Counseling Psychology

Jeffrey Daniels, Ph.D.

Ian Kellems, Ph.D.

Monica Leppma, Ph.D.

Carol Markstrom, Ph.D.

Jennifer Taylor, Ph.D.

Department of Counseling, Rehabilitation Counseling, and Counseling Psychology

Morgantown, West Virginia

2016

Keywords: Religion, spirituality, conversion, convert, college, distress, well-being Copyright 2016 Meagan Alicia Brunson 


\section{ABSTRACT \\ Conversion to Evangelical Christianity during College: An Interpretative Phenomenological Analysis}

\section{Meagan A. Brunson}

Psychology has a history of ignoring and pathologizing spiritual experiences. Many of the fathers of early psychology including Freud, Ellis, and Skinner modeled this trend. However, with the increasing awareness of the importance of multicultural factors as they relate to mental health, religion and spirituality have gained recognition in the professional literature. Research on religion and spirituality and college students has mainly consisted of survey studies collecting demographic data. The current study uses a qualitative research design to explore the experiences of college students who converted to Christianity during college. The guiding questions of this research pertain mainly to the psychological and existential effects of converting as they contribute to both well-being and distress. Nine college students who converted to Christianity during college were interviewed using a semi-structured interview, and the results were analyzed using interpretative phenomenological analysis (IPA).

Interpretative phenomenological analysis, like many qualitative methodologies, attempts to understand themes across the data. However, IPA emphasizes interpreting the data with an objective to understand the respondent's psychological world (Smith \& Osborn, 2003). Using this methodology, the first case transcript was read a number of times and significant impressions were noted in the left-hand margin. The next phase of analysis involves using the right-hand margin to denote emerging themes. Themes were organized into superordinate concepts and subordinate themes. Directories of these concepts and themes were created and corresponding quotes from each transcript were identified. The final stage is a narrative description of each theme which comprises the results section of this dissertation.

Participants reported rich information regarding their perceptions of their conversion experiences. Results were organized into ten superordinate concepts and 45 subordinate themes. The ten superordinate concepts are (a) Previous Exposure to Religion/Spirituality which pertained to participant's exposure to religious and spirituality prior to converting; (b) Unique to College consisting of statements about the unique developmental and cultural experiences in college which fostered participant's decision to convert; (c) Questioning God relating to questions and doubts about God which participant's expressed before and after their conversion; (d) God is Omnipresent and Sovereign consisting of statements about the ever-present and allknowing nature of God; (e) Positive Emotional Experiences which included descriptions of elevated emotions including happiness and love experienced during conversion; (f) Openness pertaining to openness toward God and toward other on behalf of participants; (g) Existential Meaning which included statements about experiencing new-found purpose and meaning in life after converting; (h) Challenging Emotional Experiences- Prior to Converting including statements pertaining to experiencing distressing emotions such as hardship and confusion prior to converting; (i) Challenging Emotional Experiences-After Converting referring to statements about distressing emotions including guilt and shame after converting; and (j) Supports related to statements about interacting with familial and social supports during the time of converting. Finally, a discussion of implications, limitations, strengths and directions for future research are presented. 


\section{DEDICATIONS}

To Jesus Christ, my Lord and Savior, through whom all things are possible.

To my husband, Neil, whose love and humor refresh me daily.

To my parents, Gary and Rose Rowell, who encourage me in all my endeavors.

To my Advisor and Chair, Dr. Jeffrey Daniels, who fostered my interest in qualitative research.

To Drs. Kellems, Leppma, Markstrom, and Taylor for their support and guidance with this dissertation.

To Dr. Randall Reed who audited this study and invested in research across disciplines. To the participants for their time and for sharing their personal conversion experiences 


\section{Table of Contents}

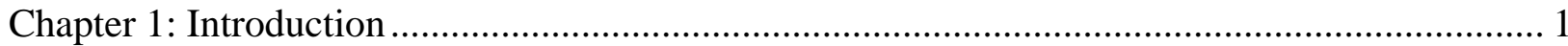

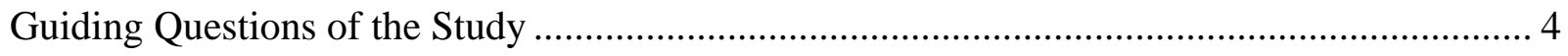

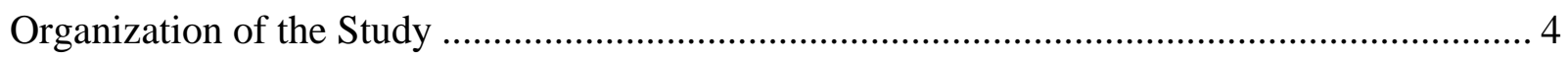

Review of the Literature.............................................................................................. 5

Recommendations for Further Research ....................................................................... 39

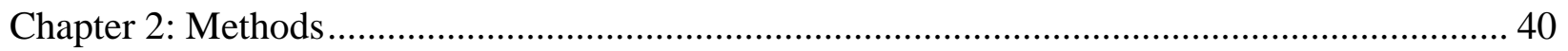

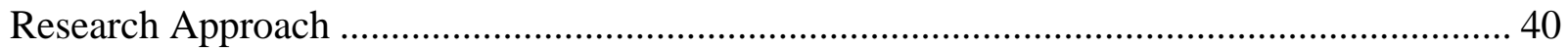

Interpretative Phenomenological Analysis................................................................ 40

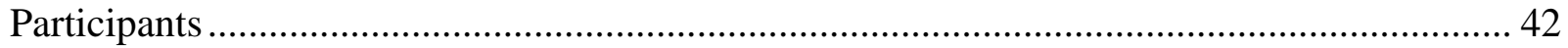

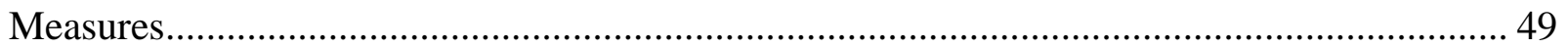

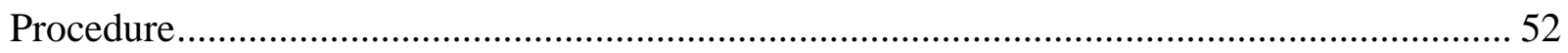

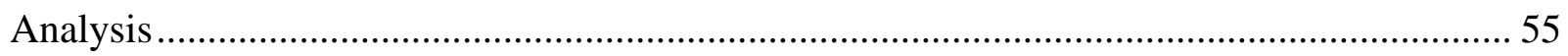

Quality and Trustworthiness of the Research ............................................................ 59

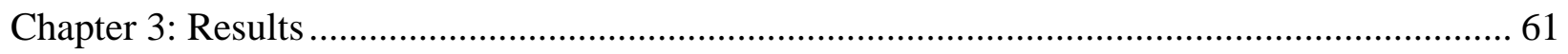

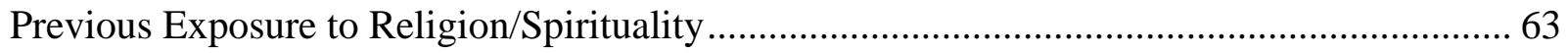

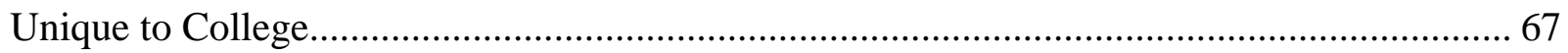

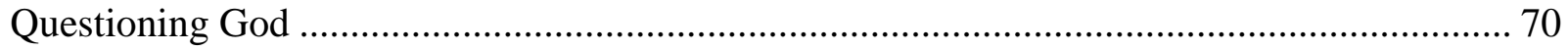

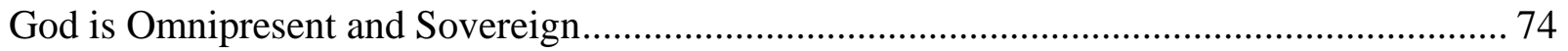

Positive Emotional Experiences.............................................................................. 77

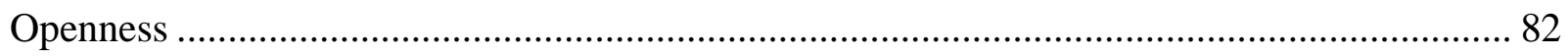

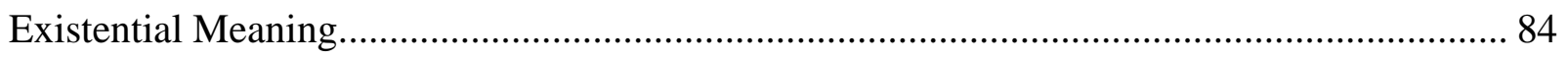

Challenging Emotional Experiences- Prior to Converting............................................... 86

Challenging Emotional Experiences- After Converting .................................................. 88

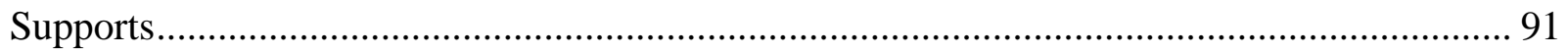




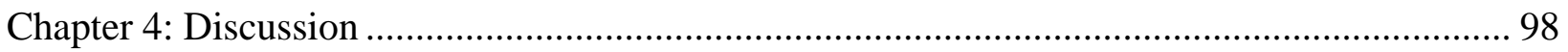

Summary and Interpretation of the Findings............................................................................. 99

Perceptions of Conversion Experience................................................................................... 99

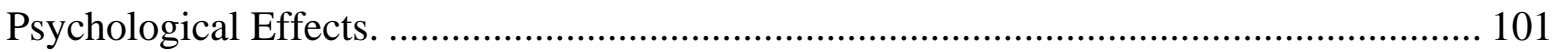

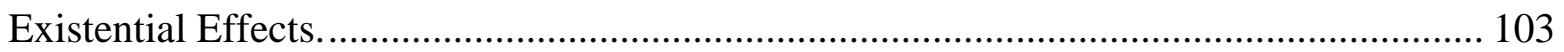

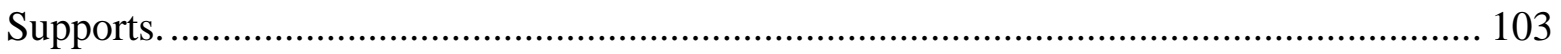

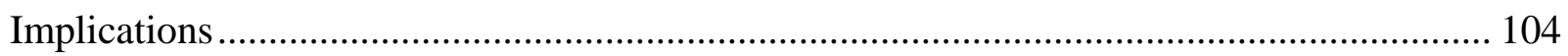

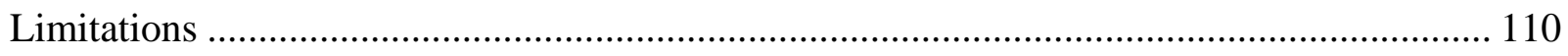

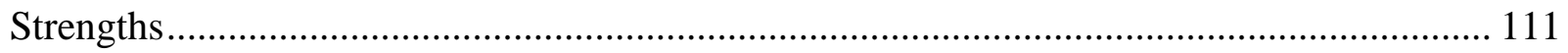

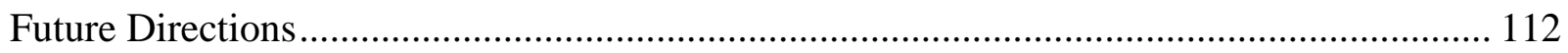

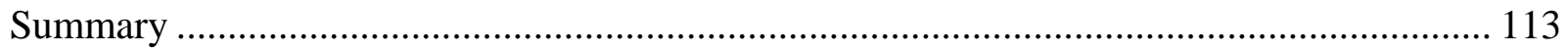

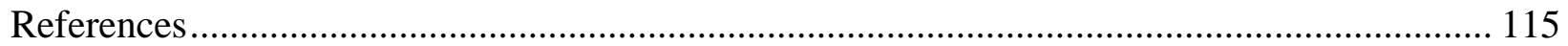

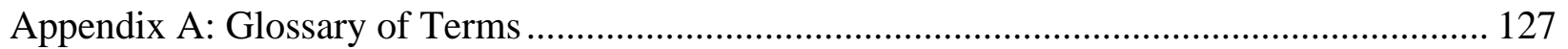

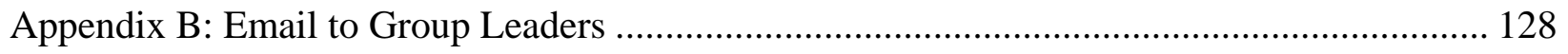

Appendix C: Verbal Script for Recruitment ………………................................................... 129

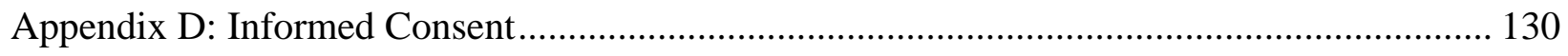

Appendix E: Cover Letter...................................................................................................... 132

Appendix F: Research Study Information Sheet ………............................................................. 133

Appendix G: Demographic Form .................................................................................. 134

Appendix H: Interview Protocol .......................................................................................... 136

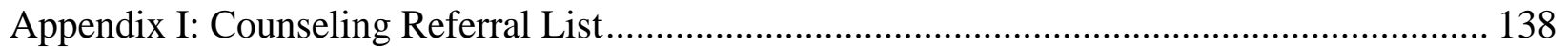

Appendix J: Theme Directory Charts by Case ……....................................................................... 139

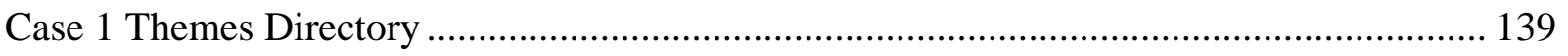

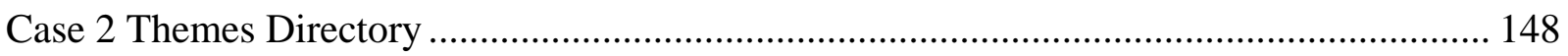

Case 3 Themes Directory ………………………………........................................... 156 


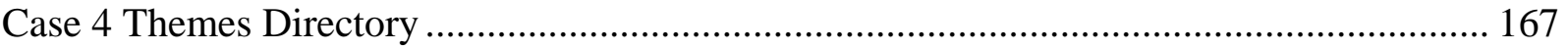

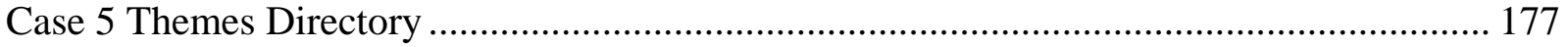

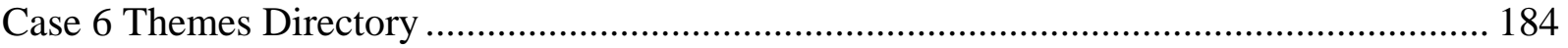

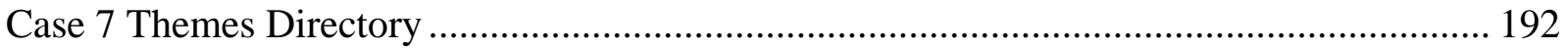

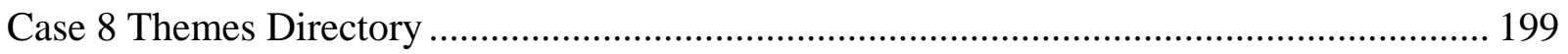

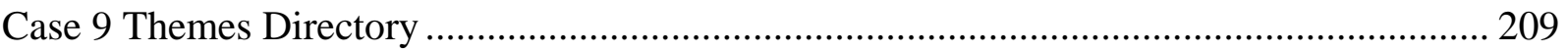




\section{Chapter 1}

\section{Introduction}

Despite the narrowly defined population served by college counseling centers, the array of clients with diverse needs and presentations treated at these centers is great (Kitzrow, 2003). In all settings, including college counseling centers, therapist's aim is to lessen psychological distress and increase human functioning, such as well-being (Ryff, 1989). If determinations can be made about factors influencing both well-being and distress among college students, college counseling center therapists may be better able to assist students during this potentially turbulent developmental period (Towbes \& Cohen, 1996). One factor associated with well-being is the presence of life-meaning through the engagement of religion and/or spirituality (Frankl, 1992).

A Gallup International Association (2012) survey, representing a population of approximately 1.25 billion people across 57 countries, found that of the over 51,000 respondents, $59 \%$ self-identified as religious, $23 \%$ identified as "not religious" and $13 \%$ indicated they were atheists. This survey indicates that religion and/or spirituality play a central role in lives of a majority of people around the world. Moreover, the United States is one of the most religious nations among developed nations with 60\% identified as religious (Gallup International Association, 2012). Adolescents, similar to adults in the United States, overwhelmingly affiliate with a religious group (84\% - 87\%; King \& Roeser, 2009). The high prevalence of religious and spiritual engagement around the world and the growing evidence that religious and spiritual engagement positively correlates with wellness are great reasons for the scientific study of religion and spirituality. Miller and Thoresen (2003) highlighted that the process involved in this positive link between religion/spirituality and wellness are not well known and thus the scientific 
study of religion and spirituality is a worthy research frontier and one that has large public interest.

In 1980, Bergin wrote an influential article in which he criticized the profession of psychology for its long-standing negative bias against religion (Richards, 1991). Bergin pointed out the potential therapeutic effects associated with religious engagement and he encouraged psychologists to be more open to the benefits of religion. Ellis (1980), in response to Bergin, argued that therapeutic solutions to emotional problems should be unreligious, as the more unreligious an individual, the healthier he or she will tend to be. He further argued that there is a significant correlation between being religiously devout, orthodox or dogmatic and experiencing emotional disturbance. While research and publications related to the psychology of religion gained some momentum in the last thirty years and beneficial outcomes are documented, potential adverse effects of religious and spiritual engagement are also highlighted in the psychology literature. Miller and Thoresen (2003) stated that these adverse effects are often based in anecdotal evidence such as religious persons experiencing guilt, depression, anxiety, intolerance, and cognitive inflexibility. They also explained that news stories of including sexual abuse by clergymen, parents’ refusal to access medical help for a child based on religious beliefs, and cult related violence, may bias the psychological opinion of religious engagement and its effects on wellness. Research on religion and spirituality effects should seek to expose both positive and negative effects on participating individuals (Miller \& Thoresen, 2003). The researcher in the current study seeks to explore both positive and negative effects experienced during one's conversion during college. The lag in psychology research on religious and spiritual issues is greater within literature specific to children and adolescents. 
Benson, Roehlkepartain, and Rude (2003) conducted a frequency review of this topic within the top developmental journals (Child Development, Developmental Psychology, International Journal of Behavioral Development, Journal of Adolescent Research, Journal of Early Adolescence, and Journal of Research on Adolescence) and from 1990 to July 2002 only 27 out of 3,123 (0.9\%) total articles referenced the key words "religion," "religious development," "spirituality," or "spiritual development." King and Roeser (2009) conducted a follow up frequency analysis using the same journals and key words from August 2002 to January 2008 and found 20 of the 1530 published articles (1.3\%) pertained to religion and spirituality. While there is limited focus in the literature on spiritual and religious development among young people, there is an increase in interest in the topic. According to the Society for Research on Adolescence, the development of spiritual and religious values and identities during adolescence is an area in need of research world-wide (King \& Roeser, 2009). College students are of particular interest in the current study and while a lot of social science research is conducted using college student samples (Peterson, 2001), there is much to learn about religious and spiritual transition during the college years.

The college years are unique in that most adolescents move away from home for the first time. This time of transition is often instrumental in establishing life patterns and life-meaning that will influence the student well after graduation and through adulthood (Arnett, 2000;

Schulenberg, Sameroff, \& Cicchetti, 2004). Recent studies show that while religious engagement may decline among college students, there is an increase in interest and engagement of spirituality during the college years (Bryant, Choi \& Yasuno, 2003; Mayrl \& Oeur, 2009). Much of the current literature on the influence of religion and spirituality on emotional well-being is mixed, and the channels through which religion and spirituality have an influence on personal 
outcomes are unknown (Miller \& Thoresen, 2003; Mayrl \& Oeur, 2009). The current study sought to determine factors related to well-being and distress among college students converting to religion/spirituality, specifically to evangelical Christianity. Furthermore, the researcher explored the existential and psychological experiences of college students who converted to evangelical Christianity, after a time of little to no faith, using a qualitative methodology. The findings are expected to help college counseling center clinicians better understand the potential needs as well as protective factors of students converting to evangelical Christianity.

\section{Guiding Questions of the Study}

In light of the purpose discussed above, the current study is guided by the following questions:

1. How do individuals who have converted to evangelical Christianity during the college years perceive their conversion experience?

2. What psychological effects, if any, does the conversion to evangelical Christianity have on college students?

3. What existential effects, if any, does the conversion to evangelical Christianity have on college students?

4. How does the conversion to evangelical Christianity contribute to both well-being and distress during college?

5. From whom do individuals seek support and counsel during the conversion experience and what qualifies these individuals as helpful supporters?

\section{Organization of the Study}

A review of relevant literature is presented below. The initial literature reviewed highlights the unique college age population under investigation. Further literature is presented 
on the variables of interest including psychological factors that may be affected by religion and spirituality, existential factors to include purpose and life-meaning, and religion and spirituality, and evangelical Christianity specifically. After a thorough review of the literature, Chapter 2 comprises a detailed outline of the proposed research design, participants, and procedures using a semi-structured interview and the qualitative analysis method Interpretative Phenomenological Analysis. The results and discussion of the research findings make up the third and fourth chapters respectively.

\section{Review of the Literature}

College age development. Erikson’s psychosocial theory (1950) is reviewed because Erikson addressed identity formation relative to religion. His adolescent and young adult stages of development provide insight into the unique developmental milestones of college students. Additionally, a review of Arnett's (2000) theory of emerging adulthood provides a framework from which to understand college student development as individuals at this time in their lives transition from adolescence to adulthood.

Psychosocial stages of development. Erik Erikson's (1950) stages of psychosocial development are widely known and accepted parameters from which to understand and gauge developmental growth. Two conflicting biological and sociocultural forces define each stage in Erikson's model. In order for an individual to pass through each developmental stage, he/she must successfully reconcile the developmental psychosocial crisis at hand (Crain, 2011). Traditional college students are between the ages of 18 and 21, with some students being younger or older. The two stages of Erikson's psychosocial development model that span across these ages are Adolescence, characterized by Identity versus Role Confusion forces, and Young Adulthood, characterized by Intimacy versus Isolation forces. Erikson highlighted the role of 
religion and spirituality in development, particularly during adolescence. He theorized that adolescents develop a sense of identity by recycling through and reworking prior developmental tasks from infancy, toddlerhood, and childhood. The reworking and resolution of these developmental tasks make provisions for adolescents to develop hope, autonomy, identity, and potentially faith. For Erikson, as well as for Fowler (whose faith development model is discussed below), religion was understood to be a source of support that validates an individual's hopes throughout his or her life span (King \& Roeser, 2009). Markstrom (1999) provided a summary of Erikson's psychosocial perspective on religiosity in adolescent development. She stated that for Erikson, religion serves the adolescent during his or her unique development in that it offers answers to complex existential questions, it enriches one's sense of purpose in life, and finally, the rituals, faith, and affirmative dogma of religion promote belongingness. Moreover, religion is an institution that facilitates trust and hope which in turn help promote the ego strengths fidelity and faith (Markstrom, 1999). Adolescence is thought to take place between the ages of 13 and 18 years old whereas the Young Adult stage takes place as early as 19 years old through as late as 49 years old, though these age divisions between developmental stages are not meant to be prescriptive. Therefore, college students may remain in the adolescent stage past the age of 18 or may transition from one stage to another during the college years.

Erikson (1968) indicated that some individuals, particularly those in industrialized cultures, may engage in a prolonged adolescence or a psychosocial moratorium. He described this time as one in which young adults explore new roles and consequently find a calling or individualized function within society (Erikson, 1968). Arnett (2000) argued that Erikson’s observation of prolonged adolescence is supportive of his own conceptualization of a new 
theoretical developmental period: emerging adulthood. However, Arnett explained that this developmental period has changed significantly in the decades since Erikson's writings.

Emerging adulthood. Arnett (2000) formulated a theory of a developmental period for individuals ages 18-25 years. The current study explored the effects of conversion on individuals who are expected to be between the ages of 18-25 years of age. Moreover, the study took place in the United States, an industrialized country, and in a higher education setting wherein occupational and relational roles may be put off until after graduation. For these reasons, Arnett's theory of emerging adulthood provides a relevant framework from which to conceptualize the study's population of interest. Emerging adulthood is a unique period of development existing only in cultures that allow for a prolonged period of exploration of independent roles during the late teens and early twenties. Arnett highlighted that in industrialized countries the emerging adulthood period is one of profound change and importance. A majority of individuals during this time engage in higher education, choose an occupation, and develop their worldview. Moreover, many of the choices made during this stage of life have enduring ramifications. A demographic shift in the age at which individuals marry and have their first child as well as an increasing number of individuals attending institutions of higher education has elongated the developmental period between adolescence and adulthood. Arnett explained that because individuals are not settling into occupational, marital or parental roles during the late teens and early twenties, as they were half a century ago, emerging adulthood represents a distinct developmental stage relevant in industrialized communities. For purposes of the current study, research pertaining to religion and spirituality among adults, adolescents, and college students is relevant and is discussed in the literature review, as 
individuals in the emerging adult stage may be more or less similar to any of these developmental age groups.

An individual in emerging adulthood is at a distinct time in life between the dependency of childhood and adolescence but not yet to the responsibilities that are normative in adulthood. Emerging adults are able to explore a multitude of life directions with regard to love, work, and worldviews. However, because this stage, like that of adolescence, according to Arnett (2000), is socially and culturally constructed, some individuals may be limited or restricted during this age period and may not be able to engage in the exploration of independence described above. The emerging adulthood developmental period is demographically defined by diversity. Arnett explained that there are few normative demographics which classify emerging adults and the differences among the groups members is a consequence of the experimental and exploratory nature of this developmental period.

Changes in residential status occur in emerging adulthood more than any other developmental time (Arnett, 2000). Moreover, Arnett explained that academic engagement varies across this group. Some emerging adults remain at home, others move to higher education institutions, while others become fully independent and work fulltime jobs. The current research is focused on emerging adults in the college and university context. College provides an environment for identity exploration, one of the distinct features of the emerging adulthood stage of development. Arnett (2000) explained, that when entering college, many emerging adults maintain a worldview which they acquired during their childhood and adolescence. College education provides exposure to varied worldviews and often leads to an emerging adult questioning his or her worldview. Arnett further stated that over the course of college, emerging adults often adopt worldviews different from those maintained earlier in life, while maintaining 
an openness to further modifying their worldviews. Specific to religious beliefs, emerging adults in varied settings tend to value an exploration, reconsideration, and solidification of their own independent worldviews. This process of exploration may not always be experienced as positive. Examining and restructuring one's beliefs may result in rejecting previously held beliefs and possibly feelings of isolation from peers and family (Arnett, 2000). The transition during the late adolescent and early adult years, which takes place across multiple domains, may in itself cause distress.

Specific to the current study, the college years are a critical time when an individual may search for meaning in life and evaluate his or her spiritual and religious beliefs and values (Bryant et al., 2003). The purpose of the current study is to explore how college students experience and create meaning around the conversion to faith during college. Transition and change in general affect individuals differently. One such reaction to transition may be psychological in nature. Psychological well-being and psychological distress may be a component of the lived experiences of college students during conversion to faith. Additionally, the college years may be marked by reflections on faith and life's purpose and meaning as students encounter questions related to suffering, evil and death, and thus these experiences may be more existential in nature (Bryant \& Astin, 2008). Psychological well-being and distress as well as existential well-being and distress are discussed in detail below.

Psychological factors. Research points to a number of factors that contribute to psychological well-being and distress. A review of these factors follows.

Psychological well-being. Ryff (1989) set out to operationalize a definition of psychological well-being. In doing so, she came up with six theory-guided dimensions of wellbeing: self-acceptance, positive relations with others, autonomy, environmental mastery, purpose 
in life, and personal growth. Ryff reinforced the idea that life-meaning is a major component of psychological well-being. In fact it is proposed that purpose and meaning in life are antecedents for psychological well-being, though the development of purpose and meaning may require discipline and hard work which may stifle short-term happiness. According to Ryff, emotional happiness alone is not a good predictor of psychological well-being. Life meaning and purpose in life are discussed in detail below as they relate to both existential and psychological wellbeing. Subjective well-being is another term used throughout the psychological research and includes the emotional responses, domain satisfactions, and judgments of life satisfaction. Factors such as personality, culture, temperament, cognitions, goals, and coping abilities moderate the influence of life events on one’s subjective well-being (Diener, Suh, Lucas, \& Smith, 1999). Diener et al. (1999) also discussed how religion may influence subjective wellbeing; a review of their discussion is provided later in this literature review.

Psychological distress. Ridner (2004) conducted a concept analysis of the term psychological distress in order to provide greater specificity and facilitate the ability for clinicians to identify psychological distress over other types of distress. She provided a working definition of psychological distress as a distinctive emotional state characterized by discomfort which is caused by a specific stressor. According to Ridner, the consequence of stress is harm to the person; harm which can be either temporary or permanent. She also described antecedents which may lead to psychological distress as well as consequences of psychological distress. Antecedents include first being a living and conscious biopsychosocial being capable of experiencing psychological distress. Second, a stressor must be present. In the case of the current study it is anticipated that spiritual transition or spiritual struggle, or any upheaval caused by the conversion to faith, may serve as that stressor. Perception on the part of the individual that the 
stressor is a personal threat and a perceived or actual loss of control are the third and fourth required antecedents for psychological distress. Finally, ineffective coping leads to psychological distress. This final antecedent demonstrates a likely path leading one to seek counsel or support for psychological distress. Consequences of psychological distress are not all negative as one might expect. Ridner described potential consequences as falling on a continuum from negative to positive. Some of the most extreme negative consequences of psychological distress include suicide and heart attack, but on the other end of the spectrum is personal growth. Ridner referenced Victor Frankl (1986), who explained that even when faced with immense psychological distress, one is resiliently capable of discovering meaning, working toward a purpose, and accomplishing personal goals. The unique ability for an individual to experience psychological distress whilst developing life-meaning and realizing personal values is of paramount interest in the current study. College students converting to religion or spirituality may experience a combination of positive and negative consequences; or a combination of wellbeing and distress across different domains.

Ridner (2004) investigated the use of the term "psychological distress” across the literature and highlighted research integral in developing a definition for the term. Ridner highlighted work by Masseé (2000) who set out to study, both qualitatively and quantitatively, psychological distress among French Québécois individuals and create a culturally sensitive measure of psychological distress. The phenomenological qualitative study led to an identification of six expressions of distress: (a) demoralization and pessimism toward the future; (b) anguish and stress; (c) self-depreciation; (e) social withdrawal and isolation; (f) somatization; and (g) withdrawal unto oneself. Masseé developed a quantitative measure of psychological distress called The Psychological Distress Manifestation Measurement Scale; however, he 
highlighted the drawbacks of studying psychological distress quantitatively as operationalizing the term removes insight into the lived experiences of individuals experiencing the phenomenon. Thus, Masseé concluded that the use of quantitative measurements alone to measure distress decontextualizes the concept into symptoms and while these symptom lists serve as good predictive tools they are not sufficient investigative tools. The study of psychological distress is better served by an understanding of the lived experiences of individuals and this context will help clinicians understand the mental and social suffering associated with distress (Masseé, 2000). This highlights the benefit of using qualitative, and more specifically phenomenological qualitative research, to help answer the questions posed in the current research study. Both psychological well-being and psychological distress could potentially develop as a result of conversion to religion and spirituality and are therefore key components under investigation in the current study. Another construct which is believed to be influenced by a conversion to religion is one's existential well-being. An overview of existentialism and phenomenology is provided followed by a review of well-being and distress as these constructs relate to existentialism specifically.

Existentialism. Existentialism became popular in Europe in the 1940s and 1950s. World War II, the deadliest military conflict in history, made apparent for the entire world the finite nature of human existence. It was in the aftermath of this war the existentialists sought to answer questions such as Why do we exist? and Is life meaningful? (Prochaska \& Norcross, 2010). Prochaska and Norcross explained that existentialism goes beyond the physical understandings of nature and physics to explore human existence. Søren Kierkegaard and Friedrick Nietzsche were some of the earliest contributors to existential philosophy. Kierkegaard emphasized human 
responsibility to give life meaning and to live a meaningful life with passion and sincerity (Crowell, 2004).

Existentialism developed out of the philosophical movement known as phenomenology (Crowell, 2004). Phenomenology is the study of human consciousness from the subjective first person perspective. Phenomenology was first conceptualized by Edmond Husserl in the early twentieth century and encompasses a vast array of topics related to human consciousness and the human perception of experiences. Life-meaning development is an internal and personal endeavor. One’s perceptions and experiences as well as his or her conscious reality are the chief influence in meaning development. Life-meaning is measured according to one's perceived level of meaning, as it is impossible to objectively explain these constructs (Smith, 2003). Also according to Smith (2003), how one understands or conceptualizes a particular object defines the meaning of that object in the individuals' current experience. Phenomenology is thus a study of meaning, which is broader than what is expressed in language and includes the unique perspective of the perceiving individual. The influence of phenomenology on philosophy and psychology is extensive (Smith, 2003). Phenomenology and existentialism both regard subjective experience and consciousness (Crowell, 2004; Smith, 2003). Existentialism more narrowly is interested in ontology over epistemology and takes into consideration the living, thinking, acting being which is experiencing a given phenomenon (Crowell, 2004).

Existential well-being. Adolescence, with its characteristic changes in thinking and feeling, is a prime time for young people to be exposed to, and engaged in, dialogue about ideas and philosophies bearing on ultimate existential questions of identity, purpose, and meaning (King \& Roeser, 2009). Existential well-being is often associated with a sense of purpose and meaning in life, or a sense of thriving. In order to thrive, one must exist in a world wherein his or 
her needs are met. Maslow’s (1943) Hierarchy of Needs provides a hierarchical model of human needs progressing through basic or deficiency needs to more secondary higher order needs. Maslow revised his theory in 1969 adding self-transcendence as the highest level of human need. This addition to his hierarchy has been widely neglected in psychological literature, specifically text books (Koltko-Rivera, 2006). Maslow was not the only one to recognize the human need of self-transcendence during this era. Viktor Frankl's (1992) greatest contribution in psychology was his emphasis on the development of purpose and meaning. Frankl highlighted the integral role that self-transcendence plays in the meaning making process (Garcia-Romeu, 2010). Frankl's and Maslow's theories of meaning-in-life and motivational needs, therefore, converge. Maslow’s (1943) Hierarchy of Needs defines an individual’s worldview and perceptions. Worldview, thus, encompasses the notion of meaning in life (Garcia-Romeu, 2010). GarciaRomeu explained that attending to the self-transcendence step in Maslow's hierarchy allows psychologists to more richly interpret meaning in life. The self-transcendence construct also lends itself well to conceptualizing human needs and motivation across multicultural domains, specifically religious and spiritual domains (Koltko-Rivera, 2006). Two components of existential well-being associated with religious and spiritual engagement are life-meaning and purpose in life (Frankl, 1992).

Life-meaning. One factor associated with well-being is the presence of life-meaning. Perceived life-meaning is positively associated with lower levels of negative functioning and higher levels of well-being (Stillman et al., 2009; Zika \& Chamberlain, 1992). Furthermore, a sense of meaningfulness is a critical human need (Frankl, 1992; Steger, Oishi, \& Kesebir, 2011). Life-meaning is the way in which one makes sense of his or her existence (Stillman et al., 2009). Furthermore, personal meaning, as defined by Reker and Wong (1988), is the awareness of 
order, consistency and purpose in one’s own existence, the establishment and actualization of worthwhile goals, and an overall sense of fulfillment. According to Viktor Frankl (1992), there are no circumstances in which life loses meaning. Intense and unavoidable suffering can exist along with meaningfulness. Development of life-meaning requires a personal assimilation of one’s life experiences, and meaning is unique for every person (Melton \& Schulenberg, 2008). Simply what happens in life is not meaning, rather it is what one decides is meaningful that gives meaningfulness to life (Melton \& Schulenberg, 2008). There are multiple conceptualizations of life-meaning, each consisting of different defining components. On example is Baumeister (1991) who postulated that meaning of life meets four basic human needs: purpose, efficacy or control, value and justification, and self-worth. From these conceptualizations, it is apparent that purpose in life and life-meaning are closely related.

Purpose in life. Life purpose is the intentionality of life-meaning (Ryff, 1989). Thus, purpose puts meaning into action and involves the setting and acquisition of life goals. Moreover, life purpose provides aim, direction, and objections for living (Ryff, 1989). Damon, Memom and Cotton Bronk’s (2003) definition of purpose contains a transpersonal dimension. They purported that purpose is an unwavering and encompassing intention to achieve something that not only has personal meaning but is also of importance to society. Attaining goals related to life purpose can help propel one closer to achieving his or her true potential and deliver deep fulfillment (Kosine, Steger, \& Duncan, 2008). Purpose has also been defined as a central life aim, which organizes and manages goals, behaviors, and provides a sense of meaning (McKnight \& Kashdan, 2009). Yalom (1980) understood meaning and purpose collectively explaining that life meaning is not only a sense of consistency understanding about our existence or a sense of order, but also a sense of purpose that provides one direction for living. Frankl (1992) also 
defined meaning in the context of purpose. He explained that meaning is a unique purpose or function to fulfill. Life-meaning may motivate action oriented purpose and in turn that purposeful action may provide meaningfulness to life (Frankl, 1992). For this reason, often both meaning and purpose are measured and studied together.

McKnight and Kashdan (2009) synthesized existing literature to formulate a comprehensive view of purpose in order to differentiate purpose from other constructs. They identified necessary elements of the construct of purpose: (a) purpose stimulates behavioral consistency and resilience to changing environmental conditions; (b) purpose generates appetitively (or approach oriented) motivated behavior; (c) purpose stimulates psychological flexibility; (d) purpose fosters efficient resource allocation and leads to more productive cognitive, behavioral, and physiological activity; and (e) purpose involves a higher level of cognitive processing and thus separates purpose from more primal motivations.

Existential distress. Frankl’s (1992) personal experience in the concentration camps in World War II allowed him to observe first hand that meaning in life can exist in the worst of conditions. Frankl also observed that when a man's meaning in life was thwarted, so too was his well-being (Frankl, 1992). He developed a theoretical framework of meaning and pointed clearly to the clinical implications of lack of life-meaning (Zika \& Chamberlain, 1992). Frankl asserted that the core of human motivation was a 'will to meaning' and without this one experiences “existential frustration” (Crumbaugh \& Maholick, 1964, p. 200). “Existential frustration” eventually results in “noongenic neurosis”, a pathological condition (Crumbaugh \& Maholick, 1964; Zika \& Chamberlain, 1992).

Maddi (1967; as cited in Zika \& Chamberlain, 1992) termed a condition similar to Frankl’s “noogenic neurosis,” “existential neurosis”. This condition develops from a belief that 
one's life is without meaning, one's affect is colored with apathy and boredom, and there is an absence of selectivity in actions. A person with existential neurosis, according to Maddi, would experience alienation from both self and society and thus, there is potential for a lack of meaning in life to result in both pathology and developmental deficiencies.

Yalom (1980) underscored the link between lack of meaning and psychopathology. Conversely, he found that positive life-meaning was linked to strong religious beliefs, membership in groups, and dedication to a cause, life values, and clear goals. Yalom further argued that meaning in life is a developmental construct and changes through the life span (Zika \& Chamberlain, 1992). Lazarus and Delongis (1983) furthered a developmental conceptualization of life purpose and meaning. They stated that meaningfulness is related to commitments in life, as commitments often reflect one's values and beliefs. One's ability to participate in commitments decreases with age, and the likelihood of existential malaise and a sense of meaninglessness increases (Lazarus \& Delongis, 1983). A commitment that may contribute to one's values and beliefs, and thus provide existential meaning, is religious involvement. The current researcher hopes to uncover existential themes, whether related to one’s well-being or distresses, which are present during his or her time of conversion to evangelical Christianity. Definitions of religion and spiritually are numerous, though researchers are increasing in consensus on the difference between these two concepts. Following a discussion of these broader terms and related research, evangelical Christianity is defined.

Religion and spirituality. Love (2001) defined religion as "a shared system of beliefs, principles or doctrines related to a belief in and worship of a supernatural power or powers regarded as creator(s) and governor(s) of the universe” (p. 8). Koenig, McCullough, and Larson (2001) provided a more functional and broad definition: 
[A]n organized system of beliefs, practices, rituals, and symbols that serve (a) to facilitate individuals' closeness to the sacred or transcendent other (i.e., God, higher power, ultimate truth) and (b) to bring about an understanding of an individual's relationship and responsibility to others living together in community. (p.18)

Spirituality, on the other hand is a mechanism by which individuals construct knowledge and meaning (Tisdell, 2003). Spirituality defines how people create awareness of the interconnectedness of all things including unconscious and symbolic processes (Tisdell, 2003). Spirituality is also defined as a quest to understand the answers to ultimate questions about life, meaning, and about the sacred or transcendent and may or may not lead to or originate from religious engagement. (Koenig et al., 2001). While approaches to spirituality differ between individuals, and may be oriented toward God, the world, or humanity, the unifying element of spirituality is the search for the sacred, or that which transcends the self (Bryant et al., 2003) Zinnbauer, Pargament, and Scott (1999) highlighted the importance of not dichotomizing religion and spirituality, which has been the case in much of the psychological literature. Some make the assumption that religion is organized and negative while spirituality is personal and positive (Zinnbauer, Pargament, \& Scott, 1999). On the contrary, the concepts relate differently to different people. Religion may be spiritual but spirituality can also stand apart from religion. Thus, some individuals may describe themselves as spiritual and not religious (Bryant et al., 2003). Zinnbauer and Pargament (2005) summarized the religious and spiritual literature pertaining to adults. However, King and Roeser (2009) stated these adequately relate to the research on adolescent's religious and spiritual involvement and are thus relevant to the current population under investigation. Zinnbauer and Pargament concluded that most people identify as both religious and spiritual with only a minority self-identifying as spiritual but not religious. 
They also contended that religiousness and spirituality are overlapping constructs in the United States though they are not identical concepts. The terms are complex, multidimensional constructs that warrant biological, mental, and social levels of analysis. Religion and spirituality develop and morph over time at both an individual and group level. Finally, they concluded that the constructs of religiousness and spirituality have evolving connotations in the United States with religion most often associated with the social and group level while spirituality is most often associated with personal and intrapersonal level of analysis.

In a large-scale study of first year college students $(n=3,680)$, there was a large overlap between those students who classified themselves as religious and spiritual and vice versa (Bryant et al., 2003). Some were highly spiritual but only “moderately” religious (38.1\%). Individuals who were highly religious were more likely to be spiritual, though the association was true to a lesser degree in the opposite direction as those who were highly spiritual were not as likely to be religious. Individuals from diverse spiritual groups characterized themselves as “highly spiritual”; 49.9\% Christians; 40.1\% Jews; 40\% Muslims; 33.4\% Baptists; 30.6\% United Church of Christ. Furthermore, students who did not identify with a particular religion indicated that they were "highly spiritual” (12.6\%) (Bryant et al., 2003). In following with Zinnbauer et al.’s (1999) recommendation to not dichotomize religion and spirituality, and because of the overlapping conceptualization of these two terms in the United States, the current researcher uses these terms together to represent the interactive relationship between them.

Correlates of religion and spirituality. Hill and Pargament (2003) reviewed the literature on religious and spiritual outcomes and found a consistent association between religion and spirituality and beneficial outcomes on physical and mental health. On the other hand, they found spiritual struggle to be negatively associated with physical and mental health problems. 
Psychological concerns cited in the literature include depression, anxiety negative mood, low self-esteem and suicidal thoughts. The potential positive and negative effects of religious and spiritual involvement are outlined below.

Religion, spirituality and well-being. Steger and Frazier (2005) pointed out the relevance of exploring religion's role on well-being. They contended that counseling psychologists have focused on strengths and factors associated with well-being and "gaining greater understanding of why religion is related to well-being is consistent with these efforts: Such understanding would benefit theory development in the study of religion and would help counselors assist their clients” (p. 574). Markstrom, Li, Blackshire, and Wilfong (2005) highlighted several positive correlates of religious involvement including a decrease in problematic and health compromising behaviors, increased social competence, resiliency, ego strength, ethnic identity, and identity commitment. Also, religious certainty, strength of one's relationship with the divine, prayer experiences, and devotional and participatory aspects of religiosity were positively correlated with subjective well-being after controlling for variables including age, income, and marital status (Diener et al., 1999).

Religion has a therapeutic effect as well as a preventative effect on mental health outcomes. Religiosity has also been positively associated with well-being, happiness, joy, fulfillment, pleasure, and contentment (Cohen, 2002). According to Myers and Diener (1995), religious people reported being happier and more satisfied with life than irreligious people. Some of the possible mediators between religiosity and well-being include marital status, healthy behaviors and activities, social support, optimism, hope, purpose and meaning in life, and internal locus of control (Cohen, 2002). Cohen (2002) also pointed to a variable that may be related to life satisfaction: spirituality. He postulated that life satisfaction may be related to 
spirituality as spirituality provides a means of explaining events, feeling close to the divine or God, experiencing beauty in the world, finding comfort in religious teachings, and believing that life has purpose. It is clear that a link between religiosity and well-being exists. Researchers have, therefore, been working to determine what factors mediate this linkage. Some of the possible mediators listed above have been studied. Most interesting and relevant to the current study is the mediating factor of life-meaning as it relates to religion.

Steger and Frazier (2005) found that meaning in life was a mediator between religion and well-being. They also found that meaning in life can develop during brief periods after engaging in religious activities. They highlighted that meaning in life as a mediator for religion and wellbeing does not explain away the importance of religion. On the contrary, Steger and Frazier (2005) contended that meaning should be an important aspect of religion as religion often addresses existential questions such as what is the purpose of life, what in life is important, and what is the nature of human experience. They also highlighted that the purpose in one's pursuit of religion is not often his or her well-being or happiness, but a connection with sacred matters. While the purpose of engaging in religious activities is not often to improve well-being, religious involvement is positively associated with well-being. This has shown to be true for persons young and old.

Faith and religious involvement has proven to be a factor mediating life-meaning and thus well-being across different age groups (Davis, Kerr, \& Kurpius, 2003; Steger \& Fraizer, 2005). A central characteristic of resilient children is an ability to use faith to maintain a positive view of a meaningful life (Werner, 1984). Furthermore, adolescents who lack perceived purpose are more likely to participate in risky behaviors including unsafe sexual behavior, delinquency, substance abuse, and suicide (Davis et al, 2003). In their study to determine the effects of 
religion and spirituality on mental health, Davis et al. (2003) determined that greater spiritual well-being predicted lower trait anxiety among at-risk adolescents. It is important to determine the role of religion and spirituality as it affects other mental health presentations and lifemeaning across the life-span. The stage in life that is of particular interest in the current study is during the college years. College students are, for the first time, independent from their familyof-origin and making decisions that may reflect or influence their life-meaning. In addition to the development of life-meaning and psychological benefits, social benefits come with religious involvement.

Religion provides individuals with a collective identity and a reliable social network made up of individuals who maintain similar attitudes and values. Individuals who lack social support may experience greater benefits from religious involvement because of the increased social supports found through religious engagement (Diener et al., 1999). This may also be true for a college student joining a religious or spiritual community during college; as social support systems which were in place during high school may no longer be accessible. Social support, psychological and subjective well-being, and a sense of meaning are potential benefits of religion, and most of the research discussed above highlights the benefit of religion. However, there may be potential negative experiences related to engagement in religion.

Religion, spirituality and distress. Much of the literature focuses on the benefits of religious and spiritual engagement; however, there is also evidence that religious and spiritual development may lead to negative social outcomes and developmental forms of psychopathology (King \& Roeser, 2009). If religious traditions emphasize the faith community to a much greater extent than the community members, unique identity exploration among young individual members may be thwarted. For example, an individual may experience pressure to adopt the 
ideologies of the larger religious group, and he or she may be at risk for identity foreclosure. Some conservative Christian traditions may emphasize individual member’s relationship with God resulting consequently in isolation from the larger community and a neglect of societal contribution. On the other extreme, some forms of religion or spiritualty that exalt the individual over a greater good may promote narcissism, entitlement, and lack of connectedness with the larger community (King \& Roeser, 2009).

Religion, spirituality and college student outcomes. Studies using college student samples have successfully demonstrated the relationship between life-meaning and well-being, as well as between religion or spirituality and well-being. Mascaro and Rosen (2008), in a longitudinal study, set out to conceptualize and measure existential meaning in a psychometrically and theoretically sound manner and compare this measure to depression levels in college students. Over the course of two months, during three separate testing sessions, 395 undergraduate students completed meaning and depression assessments. Mascaro and Rosen found that low levels of existential meaning indicated more vulnerability to depressive symptoms over an extended period of time. Taliaferro, Rienzo, Pigg, Miller, and Dodd (2009) explored religious and spiritual well-being in addition to existential meaning. They found that college students who attended church and had regular and frequent involvement in church services or activities had reduced suicidal ideation compared with students who were not involved in religious activities. Their findings supported the inverse relationship between high levels of church involvement and mental health found in previous research. In addition, students with higher levels of religious, existential, and spiritual well-being reported lower levels of suicidal ideations. However, existential well-being proved to be most strongly related to lower levels of suicidal ideation. It is evident that the existential gains or life-meaning gains from religious 
involvement are positively associated with well-being (Taliaferro et al., 2009). Little research has evaluated the impact of a religion or spiritual conversion in college on a student's psychological and existential well-being. Before discussing religious and spiritual conversion, evangelical Christianity is defined, as this is the specific religious and spiritual group under investigation in the current study.

Evangelical Christianity. The current researcher is concerned with the conversion of college students to evangelical Christianity specifically for several reasons. The National Study of Youth and Religion (NSYR) found that a significant majority of youth in the United States self-identify as Christian (75\%) consisting of Protestant (52\%) and Catholic (23\%). Other religions were represented to a considerably lesser degree among adolescents including Mormonism (2.5\%), Judaism (1.5\%), Muslimism (0.5\%) and others (1-2\%) (Smith \& Denton, 2005). The more specific narrowing of focus on evangelical Christianity provides a framework of beliefs among participants and furnishes inclusion and exclusionary criteria for sample selection. Evangelical Christianity, as defined by the Institute for the Study of American Evangelicals, is a broad term encompassing Protestant faith traditions. The four hallmarks of evangelical Christianity according to historian David Bebbington (1989) are: conversionism, activism, biblicism, and “crucicentrism.” Conversionism is the belief that lives need to be changed or converted, activism is the behavioral expression of the gospel, Biblicism is having particular regard for the Bible, and “crucicentrism” is the emphasis of Jesus Christ's sacrifice on the cross (Defining Evangelicalism, 2013). Again, the stage of faith which the current study is concerned is the conversion to evangelical Christianity after a time of little to no faith.

Religion and spiritual conversion. In the current study, the term conversion refers to a new development of spiritual or religious beliefs, involvement, and commitment with little or no 
history of religious or spiritual engagement. The current study is relevant to psychology and the public at large as faith among Americans is characterized by great fluidity (King \& Roeser, 2009). Approximately 28\% of American adults have left the faith tradition in which they grewup as a child to engage a different religion or disengage from religion all together (King \& Roeser, 2009). As discussed above, a large number of adults and adolescents self-identify as religious; however, both the number of religiously unaffiliated adults and adolescents seems to be rising (Wallace, Forman, Caldwell, \& Willis, 2003). The decline in religiousness seems to increase more during older adolescence and may be a trend seen more during college than in high school (Bryant et al., 2003; King \& Roeser, 2009). This trend is one reason the current study aims to explore college students' conversion to faith, as this conversion is counter to the overall trend of disengagement from religion and spirituality during college. This countercultural transition is unique to this developmental stage and may produce distinctive experiences among those who have gone through it. A review of religion, spiritual, and faith development below provides guiding theories for the current study.

Spiritual development. Theories related to religious and spiritual development in adults and religion and spirituality development in adolescents are lacking (King \& Roeser, 2009). Though sound theories are scarce, several key theoretical strands are consistently present across the current literature on religious and spiritual development. According to King and Roeser, the religious and spirituality development literature addresses (a) the relational system resulting in security and a decrease in anxiety; (b) a meaning system providing existential answers to life’s boundaries (e.g., death) and to otherwise incomprehensible life events; (c) the development of cognitive schemas which foster religious phenomena such as prayer and one's understanding of God; (d) an identity-motivational system organized around religious and spiritual goals and 
values; (e) states and stages of awareness that goes beyond ego-consciousness which is otherwise bound by time and space (e.g. mystical experiences); and (f) a dynamic developmental system perspective in which religious and spiritual development relates to multiple contexts, people, and symbol symptoms (King \& Roeser, 2009). This summary of themes across models of religious and spiritual development highlight the complexity and broad reaching influence of religion and spirituality in one’s life.

In another summary, Love and Talbot (1999) outlined five interrelated processes defining spiritual development to include: (a) identity development involving an internal process of seeking personal authenticity, genuineness, and wholeness; (b) the process of transcending one’s current locus of centricity; (c) increased connectedness to self and others through relationships and community engagement; (d) deriving meaning, purpose, and direction in one's life; and (e) increasing openness to exploring a relationship with an intangible and pervasive power or essence that exists beyond human existence and rational human knowledge. Each of the above processes is thought to develop over time as one grows in religiousness, spirituality and faith. Adolescence is a time of heighted readiness to explore and engage religion and spirituality. Markstrom (1999) indicated three reasons why this is the case. Adolescents are able to engage in formal operational thought and conceptualized abstract concepts characteristic of existential and transcendental realms. Second, individuals at this stage are in the process of identity formation and religion and spirituality may serve as meaningful resources during this time. Finally, religious or spiritual involvement may provide some with a sense of self-worth as they perceive themselves as connected to a larger purpose or Supreme Being. Developmental psychologist James Fowler (1981) conceptualized one of the most well respected and most researched theories of faith development and the above themes are present in his stage model theory (Streib, 2005). 
Fowler's Stages of Faith Development. In addition to religion and spirituality, there is yet another term present in the psychology of religion literature that is important to discuss. Faith as defined by Fowler (1981) is a way of understanding and committing one's self to collective values and power that provides ordering focus to his or her life. Fowler described faith as a universal human activity of meaning making grounded in structures such as cognitive development, level of moral reasoning, locus of authority, bounds of social awareness and the role of symbolic function. He conceptualized religion as a cultural expression of faith (Parker, 2011). Fowler constructed a theory of faith development based in his own research and using concepts from the developmental theories of Erikson (1968), Piaget (1970), and Kohlberg (1976). He argued that faith development consists of an interactive and complementary relationship between seven structures: (a) logic or Piaget’s (1970) levels of cognitive development; (b) moral reasoning from Kohlberg’s (1976) stages of moral development; (c) perspective taking from Selman's (1976) distinction between singular and multiple frames of reference; (d) world coherence, or how an individual makes sense of his or her world; (e) locus of control, or whether one looks inward or outward for support of beliefs and actions; (f) bounds of social awareness, referring to those included or excluded in an individual's meaning making processes; and lastly (g) the role of symbolic function (i.e. symbols such as the Star of David or the Crucifix, archetypes, acts, or events to which meaning is attributed). Fowler emphasized the multidimensional nature of faith and emphasized that faith cannot be reduced to one or a few of these structures but must be a collection of all of these structures. Furthermore, the use of these seven structures was a way for Fowler to recognize the cognitive, affective, and relationship dimensions of faith. Regarding the stage-type theory, Fowler understood faith development as a 
stage-like progression of greater complexity and comprehensiveness across all seven structures outlined above (Fowler, 1981; Fowler 1996; Parker, 2011).

His original research, from which he developed his theory, consisted of conducting a four-part interview with 359 subjects 13 to 84 years in age(Fowler, 1981). Fowler analyzed the transcripts from these interviews and described seven stages of faith. He also identified typical developmental crises and transitions that are characteristic for individuals moving from one stage to another.

Young adults in the college and university settings are in a specific and unique developmental stage, thus Fowler's model is pertinent and helpful in informing the current research. Specifically, Das and Harries’s (1991) research and Fowler’s (1981) original research have college age students in or between stages three and four of his seven-stage model. Fowler's seven-stage model is described below.

Fowler (1981) developed a pre-stage (Stage 0) which occurs during the first year of life. This stage is characterized by preverbal development in which the individual establishes a foundation of trust or mistrust on which subsequent faith development is built. Fowler's Stage 1 of faith development is Intuitive-Projective Faith and is characteristic of children ages two to seven years old. In this stage, children's faith is largely influenced by teaching and example of significant adults. Faith, at this stage, may be a product of the child's fluid and fantasy thought patterns and the children's preoperational thinking and largely egocentric perspective taking. Stage 2 of Fowler's faith development theory is Mythic-Literal Faith. This stage of faith development coincides with the cognitive formation of concrete operations as described by Piaget (1970). Children begin to understand and appreciate the narratives of their faith tradition and begin to adopt these narratives as a way to understand meaning and purpose to human life. 
Fowler’s Stage 3 typically begins in adolescence and may be seen in college-age individuals.

Synthetic-Conventional Faith is defined by new cognitive abilities which emerge in adolescents that allows for higher level storytelling. This cognitive capacity allows individuals to make new meaning from past experiences as well as anticipate future roles and relationships. Interpersonal relationships become of paramount importance and self-worth may be determined by approval from others. Individuals at this stage form a sense of personal identity. Specifically pertaining to faith, individuals in this stage hold beliefs and values tacitly instead of explicitly examining them. The emergence of an executive ego in the next development stage causes a shift toward taking responsibility to examine and make personal choices about beliefs and lifestyle. Individuals in this Stage 4 may distance themselves from previous assumptive value systems. Stage 4 is Individuative-Reflective Faith, which is impacted by an increase in individuation from others. A limitation of this stage is the over dependence on logic and reason to solve social or cognitive dilemmas. For this reason, individuals in Stage 4 tend to demythologize symbols and translate them instead to conceptual meanings. Fowler named this stage the "demythologizing stage”.

Stage 5 of Fowler's faith development therapy, Conjunctive Faith, is a stage in which people move beyond the dichotomizing logic of Stage 4. Individuals in this stage develop a “second naïveté” wherein symbols and what is symbolized are reunited. Also during this stage, one creates new meaning from past experiences and becomes increasingly open to the deeper self or to his or her unconscious motives. Stage 5 is also witness to an understanding that truth is multidimensional and organically interdependent. Fowler's sixth and final stage is Universalizing Faith. Fowler claimed that this stage is empirically rare and he encountered only one person in this stage from his sample of 359. Universalizing Faith includes making tangible 
the imperatives of absolute love and justice whereas these imperatives are only partly understood in Stage 4. Most college students would likely be in Stage 3 or Stage 4 of Fowler’s faith development theory.

Fowler's (1981) original research found that the majority (62.5\%) of individuals age 13 to 20 years-old were in Stage 3 or were in transition from Stage 2 to Stage 3. He determined that $34.0 \%$ of the persons in this age group were in Stage 4 or were transitioning from Stage 3 to Stage 4 . In the next age group, the majority (73.3\%) of individuals ages 21 to 30 years-old were in Stage 4 or were in transition from Stage 3 to Stage 4 and only 22.2\% were in Stage 3 or were transitioning from Stage 2 to Stage 3. Das and Harries (1996) conducted a study validating Fowler's theory of faith development with college students. In their small sample of 32 students, they found a larger number (46.8\%) of 21 to 30 year-olds in Stage 3 or transitioning from Stage 2 to 3 and only 31.2\% in Stage 4 or transitioning into Stage 4 with more women and older respondents presenting in Stage 4. According to Jablonski (2001), Spiritual development is a learning process by which students encounter the transcendent and ultimate meaning in life. Spirituality is an ongoing process which facilitates a student's quest toward clarifying and fulfilling personal destiny (Capeheart-Meningall, 2005). For some, spiritual development or spiritual transition may be characterized as spiritual struggle.

Spiritual struggle. Much of the above literature review has outlined the positive effects of religion and spirituality on existential and psychological well-being. However, there are a growing number of people who experience psychological distress due to religion and spiritual issues (Bryant \& Astin, 2008). For the first time, the Diagnostic and Statistical Manual of Mental Disorders-IV (DSM-IV; American Psychiatric Association, 1994) included a diagnostic code for Religious or Spiritual Problems. More recently the fifth addition of the DSM (American 
Psychiatric Association, 2013) was published and included this diagnosable condition as well. The manual indicates that a Religion and Spiritual Problem may consist of, “distressing experiences that involve loss or questioning of faith, problems associated with conversion to a new faith, or questioning of spiritual values that may not necessarily be related to an organized church or religious institution” (American Psychiatric Association, 2013, p. 725).

According to the above definition of Religion and Spiritual Problems in the DSM-5 (American Psychiatric Association, 2013), there may be multiple causes for this distress. In a study by Johnson and Hayes (2003) of 5,550 college students from 39 colleges and universities in the United States, $44 \%$ of the students indicated that they had at least some degree of distress regarding religious and spiritual concerns. A quarter of the participants indicated that they were experiencing a large degree of distress related to religious and spiritual concerns. In this particular study, correlates associated with spiritual and religious concerns included confusion about beliefs, suicidal thoughts, loss of a relationship, sexual assault, and homesickness (Johnson \& Hayes, 2003). Spiritual struggle may not be exclusively related to those questioning spiritual or religious beliefs.

Kellems, Hill, Crook-Lyon, and Freitas (2010) conducted a survey of college counseling center therapists $(n=220)$ to identify religious and spiritual issues among student clients. They asked college counseling center clinicians to report one case which involved religious and spiritual matters and found that $58 \%$ of these therapists engaged in processing issues related to religion and spirituality in most or almost all sessions with the particular client of note. Moreover, religious and spiritual issues varied and were both ego-syntonic and ego-dystonic. The top four issues related to religious and spiritual issues which they highlighted in descending order were (a) incongruence between beliefs and sexual behavior; (b) abandonment of family 
religious/spiritual traditions; (c) use of religion and spirituality as strength; and (d) exploration and defining of religious beliefs. In addition to the issues discovered in the above study, students who affiliate with a religion or spirituality may experience struggle with their identity and connectedness to a respective culture group. For example, a Jewish individual may experience distress if he or she encountered anti-Semitism. In addition to identity issues, a factor related to spiritual struggle may include wondering about God and questioning one’s beliefs about God. Questions may arise such as “Can God really do everything?”, “Does God care about me?” and “What did I do for God to punish me?” Gender and sexual orientation may also present challenges that foster religious struggles; for example, women's roles in religion and potential intolerance of gay and lesbian individuals (Bryant \& Astin, 2008). While there are negative consequences of spiritual struggle, there are also potential positive consequences of spiritual struggle. Individuals who have experienced spiritual struggle are more likely to be open-minded, have tolerant values, promote tolerant action, and engage in principled moral reasoning and in helping behaviors. Moreover, spiritual growth can occur from spiritual struggle (Bryant \& Astin, 2008). This tendency of spiritual growth subsequent to spiritual struggle is congruent with many developmental frameworks that describe the necessary role of crisis as it promotes growth.

According to Erikson (1968) crisis is a point of transition and not necessarily a tragic event. Chickering and Reisser (1993) pointed to the college environment as one that fosters crisis or transition explaining that an increase in education and development can produce disruption and disequilibrium. The college experience entails powerful developmental forces and with these developmental changes, turmoil such as temporary dislocation and disorientation, is likely to be present. Holcomb and Nonneman (2004) supported the notion of crisis being an impetus for development. In their longitudinal study of students attending evangelical Christian colleges, the 
Faith Change project defined crisis as a sustained period of exploring or engaging opposing roles and ideologies or any experience wherein one is challenged to scrutinize what he or she believes and why. Three general categories of crisis emerged: (a) significant exposure to diverse perspectives; (b) substantial multicultural exposure; and (c) general emotional crisis. They noted that all three forms of crisis result in movement toward more complex and reflective faith. Holcomb and Nonneman also asserted that for spiritual growth to happen there must be a balance between challenge and support. Without challenge faith may remain stagnant and without support faith may be lost. Contrary to the findings of Hocomb and Nonneman (2004), Bryant and Astin (2008) found that spiritual struggle was not correlated with religious growth.

Bryant and Astin (2008) sought to determine what factors may predispose students to spiritual struggle and the experiences in college that may lead to spiritual struggles. The authors also wanted to ascertain what secondary impact spiritual struggles had on students’ physical well-being, self-esteem and level of psychological distress. Finally, they explored whether spiritual struggles result in growth in religiousness and spirituality and growth in acceptance of people with differing religious/spiritual views. Bryant and Astin utilized two national college student surveys created by the Higher Education Research Institute of the University of California, Los Angeles (The 2000 Cooperative Institutional Research Program Freshman Survey and the 2003 College Students’ Beliefs and Values Survey). From the 3,680 usable surveys across 434 colleges and universities, they found that spiritual struggle was indeed positively associated with psychological distress (to include depression, feeling overwhelmed, and feeling stressed or anxious). They also concluded that spiritual struggle predicted psychological distress $(r=0.35)$ and was a negative predictor of physical health $(r=-0.11)$ and self-esteem ( $r=-0.12)$. On the other hand spiritual struggle positively predicted religious 
tolerance $(r=0.14)$ but was not a predictor or religious growth $(r=0.0)$. Bryant and Astin highlighted the significant implications of struggling spiritually during college and called higher educators to take note. They highlighted the influence of spiritual struggle on student's sense of well-being and the impact that a spiritual struggle may have on a student's ability to adjust to his or her environment. Failure to recognize and act on these implications could result in students navigating the quest for central issues of meaning without support. Bryant and Astin recommended educators seek to appreciate the nuances inherent in spiritual struggling and the significance of this experience on the lives of students.

Religion/spirituality and college students. Several large-scale research projects discussed below have been developed across the country which aimed to investigate spirituality and/or religion among undergraduate college students. One such project, briefly discussed above, was the Spirituality in Higher Education project at UCLA's Higher Education Research Institute (HERI). In this project, researchers explored spirituality in students and eventually extended to an exploration of spirituality among college and university faculty. The first noteworthy finding, and most relevant to the current study was that students expressed an interest in spirituality and the majority of students surveyed indicated that spirituality was relevant to their life, that spirituality is often under-discussed, and that because spirituality is somewhat private students were hesitant to discuss the topic other than with those whom they have a close and trusted relationship. In an interview, project leader Lindholm (2009) also indicated that the research from the Spirituality in Higher Education project pointed to a trend among students to engage in spiritual issues and to consider spiritual questions such as "What is important in my life?” and “How can I understand the world around me?” Lindholm further pointed out that, though a student may decrease his or her participation in formal religious activities, his or her engagement 
in spiritual issues and concerns may increase during college. According to survey findings, students expect that their public and secular institutions will provide support surrounding spiritual dimensions in their lives as well as be supportive of their expressions of their personal spirituality. Lindholm highlighted the benefit of simply engaging students in a discussion about their thoughts and feelings related to spirituality in order to foster their spiritual development.

Research findings on students’ emotional well-being related to religiosity are mixed (Mayrl \& Oeur, 2009). Phillips and Henderson (2006) conducted a study using survey data from 14,521 college students from the National College Alcohol Study which indicated that students who reported being at a minimum somewhat religious experienced fewer symptoms of depression than their non-religious student peers. On the other hand, Bryant (2007b) conducted a survey study of 3,600 freshman college students and found a negative correlation between emotional well-being and religious involvement alone. Bryant found that the development of friendship networks due to the engagement in religious activities was the mediating factor between religiosity and emotional well-being. Smaller scale studies using single campus samples also depicted mixed results. One such study by Pollard and Bates (2004) found that students who maintained personal meaning in religion coped better with stress when compared to those who did not find meaning in religion. An earlier study, however, found that increased spirituality among college students was correlated with higher levels of personal distress (Schafer, 1997). Furthermore, Blaine and Crocker (1995) discovered differences between personal outcome effects of religion on white and black students. They found that religiosity promoted well-being among black students but not in white students. While the research on emotional well-being and religion and spirituality are more mixed, satisfaction in college, in and outside of class, is consistently positively affected by religious and spiritual engagement in college (Mayrl \& Oeur, 
2009). In response to the varied findings related to student outcomes, Mayrl and Oeur (2009) provided recommendations for future research. It is unknown why religion may exert a beneficial effect on some outcomes and not others. For this reason, Mayrl and Oeur recommended that future research seek to discover student outcomes as a whole and work to determine why religion influences student outcomes and through what channels.

The current study seeks to uncover the existential and psychological experiences of college students who have converted to religion or spirituality, and the findings are expected to help college counseling center clinicians better understand the potential needs of students converting to evangelical Christianity. Psychological and existential domains are not however, the only domains that a religious or spiritual conversion may influence. Furthermore, college counseling centers may not be the only places on college campuses wherein students may find direction in their religious or spiritual endeavors. Education researchers are becoming increasingly aware of the need for college curricula and student affairs programing to facilitate or encourage holistic student growth including spiritual and religious growth (Capeheart-Meningall, 2005; Mayrl \& Oeur, 2009). Thus the findings from the current study may be helpful in developing more comprehensive campus initiatives that no longer ignore the religious and spiritual needs and interests of college students.

Predictors of religion/spirituality in college students. Bryant et al. (2003) conducted a study wherein they examined the particular challenges of first year college students related to spiritual and religious development. Using data from the 2000 Cooperative Institutional Research Program Freshman Survey, part of the Higher Education Research Institute's (HERI) research at UCLA, and the 2001 Your First College Year Survey, a survey of both the HERI and Policy Center on First Year of College at Brevard College, the authors compiled and analyzed data of 
3,680 first year students from 50 different four-year colleges. Bryant et al. (2003) identified both positive and negative predictors of spirituality and religion respectively among college students.

Negative predictors of spirituality for first year students included identifying oneself as White ( $r=-.04)$, having no religious affiliation $(r=-.36)$, adopting a liberal political orientation $(r=-.23)$ and hours per week surfing the internet $(r=-.12)$. Negative predictors of religiosity among first year college students included adopting a liberal political orientation $(r=-.27)$, having a personal goal of obtaining recognition from colleagues $(r=-$. 06), being Buddhist $(r=$ .09), hours spent partying each week $(r=-.19)$, and having parents that are divorced or separated $(r=-.03)$. On the other hand, positive predictors of spirituality for first year college students included attending religious services in high school and praying/meditating in high school $(r=$ .51 and $r=.57$, respectively). Also, religious service attendance in college and hours spent attending religious services were positive predictors of spirituality $(r=.60$ and $r=.61$, respectively). And lastly, discussing religion $(r=.45)$ and time spent with family $(r=.08)$ were also positive predictors of spirituality among students. Positive predictors for religiousness for first year college students included having a goal of integrating spirituality in one's life ( $r=.61)$, high school GPA ( $r=.17)$ participating in community services $(r=.31)$ and rating one's self as spiritual $(r=.60)$. Many variables seem to be related to students’ engagement of religion and spirituality. The current study hopes to ascertain aspects of students' lives that may influence their conversion to Christianity and how this conversion influences psychological and existential health. College students who grow in faith and who convert to religion are in the minority (Bryant et al., 2003). Despite the increased interest in spirituality during college, many students disengaged from their childhood religion. 
Discrepancy between interest and engagement. While religious participation typically wanes in college, interest in and engagement in spirituality may actually increase. Bryant et al. (2003) supported these findings. First year students became less religiously involved with a 27\% decrease in participation in religious services. Furthermore, $10.3 \%$ of first year students indicated that they stopped praying or meditating altogether. However, the percentage of students that indicated that integrating spirituality into their lives was "essential” and "very important" increased across the first year. Despite the interest in integrating spirituality into their lives, students' ratings for themselves as "spiritual” declined over the first year. The authors proposed that this discrepancy between the importance of spirituality and actually emulating it may be related to students' decrease in religious involvement. Students may have felt that they could not rate themselves as highly spiritual because their diminished participation in religious activities was perceived on their part as diminished spirituality. In response to this discrepancy and in hopes to foster religious and spiritual development among college students the authors provided recommendations for higher education institutions.

Bryant et al. (2003) explicated the obvious need for higher educators and studentcentered programs to address student's spiritual needs and interests, as it is clear that students desire spirituality to be an aspect of their lives. They also recommended that campuses encourage congruence between the importance of religion and spiritualty of the student and their perceptions of themselves as spiritual persons by supporting programs, organizations, and curriculums that provided opportunities for students to reflect on existential questions. Bryant et al. (2003) emphasized the importance of religion and spirituality not being a sideline issue on college campuses as it is a large contributing factor to many students' self-identification. They also recommended further research on students’ self-perceptions of their religiosity and 
spirituality as opposed to much of the previous literature which utilizes behavioral measures, such as religious service attendance. The current study explored students' self-perceptions with the use of a phenomenological research design. This methodology allows for a rich investigation of the complex factors associated with students' religious and spiritual conversion experiences and development.

\section{Recommendations for Further Research}

Mayrl and Oeur (2009) outlined the three major research avenues of religion and students in higher education: (a) college student beliefs and how college students practice what they believe; (b) how college experiences affect students’ religious beliefs and practices; and (c) how students' religious commitments affect academic and personal outcomes. The current study is primarily in line with the third research avenue described by Mayrl and Oeur, though components of the first and second research objectives described are also discussed and explored. Pertinent to effects of religious beliefs and practices on student outcomes, Mayrl and Oeur described three primary areas of students’ outcomes that have been explored: academic achievement; personal growth, maturation, and emotional well-being; and social activities such as drinking, sexual, and partying behaviors. The current study focuses on personal growth, maturation, and emotional well-being. However, the expectation of student outcome is not strictly biased toward the positive. It was expected that students experienced a level of both existential and psychological distress related to conversion to religion and spirituality. At the same time, much of the literature reviewed points to the benefits of religious and spiritual engagement and thus, existential and psychological gains are also expected. 


\section{Chapter 2}

\section{Methods}

\section{Research Approach}

Research on the effects of a religious conversion, specifically into Christianity, on college students is underdeveloped; thus, it would be difficult to develop specific hypotheses to be studied quantitatively. Moreover, the complex nature of this phenomenon and the current research questions are more suitable to qualitative research. Qualitative research allows for an investigation of individual meanings ascribed to events as well as an exploration into the intrapersonal experiences of participants (Willig, 2001). As discussed in the literature review section, life-meaning development involves a personal assimilation of one’s lived experiences, and meaning is distinctive for every person (Melton \& Schulenberg, 2008). The happenings in life are not in and of themselves meaningful; rather, one's ascription of meaning to these events results in meaningfulness to life (Melton \& Schulenberg, 2008). For these reasons, it was imperative to use a research method that would allow the researcher to evaluate the narrative meaning which a participant ascribes to his or her conversion experience. Willig (2001) explained that qualitative methods allow for individual differences to emerge in the data as well as highlight the general themes of a shared phenomenon. Insight into nuances among participants may foster a deeper understanding among research consumers and thus facilitate the applicability of the research to counseling practice. For these reasons, Interpretative Phenomenological Analysis (IPA; Smith, 1996) was chosen to structure this study.

\section{Interpretative Phenomenological Analysis}

Interpretative Phenomenological Analysis (IPA) is a relatively new qualitative research method developed in the 1990's by Jonathan Smith and was a collaborative effort with students 
and colleagues. IPA is focused on the idiographic exploration of an individual's experience as he or she deals with a specific event or situation (Larkin, Watts \& Clifton, 2006). According to Smith (2011), IPA allows for an in-depth examination of the lived experience of an individual, the personal meaning he or she ascribes to the experience, and how exactly the individual makes sense of the situation or event. The objective of IPA is to uncover and describe the essence of one's lived experiences. Furthermore, IPA is ideal for exploring how an individual perceives a particular situation or experience he or she is facing or has faced. IPA also allows for exploration of the means by which an individual makes sense of his or her personal and social world (Smith \& Osborn, 2003). The analysis of participants’ accounts are conducted in two stages; a first-order analysis consisting of description of what a participant's world is like and a second-order analysis consisting of describing what his or her experience of the world means (Larkin et al., 2006). Many IPA studies have examined participant experiences pertaining to identity and more specifically life-altering events, decisions, and major existential questions (Smith, 2004; 2011). Smith (2004) explained that IPA is well suited for researchers interested in the complex nature, process, or novelty of an experience. The successful use of IPA to explore faith and life transitions (e.g. Golsworthy \& Coyle, 1999; Millward, 2006; Todorova \& Kotzeva, 2006; Ross, 2009) demonstrates the appropriateness of IPA for the research and data analysis of the current study.

Theoretical underpinnings. The theoretical roots of IPA are phenomenology, hermeneutics, and ideography (Larkin et al., 2006). Phenomenology is a philosophical movement founded by Edmond Husserl (1859-1938) in response to his disagreement with the prevailing philosophy of his time, Cartesian dualism, where there is a separation between egos and worlds or between subject and object (Larkin et al., 2006). Phenomenology is concerned 
with one's lived experience from the perspective of the one who lived the experience, as his or her experience cannot be separated nor understood independent of his or her conscious perception of that experience. Likewise, the researcher's experience of the participant's account of an event is indivisible from the researcher's own conscious perception of the data. This speaks to the unique emphasis on the interpreter and his or her presuppositions in IPA (Larkin et al, 2006). Tappan (1997) stated that when interpreting the data the research analyst continuously refers to his or her own perspective which is based on biases, preconceptions, assumptions, and expectations shaped by his or her life experiences, culture, and traditions.

\section{Participants}

Qualitative research highlights the importance of not only identifying the characteristics and demographics of the interview respondents but also identifying those of the researcher, as the researcher is the interpretative instrument in the interview and analysis process (Tappan, 1997). Tappan also stated that providing information about the researcher and her history with the topic under investigation allows the reader to make his or her own judgments about the perspective and potential biases of the researcher. Below is a description of the respondent group as well as the bracketing, or personal reflective statement, of the researcher.

Respondents. According to Smith and Osborn (2003) sample sizes are small, but there is no standard sample size used in IPA. They advised that sample size should depend on the degree of commitment on behalf of the researcher to the case study level of analysis and reporting, the constraints under which one is working, and the richness of the individual cases. Unlike other qualitative methods that strive for data saturation, IPA that is done well seeks to achieve coherence and integration while preserving nuances within the data (Brocki \& Wearden, 2006). Smith et al. (1999) argued that data saturation is an unrealistic goal within IPA as it is 
idiographic in nature and does not strive to be a nomothetic approach. In other words, the knowledge and information gleaned from an IPA study pertains to the particular group of participants under study as they relate to the particular phenomenon being investigated. The findings may or may not be generalizable to a larger population (Smith \& Osborn, 2003). Smith and Osborn also explained that larger sample sizes do not allow for the desired depth of exploration into cases. They recommend novice students start with a sample size of three as this produces more data than is initially expected. Due to the breadth of the dissertation project and the previous experience of the researcher in using qualitative methodology (Consensual Qualitative Research; Hill et al., 2005; Hill, Thompson, \& Williams, 1997) the researcher sought to recruit a sample size of 8 to 15 participants. A sample size between 8 and 15 participants is in agreement with recommendations made by Creswell (1998) who recommended the use of five to 25 participants (p. 64) and Morse (1994) who recommended at least six participants (p. 225) in phenomenological interview research. Finally, this sample size is analogous with the majority of published Ph.D. level qualitative research study sample sizes using phenomenological analysis methods (Mason, 2010).

The participant group was nine adult college students who (a) endorsed having experienced a conversion to the Christian faith during college; (b) were previously uninterested/uncommitted to evangelical Christianity; (c) currently self-identify as evangelical Christian; (d) regularly attended (at least once per week) an evangelical Christian church or organization; (e) were 18 years or older; and (f) speak English fluently. Evangelical Christianity, as defined by the Institute for the Study of American Evangelicals, and for the purpose of this study, is a broad term that covers a wide range of Protestant traditions, denominations, organizations, and churches. As discussed above, British historian David Bebbington’s (1989) 
definition of evangelicalism is widely accepted by most scholars. Evangelicalism according to Bebbington consists of four hallmarks: conversionism, activism, biblicism, and “crucicentrism” (Bebbington, 1989). Conversionism is the belief that lives need to be changed, activism is the behavioral expression of the gospel, biblicism is having particular regard for the Bible, and “crucicentrism” is the emphasis of Jesus Christ's sacrifice on the cross (Defining Evangelicalism, 2013). Participants possessed these identifying features of evangelicalism as well as regularly participated in Christian services, attending at least one regular church service, prayer meeting or Bible study, or church social group each week. Exclusionary criteria included being under the age of 18 years old, being out of college, denying one or more of the identifying hallmarks of evangelical Christianity, attending fewer than one Christian service/activity each week, and having converted to Christianity at a time other than during the college years.

Recruitment. IPA uses purposive sampling to achieve a fairly homogenous sample with the understanding that individual differences are anticipated and that these differences contribute to the richness of the data (Smith \& Osborn, 2003). Initially the researcher's sole recruitment plan was to invite participants to participate in the research, in person by the researcher, at multiple evangelical Christian churches and organizations in a southeastern town in the United States. The researcher reached out to campus ministry leaders informing them of the research and requested to attend a weekly ministry meeting to inform students about the research and invite the involvement of participants. When this recruitment plan alone proved to produce too few participants the researcher submitted an amendment to the Institutional Review Board (IRB) protocol to allow for the voluntary referral of participants by campus ministers (though an amendment was not necessary due to there being no change in the exemption status of the research project). A script for the in-person recruitment of participants is attached (Appendix C). 
The researcher provided a cover letter (Appendix E) and an information sheet (Appendix F) including the details of the study and inclusionary criteria to those interested in participating in the study. Potential personal gains from participating in the research project including increased personal insight into one’s conversion experience, a deeper appreciation for personal experiences, and sharing one's conversion experience with the researcher and future research consumers were highlighted. During the in person recruitment process, individuals interested in participating in the study were asked to provide the researcher their contact information (phone number and email address). Contact information of voluntary referrals was also obtained from a number of campus ministers. At that time the researcher followed up with the interested party by phone and email to discuss the study in detail, answer any questions that arose, and establish verbal informed consent. The researcher also asked several questions to insure that individuals met the study inclusion criteria and subsequently scheduled an in person interview with the eligible participants. Information packets, to include the cover letter (Appendix E), the research study information sheet (Appendix F), the demographic form (Appendix G), and the interview questions (Appendix H), were sent via email to interested and eligible individuals. Participants were informed about their ability to drop out of the study at any time prior to the start of data analysis. Participants were notified via email two-weeks prior to the data analysis start date.

Study participant sample. A total of nine college students participated in this research study, six female and three male. Participants ranged in ages from 19 to 22 including one 19 year old, two 20 year olds, three 21 year olds, and three 22 year olds. Participants included one first year student, three juniors, four seniors, and one graduate student. Participants were non-married singles and all but one participant identified as Caucasian. One participant identified as Middle Eastern. The length of time since participants converted to Christianity to the time of the research 
interviews varied from one to three years. Eight out of nine participants reported attending a Christian group at the time of their conversion with the ninth participant not attending a religious group at the time of conversion. All participants reported attending regular evangelical Christianity meetings at the time of their research interview to include both church and campus ministry gatherings. Participants’ affiliation with Christian denominations were not mutually exclusive and included non-denominational (5), Presbyterian (2), Methodists (3), Baptist (1). One participant did not identify a denomination for which he or she was affiliated. The number of religious events or activities attended by group members each week ranged from one to six meetings per week with two to nine hours of involvement each week. Participants reported engaging in two to 12 hours of spiritual development (e.g. prayer, meditation and reading scripture) per week. Table 1 below denotes the gender and age of each participant. This will allow the reader to keep in mind the demographics of the participants when reading their quotes that are referenced in the results section.

Table 1

Gender and Age of Participants

\begin{tabular}{lll} 
Participant & Gender & Age \\
\hline Participant 1 & female & 22 \\
Participant 2 & male & 20 \\
Participant 3 & female & 21 \\
Participant 4 & male & 22 \\
Participant 5 & female & 22 \\
Participant 6 & male & 19 \\
Participant 7 & female & 20 \\
Participant 8 & female & 21 \\
Participant 9 & female & 21 \\
\hline
\end{tabular}


Finally, the researcher is considered a participant in the IPA research methodology due to the constructivist and interpretation role of the researcher during analysis. Therefore, the researcher's personal reflective statement is presented below.

Personal reflective statement. The researcher is a Caucasian, married, female counseling psychology doctoral student who identifies as evangelical Christian. A first person account of her conversion to faith is presented below.

I grew up attending a United Methodist Church but, apart from regularly attending church on Sunday mornings, religion and spiritual traditions were not practiced in the home. I do not recall praying with my family, reading the Bible, or blessing meals before eating. I would have identified myself as a Christian during the time I was attending church and prior to going to college. However, since I converted and came into a deeper understanding of my Christian faith during college, it is now my belief that I was indeed not a Christian during those earlier years. I do believe, however, that these early experiences in church contributed to my foundational knowledge of religion and may have contributed to my later conversion. During middle school, and particularly in high school, I recall having a nagging expectation that there was "more to life” and that "something is missing." The transition from high school to college seemed to amplify the anticipation of something more, something meaningful, and something worthy of devotion.

I was intentional in my search for answers and attended an organized event on the first Sunday of my first semester to introduce students to the myriad of religious and spiritual clubs, organizations, and churches in and around campus. At this meeting, I was captivated by a student leader who described a church wherein the members “passionately worship a living God.” He described God as "living and active” and interested in being in relationship with His people. I 
attended this church and campus ministry only a few times that semester only to disengage for the remainder of the year. It would be another year before I converted to the Christian faith.

After converting, I recall making difficult decisions to change my lifestyle, which ultimately meant ending several significant relationships. My faith became the most important aspect of my day-to-day life and became the foundation of my identity. My family, while supportive, did not fully understand the depth of conviction and change which defined my conversion experience. My faith was and still remains a source of purpose, meaning, joy, peace, and security. Nevertheless, my conversion to faith was also a time of questioning, confusion, uncertainty, anticipation, and hope. My faith influences my view of the world, and this epistemological viewpoint is integral to my interest in qualitative research and constitutes the lens through which I understand and interpret the current study’s data.

Personal epistemological viewpoint. I consider my epistemological presupposition to be both absolutist and a constructionist. These may seem contradictory but I will argue that they are not. While I believe that an absolute truth exists; an ultimate reality, I do not believe that absolute truth or this ultimate reality is comprehensible by the human mind. It is my understanding that biological, psychological, and social events throughout one's life influence one's perception of the world, and through a personal perceptive lens, one constructs his or her version of reality. Thus, I endorse a constructivist philosophical stance and believe this facilitates my ability to value and respect the varied views of others. Moreover, my epistemological understanding is congruent with that of IPA. Larkin et al. (2006) provided a general statement regarding the hermeneutic nature of "reality" stating, "What is real is not dependent on us, but the exact meaning and nature of reality is” (p. 107). 


\section{Measures}

Qualitative methodology was chosen for the current study as little research has the focused on students converting to faith during college. Semi-structured interviews as a means of data collection are suitable for the current study due to the study's phenomenological emphasis and the desire on behalf of the researcher to obtain an information-rich understanding of individuals' perspectives of this conversion (Smith, 2010). Semi-structured interviews allow for flexibility as interview questions are more of a guide and not an exact script (Smith, 2010). Within IPA, participants are considered to be the "experimental expert” on the phenomenon under investigation (Smith, 2010). The semi-structured interviews promote a participant's ability to tell his or her own story and introduce issues not previously thought of by the researcher. The semi-structured interview was developed to address the following research questions: (a) How do individuals perceive conversion to evangelical Christianity during the college years; (b) What psychological effects, if any, does the conversion to evangelical Christianity have on college students; (c) What existential affects, if any, does the conversion to Christianity have on college students; (d) How does the conversion to evangelical Christianity contribute to both well-being and distress during college; and (e) From whom do individuals seek support and counsel during the conversion experience and what qualifies these individuals as helpful supporters? Item development of the semi-structure interview was guided by the relevant literature on religious and spiritual development (Fowler, 1980), spiritual struggle (Bryant \& Astin, 2008), college-age development (Erikson, 1969; Arnett, 2000; Schulenberg et al, 2004), religious and spiritual involvement during college (Bryant et al., 2003; Mayrl \& Oeur, 2009) and existential and psychological distress (Masseé, 2000; Ridner, 2004) and well-being constructs (Frankl, 1992; Ryff, 1989). 
Demographic form. An information packet sent to participants prior to the start of formal data collection included a demographic form created for this study. On this form, participants were requested to provide information about their age, sex, and race/ethnicity, year in college, marital/relationship status, and current and past religious affiliation. For the purposes of this study, the researcher was interested in gathering information germane to the participants' religious conversion experience and current religious affiliation. Therefore, the demographic form included questions ascertaining the approximate or specific date participants consider to have converted to evangelical Christianity (i.e., conversion experience), the name of the church or evangelical Christian organization in which the participant was engaged during the time of conversion (if applicable), the name of the church or evangelical Christian organization in which the participant was involved at the time of the research interview, the denomination of the church or organization, the number of meetings or gatherings at his or her church or organization the participant attended each week, the average number of hours per week spent attending formal or informal group events, and the average number of hours per week spent engaging in spiritual or religious activities. If a participant attended multiple churches or organizations at the time of his/her conversion or at the time of the research interview, the preceding information was requested of each institution. The demographic form was completed by the participants and brought to the in person interview. The information on the demographic form was reviewed with the participant at the start of the interview as a means of information verification and as a means of building rapport with participants. The demographic form can be found in Appendix G.

Interview questions. The interview protocol consisted of a semi-structured interview with more general questions at the start of the interview funneling down to assess more detailed components of the participant's faith conversion experience. The open-ended interview questions 
were used to ascertain participants’ descriptions of their experience converting to evangelical Christianity, their existential and psychological experiences related to this conversion, how being in college may have impacted their conversion experience and from what sources individuals sought support during this conversion. The following open-ended questions were asked during the audio recorded interviews:

1. Please tell me about your exposure to religion/spirituality before becoming a Christian.

2. What do you think was a catalyst for your conversion to the Christian faith?

3. Please tell me about your experience converting to the Christian faith.

4. If you can remember back to this time in your life, what kind of thoughts and feelings did you experience during this time of conversion?

5. What were some of the positive experiences, if any, you had during your conversion?

6. What were some of the most challenging experiences you had during your conversion?

7. Did your conversion to faith impact you psychological or emotionally? If so in what ways?

8. Did your conversion to faith impact your thoughts about your future? If so in what ways?

9. Was any part of your conversion distressing?

a. If so, what was distressing?

b. At the time, how did you cope with this distress?

10. Did you seek support or counsel at the time of your conversion?

a. If so, from whom? 
b. And what about that person or persons lead you to seek their support?

11. How did your friends and family react to your conversion?

12. How do you think this conversion to the Christian faith was impacted by the fact that you were in college?

13. How does your conversion to the Christian faith affect you today?

a. What thoughts or feelings do you have when you think back to that time in your life?

14. Is there anything I did not ask you about your conversion to Christianity that you think might be beneficial for me to know?

\section{Procedure}

This research project was approved by the dissertation committee, West Virginia University’s IRB, and Appalachian State University’s IRB. The following materials, along with a research application, were submitted to IRB: (a) a formatted email which was sent to organization and church leaders requesting permission to visit their group and recruit participants (Appendix B); (b) a script for the researcher to inform potential participants about the research and to directly recruit participants for the study (Appendix C); (c) an informed consent form for participant involvement (Appendix D); (Prior to approval, the West Virginia University IRB requested the omission of a written consent form and recommended the use of a cover letter to provide information about the research project with the understanding that one's engagement in the research project was a demonstration of his or her consent (Appendix E)); (d) a research study information sheet providing interested individuals with details about the research project's purpose, methods, and procedures (Appendix F); (e) a demographic form (Appendix G) and (f) the interview protocol, which was sent to participants prior to the scheduled interview as well as 
was be used by the researcher when conducting the interviews (Appendix H). After approval by the IRB the researcher began the recruitment of participants.

The researcher attended a monthly meeting of student spiritual group leaders entitled the Appalachian Spiritual Life Association. At this meeting the researcher was able to obtain contact information for Christian campus ministry leaders and discuss the research project with them in person. These Christian campus ministry leaders were contacted by the researcher and requested permission, via email, for the researcher to attend their weekly meetings in order to provide information to their groups about the opportunity for students to voluntarily participate in the current study (Appendix B). If the organization leader allowed the researcher to do so, the researcher scheduled a time to attend a regularly scheduled meeting of the organization. At this meeting the researcher stood in front of the group, using the script (Appendix C), described the research study and expressed the need for voluntary participants who meet the inclusion criteria for participation. Later in the recruitment process, I used referral sampling wherein campus ministry leaders provided names and contact information of students who expressed interest in participating in the research after being informed about the research by these campus ministry leaders.

Interested participants were provided the cover letter (Appendix E), the research study information sheet (Appendix F), the demographic form (Appendix G), and the interview protocol questions (Appendix $\mathrm{H}$ ) and requested to provide their contact information to the researcher. The researcher reached out to these potential participants and engaged in an informal conversation about the research study and answer any questions they may have. Also during this telephone communication, the researcher insured that individuals met inclusion criteria and did not meet exclusionary criteria. The researcher then scheduled a time to interview as well as arranged a 
location for the interview which was convenient for the participant. Only one individual who expressed interest in participating it the study was ineligible due to being out of college. Eligible participants who completed a face to face audio recorded interview make up the participant group, and each participant was assigned an identification number by which to identify and store each of their respective data confidentially. Once participants were selected and interviews were scheduled, the data collection phase of the study began.

The data collection phase of the study involved interviewing participants in person. One days prior to the scheduled interview, the researcher contacted the participant and confirm the agreed upon time and location of the interview via email or text. At the time of the interview, the researcher and participant met in a private room in a university library to insure no risk of a third party overhearing the interview. The researcher reviewed the purpose of the research project, reviewed the limits to confidentiality, and reminded participants that they can decline to answer any question they do not want to answer and they are free to withdraw their information from the study prior to the data analysis phase.

The researcher, who is also the interviewer, followed the interview protocol (Appendix $\mathrm{H})$ and recorded the interviews using a digital voice recorder. The researcher took some notes during the interviews to note significant information and identify information that may need further clarification and further prodding by the interviewer. At the end of the interview protocol, participants were given ample time to ask questions or discuss any concerns. Participants were reminded of the contact information of the researcher, the researcher's advisor, the West Virginia University IRB, and the Appalachian State University IRB. Participants were encouraged to contact the researcher or the researcher's advisor should questions or concerns arise at a later date. They were also informed that the West Virginia University IRB and/or the Appalachian 
State University IRB should be contacted should the researcher or research advisor not resolve an issue to their satisfaction. Finally, participants were provided a list of local counseling providers should they need any ongoing support after engaging in the interview process (Appendix I).

After each interview was completed, the digital audio recording was downloaded and encrypted onto a compact disc. The digital recording was erased from the recording device. The compact discs and any notes taken during the interviews by the interviewer were labeled with the participant's identification number, and these materials were placed in a locked container in the researcher's secure office. The key with both participant names and identification numbers is stored in separate locked container in the researcher's residence. Following interviews, the researcher transcribed the interviews verbatim. Electronic transcripts were saved using participant identification numbers and proper names in the transcript were changed to pseudonyms. Audio files were destroyed following transcription.

\section{Analysis}

The researcher used IPA methods to analyze the data. These methods are outlined in Smith and Osborn (2003) and briefly reviewed here. IPA is similar to many qualitative methodologies in that the researcher attempts to understand themes across the data. What is different about IPA is the emphasis on interpretation of the interview transcript with a goal of learning about the respondent's psychological world (Smith \& Osborn, 2003). In IPA, the story or narrative that the respondent provides is a representation of a piece of the respondent's identity (Smith, 2003). The researcher, during the analysis process, attempts to understand both content and complexities of meaning that are imbedded in the respondent's story. Frequencies of themes are of less interest than are themes that are most salient to the respondent's identity and 
psychological and social worlds. This depth of analysis is only possible when the researcher approaches the transcript from an interpretative stance. Smith and Osborn (2003) refer to this process as engaging in an "interpretative relationship with the transcript" (p. 66). IPA is an idiographic approach to analysis and starts with reading and interpreting one case before moving on to the second case and subsequent cases (Smith \& Osborn, 2003).

The first case transcript is read a number of times using the left-hand margin for noting interesting or significant impressions of the respondent's narrative. There are no limitations to what can or should be noted during this phase of the analysis. Some of the notes typically ascribed during this time include summarizations and paraphrasing or noting similarities, differences, echoes, amplifications, and contradictions within the data. The objective during this phase of analysis is to become as familiar with the transcript as possible. Once the transcript has been read a number of times and the researcher has sufficient familiarity with the data, the righthand margin is used to document emerging theme titles. The titles are concise phrases that capture the essence of content and meaning found in the text. Creating theme titles requires a higher level of abstraction on behalf of the researcher. Ideally, the themes would be of a high level of abstraction so that if similar themes arose in the same or different cases this could be noted. However, it is also imperative that these higher order abstractions are not too far removed from the transcript so that they lose the original intended meaning of the respondent (Smith \& Osborn, 2003). Throughout the analysis process, the researcher returned to the transcript to insure that themes are representative of the data. After both the right and left-hand margins of the transcript have been used to denote impressions and themes respectively, the emergent themes are listed in chronological order as they appear in the transcript (Smith \& Osborn, 2003). 
The researcher looked across the emergent themes for connections or thematic similarities. The themes were then relisted in a more analytical order. Some themes clustered together and some themes emerged as superordinate concepts which overarch other themes. Smith and Osborn (2003) recommended the researcher create directories wherein page and line numbers from the transcript, as well as quotes representing each theme, are noted next to the themes and clusters of themes. This held the researcher accountable to checking and rechecking the original data for congruence with higher order abstractions. The final stage of analysis with the first case is creating a table of themes. In this table, clusters of themes are given a representative title under which the related themes are listed. Some themes were omitted at this stage as they did not fit the overall theme structure evident in the transcript or if the theme was not as rich as other themes present in the transcript. The directory of information, including page and line numbers and respondent quotes, are listed to the right of each theme. After the analysis of the first case is complete, the researcher moves on to analysis of the second case, and so on (Smith \& Osborn, 2003).

A researcher using IPA can opt to either use the table of themes discovered in case one as a guide for the analysis of case two or he or she may choose to analyze the second case independent of the themes already established. The latter strategy is typically used when there are very few cases (Smith \& Osborn, 2003). The current study involved nine participants: thus, the researcher utilized the former method, utilizing emergent themes from previous cases as a guide for analysis of later cases. However, every effort was made to respect similarities and differences between cases allowing new themes to emerge as the cases diverge from one another. The second and subsequent cases were analyzed just like the first. Once all cases were analyzed using this interpretative process, a master table of themes across cases was created. This stage 
was somewhat challenging as it required the researcher to prioritize and reduce the data down to those themes that are most representative of the data's essence and meaning. Again, frequency of themes is only one factor when considering the final list of themes, as richness and connection among themes is most important. After the master table of themes was created, the researcher turned her attention back to the original transcripts for each case, and identified within each case the presence of themes which emerged after analyzing that particular case. The master table of themes includes references from each case (page and line numbers) which correspond to themes (Appendix J). The master table is one of the two products produced by the analysis process; the second product is the narrative write up of themes which comprise the result section of this dissertation (Smith \& Osborn, 2003).

In the write up process, the researcher was challenged with the task of expanding the themes, which were reduced to short descriptive titles in the initial analysis phase, into narrative form. The narrative description of each superordinate theme include references to the subordinate themes within that cluster and used quotes from cases to illustrate the presence of that theme across the data; this narrative description makes up the results section below. The researcher was careful to make clear what part of the narrative is the interpretative work of the researcher and what was said by participants (Smith \& Osborn, 2003). After analysis of the data, the findings including themes, clusters, and definitions of themes, along with the original transcripts were sent to an external auditor for review. The external auditor was a senior colleague in the Religious Studies department at Appalachian State University, Dr. Randall Reed, who was not involved in any other part of the research study. This process serves as a methodological "check" of the data and is one means of triangulation (Williams \& Morrow, 2005). Additional means of enhancing trustworthiness of the data are described below. 


\section{Quality and Trustworthiness of the Research}

Ensuring trustworthiness and rigor of qualitative research is the equivalent of ensuring reliability and validity in quantitative research. Several criteria and strategies were employed to ensure trustworthiness and rigor in the current study. According to Morrow (2005), criteria for trustworthiness vary depending on the paradigmatic underpinnings of the particular investigation being carried out. IPA fits well into Morrow’s Interpretivism-Constructivism paradigm. Her criteria for trustworthy interpretivistic-constructivistic research are laid out and the corresponding efforts and strategies which the researcher employed are outlined.

Morrow (2005) highlighted the importance of acknowledging and embracing subjectivity of the researcher. The researcher's disclosures provided in the Personal Reflective Statement and Personal Epistemological Viewpoint sections in the Participants section are an effort to be upfront about the subjectivity of the researcher. Also, personal reflections are identified as such in the discussion section of the final research document. Triangulation is another technique used to increase the rigor of the current research by helping to capture and respect multiple perspectives (Marrow 2005; Williams \& Marrow, 2009). A review of the relevant literature, exploration of developmental theories, use of multiple participants with varying perspectives and the use of an outside auditor are all means of triangulation that were used to enhance the trustworthiness of the current research. The auditor, Dr. Randall Reed is conducting his own research on millennials leaving the church and whether the emerging church would fit their spiritual needs. Dr. Reed was aware of the psychological focus of this study and his expertise in Religious Studies made him an ideal auditor for this research project.

Authenticity, particularly ontological authenticity, is another criterion defined by Morrow (2005) as a means toward trustworthiness. This involves facilitating a raised level of awareness 
among participants. Gradually increasing the specificity in interview questions, using probing questions, and having multiple contacts with participants helped facilitate ontological authenticity in the current research. Verstehen, a deep understanding of participant's intended meaning, is extremely important and efforts were made to increase understanding. Efforts include using a contextual lens in analysis and "recontexualizing” data as it relates to participants' and the researcher's context, culture, and rapport. Particularity is also important in interpretative research and relates to “doing justice” to each unique case before moving on to analyze additional cases (Morrow, 2005). IPA requires full analysis of one case before moving on to analyses of the second, third, and following cases. As with many methods of qualitative analysis, the IPA researcher continuously refers back to the transcript under investigation to ensure abstracted themes are indeed representative of the original data. Finally, the use of a pilot study using one volunteer was conducted (interview only) in order to better and more fully inform later research participants. With input from the pilot study volunteer I learned the importance of fully defining the terms "converting, conversion, and conversion experience” to participants prior to the interview. Also, I identified some effective probing questions to increase ontological authenticity among participants. While multiple strategies are being used to enhance trustworthiness and rigor of the current study, there are several potential limitations which are outlined in the Discussion chapter. 


\section{Chapter 3}

\section{Results}

Themes were conceptualized using 516 quotes from the nine participant interview transcripts. Selected quotes were included based on their relevance to the research questions and the significance of that statement as evidenced by the participant during the interview. The quotes were arranged into 45 themes and organized under 10 superordinate concepts. Superordinate concepts and themes, along with the number of participant interviews which contain each particular theme, are listed in Table 2. Appendix J contains the theme directory charts for each case with all of the quotes extracted from the nine transcripts. The discussion of themes below is organized by superordinate concepts, and numbers in parentheses represent the total number of participants endorsing that theme (denoted by “ $n$ ”) and the total number of units, or quotes, included for each theme (denoted by “ $k$ ”). The themes are highlighted using participants’ quotes and all proper names and nouns have been altered using pseudonyms. Participants’ numbers are used to identify their respective quotes (i.e., Participant 1, Participant 2, etc.). See Table 1 to reference gender and age of each participant.

Table 2

Superordinate Concepts and Themes with Frequencies

Superordinate Concept Previous Exposure to Religion/Spirituality

Unique to College
Family Involvement

Friend Involvement

Significant Influential Persons

Lack of Exposure

Negative Experiences

Theme

\# of Participants

8

6

9

4

7

Independence

Parties are Unsatisfactory 
Table 2, Continued:

Questioning God

Self-Exploration 6

Wrestling with Evil 3

Doubting God 8

Doubting Allah 1

Dismay with Islam 1

Reconciling Science and Supernatural 2

God is Omnipresent and Sovereign

Resistant to Convert 6

Positive Emotional Experiences

$\begin{array}{ll}\text { All Sufficient } & 5 \\ \text { Evidence of God } & 8 \\ \text { Confidence in God's Sovereign Plan } & 8\end{array}$

Peak Experiences 8

Newfound Hope 6

Gratitude 5

Healing 5

Relief 6

Understanding 8

Happiness 8

Love 6

Freedom from Legalism 1

Openness

Existential Meaning

Open to God 5

Open to Others 6

True Identity 7

Life Purpose and Meaning $\quad 4$

Altruistic Plans 6

Challenging Emotional Experiences- Prior to Converting

Abandonment 1

Hardship 6

Confusion 4

Challenging Emotional Experiences -After Converting

Spiritual Warfare 2

Discord with Others $\quad 7$

Ongoing Hardship 4

Guilt and Shame $\quad 5$

Supports

Loss of Friends $\quad 7$

Current Critical Evaluation $\quad 7$

Commonality 5

Truth in Love 4

Support 9 
Table 2, Continued:

Strong Relationships

Relationship with God
7

3

\section{Previous Exposure to Religion/Spirituality}

The first superordinate concept contains themes which reference participants' exposure, or lack thereof, to religion and spirituality prior to converting. It includes family involvement, friend involvement, significant influential persons, lack of exposure, and negative experiences.

Family involvement $(\boldsymbol{n}=\mathbf{8} ; \boldsymbol{k}=\mathbf{1 1})$. Participants discussed their exposure to religion and spirituality prior to converting to Evangelical Christianity. This particular theme refers to their exposure due to immediate or extended family’s involvement in a religious or spiritual group. With the exception of one participant's exposure to Islam due to family involvement, participants’ exposure was to Christian and Catholic faiths. Participant 1 reported, “I grew up Catholic. Um, so I came to the United States when I was five years old and my adoptive parents were Catholic...”

Participants described their exposure to religion and spirituality in differing degrees. Participant 2, whose exposure was quite limited explained, "I could probably name off one hand how many times I'd been to church growing up.” Several participants described having changes in the frequency of church attendance across their childhood. For example, Participant 9 stated “...my parents stopped going to church. They only went during holidays so it wasn’t really a big part of my life anymore.” Some participants expressed a sense of being unwillingly exposed to religion and spirituality. The exchange I had with the former Muslim participant (Participant 5) demonstrates this: “I: Okay. So can you tell me just a little bit about your background as a Muslim person? P: It was forced. It’s forced on you when you are young.” 
Friend involvement $(\boldsymbol{n}=\mathbf{6} ; \boldsymbol{k}=\mathbf{1 0})$. Similar to the above theme, these were reference to exposure to religion and spirituality prior to converting to Evangelical Christianity; however, this theme represents exposure due to their connection with a friend who was directly involved in a religious or spiritual group. Each participant, exposed through friend involvement, was exposed to either Christian or Catholic faiths. Participant 3 stated, "I had a couple friends were going to [a Christian ministry] and they invited me to come with them.”

Participants described being motivated to attend church events due to their existing connections with friends. Participant 1 recalled, “And then with the Anglican Church um, basically I was going for the wrong reasons because my friend went...” Another participant, Participant 2, stated that his girlfriend's involvement in a musical production at her church led him to feel a sense of obligation to attend the church. He stated, "I remember it was my girlfriend's, she was in like the worship team... she's a good singer, but they had a Christmas concert, at, at her church and of course I feel the need to go.” Other participants explained that they were exposed to religion and spirituality simply though being acquainted with other Christians. Participant 7 explained, "Yeah, so one of the first girls I met at [this University] was really involved in the [campus ministry] community...”

Significant influential persons $(\boldsymbol{n}=\mathbf{9} ; \boldsymbol{k}=\mathbf{2 8})$. Each of the nine participants discussed having a person or multiple people in their lives that were instrumental in encouraging their conversion to Christianity. These influential people were Christians and included friends, campus ministers, and for one participant, a stranger who invited her to a Christian meeting. Most of the significant influential persons described by participants demonstrated love and caring in a way that was distinct from interactions the participant had experienced in the past. 
Furthermore, most of these people were a source of support to participants during their transition into the Christian faith. Participant 6 recalled:

I told Jackson while I was drunk, I said, ‘you know Jackson the only way that I would ever believe in a God again is because I see people like you who show love and who care for people and who are completely, you know, accepting of people despite what they have done in the past, that kind of thing.'

Participants described experiencing support from these significant influential persons in many ways. Participant 1 recalled, "So he [a campus minister]... talked to me about my adoption and just the things that I was struggling with or like all the questions I had about God um he was there to kind of listen to me.” Participant 3 stated clearly the link between her friend and her conversion saying, "I remember, I think Jessica is probably the biggest instrument in my conversion experience, I mean God used her it's not her.” The behavior and actions of these significant individuals, more so than anything they said, often proved to be the most instrumental in affecting participants. In answering a question about the catalyst for her conversion to the Christian faith, Participant 7 explained, “...probably people that didn’t talk about Christian... augh, they, they didn't, they showed me Jesus through their actions more than speaking it at me because I wasn’t willing to really listen to it after a while.”

Lack of exposure $(n=4 ; k=4)$. These were references pertaining to the lack of exposure to religion and spirituality on behalf of a participant. For several participants the lack of exposure was for the full duration of time prior to college while for other participants, this lack of exposure was for a significant period of time after previous exposure to religion or spirituality. Participant 4 explained, “Well, growing up I was, my family has never been very big into religion. My mom is a pagan my dad is an atheist.” While Participant 8 stated, “... we just 
stopped going to church altogether and so I, my family has not gone to a church in, since I was $11 \ldots ”$

Participant 2 discussed the lack of religion and spirituality exposure across both friend and family domains, explaining:

... the people that I surrounded myself with, basically the way I was raised, not going to church no friends or family that were really like outgoing in their faith, or profound in faith. My mom’s very internal as far as faith goes and like, I don’t know, my dad, yeah he is spiritual, I don't know, he’s a farmer, he works all the time so, he never really has time to really go to church.

Despite Participant 9's eagerness to engage in religion and spirituality, the family ending their church involvement hindered her exposure. This participant stated, "So I always grew with an excitement and an excitement to talk about God but I guess I got, it just kind of died off when we stopped going to church.”

Negative experiences $(\boldsymbol{n}=7 ; \boldsymbol{k}=\mathbf{1 4})$. This theme refers to a participant having negative experiences with regard to spirituality and religion prior to converting to evangelical Christianity. Experiences are varied and include experiencing Christian’s as hypocritical and judgmental, having knowledge of immoral behavior by a spiritual leader, and observing others’ punishment by an Imam for improper Arabic pronunciation. Participant 8 explained, “So, and then the pastor was caught watching child pornography on the church computers and had to leave the church.”

Participants expressed having challenging experiences with patrons of the church, spiritual leaders, and doctrine presented in the church. Participant 2 explained that his family did 
not attend church due to having conflict with family members that attended the church and perceiving these family members as hypocritical. This participant stated:

...then my mom told me growing up that she never took me church because that's where they all went; they all went to that church. And if you have a bunch of Christians quote on quote going to church and being two faced my, she did not want to raise me and my brother and surround us, around people that were going to be hypocrite.

Participant 5 recalled her negative experience in a mosque learning Arabic, “Then you had to go and say whatever to the main guy there and when you make mistakes, he smacks you on the head.” Finally, Participant 6 described being exposed to teachings about God which were harmful. He remarked, “...I had been raised in with you know the loving God with a hateful hand...”

\section{Unique to College}

The researcher was interested in the role that being in college played for participants converting to the Christian faith. The following themes represent statements that participants deemed unique to being in college and integral to their converting to the Christian faith. Themes include independence, parties are unsatisfactory and self-exploration.

Independence $(\boldsymbol{n}=\mathbf{5} ; \boldsymbol{k}=\mathbf{7})$. When asked about how their conversion to the evangelical Christian faith was impacted by the fact that they were in college, a large number of participants referenced the fact that college allowed greater independence. Participants discussed being away from home and having freedom to make decisions independent of their parents. Participant 1 explained, “... and so I just think that that aspect of that freedom or that independence helped me to be able to pursue what I needed to as an individual without their kind of guidance or say as to what I should or should not do.” 
Participant 6 explained that this independence was a novel experience, explaining the following about college, “It's the place where most young people first become independent.” Participant 4 contrasted life in high school and life as an independent college student stating, "I went to high school living under my parent's roof with what their rules were, what they believed in, got to college and I wanted to live my life my way...” Lastly, for Participant 7, who was active in church during high school, this independence resulted in her leaving the Christian faith prior to converting. She remembered,

Um, yeah and so I came to college and was like, 'I'm going to do my own thing, I don't need this lifestyle because I am my own person now, I don’t have to listen to my parents and I don't have to do these things, I can do whatever I want to.'

Parties are unsatisfactory $(n=4 ; k=8)$. These were comments referencing the lack of fulfillment or satisfaction that college partying provided. Participants stated that partying, drinking, and using drugs lost its appeal and did not contribute to their need for meaningful living. Participant 6 stated:

I honestly think it was a desperation for meaning to my life because out of everything that happened whenever I first came to [this university], you know, I did a lot of partying and I did a lot of drinking and that kind of thing and I saw in no way that my life was going forward and I didn't know what I was doing.

Another participant, Participant 1, alluded to lack of satisfaction found in partying, recalling, “...before I became a Christian I went to some clubs and partied and really did not find satisfaction in that and realized that there had to be something more than doing that.” Yet another participant looks back and sees similarities between herself and a current friend who seeks satisfaction in partying in vain. Participant 3 explained: 
...one of my friends that's a freshman now and she is not a Christian and does a lot of drugs and doesn't know why she coming to [campus ministry] and she’s like, 'I just want something more and I'm tired of what's happening.' I think that's where I was.

Self-exploration $(\boldsymbol{n}=\mathbf{6} ; \boldsymbol{k}=\mathbf{8})$. Some participants spoke of college being a time and place of self-exploration which aided in their ability to explore their spiritual and religious beliefs and ultimately convert to evangelical Christianity. Participant 7 remarked, "I think people are trying to figure out who they are, who they want to be, where they're supposed to be, who their friends are, just all those questions.” Participant 9 discussed how this self-exploration paralleled her exploration of God, stating:

And it was just a time for me to actually explore God on my own time and I had to make my own schedule and explore who I was and I ended up finding it. And so I think college offered the freedom I needed to be freed in a way.

Participants also alluded to finding a meaningful culmination to some of their selfexploration through their conversion to the Christian faith. Participant 4 reported, "Like I was always searching, creating myself, trying to find myself, and as it happened after I converted...” Participant 3 expressed her understanding that God was orchestrating part of this self-exploration so that she would ultimately find Him. This participant recalled:

Like God had worn me down and I was tired of trying to be good and screwing up and not knowing who I was and not knowing where my identity was, which I feel like is such a big part of the college experience is 'Where is your identity?' and having to find the answer. So I think that, or I think college provided that sort of environment to prompt me to become a Christian. 


\section{Questioning God}

The themes below represent participants’ questions and doubts about the Christian God and, for one participant, questions and doubts about Allah. This superordinate concept consists of the themes wrestling with evil, doubting God, doubting Allah, dismay with Islam, reconciling science and supernatural, and resistant to convert.

Wrestling with evil $(\boldsymbol{n}=3 ; \boldsymbol{k}=4)$. Prior to converting, participants reported having questions about the existence of evil. Participants seemed to attempt to make sense of the presence of evil while also reconciling the existence of an all-powerful God. For example, Participant 1 stated, “...I’ve learned about things such as sex trafficking or um just things that are really kind of hard and dark and I question God in that and questioned whether he was real.” Participant 2 questioned the existence of God based on his personal life experiences, stating, "Just like a lot like that went wrong in like my life and just in the world in general, I thought, 'How could there be a God?’” Another participant, Participant 4, recalled identifying contradictions in theology prior to his conversion. He noted:

I guess it was the whole, contradiction parts of the Bible, and the whole if He's so omniscient, why does he know what's going to happen to us sometimes stuff like, why does he let bad things happen, and just those things, everything that atheists question about the Bible...

Doubting God $(\boldsymbol{n}=\mathbf{8} ; \boldsymbol{k}=\mathbf{2 3})$. This theme represents statements about having doubts about the existence of God. Participants also expressed having questions about God's character, theology, creationism, and the truth of the Bible. This doubt was present prior to converting and for some participants this doubt and questioning remained during the early time of their 
conversion. Participant 6 explained, "I heard that message and then I was like, 'That sounds too good to be true, I'm going to, I'm going, I'm going to run...’”

Participant 4, who previously identified as an atheist, remembered not only his doubts but his argumentative stance against the Christian faith. He recalled having, “...never been introduced to the Bible before really, other than to use it as an argument against it sort of thing.” Negative personal experiences also led one participant to doubt the existence of God. Participant 2 stated, “I just doubted creation and His existence based on like what happened in my life.” Lastly, Participant 1 questioned God right up to the moments prior to converting. She remembered being at a Christian conference and stated, “...I was like outside kind of questioning God and wondering whether I really wanted to do it [convert]...”

Doubting Allah $(\boldsymbol{n}=\mathbf{1} ; \boldsymbol{k}=\mathbf{4})$. These were statements by one participant who expressed having doubts about the Islamic god prior to her conversion to Christianity. The participant explained that having doubts in Allah as a Muslim is very rare. She explained that doing research on Islam and reading the Quran led to this doubt. Participant 5 stated:

I found some terrible verses found in the Quran ... and it said terrible things like the unbelievers you're supposed to slay them wherever you find them, chop off their fingertips, don't make friends among them. Why would God hate his creations that much?

In an exchange during the interview, this participant expressed her initial fear in questioning Allah:

I: Okay. Yeah. So you said you didn’t question the Muslim god until you...

P: I was always afraid to.

I: Uh huh. 
P: Even like praying five times a day, I'd always be afraid that he would hate me.

I: Who would hate you?

P: Allah.

When asked about the catalyst for her doubt in Allah, this participant explained, "Just the evil verses in the Quran and everything Muhammad used to do, he was a terrible person, he was a fake prophet."

Dismay with Islam $(\boldsymbol{n}=\mathbf{1} ; \boldsymbol{k}=\mathbf{6})$. Participant 5, who was Muslim prior to her conversion, expressed dismay at Islam. This participant's dismay was with teachings in the Quran and the behavior of the Islamic prophet, Muhammad. She noted, “It's a terrible religion. I hate when people defend it. They don’t know anything about it or they have Muslim, good Muslim friends, that's why they defend it. They don't do their research.” This participant further expressed her perceptions of peoples’ misconceptions of the Muslim faith, stating:

I don’t even think they understand how difficult Islam is. You have to be Muslim or have gone through it to realize it. A lot of people don’t believe me when I tell them how difficult it is. It's hard for them to believe but it's true, everything's true, I take it seriously.

This participant’s dismay with Islam was most pronounced when she indicated, "I feel like terrorists would be true Muslims. It says you're supposed to kill non-Muslims. That's what they do they follow it fully.”

Reconciling science and supernatural $(\boldsymbol{n}=\mathbf{2} ; \boldsymbol{k}=\mathbf{6})$. Two participants express questions about scientific phenomena particularly evolution, and attempted to reconcile what they see as seemingly contradictory truths in science and supernatural occurrences. Participant 2 expressed distress about this reconciliation process in the following context: 
P: As in, what was stressful?

I: Yeah.

P: Uh, the science without a doubt, evolution versus religion thing, whether or not God is real; that like you could not see Him or prove His existence through stuff like with hardcore facts or evidence like science.

For this same participant, reconciling science and the supernatural was paramount in his ability to convert. He stated, “...you can have a happy medium with both science and religion regardless of what people say. So that was, that meant a lot to me. That was huge in my book.” Similar to the Participant 2, Participant 5, whose comments helped define this theme, was pursuing a career in the sciences. This participant supported the notion that a creator God initiated evolution. She stated:

I feel like evolution could have been God driven. There’s not enough proof for it but the big bang doesn’t make much sense. How did that start? And they haven’t been able to reproduce abiogenesis in the lab: living things coming from nonliving things.

Resistant to convert $(\boldsymbol{n}=\mathbf{6} ; \boldsymbol{k}=\mathbf{1 2})$. This theme was employed to classify participants' initial feelings of hesitance, resistance, and even fear of moving from a place of unbelief to belief or making a decision to convert. Participant 7 reflected on her long journey of resisting conversion, stating, “... I think I knew the truth in high school but I had just run from it for so long.” Several individuals expressed coming to a time and place where their resistance or hesitation could no longer be justified. Participant 4 explained, “I didn’t think I was fully going to accept it until he [a campus pastor] said that [communion at that particular event was only for believers], then something moved me to just say, 'I have no more reasons not to believe.'” 
Regarding resistance based on feelings of fear, participants seemed intimidated by the prospect of believing wholeheartedly in God and taking a leap of faith. Participant 1 recalled a friend nudging her toward conversion stating, “...I was hesitant to get saved ...I think my friend kind of volunteered me, or something like that, 'cause I was scared”. Another participant, Participant 4, compared the choice to convert to a risky jump, explaining, "That was, like that thing where you sit on the side of a waterfall and say well I mine as well jump.”

\section{God is Omnipresent and Sovereign}

The conceptualizations of themes within this superordinate concept come from participant statements about the ever-present work of God prior, during, and after their conversion. Moreover, participants highlighted that God is capable of all things and can be trusted to orchestrate the future. The themes are all sufficient, evidence of God, and confidence in God's sovereign plan.

All sufficient $(\boldsymbol{n}=5 ; \boldsymbol{k}=\mathbf{8})$. More than half of the participants mentioned God as fully capable of handling any and all problems that they may encounter. In these statements, participants clearly acknowledged their own limitations and the limitations of others while pointing to the sufficiency of God. Participant 1 claimed, “...you just can’t rely on yourself, you realize you can't be your own savior um and that the problems that you have you can’t fix yourself or other people can’t necessarily fix it for you.” Participant 9 stated, “I felt like anything could come my way, even if I had a bad day, or like the world um came crumbling and I didn't know what to do like God would have my back.”

Participants alluded to God being the most viable source of support in their lives. They expressed comfort in knowing that God redeems not only their lives but also all the wrongs in the world. Participant 1 noted, “Yeah, I guess just realizing that I don’t know what else I would 
have other than being able to rely on Him.” Participant 3 contrasted God’s all sufficient nature with her own human limitations, stating:

I was like, ‘this isn’t in my hands' and 'I’m just an instrument and I am very small but God is very big, and He can do big things and He can use me or He can’t, that's okay.' And just having hope that one day this will all be redeemed and there won't be poverty, we won’t have to worry about carbon emissions.

Evidence of God $(\boldsymbol{n}=\mathbf{8} ; \boldsymbol{k}=\mathbf{2 1})$. This theme represents statements made about the evidence of God in participants’ lives prior to their conversion. Participants expressed an understanding that God had been working to bring them into a saving knowledge of Himself prior to the time of conversion. Some participants also discussed how God used pain and heartache for good. One participant saw evidence of God in her life while going through a challenging break-up and when a friend started a "random” small group Bible study in her hometown the summer prior to conversion. Participant 8 recalled, “Um, I really, looking back, God was just coming after me, my whole, I mean my whole life.” Participant 2 explained, “I don't know, I just, like going through all the struggles but like, He helped guide me and shape me into my own.”

Most participants described God as active in pursuing them prior to any willful decision of their own to convert to the Christian faith. Participant 1 remarked, "So, I guess seeing how the Lord worked even before I really surrendered my life to Christ.” Participant 3 saw evidence of God’s presence in her life prior to converting. She stated, “...but I feel like He was revealing just like His presence in my life...” Several participants saw the evidence of God through the actions of other people in their lives. They attributed the kind gestures of others to be God working through those individuals in order to bring the participants to a place of converting to the 
Christian faith. Participant 5 explained, "I noticed He sends people into your life exactly when you need them, it’s very strange.” Participant 4 stated, “And so, she asked me if I wanted to go to her campus ministry...the Holy Spirit was speaking to her.”

Confidence in God's sovereign plan $(n=8 ; \boldsymbol{k}=24)$. The majority of participants remarked about trusting in God's supreme plan for the future and more specifically for their personal futures. They expressed a relinquishing or a surrendering of their plans for themselves and trusting that God would orchestrate their future as He sees fit and that this future would be significantly better than any future they could think or imagine for themselves. Participant 9 remarked, "I feel like He changed my perspective on my future because He gave me hope in it. And even if I didn't know what I was doing, I knew that He was in control, that's all I needed to know.”

Confidence in God’s sovereign plan also seemed to provide hope to participants. Participant 2 stated, “...there’s more of a fulfillment in life, knowing that you're saved. Knowing that there's something more; you find restitution in something like that then just nothingness.” Also encompassed in this theme, is the activeness of God, He is considered the author and finisher of a believer's fate. Participant 3 explained it this way, “And the fact that there is a plan and it's not up to me to make it all happen.” This final quote, from Participant 6, demonstrates the contrast between one leading his own life plan and surrendering to God's sovereign plans:

I was going to get a tattoo of you know, 'I am the master of my fate, I am the captain of my soul,' [laughs] and I am so glad I did not get that because it would have been like, ‘Oh goah, I can’t believe I just got that and now I believe in God and gave my fate to Him.’ 


\section{Positive Emotional Experiences}

This group of themes represents the positive feelings and experience of participants at the time of their conversion and after their conversion. They are peak experiences, newfound hope, gratitude, healing, relief, understanding, happiness, love, and freedom from legalism.

Peak experiences $(\boldsymbol{n}=\mathbf{8} ; \boldsymbol{k}=\mathbf{1 5})$. This theme refers to significant experiences which contributed to an increase in faith, a sense of greater revelation, feelings of euphoria, or produced a "spiritual high.” For Participant 5, who converted to Christianity from Islam, simply going to church was a peak experience. This participant stated, “I’ve never experienced anything like that. They were singing and dancing and I never got that at mosque.” For some this peak experience was their conversion experience and for others it was a particular experience at retreats or church event. Several participants alluded to the challenge of realizing that this peak experience and euphoric feeling is time limited. Participant 1 stated:

I think, especially, cause if you go on retreats or anything like that, I think that's what I struggled with is, you get to a spiritual high and, I mean I was saved so that was a really big stepping stone but, you go back into the real world...

At times this peak experience produced a sense of great possibility and capacity for what the future holds. For example, Participant 1 recalled, “...I was on such as spiritual high from that conversion that I felt like that any problems that came my way that I would be able to handle.” Many of the peak experiences described may have seemed like mundane or ordinary moments to an observer; however, for the participants God met them in a significant way in those moments. Participant 6 had a peak experience on a late evening when he was locked out of his dorm room and slept on the dorm lobby couch. He recalled, “I had this, this just, this moment where God showed himself to me.” 
Newfound hope $(\boldsymbol{n}=\mathbf{6} ; \boldsymbol{k}=\mathbf{1 3})$. Several participants expressed a newfound hope for the future after converting. They expressed a feeling of expectation that positive things would happen in their lives and a trust in God that He would bring to fruition a better future than the future destined to them prior to conversion. Several participants contrasted this newfound hope with emotional challenges and perhaps a sense of hopelessness prior to converting. Participant 3 stated,

And like being, like struggling, or like having this underlying theme of struggling my whole life. ... just not feeling like peace about the decisions I was making or the things going on around me, like things that are happening in the world, and having this new sense of hope.

Two participants discussed living with mental illness before and after converting and highlighted how this newfound hope affects them. Participant 4 stated, "I was still depressed afterwards it’s just depression is not something that goes away after a day. And, but it has gave me something to, to hold on to, hope that there’s something better out there.” While Participant 8 stated: ...I'm a lot more calm. I actually have a severe panic disorder that I'm medicated for so I'm sure the medication helps but I'm a lot more calm now. I, I know where my hope is and that just makes a person calm, you know.

Gratitude ( $\boldsymbol{n}=\mathbf{5} ; \boldsymbol{k}=\mathbf{6})$. These were references participants made about feeling thankful for their conversion experience. They expressed feeling grateful that their lives changed and that they converted to the Christian faith. Participant 3 explained, "So I think I look back and I am thankful for my conversion experience and I am thankful that I can look back and see so much of His presence in that time...” Participant 1 expressed gratitude for the life changing work God initiated in her life, stating: 
I am thankful for my conversion and I guess I never really thought about what would happen if I hadn’t been converted. But I think that everything happens within its timing and that the Lord was, was leading me to that conversion. So I guess I'm just thankful for it.

Lastly, when Participant 2 was asked how he felt when thinking back to the time of conversion, he stated, "Lucky. I feel really lucky in; well not lucky, blessed is the word.”

Healing $(\boldsymbol{n}=\mathbf{5} ; \boldsymbol{k}=\mathbf{9})$. Some participants spoke of experiencing healing from pain and distress as a result of their conversion. Participants described a range of concerns for which they received healing including a sense of abandonment, depression, substance use, and a general sense of brokenness. Participant 1, who was adopted and experienced a sense of abandonment, recalled, "I knew that I was going through a healing process and that it was healthy.” A different participant, Participant 6, who overcame substance use concerns after converting explained:

Um, listening to the voice of God and just seeking after him has replaced any desire that I have for you know drinking or for anything like that. And anytime I get really depressed and stuff, I just, I don’t immediately think, 'Hey, I’m going to go and drink a whole bunch of beers and forget about it.' I really try to deal with it head on. Participant 9 experienced a sense of freedom after overcoming depressive feelings. This participant stated, “...I had great feelings and bad feelings all at the same time, and God, every bad feeling I had, God overcame. So, all those chains are broken.”

Relief $(\boldsymbol{n}=\mathbf{6} ; \boldsymbol{k}=\mathbf{1 8})$. A prevalent emotion experienced by participants as a result of their conversion was that of relief or peace. This feeling was characterized by reassurance and relaxation after conversion and allowed a release of distress. A word used by many Christians as synonymous with conversion is “salvation.” Participants seemed to express a sense of being 
saved from pain or demise. Participant 4 explained, “... it was more like, or at the moment it was a relief. It just, it felt right.” Participant 3 expressed relief that Jesus died on the cross to save her from the wages of sin stating “And I think relief and trust comes from looking at Jesus and looking at the fact that he died on the cross for all these sins that I continue to find out about.” Several participants expressed feeling a sense of burden being removed after converting to the Christian faith. Participant 2 explained, “I don’t know it’s like a huge weight was lifted off your shoulders.” For the individual who converted from Islam (Participant 5), leaving the Islamic faith felt relieving. She stated, “It's a relief, I am glad I got out of Islam; it’s the best thing that's ever happened to me.”

Understanding $(\boldsymbol{n}=\mathbf{8} ; \boldsymbol{k}=\mathbf{1 2})$. This theme included statements about participants’ experiencing a new sense of understanding and faith in God at the time of converting and after converting. Some expressed having questions answered, doubts being dispelled, belief in the Holy Scriptures, and a greater understanding of their place in the world. Participant 4 remembered how his questioning the Christian faith lead to understanding it. This participant noted:

...I had questions, and week after week, those questions got shot down by either [campus pastor], or the Holy Spirit, and God Himself. And at that point, I started, I looked and like well I have no reasons anymore not to believe.

When asked about positive experiences related to her conversion Participant 3 highlighted the importance of new revelation or understanding. She stated:

I think more so emotions about like peace and happiness and finally understanding, just like understanding. Which was really important to me because I felt like I'd like heard all 
these things my whole life about religion and Christianity but I never really like understood them or could grasp them.

Participant 7 had a similar experience of encountering the same religious information but being able to have faith and understanding in its truth. This participant recalled, "I think it was sort of turning back around and seeing the truth again but finally accepting it for what it was and not letting myself be so hard to it.”

Happiness $(\boldsymbol{n}=\mathbf{8} ; \boldsymbol{k}=\mathbf{1 7})$. One of the most common responses among participants regarding emotions experienced during the conversion experience was happiness. Participants described feeling happy and joyful as a result of their conversion, happier since the time of conversion, and happiness talking with the researcher about their conversion. When asked how she felt discussing the topic of converting, Participant 9 stated, "Joyful, I love talking about God and what He’s done.”

A number of participants experienced more joy in their day to day lives after converting. Participant 3 explained:

And so, and not every day is this super awesome conversion experience but finding like joy in small ways that God chooses to reveal Himself to you or like show His presence to you whether that be through like a relationship...or being a camp counselor... Participant 2 noted, “You find, I find myself happier, more answered prayers, less difficulties in life that's for sure.” Also, recognizing the goodness of God produced joy and happiness in respondents. Participant 6 explained, “And then after that I was just full of joy and I was happy and I was just like, ‘Wow this is awesome God. You're just, you're incredible.’”

Love $(\boldsymbol{n}=6 ; \boldsymbol{k}=7)$. A majority of participants reported an increase in the experience of love both from God and from Christian peers. Regarding the love of God, Participant 9 stated, "I 
think as soon as you have a perspective that He is love, everything changes. So I think that's like the underlying foundation for every small and big moment that was positive.” Participant 1 described experiencing God’s love as a personal breakthrough. She explained, “...it was that breakthrough I guess of... being able to experience God’s love, not just knowing that God loves you but feeling it your heart...”

Regarding the love between Christian peers, participants described this affection and love as somewhat distinct from that of the affection experienced with peers prior to converting. Participant 8 explained, “And I don’t know we just, we just love each other, and it’s not like, 'Love you girl, bye.’ It’s like we love each other.” Participant 3 described experiencing unconditional love from a friend, not just through the friend's kindness but also her challenging honesty, stating, "I think, well for Jessica, I knew that she would love me no matter what I told her but also that love looked like her being honest with me.”

Freedom from legalism $(n=1 ; \boldsymbol{k}=\mathbf{4})$. Participant 5 expressed relief after leaving the Islamic faith and no longer engaging in a rigid system of religious rules. She expressed, “And the biggest relief was not having to do the five times a day prayer. There's a giant snake that attacks you in your grave for every prayer you missed and you sink like 70 feet underground. I believed that.” This participant went on to say, "It says in the Bible that there is no fear in love and Islam is based off of fear like punishments, the giant snake.” She contrasted her perceptions of legalism in the Islamic faith with the lack of rules in the Christian faith, stating, "No more rules about Islam. There’s too many rules. The Bible says it does not matter what you eat...”

\section{Openness}

The two themes below represent participants’ statements about being transparent and accepting of God and others, respectively. The themes are open to God, and open to others. 
Open to God $(\boldsymbol{n}=5 ; \boldsymbol{k}=\mathbf{1 4})$. These were statements related to having an open heart and mind toward the person of God and the truths of God. This openness for most participants was present just prior to the conversion, which allowed them to begin the conversion process, and for others this openness toward God was progressive during the early stages of their conversion. Most participants described this openness toward God as novel, whereas they were formerly closed off toward God and to the Christian faith. Participant 1 recalled:

...even without somebody telling me, I was able to open up my heart to God and I had definitely been closing it to Him and so once I kind of released my heart to Him and it was very freeing...

Participant 4 described being open to new experiences when attending church services, stating, “I just came into it just like 'Aw, I’ll give it a try and try and listen I am not going to close my eyes and heart off away from it.”,

Open to others $(\boldsymbol{n}=\mathbf{6} ; \boldsymbol{k}=\mathbf{6})$. This theme represents statements about participants' ability to open up to others after converting. Several of these participants explained that they were judgmental and closed off toward others prior to converting and that converting resulted in them being less judgmental and more accepting of others. Participant 6 stated:

...I broke barriers that I guess that I had inside of, inside of me. Like just barriers of talking to certain people, like, like um I was very judgmental...Just it broke a lot of my judgmental barriers toward people whenever I did, you know, convert to Christianity. Several participants described this openness as an ability to trust others and be vulnerable in ways they had not prior to converting. Participant 7 explained, "I finally um trusted people enough to talk about things that I’ve experienced.” Participant 9 described God overcoming her walls toward others, stating: 
Um, I would say overcoming my own walls I had against others and against, even like my walls against God, and let, against letting people in. Um, so I think that's how God used my fiancé first because He overcame those walls with him so that He could be let in...

\section{Existential Meaning}

Themes under this superordinate concept represent statements referring to the development of personal meaning and personal discoveries about the purpose of one’s existence. Also included is a theme related to future plans which give existential meaning to participants. The themes within this superordinate concept are true identity, life purpose and meaning, and altruistic plans.

True identity $(n=7 ; \boldsymbol{k}=12)$. These were references about finding identity in Christ Jesus and in being a Christian. For those participants who referenced their identity, being a Christian seemed to be not only a facet of how they identify but also a cornerstone of their identity. Christianity seems to give them personal meaning in that way. Participant 8 explained that her Christian faith is inseparable from her identity:

I: How does your conversion to the Christian faith affect you today?

P: Um, it, that's kind of a hard question, it's just who I am now. It just, how does it affect who I am? I just feel like it is who I am, I can’t really, um, I mean it’s part of everyday life now.

Another participant, Participant 1, discussed how her source of personal identity is shifting away from how others perceive her identity in Christ:

I: Are there other ways your conversion to faith, or to Christianity impacts you still? 
P: Um, I think definitely in terms of my identity in Christ because before I became a Christian I think I relied a lot on, and guess I still struggle with it a lot, how other people view me...

A number of participants explained how this identity shift changes their perspective on their future. Participant 9 highlighted the importance of one knowing who he or she is before he or she are able to fulfill the calling God has for their life. This participant explained, "He was like changing my perspective on my identity before He changed my perspective on my future because I don't think anyone's ready for the calling God has for them until they know who they are in Christ.”

Life purpose and meaning $(n=4 ; k=11)$. Several participants remarked on the purpose and meaning that being a Christian provides. They expressed having a lack of purpose and meaning in life prior to converting and after converting having a reason to live and a focused purpose in living for Christ while some also mentioned a purpose in helping others. Participant 4 stated, “I just don’t have that reluctant feeling anymore it’s like, 'what's the point.' Now there’s, there's like a point to everything. I have a reason to keep going forward...”

This sense of purpose and meaning provided positive emotions for participants. Participant 4 stated, “...I was ecstatic because I finally found something to live for...” Similar to the true identity theme above, most of the individuals who discussed having life purpose and meaning were future oriented and discussed what this means for their future. Participant 6 commented, “I guess that I'm supposed, that I realized that I'm supposed to take care of the world and that I'm supposed to you know I guess spread hope to the people that are in it and to love them.” Participant 6 said: 
And just, I don’t know, belonging in this world. I mean we've had a lot of issues with like suicide on this campus...really just belonging. You have a purpose here, you were given the breath of life for a reason and you're meant to do something with it. It's truly profound.

Altruistic plans $(\boldsymbol{n}=\mathbf{6} ; \boldsymbol{k}=\mathbf{7})$. These were statements by participants about how converting to evangelical Christianity resulted in the development of altruistic plans for the future. Participants expressed a desire to help others and to make the world a better place. Some altruistic plans related to occupational endeavors while others were simply about supporting others around them. Participant 2 explained his altruistic plans which were, “To, in general, just to be a better person and like to do good in this world and do the little things to make someone's day, whether it be a compliment or a joke...”

For some individuals these altruistic plans were related to helping people that may have experienced heartache or pain similar to them. Participant 1 stated, “...I can reach out to other people who are struggling or who have been adopted and are going through the same things.” Others felt compelled to be a support to others in ways they had been supported by friends during their conversion process. Participant 6 stated:

I guess it makes me feel uh responsible for being that person to someone else as well like Jackson and Jackie were for me, it makes me want to be there for people, um, if they are going through something just to be a friend and to show them love.

\section{Challenging Emotional Experiences- Prior to Converting}

The following themes highlight participant statements about challenging emotional experiences they encountered prior to converting to the Christian faith. They are abandonment, hardship, and confusion. 
Abandonment $(\boldsymbol{n}=\mathbf{1} ; \boldsymbol{k}=2)$. Participant 1 described experiencing feelings of abandonment, as she was adopted as a baby from a different country. This sense of abandonment seemed to prevail in her life prior to converting and much of this participant's prior identity related to feeling as if she was an orphan. This participant recalled, “...how lonely I was or how um kind of abandoned I was...I knew that there, I guess, was something wrong with me and I couldn't continue to live in that way.” She also explained, “I think it just takes time to get to that point and realizing also, that I don't know what I would have without God so that feeling of loneliness, or abandonment, or feeling like an orphan I would never want to go back to that.”

Hardship ( $\boldsymbol{n}=\mathbf{6} ; \boldsymbol{k}=\mathbf{1 6}$ ). This theme represents statements about experiencing hardships prior to converting. For some, these hardships were catalysts for their search for hope and healing which led to their conversion to evangelical Christianity. Participants referenced having their own hardships including experiencing depression, anxiety, and broken relationships. Participant 8 remembered, “...my freshman year was...the darkest point in my life. I was like partying a lot and I don't know, I was very on and off with the boyfriend that I had had all through high school.” Participant 9 recalled experiencing such hardship that she thought about ending her life. She stated, “...I used to be suicidal and um I hated everyone and everything, I was really bad, like I would say I was a very angry person and I was angry at God originally...”

Others’ hardships related to having family members diagnosed with cancer or other family hardships. Participant 4 remembered, “I didn’t think I was struggling any more than usual but, I guess the loss, my job and my aunt [who died of cancer], really had thrown me into deeper depression and it was just, it was a rough time.” A different participant, Participant 2, also experienced turmoil in his family which contributed to distress. He recalled, "My family went 
nearly bankrupt so my dad had to sell the farm... And, I mean we were basically driving ourselves into the ground with like paying for lawyers and all the court dates and all.”

Confusion $(\boldsymbol{n}=\mathbf{4} ; \boldsymbol{k}=\mathbf{8})$. Several participants described experiencing feelings of confusion leading up to their conversion. They expressed having a lot of questions and at times having a sense that they did not know what they were doing. Participant 8 stated, "But I think that while it was happening it was probably, I mean confusing because it’s not what I knew, it was like unknown territory and I was also changing so much... so many things about me were changing...” This same participant explained that the feelings of confusion were not detectable until later when looking back to her conversion experience. She explained:

I, like thinking about it like this seems confusing, but when it was happening I never identified it as being confusing. But now it seems like I was being pulled in all these different directions, but I don’t think I thought of it that way when it was happening. But now, it seems confusing.

Feelings of confusion seemed to also be present when participants experienced both positive and challenging emotions at the same time. Participant 2 stated, "Leading up it [conversion] was a lot of wonder, a lot of confusion.” Participant 3 recalled making a hard decision prior to her conversion which resulted in mixed feelings, “Um, I was upset because I didn't want to be put into a situation of having to like end a relationship with someone but also I felt a lot of peace ...”

\section{Challenging Emotional Experiences- After Converting}

Themes in this category include participant disclosures about the challenging emotional experiences they encountered after converting to the Christian faith. The themes are spiritual warfare, discord with others, ongoing hardship, and guilt and shame. 
Spiritual warfare $(\boldsymbol{n}=2 ; \boldsymbol{k}=3)$. Two participants discussed having an awareness of a spiritual enemy that was against them. Awareness of spiritual warfare of the existence of a spiritual enemy was distressing to them after converting. One of the two participants, Participant 9, stated, “Like I'd hit a high and then I'd hit a really low point um so I think it was just hard because the enemy had it out for me in a way. Um, I'm talking about the spiritual enemy.” The second participant, Participant 1, discussed experiencing this warfare in her family's home. This participant stated that her parents have spiritual authority over their home and the participant does not. She stated, "I think that the enemy has room to reign in my household and I think that's what is the most difficult, um, is experiencing I guess like spiritual battle or even before I could identify like spiritual warfare.”

Discord with others $(n=7 ; \boldsymbol{k}=26)$. A majority of participants experienced discord with family and friends after converting to evangelical Christianity. This produced stress for most participants as their family or friends expressed disappointment and disagreement with their decision to convert. Participant 4 noted, "I was worried about what they [his family] would think, what they would say, because they're very, very, what's the word for it, I guess judgmental is a good word for it. If it's not what they believe in it's not right...”

The discord between participants and others took many forms. A few participants discussed how their zeal for their new faith resulted in others thinking that the participants thought they were better than them. Participant 1 had this experience within her family:

I think even recently, they [her parents] maybe think that, like I think that, that I'm better than them. And that's not the case, I think there's been a lot of miscommunication between us and it's hard for me to love them as Christ loves them. 
A different participant's family could not comprehend the depth of faith and devotion that she maintained. Participant 9 explained:

...but my parents and I had a lot tension because how I viewed God was not how they viewed God...my dad was shocked that I said that if God called me to it I'd be willing to die for my faith because He is more important, they just don't understand it.

Several participants were not supported by their friend groups and when participants changed their lifestyles, friends were skeptical about the authenticity of these changes. Participant 6 explained:

My friends, it depended. A lot of people were annoyed at the fact that I switched so fast, I guess, they were like, 'Well then was he, there is no way this is real, he, he's probably just going through a phase of this whole hope thing, before he goes back,' that kind of thing.

Ongoing hardship ( $n=4 ; \boldsymbol{k}=\mathbf{9})$. This theme represents statements about recognizing the presence of hardship and struggles after converting. Hardships discussed within this theme included temptation to sin and the presence of emotional distress. Participant 3 explained, “...but you're not promised not having hardship in the Christian life and I still did and so I think it was really difficult for me to not resort to shame and guilt when I messed up but instead look at the gospel...”

Several participants discussed having ongoing distressful thoughts and feelings. Participant 9 stated, “...I still dealt with them [depressive feelings] and even now I'll deal with insecurities, just not that awful anymore.” Participant 1 reflected on the positive feelings after converting being short-lived and returning to a realization that this world is flawed. She explained, "Um and I think that's the realization and the kind of um, I guess just realizing that 
that feelings doesn't last and that's why because we live in a world where there is sin.” Finally, another participant, Participant 7, experienced the emergence of emotional concerns after changing her party lifestyle. She recalled, “... once I stopped doing all that stuff [drinking and using drugs], I was diagnosed with depression, which is like, ah that sucks but it's I'm good because I have Jesus um so that was something...”

Guilt and shame $(\boldsymbol{n}=5 ; \boldsymbol{k}=\mathbf{1 0})$. Participants described feeling blameworthy of wrongdoing. Participants also described feeling shame due to experiencing judgment by others. Several participants expressed feeling guilt and shame after converting due to their lack of faith prior to converting. Participant 2 recalled, "I was guilty of like the things I had done and doubting in God and betraying him that way." Some participants expressed feeling as though they were not as righteous or mature in their faith as they should be. Participant 3 explained, “...being like, 'Why am I not there? Why couldn’t I have been a Christian my whole life?’ And just becoming kind of bitter about that and then like shaming myself for not being that.” Lastly, a participant described experiencing a sense of guilt that is often valued by Christians, that is conviction about one's own sin, which is often a means of turning to God and experiencing forgiveness. Participant 1 stated:

...it's still a struggle because I give into temptation and either I sin or I make mistakes and it's I guess it's, I guess like a daily or a weekly process of either repenting or coming back to the Lord and, and realizing my need for him.

\section{Supports}

This superordinate concept contains themes which represent statements about interpersonal and familial supports. Themes include both positive and challenging aspects related 
to supports. The themes are loss of friends, current critical evaluation, commonality, truth in love, support, strong relationships, and relationship with God.

Loss of friends $(\boldsymbol{n}=7 ; \boldsymbol{k}=\mathbf{1 6})$. For the majority of participants converting to evangelical Christianity resulted in the loss of friends. For the most part, participants did not want these losses and these losses caused a great deal of sadness and distress on behalf of the participants. Participant 8 stated:

I lost all my, I mean not all my friends, I have one friend from freshman year that is still friends with me... But anyway, they all thought I was trying to be holy then thou. And so I lost most of my friends. It was really hard...”

Some participants experienced their friends to be quite harsh and judgmental about their conversion to evangelical Christianity, particularly friends who were engaged in a partying lifestyle that participants were no longer willing to engage after converting. Participant 8 remembered, “Well at the time, friends would, 'Oh you're a Christian now, you don’t do this and you don’t do that' and being I guess like ridiculed.” Participant 7 experienced something similar. She recalled:

And I have friends up here that came up with me from high school that I mean that I see on occasion and it's a little bit awkward ... I had to be like, 'I can’t do what you're doing' And they just kind of like dropped me off because they were like, 'You're weird, why are you like Christian?' They were like, 'I’m a Christian too,' they’re like, 'Stop judging me,' and I was like, 'I’m not, I just can’t keep doing this to myself,' um and so it's still a little bit awkward.

For others their separation with friends was not conflictual but was more gradual, yet still disappointing. Participant 1 explained, “...they didn’t, they never ostracized me or anything like 
that or said that what I was doing was wrong but it was just kind of like a... a neutral separation, even if I didn’t necessarily want that to happen.”

Current critical evaluation $(\boldsymbol{n}=7 ; \boldsymbol{k}=\mathbf{1 5})$. These were critical evaluative statements participants expressed about their family’s expression of faith or lack thereof. Participants conveyed a sense of personally practicing Christianity in a right manner while charging their families with insufficient or absent faith. Participant 1 noted, “...based off of my experience with Christianity and being saved I don’t think that they’ve had that and I don't think they are open to it...” Participant 5, who converted from Islam, expressed critical evaluation of how her and other Muslim families promote their faith. She stated, “...your parents brainwash you, and going there just, and just the other Muslims, they all believe it. You say something bad about Muhammad they get really mad. I used to be like that.”

For several participants, paired with this critical evaluation of their family’s expressions of faith was a concern for their family’s wellbeing. Often for a Christian, his or her utmost concern is for the salvation of others through faith in Jesus, as Jesus is understood to be the one true Messiah, and only through Him can one have eternal life. The concern is evident in the comments by several participants. Participant 3 explained:

...I've been going to church and like following Jesus but like it wasn't what I thought it was. Which was like kind of hard to come to terms with cause then it caused me to like question like, is like my family, are they like believers, because I thought I was and I wasn't. So that led to a lot of questioning about my family’s salvation...

Another expressed desperation for her mother's salvation. Participant 8 stated:

I would literally trade my spot to heaven with my mom if I could, easily, because she's been so close to dying that it really freaks me out... like I know where I'm going, it's not 
like a big deal and I just wish I felt like it wasn’t a big deal if something happened to my mom. But I feel like it’s a huge deal because I don’t know where she stands.

Commonality $(\boldsymbol{n}=5 ; \boldsymbol{k}=\mathbf{1 0})$. Several participants described seeking and finding support from individuals who possess common interests and qualities as themselves. These supports were most often fellow Christians and the participant perceived that they have experienced similar struggles or had similar conversion experiences. Participant 1 described:

...seeking people that are either in the church, that are going to church and that are around brothers and sisters, and that are like daily basically in the Word ....and they could be able to support me with my problems because either, they had been through them or that they had been through similar situations...

Participant 2 had his passion of biology and his faith in common with a best friend. This participant stated:

My best friend is a lot like me. He’s a biology major but he grew up with the Church as well so he believes, he’s already believed in both and still does, so him and I have had plenty of deep discussions about that, those sorts of topics.

Participant 4 described assessing support from a campus minister and learning that they had more than faith in common. This participant remarked, “[Campus pastor], it became a friendship more than anything...we met every Wednesday for coffee to talk about the Bible and, and we'd find out we are both [sports team] fans and we hung out then a lot...”

Truth in love $(n=3 ; \boldsymbol{k}=4)$. Three participants described having and valuing peers that communicated honestly and candidly with them even when it may have been challenging to hear. The presence of this quality in a peer allowed participants to engage in trusting relationships with these particular peers. Participant 7 explained, “And they were bold, they kind of told me things 
I didn't want to hear and things that I knew were true but that no one else would tell me...”

Participant 3 also recalled being challenged by her Christian peers in a way that communicated love. She recalled:

...I've been afraid of what she was going to tell me. But she also, and like Tina and Sue, have always been very honest with me and telling me like, '[Participant's name], this is how it is,' like 'this is the truth,' and showing me the truth but is a loving way, never in a harsh mean kind of way.

Support $(\boldsymbol{n}=\mathbf{9} ; \boldsymbol{k}=\mathbf{2 4})$. All participants made statements about accessing support from peers and/or family members after converting. The support participants received contributed to their sense of well-being after converting. Participant 4 noted:

Most of my friends were very ecstatic about it. There was two of my good friends from freshman year of college ... they were always praying for me and when they found out that I was going to get baptized, they kind of freaked out.

For some of the participants, this support came from people they knew well. Participant 2 recalled, “...they were like, 'You’re saved' and like my girlfriend was crying and, like her mom was crying and, they were telling other women who were crying and smiling and hugging me...”

Other participants experienced support from people they did not know well; however, this support was a source of peace and encouragement. Participant 3 shared:

...but also I felt a lot of peace and a lot of encouragement and comfort from other people that I've never felt before. I had like this whole new set of community around me...of people like supporting me even when they didn't even know me.

Finally, the participant who converted from Islam and has kept her conversion a secret from most of her Muslim family and friends, was able to experience this support from on long-time friend. 
This participant, Participant 5, stated, "I told one girl, we, she was my friend since when I was young, I told her but she supports me. She said, 'It's your life do whatever you want.' She had secrets too.”

Strong relationships $(\boldsymbol{n}=7 ; \boldsymbol{k}=\mathbf{1 8})$. This theme represents statements about strong relationships which participants experienced after converting. All but two of the participants made references about having deep relationships that were distinctly different from those they had prior to converting. Participant 3 highlighted this theme stating:

I think the most positive was like I said, just this sense of community that I've never felt before. In [campus ministry], I had so many, or I have so many friends in [campus ministry], just these people that wanted to know like all parts of me and, when they found out, still loved me and were encouraging and held me accountable and gave me like good advice and wisdom.

Participants seemed to feel that these new relationships were more authentic then other relationships they have experienced. Participant 7 explained, “...hanging out with more of the Christian community or just people that were good people that didn't have an alternative purpose of loving me...” Participant 2 alluded to the fact that a strong bond does not require a long time to develop when the relationship is founded in a mutual faith. He noted:

I’ve known them for three and a half months. I'm, I feel like I have a stronger bond and relationship through God then I ever had with the kids I grew up with my whole life back in [a northern state]. I, I consider them truer friends than I ever had back home.

Relationship with God $(\boldsymbol{n}=\mathbf{3} ; \boldsymbol{k}=\mathbf{6})$. Several participants described having an interactive relationship with God. For these participants, converting to Christianity was a conscious decision to know the person of God and not simply engage in religious formalities. 
Participant 9 explained, “...so I decided I didn’t just want to know about God, and know of God I wanted to know Him on a personal level like I know my fiancé or like I know any of my best friends... I decided I was going to get to know Him as a relationship...”

Several participants contrasted this relationship with God after converting to their former religious engagement or former perspectives on God. Participant 1, her former religious involvement was defined by rules and custom. This individual explained, “...in terms of Catholicism, and the problems that I've had with it, is that it's more I guess traditional and it's more religious and it's more about rules and law than having a relationship with Christ.” Participant 6 described shifting his focus from a "head knowledge” of God to a relational understanding of the person of God. He explained:

So, and like I said, I had a lot of head knowledge but I didn’t have the actions. I saw God as a figure that controlled things but didn't act like on the earth like I guess it was more of a "big guy in the sky" rather than a personal relationship.

Participants' accounts of their conversion experiences reflected many themes related to both psychological well-being and distress. Individuals expressed having questions and doubts about God and about the Christian faith which ultimately culminated in increased faith in God and in His plan for their lives. Converting to evangelical Christianity resulted in positive and challenging emotional experiences for respondents and participants gained existential meaning and an increased sense of social connectedness. These themes provide clear answers to the guiding questions of this dissertation. These guiding questions are reviewed in the discussion chapter. Theoretical and clinical implications as well as limitations and strengths are also discussed in the discussion chapter which follows. 


\section{Chapter 4}

\section{Discussion}

College is a unique time in an individual's life when he or she establishes independence from his or her family of origin and begins to establish personal patterns and beliefs that often influence his or her life beyond graduation (Arnett, 2000; Schulenberg, Sameroff, \& Cicchetti, 2004). This dissertation explores the spiritual or religious transition of college students, namely conversion to evangelical Christianity during college. Bryant et al. (2003) and Mayrl and Oeur (2009) found that religious practices decline among college students despite the increase in religious and spiritual interests during this formative time. Thus, the students who participated in this study represent a counter-cultural trend toward increased participation and evolvement in their faith. Literature on the influence of religion and spirituality on emotional well-being is mixed and the means by which religion and spirituality have an influence on personal outcomes is largely unknown (Mayrl \& Oeur, 2009; Miller \& Thoresen, 2003). This study sought to discover factors related to well-being and distress among college students converting to evangelical Christianity. Also, based on the understanding that existential meaning, or lifemeaning (Stillman et al., 2009; Zika \& Chamberlain, 1992), and social inclusion (Cohen, 2002) affect subjective well-being, these factors, as they relate to one's conversion experience, were also explored.

The following discussion presents the summary of the research findings organized in a review of the study's guiding questions. Interpretations of the findings are outlined and links to the existing related body of literature are presented. Theoretical and clinical implications are discussed. A discussion of the limitations and strengths are presented and lastly, recommendations for future research are delineated. 


\section{Summary and Interpretation of the Findings}

Ten superordinate concepts and 45 subordinate themes comprise the research outcomes. To understand more fully these results, a discussion of how these concepts and themes answer the guiding questions of this study is presented. Superordinate concepts and themes are identified in italics to make the direct connection to the research outcomes clear.

Perceptions of Conversion Experience. The first guiding question for this study was, "How do individuals who have converted to evangelical Christianity during the college years perceive their conversion experience?” There are many ways in which to answer this question based on the research findings. However, it should be noted that Lindholm (2007) found that college students are often reserved about discussing religious and spiritual matters with others, particularly at institutions where religious or spiritual involvement is not encouraged. Despite some initial reservations on behalf of campus ministers to allow the researcher to attend their meetings, nine participants volunteered to participate in the research. Lindholm's finding leads one to question the degree of apprehension on behalf of participants and perhaps that resistance to participate on behalf of individuals who did not volunteer. That being said, nine participants gave what seemed to be candid and elaborate responses to the protocol questions.

First, participants discussed their previous exposure to religion and spirituality and described their conversion to Christianity as distinctly different from their former involvement in the church or in another faith group (Previous Exposure to Religion/Spirituality). Previous involvement in religion and spirituality was often framed in the context of participation through affiliation with either a family member or friend who initiated the religious or spiritual involvement (Family Involvement, Friend Involvement). This is congruent with Bryant et al.’s (2003) finding that attending religious services and praying in high school are positive indicators 
of spirituality during college. A majority of participants described having negative experiences in the early exposures. This supports Johnson and Hayes' (2003) finding that 44\% of the 5,550 college students surveyed reported having past experiences of distress related to religious and spiritual concerns. However, all participants described their voluntary participation and conversion experience in an overall positive light.

In describing their conversion, participants spoke of making a personal choice or decision to convert to the Christian faith and highlighted the role that being in college played in this decision making progress (Unique to College). They explained that college allowed for personal exploration and independence from familial norms or parental expectations (Self-Exploration and Independence). This is compatible with Arnett's (2000) explanation of emerging adults’ exposure to education and varied worldviews while in college which can lead individuals to question previously held worldviews. This finding is also compatible with Kellems et al.’s (2010) finding that the fourth most discussed issue in college counseling related to religious and spiritual issues in exploration and defining of religious beliefs. This independence and selfexploration seemed to result in an openness toward the possibilities of the existence of God and the eventual newfound understanding or faith in the Christian tenets (Openness toward God, Understanding). Participants perceived their conversion as a process that took time and thoughtfulness. They navigated doubt, questioning, and resistance to conversion prior to coming to a place of belief and commitment in the Christian faith (Questioning God). The process of conversion was not without challenges.

Participants described having challenging experiences during the time of conversion, such as challenging emotional experiences and turbulent interpersonal and familial relationships (Challenging Emotional Experiences, Supports). This is congruent with Kellems et al.'s (2010) 
finding that the second leading issue related to religious and spiritual issues discussed in counseling according to 220 college counselors was abandonment of family religious/spiritual traditions. Most participants discussed conflict between themselves and family members which arose due to a changes in expressions of faith on behalf of the participant. However, it should be noted that participants minimized these experiences as they explained the time limited nature of the challenges and expressed faith that God has a plan to turn hardships into benefits or simply overcome them (God is Omnipresent and Sovereign, Healing, and Relief). Participants also perceived their conversion experiences as overall positive.

Experiences that contributed to these positive perceptions were positive emotional experiences, discovery of meaning and purpose in life and the development of new and stronger social supports (Positive Emotional Experiences, Existential Meaning, Supports). This aligns with Frankl's assertion that the core of human motivation is a 'will to meaning' and without it one experiences “existential frustration” (Crumbaugh \& Maholick, 1964, p. 200). Several participants expressed gratitude for their conversion and for their commitment to the Christian faith (Gratitude). Participants’ perceptions of their conversion were unique but also converged in many ways. In general, participants perceived their conversion experiences as a personal decision that proved challenging at times but culminated in a number of significant positive changes in their life. More on the challenges and positive changes participants experienced follows in the summarization of the psychological and existential effects of converting.

Psychological Effects. The second guiding research question was, "What psychological effects, if any, does the conversion to evangelical Christianity have on college students?” Participants experienced both positive and challenging emotional experiences (Positive Emotional Experiences, Challenging Emotional Experiences- Prior to Converting, Challenging 
Emotional Experiences- After Converting). Regarding challenging emotional experiences, participants described experiencing a sense of abandonment, distress related to familial or personal hardships, and confusion prior to converting. Following their conversion, participants experienced distress related to a new awareness of spiritual warfare, the acknowledgement or recognition of continued hardships, and feelings of guilt and shame. In spite of the hardships one may face, individuals have a capacity for positive change through resilience. Frankl (1986) and Ridner (2004) highlighted the capacity for individuals to demonstrate resilience in the face of immense psychological distress. They noted that often out of distress one is able to discover meaning, work toward a purposed end, and accomplished personal goals. This was indeed the case for the nine participants interviewed for this study. Regarding positive emotional experiences, participants described experiencing hope, feeling gratitude for their conversion experience, experiencing psychological healing and feeling relief, understanding, happiness, and love. The positive emotional experiences outlined here support Taliaferro et al. (2009), who found that regular involvement in church correlates with improved well-being and reduced suicidal ideations compared with students not engaged in religious activities. In addition to emotional experiences, participants described events that took place during the time of their conversion which contributed to their psychological distress and psychological well-being.

The fourth guiding question of this project was, "How does the conversion to evangelical Christianity contribute to both well-being and distress during college?” Events which seemed to contribute to psychological well-being included peak spiritual experiences, having confidence in God's sovereignty, and gaining social supports in a Christian community. Events which seemed to contribute to psychological distress included doubting God or Allah and discord in 
relationships with family and peers as a result of converting. The existential effects of conversion were also of interest in this study.

Existential Effects. The third guiding question of this research project was, "What existential effects, if any, does the conversion to evangelical Christianity have on college students?” King and Roeser (2009) noted that adolescence is a crucial time during which individuals engage in dialogue and explore ideas and philosophies witch contribute answers to existential questions of identity, purpose, and life meaning. A majority of participants seemed to gain a sense of personal meaning and identity through their Christian faith (True Identity). Markstrom (1999) highlighted Erik Erikson's statements about the positive existential effects of religious development during adolescence. She explained that religion offers an understanding to existential questions, enhances one's sense of purpose in life, and promotes belongingness. Several participants described experiencing purpose and meaning in life through their faith in God and their engagement in a Christian community (Life Purpose and Meaning). Furthermore, participants described having meaningful occupational or goal-oriented plans which were altruistic in nature and connected to a calling they felt from God (Altruistic Plans). This finding supports Yalom’s (1980) research which asserted that positive life-meaning is linked to strong religious beliefs, membership in groups, dedication to a cause, life values, and clear goals. Taliaferrro et al. (2009) also supported the claim that existential gains from religious and spiritual engagement are positively associated with well-being. Another factor which seems to contribute to well-being as it relates to religion and spirituality is social inclusion or supports.

Supports. The fifth and final guiding question for this research was, "From whom do individuals seek support and counsel during the conversion experience and what qualifies these individuals as helpful supporters?” Participants reported accessing support and counsel from a 
number of parties during the time of their conversion. All participants recalled having an influential person or persons in their life at the time of their conversion that provided guidance or support when needed and influenced their decision to convert to Christianity (Significant Influential Persons). Peer supports were also a main source of support for participants and were often described as having common interests and being fellow Christian believers (Support, Commonality, and Strong Relationships). This finding supports Bryant's (2007b) conclusion that emotional well-being and religious involvement alone are not positively correlated but are mediated by the development of friendship networks through religious activities. Many of these findings correspond well to Ryff's (1989) six theory-guided dimensions of psychological wellbeing which included self-acceptance, positive relations with others, autonomy, environmental mastery, purpose in life, and personal growth.

\section{Implications}

A number of theoretical and clinical implications arise from the current research findings. These implications are discussed in detail below.

Theoretical implications. In the literature review, several theories related to spiritual development and spiritual struggle were reviewed. The results of this dissertation lend support to many of these existing theories and expanded upon them. There are five interrelated processes defining spiritual development according to Love and Talbot (1999), each of which was supported by the current research. The first process defining spiritual development is identity development involving an internal process of seeking personal authenticity, genuineness, and wholeness as a process of spiritual development, which is supported by the current research theme True Identity. One participant explained, “... just the Holy Spirit opening my eyes to, this 
is who I am. Like I was always searching, creating myself, trying to find myself, and as it happened after I converted, it became more clear.”

Love and Talbot's second process of spiritual development was the process of transcending one's current locus of centricity which is supported by the theme in the current research finding of All Sufficient. One participant stated, “...you just can’t rely on yourself, you realize you can't be your own savior...” The third component of their theory, increased connectedness to self and others through relationships and community engagement, is at least in part supported by the superordinate concept of Supports which includes the Strong Relationships, and Support themes. Participants expressed feeling more deeply connected with peers after converting when compared to relationships prior to their conversion.

The fourth component of Love and Talbot's (1999) theory, deriving meaning, purpose, and direction in one's life, is supported by the Existential Meaning superordinate concept which contains the Life Purpose and Meaning and Altruistic Plans themes. Participants reported experiencing life meaning and purpose as a result of being connected with God, experiencing a calling in their lives, and feeling confident in God's plans for their future. Finally, their fifth component, increasing openness to exploring a relationship with an intangible and pervasive power, is supported by the theme Open to God. One participant explained, "I was more open to it, to religion, to a creationism, and like the middle gray area that gets overlooked quite often unfortunately.”

A component that may extend beyond the Love and Talbot (1999) framework includes the presence of questioning God and religious concepts which eventually fosters openness to a transcendent power. Most of the participants explained having questions that were answered by 
their new faith and thus gave them reason to believe and convert to the Christian faith. The current research findings also fit well with Fowler's third stage of spiritual development.

Fowler's third stage of development, Synthetic-Conventional Faith, is typical of adolescence and is defined by higher level of storytelling capabilities due to new cognitive abilities. These abilities allow individuals to make new meaning from past experiences and anticipate future roles and relationships. Interpersonal relationships are of great importance during this time. During this stage, individuals are examining and making choices about their values and beliefs. Participants could fit easily into this stage as evidenced by themes from the current research findings including Wrestling with Evil, Reconciling Science and Supernatural, Evidence of God and Strong Relationships. Participants questioned the existence of evil in a world founded by a just and loving God. They also questioned the co-existence of science and supernatural, specifically evolution and creationism. Participants looked back to previous experiences and attributed spiritual meaning to these events that had previously been understood as ordinary. Finally, participants seemed to be influenced by others in their decisions to convert and their fellowship with others was a large component of their current faith practices. Also discussed in the literature review where theories related to religious struggle.

Byant and Astin (2008) noted that spiritual growth can occur after one experiences spiritual struggle. This was true for several of the participants in this study as many of them experienced hardship and questioned God prior to converting (Hardship, Questioning God). In addition, this research uncovered themes related to the potential for seemingly contributory simultaneous emotional experiences, which has not been previously identified in the literature. Participants reported having both challenging and positive emotional experiences as a result of 
converting as represented in the Challenging Emotional Experiences and Positive Emotional Experiences themes.

Also discovered was the impact of participants’ newfound Christian faith on their plans for the future. Many participants described having altruistic intentions for their occupational planning (Altruistic Plans) in that they want to help others or better the world in some way. Finally, the social impact of converting was apparent and was mixed with rewarding and hurtful experiences. Participants lost relationships and experienced conflict after converting while at the same time forming relationships which they described as strong and distinct in ways that differed from former relationships. In addition to corroborating and expanding on existing theories, one can draw some original theoretical implications from the data on which to base theory development.

Namely, the study outcomes demonstrate the multifarious nature of the conversion experience for college students. One converting to evangelical Christianity during college will likely experience seemingly contradictory or paradoxical experiences. This is evident in the contrasting themes that exist within the current data. For example, at times during the conversion process, participants experienced resistance to converting and questioned God and at other times experienced openness toward God and sought a personal relationship with Him. Furthermore, participants lost friends and experienced discord with others contrasted with the gain of social supports and experiencing stronger relationships. This speaks to the variable social experiences that can be present for an individual in the conversion process. Regarding psychological experiences, participants had positive emotions and challenging emotions during the conversion process, and at times these confounding emotions existed simultaneously (e.g., confusion and relief, skepticism and hope, freedom and guilt). These examples highlight the inability to 
completely separate the concepts of spiritual development and spiritual struggle. Future theories should strive to incorporate the paradoxical experiences of individuals, particularly college students, converting to evangelical Christianity and integrate the existence of both distress and well-being outcomes, social inclusion and isolation experiences, and spiritual struggle with spiritual growth. These theoretical implications lead us to a clear understanding of clinical implication of this study.

Clinical implications. Converted Christian college students are not devoid of emotional distress, mental health concerns, or other stressors that may lead them to seek psychological services. Several participants in this study reported having mental health diagnoses, including depression and anxiety and taking psychotropic medication for their conditions. Other participants reflected on distressing emotional and social content that would warrant clinical intervention. Therefore, it is important for clinicians to be aware of the multicultural factors that influence students converting to Christianity or who have converted to Christianity. These students would likely present their emotional or mental health concerns to individuals in their church or campus ministry communities, as the research findings highlight students' tendency to seek support from fellow Christians and people who have common interests and values. Thus, outreach efforts through liaison and consultation relationships may be one of the first lines of contact between these Christian groups and the available mental health services on the college campus. Through liaison and consultation relationships, psychologists can provide information about counseling center services, help reduce stigma related to seeking support, and present a welcoming and affirming message to Christian ministers and students. These outreach connections would likely improve the impetus for Christian leaders on campus to refer Christian students to counseling center services. Once Christian students, particularly those who have 
converted in college, are engaged in psychological services there are several important findings within this study to keep in mind.

College students who converted to Christianity during college experience both challenges and protective factors as a result of this transition, which may be topics in therapy. It is imperative to be attentive to and assess the aspects related to their conversion that may contribute to distress and well-being. According to the current research findings, students experience many aspects that contribute to well-being as a result of their conversion, including a new sense of purpose and meaning, identity, social inclusion, and positive emotions. There are challenging experiences related to the conversion experience as well, including understanding that life hardships continue after one converts, questioning God, challenging emotions, and loss of relationships. While the counseling relationship and interventions are empirically supported to help ameliorate distress, Christian students may want to incorporate their faith as a resource for personal growth. A majority of participants described having confidence in God's plan for their lives. They expressed assurance that God is faithful and that His love and support is sufficient to see them through challenging times. Kellems et al. (2010) noted that the third most discussed issue in college counseling settings related to religion and spirituality is the client's view of religion and spirituality as a personal strength. A potential factor in building rapport with these clients may be the ability of the therapist to expressively support this view on behalf of the client. Also important with regard to building a productive therapeutic rapport, clinicians should be mindful that many of these students have experienced rejection from people who maintain differing religious and spiritual views, even from members of their own family. Thus, it is imperative to extend unconditional positive regard and assure them that their religious and spiritual beliefs are viewed as strengths or protective factors and not assumed to be pathologies, 
as has been a historically held view in the field of psychology. Finally, clinicians should understand that it may be easier for a Christian student to seek counsel from a Christian; therefore, referrals to pastoral counselors, campus ministers, and pastors for spiritual direction may be beneficial. In order to ensure the quality of care of clients, it is ideal that the referring psychology have established relationships with the referral sources if possible.

\section{Limitations}

Some limitations exist with regard to the homogeneous sample of participants. Participants for this study were recruited at a southeastern university in the United States. Therefore, the findings were likely influenced by the regional culture of the area in which the study took place. The recruitment of participants was limited to those affiliated with a campus ministry. Though this facilitated encountering participants that met the inclusion criteria, it may have excluded a number of college students either who were not involved in a formal Christian group or who attended a community church group. Limitations also pertain to the narrow ethnic demographics of the group. All but one of the nine participants identified as non-Hispanic Caucasian with one identifying as Middle Eastern. There was an unequal distribution of men and women with three men and six women. According to Francis (1997), Stark (2002), and Bryant (2007a), women demonstrate greater engagement in religious beliefs and practice; however, the difference between men and women only varies between 8\% (expressed commitment or belief) and 4\% (behavioral indicators) (Bryant, 2007a). Thus, the discrepancy between the number of men versus women participants in this study is not representative of the actual minimal gender gap.

A second potential limitation is the limited or idealistic view of participants as they recall their conversion experiences. Participants converted to evangelical Christianity during college 
and participated in this study while still in college, with a typical college career being four years. Given the proximity, with regard to time, in a participant's conversion and his or her participation in the research interview, he or she may not have fully engaged in personal reflection about both distressing and beneficial components of the conversion experience. This may result in an overly idealistic description of one’s conversion experience.

Another limitation is the limited sample size. The objective of interpretative phenomenological analysis (IPA) is not necessarily to find common experiences among participants so much as it is to find individualistic essences of a participant's meaning related to his or her conversion to evangelical Christianity. For this reason, generalizability is not an aim of the current research. The small-scale nature of this study provides rich data but does not allow us to make generalities about all college students’ conversion experiences. A larger scale study across multiple universities, with a more diverse group of participants is needed to gain these outcomes. A limitation related to all qualitative research, and thus the current study, is the interpretative license used in interpreting the results. Measures were taken to increase the trustworthiness of the study, including triangulation, constant reference back to the original transcripts, and using an outside auditor. However, qualitative research is never void of the researcher's presuppositions, which influence how she interacts with the raw data and draws conclusions.

\section{Strengths}

There are also several strengths of this research project to highlight. This research explores the psychological and existential effects of converting to Christianity during college, whereas much of the previous existing research has been survey format and demographic in nature. This research is also unique in that it was conducted at a time in history when a large 
majority of millennials are leaving the church, and thus the research explores the experience of a group that is acting in a counter-cultural manner. The topic of converting to a religious group is one that fits well into the value of multiculturalism within counseling psychology and the findings provide helpful clinical insights about students of this specific religious group.

With regard to the research design, the qualitative semi-structured interview format allowed participants to describe their experiences in detail, which allowed for rich data. Also, participants were recruited from diverse Christian denominational groups which allowed for some variation in doctrinal and theological understandings. The diversity in age from first year to graduate level as well as the variable number of years participants were removed from their conversion experiences provided differing perspectives on the conversion experience. With regard to the participant group, though there was little diversity, one participant identified as Middle Eastern and her responses provided insight into converting to Christianity from Islam. That interview delivered interesting data and could be the foundation for further exploration of this unique experience. Finally, the use of a pilot study and a third party auditor helped increase the trustworthiness of the research, specifically the researcher's data analysis and the research outcomes. A discussion of possible future directions is discussed below.

\section{Future Directions}

Replication of the current study at different universities in different geographical regions and countries is recommended. Also, expanding beyond a college age sample would provide insight into the conversion experiences of diverse age groups. The research outcomes from this study could be used to develop quantitative studies, which could reach a larger number of participants and result in generalizable findings. The themes captured in this study could be used to develop quantitative assessments or questionnaires that would again be used in larger scale 
research. The current research findings pointed to a number of unanswered questions related to the psychological, existential, and social effects of converting to Christianity.

Several questions which should be explored in future research include:

- How do the experiences of college students converting compare to individuals of a similar age who convert and are not in college?

- In what ways would participants’ perspective change regarding their conversion experiences if more time passed between their conversion and the time of the interview?

- How would individuals who converted at a younger or older age answer similar interview protocol questions?

- How do the experiences of this college sample compare to other possible college samples from different regions of the country?

- The findings in this research pointed to emotional, existential, and social components of well-being; how may converting contribute to other aspects of well-being such as physical health or self-worth?

- What do college students who converted to Christianity think specifically about seeking secular psychological services and how do these thoughts facilitate or impede their willingness to seek help?

Future research is recommended to address the above questions.

\section{Summary}

The researcher for this dissertation used IPA qualitative methodology to explore the experiences of college students converting to evangelical Christianity. Their perceptions of their conversion experiences were elicited using a semi-structured interview protocol which addressed questions related to the factors during their conversion experiences which contributed to 
psychological well-being and distress, existential meaning, and social and familial implications. Rich personal accounts shared by the nine college student participants shed light on both unique and common experiences among the group from which 10 superordinate and themes 45 themes emerged. These findings answered the study’s guiding questions and provided insight into theoretical and clinical implications related to college students converting to evangelical Christianity. The objective of this dissertation research was to provide the field of counseling psychology, and those practicing in a college counseling setting, insight into the unique multicultural experiences of college students converting to evangelical Christianity, and this objective was met. 


\section{References}

American Psychiatric Association. (2013). Diagnostic and statistical manual of mental disorders (5th ed.). Arlington, VA: American Psychiatric Publishing.

Arnett, J. (2000). Emerging adulthood: A theory of development from the late teens through the twenties. American Psychologist, 55(5), 469-480. doi:10.1037/0003-066X.55.5.469

Baumeister, R. F. (1991). Meanings of life. New York, NY: Guilford Press.

Bebbington, D. W. (1989). Evangelicalism in Modern Britain: A History from the 1730s to the 1980s. London: Unwin Hyman.

Benson, P. L., Roehlkepartain, E. C., \& Rude, S. P. (2003). Spiritual development in childhood and adolescence: Toward a field of inquiry. Applied Developmental Science, 7(3), 204212.

Bergin, A. E. (1980). Psychotherapy and religious values. Journal of Consulting and Clinical Psychology, 48, 95-105.

Binder, P., Holgersen, H., \& Nielsen, G. (2009). Why did I change when I went to therapy? A qualitative analysis of former patients' conceptions of successful psychotherapy. Counselling \& Psychotherapy Research, 9(4), 250-256.

Blaine, B., \& Crocker, J. (1995). Religiousness, race, and psychological well-being: Exploring social psychological mediators. Personality and Social Psychology Bulletin, 21(10), 1031-1041.

Bryant, A. N. (2007). Gender Differences in Spiritual Development during the College Years. Sex Roles, 56(11/12), 835-846. doi:10.1007/s11199-007-9240-2

Bryant, A. N. (2007). The effects of involvement in campus religious communities on college student adjustment and development. Journal of College and Character, 8(3), 1-25. 
Bryant, A. N., \& Astin, H. S. (2008). The correlates of spiritual struggle during the college years. The Journal of Higher Education, 79(1), 1-27.

Bryant, A. N., Choi, J. Y., \& Yasuno, M. (2003). Understanding the religious and spiritual dimensions of students' lives in the first year of college. Journal of College Student Development, 44(6), 723-745.

Capeheart-Meningall, J. (2005). Role of spirituality and spiritual development in student life outside the classroom. New Directions for Teaching and Learning, (104).

Chickering, A. W., \& Reisser, L. (1993). Education and identity (2 ${ }^{\text {nd }}$ ed.). San Francisco, CA: Jossey-Bass.

Cohen, A. B. (2002). The importance of spirituality in well-being for Jews and Christians. Journal of Happiness Studies, 3(3), 287-310. doi:10.1023/A:1020656823365

Confirmation Overview (2013). Retrieved from http://www.umc.org/site/c.lwL4KnN1LtH/b.1697421/k.65F6/Confirmation_Overview.ht m on December 9, 2013.

Crain, W. (2011). Theories of development: Concepts and applications (6 ${ }^{\text {th }}$ ed.). Upper Saddle River, NJ: Pearson Education, Inc.

Creswell, J. (1998). Qualitative inquiry and research design: Choosing among five traditions. Thousand Oaks, CA: Sage

Crowell, S. (2004). Existentialism. In E. N. Zalta (Ed.), The Stanford encyclopedia of philosophy (Winter 2010 ed.). Retrieved from http://plato.stanford.edu/archives/win2010/entries/existentialism/ 
Crumbaugh, J. C., \& Maholick, L. T. (1964). An experimental study in existentialism: The psychometric approach to Frankl's concept of noogenic neurosis. Journal of Clinical Psychology, 20(2), 200-207.

Damon, W., Menon, J., \& Cotton Bronk, K. (2003). The development of purpose during adolescence. Applied Developmental Science, 7(3), 119-128.

Das, A., \& Harries, B. (1996). Validating Fowler's theory of faith development with college students. Psychological Reports, 78(2), 675-679.

Davis, T. L., Kerr, B. A., \& Kurpius, S. (2003). Meaning, purpose, and religiosity in at-risk youth: The relationship between anxiety and spirituality. Journal of Psychology and Theology, 31(4), 356-365.

Defining Evangelicalism (2003) Retrieved from http://www.wheaton.edu/ISAE/DefiningEvangelicalism on December 10, 2013.

Diener, E., Suh, E. M., Lucas, R. E., \& Smith, H. L. (1999). Subjective well-being: Three decades of progress. Psychological Bulletin, 125(2), 276-302. doi:10.1037/00332909.125.2.276

Ellis, A. (1980). Psychotherapy and atheistic values: A response to A. E. Bergin’s “Psychotherapy and Religious Values.” Journal of Consulting and Clinical Psychology, 48, 635-639.

Erikson, E. H. (1950). Childhood and society. New York, NY: Norton.

Erikson, E. H. (1968). Identity: Youth and crisis. New York, NY: Norton.

Fowler, J. W. (1981). Stages of faith. San Francisco, CA: Harper \& Row.

Fowler, J. W. (1996). Pluralism and oneness in religious experience: William James, faithdevelopment theory, and clinical practice. In E. Shafranske (Ed.), Religion and the 
clinical practice of psychology, 165-186. Washington, DC: American Psychological Association.

Francis, L. J. (1997). The psychology of gender differences in religion: A review of empirical research. Religion, 27, 81-96.

Frankl V.E. (1986) The Doctor and the Soul ( $3^{\text {rd }}$ ed.). New York, NY: Vintage Books .

Frankl, V. E. (1992). Man’s search for meaning: An introduction to logotherapy. Boston: Beacon Press (Originally published in 1959).

Gallup International Association. (2012). WIN-Gallup international global index of religiosity and atheism. Accessed on December 20, 2013, from http://www.wingia.com/web/files/news/14/file/14.pdf

Garcia-Romeu, A. (2010). Self-transcendence as a measurable transpersonal construct. Journal of Transpersonal Psychology, 42(1), 26.

Golsworthy, R., \& Coyle, A. (1999). Spiritual beliefs and the search for meaning among older adults following partner loss. Mortality, 4(1), 21-40.

Hill, C. E., Knox, S., Thompson, B. J., Williams, E. N., Hess, S. A., \& Ladany, N. (2005). Consensual qualitative research: An update. Journal of Counseling Psychology, 52(2), 196-205.

Hill, C. E., Thompson, B. J., \& Williams, E. N. (1997). A guide to conducting consensual qualitative research. The counseling psychologist, 25(4), 517-572.

Hill, P. C., \& Pargament, K. I. (2003). Advances in the conceptualization and measurement of religion and spirituality: Implications for physical and mental health research. American Psychologist, 58(1), 64-74. 
Holcomb, G. L., \& Nonneman, A. J. (2004). Faithful change: Exploring and assessing faith development in Christian liberal arts undergraduates. New Directions for Institutional Research, 2004(122), 93-103.

Johnson, C. V., \& Hayes, J. A. (2003). Troubled Spirits: Prevalence and predictors of religious and spiritual concerns among university students and counseling center clients. Journal of Counseling Psychology, 50(4), 409.

Kellems, I. S., Hill, C. E., Crook-Lyon, R. E., \& Freitas, G. (2010). Working with clients who have religious/spiritual issues: A survey of university counseling center therapists. Journal of College Student Psychotherapy, 24(2), 139-155.

King, P. E. \& Roeser, R. (2009) Religion and spirituality in adolescent development. In Handbook of Adolescent Psychology: Individual Bases of Adolescent Development. Retrieved from http://www.libproxy.wvu.edu/login?url=http://www.credoreference. com/entry/wileyapi/religion_and_spirituality_in_adolescent_development

Kitzrow, M. A. (2003). The mental health needs of today’s college students: Challenges and recommendations. NASPA Journal, 41(1), 167-181.

Koenig, H. G., McCullough, M. E., \& Larson, D. B. (2001). Handbook of religion and health. New York, NY: Oxford University Press

Kohlberg, L. (1976). Moral stages and moralization: The cognitive-developmental approach. In T. Lickona (Ed.), Moral development and behavior: Theory, research, and social issues, 31-53. New York, NY: Holt, Rinehart \& Winston.

Koltko-Rivera, M. E. (2006). Rediscovering the later version of Maslow's hierarchy of needs: Self-transcendence and opportunities for theory, research, and unification. Review of General Psychology, 10(4), 302. 
Kosine, N., Steger, M. F., \& Duncan, S. (2008). Developing student strengths in identifying satisfying career options: The case for Purpose-Centered Career Development. Professional School Counseling.

Lazarus, R. S., \& DeLongis, A. (1983). Psychological stress and coping in aging. American Psychologist, 38(3), 245.

Lindholm, J. (2009). College experiences and spiritual outcomes: An interview with UCLA Spirituality in Higher Education Project director. Journal of College and Character, 10(3), 1-6.

Lindholm, J. A. (2007). Spirituality in the academy: Reintegrating our lives and the lives of our students. About Campus, 12(4), 10-17.

Love, P. G. (2001). Spirituality and student development: Theoretical connections. In M. A. Jablonski (Ed.), The implications of student spirituality for student affairs practice (New Directions for Student Services No. 95, pp. 7-16). San Francisco: Jossey-Bass.

Love, P., \& Talbot, D. (1999) Defining spiritual development: A missing consideration for student affairs. NASPA Journal, 37(1), 361-375.

Mason, M. (2010). Sample size and saturation in PhD studies using qualitative interviews. Forum Qualitative Sozialforschung / Forum: Qualitative Social Research, 11(3), Art. 8, http://nbn-resolving.de/urn:nbn:de:0114-fqs100387.

Markstrom, C. A. (1999). Religious involvement and adolescent psychosocial development. Journal of Adolescence, 22(2), 205-221.

Markstrom, C. A., Li, X., Blackshire, S. L., \& Wilfong, J. J. (2005). Ego strength development of adolescents involved in adult-sponsored structured activities. Journal of Youth and Adolescence, 34(2), 85-95. 
Mascaro, N., \& Rosen, D. H. (2008). Assessment of existential meaning and its longitudinal relations with depressive symptoms. Journal of Social and Clinical Psychology, 27(6), 576-599.

Maslow, A. H. (1943). A theory of human motivation. Psychological Review, 50, 370-396.

Massee' R. (2000) Qualitative and quantitative analyses of psychological distress: methodological complementarity and ontological incommensurability. Qualitative Health Research 10, 411-423.

Mayrl, D. \& Oeur, F. (2009). Religion and higher education: Current knowledge and directions for future research. Journal for the Scientific Study of Religion 48(2).

McKnight, P. E., \& Kashdan, T. B. (2009). Purpose in life as a system that creates and sustains health and well-being: an integrative, testable theory. Review of General Psychology, 13(3), 242.

Melton, A. M., \& Schulenberg, S. E. (2008). On the measurement of meaning: Logotherapy's empirical contributions to humanistic psychology. The Humanistic Psychologist, 36(1), $31-44$.

Miller, W. R., \& Thoresen, C. E. (2003). Spirituality, religion, and health: An emerging research field. American Psychologist, 58(1), 24-35.

Millward, L. J. (2006). The transition to motherhood in an organizational context: An interpretative phenomenological analysis. Journal of Occupational and Organizational Psychology, 79(3), 315-333.

Morrow, S. L. (2005). Quality and trustworthiness in qualitative research in counseling psychology. Journal of Counseling Psychology, 52(2), 250-260. 
Morse, J. M. (1994). Designing funded qualitative research. In N. K. Denzin \& Y. S. Lincoln (Eds.), Handbook of qualitative research (2nd ed., pp.220-235). Thousand Oaks, CA: Sage.

Myers, D.G. \& Diener, E. (1995). Who is happy?. Psychological Science 6(1), 10-19.

Parker, S. (2011). Spirituality in counseling: A faith development perspective. Journal of Counseling and Development (89).

Peterson, R. A. (2001). On the use of college students in social science research: Insights from a second-order meta-analysis. Journal of Consumer Research, 28(3), 450-461.

Phillips, R., \& Henderson, A. (2006). Religion and depression among US college students. International Social Science Review, 81(3/4), 166.

Piaget, J. (1970). Science of education and the psychology of the child. Trans. D. Coltman.

Pollard, L. J., \& Bates, L. W. (2004). Religion and perceived stress among undergraduates during fall 2001 final examinations. Psychological Reports, 95(3), 999-1007.

Prochaska, J. O., \& Norcross, J. C. (2010). Systems of psychotherapy: A transtheoretical analysis ( $7^{\text {th }}$ ed.). Belmont, CA: Brooks/Cole.

Reker, G. T., \& Wong, P. T. (1988). Aging as an individual process: Toward a theory of personal meaning. In J. E. Birren \& V. L. Bengston (Eds.), Emergent theories of aging (pp. 214246). New York, NY: Springer Publishing Co.

Richards, P. (1991). Religious devoutness in college students: Relations with emotional adjustment and psychological separation from parents. Journal of Counseling Psychology, 38(2), 189-196.

Ridner, S. (2004). Psychological distress: concept analysis. Journal of Advanced Nursing, 45(5), 536-545. doi:10.1046/j.1365-2648.2003.02938.x 
Ross, K. H. (2009). Losing Faith in Fundamentalist Christianity: An Interpretative Phenomenological Analysis (Doctoral dissertation, University of Toronto).

Ryff, C.D. (1989). Beyond Ponce de Leon and life satisfaction: New directions in quest of successful ageing. International Journal of Behavioral Development, 12, 35-55.

Schafer, W. E. (1997). Religiosity, spirituality, and personal distress among college students. Journal of College Student Development 38 (6)633-643.

Schulenberg, J. E., Sameroff, A. J., \& Cicchetti, D. (2004). The transition to adulthood as a critical juncture in the course of psychopathology and mental health. Development and Psychopathology, 16(4), 799-806.

Selman, R. L. (1976). Social-cognitive understanding: A guide to educational and clinical practice. In T. Lickona (Ed.), Moral development and behavior: Theory, research, and social issues, 299-316. New York, NY: Holt, Rinehart \& Winston.

Smith, C., \& Denton, M. (2005). Soul searching: The religious and spiritual lives of American teenagers. New York: Oxford University Press.

Smith, D. W. (2003). Phenomenology. In E. N. Zalta (Ed.). The Stanford encyclopedia of philosophy (Fall 2011 ed.). Retrieved from http://plato.stanford.edu/archives/fall2011T/entries/phenomenology/

Smith, J. A. (1996). Beyond the divide between cognition and discourse: Using interpretative phenomenological analysis in health psychology. Psychology and Health, 11, 261-271.

Smith, J. A. (2004). Reflecting on the development of interpretative phenomenological analysis and its contribution to qualitative research in psychology. Qualitative Research in Psychology, 1(1), 39-54. 
Smith, J. A. (2011). Evaluating the contribution of interpretative phenomenological analysis. Health psychology review, 5(1), 9-27.

Smith, J. A., \& Osborn, M. (2003). Interpretative phenomenological analysis. Qualitative psychology: A practical guide to research methods, 51-80. London: Sage.

Stark, R. (2002). Physiology and faith: Addressing the “universal” gender difference in religious commitment. Journal for the Scientific Study of Religion, 41, 495-507.

Steger, M. F., \& Frazier, P. (2005). Meaning in life: One link in the chain from religiousness to well-being. Journal of Counseling Psychology, 52(4), 574-582. doi:10.1037/00220167.52.4.574

Steger, M. F., Oishi, S., \& Kesebir, S. (2011). Is a life without meaning satisfying? The moderating role of the search for meaning in satisfaction with life judgments. The Journal of Positive Psychology, 6(3), 173-180.

Stillman, T. F., Baumeister, R. F., Lambert, N. M., Crescioni, A., DeWall, C., \& Fincham, F. D. (2009). Alone and without purpose: Life loses meaning following social exclusion. Journal of Experimental Social Psychology, 45(4), 686-694.

Streib, H. (2005). Faith development research revisited: Accounting for diversity in structure, content, and narrativity of faith. The International Journal for the Psychology of Religion, 15(2), 99-121.

Taliaferro, L. A., Rienzo, B. A., Pigg, R. R., Miller, M., \& Dodd, V. J. (2009). Spiritual wellbeing and suicidal ideation among college students. Journal of American College Health, 58(1), 83-90. doi:10.3200/JACH.58.1.83-90

Tappan, M. B. (1997). Interpretive psychology: Stories, circles, and understanding lived experience. Journal of Social Issues, 53(4), 645-656. 
Tisdell, E. (2003). Exploring spirituality and culture in adult and higher education. San Francisco: Jossey-Bass

Todorova, I. L. G., \& Kotzeva, T. (2006). Contextual shifts in Bulgarian women’s identity in the face of infertility. Psychology \& Health, 21(1), 123-141.

Towbes, L. C., \& Cohen, L. H. (1996). Chronic stress in the lives of college students: Scale development and prospective prediction of distress. Journal of youth and adolescence, 25(2), 199-217.

Wallace, J. M., Forman, T. A., Caldwell, C. H., \& Willis, D. S. (2003). Religion and American youth: Recent patterns, historical trends and sociodemographic correlates. Youth and Society, 35, 98-125.

Werner, E. E. (1984, November). Resilient children. Young Children, 68-72.

Williams, E. N., \& Morrow, S. L. (2009). Achieving trustworthiness in qualitative research: A pan-paradigmatic perspective. Psychotherapy Research, 19(4-5), 576-582.

Willig, C. (2001). Qualitative research in psychology: A practical guide to theory and method. Buckingham: OUP.

Yalom, I. D. (1980). Existential psychotherapy. New York, NY: Basic Books.

Zika, S., \& Chamberlain, K. (1992). On the relation between meaning in life and psychological well-being. British Journal of Psychology, 83(1), 133-145.

Zinnbauer, B., \& Pargament, K. I. (2005). Religiousness and spirituality. In Paloutzian, R. \& Parks, C. (Eds.), Handbook of psychology and religion (pp. 21-42). New York, NY: Guilford Press. 
Zinnbauer, B. J., Pargament, K. I., \& Scott, A. B. (1999). The emerging meanings of religiousness and spirituality: Problems and prospects. Journal of Personality, 67(6), 889-919. 


\section{Appendix A}

\section{Glossary of Terms}

Activism - one of four hallmarks of evangelical Christianity; behavioral expression of the gospel (Bebbington, 1989)

Biblicism- one of four hallmarks of evangelical Christianity; having particular regard for the Bible (Bebbington, 1989)

Conversion - a new development of spiritual or religious beliefs, involvement, and commitment with little or no history of religious or spiritual engagement.

Conversionism - one of four hallmarks of evangelical Christianity; the belief that lives need to be changed or converted (Bebbington, 1989)

Crucicentrism- one of four hallmarks of evangelical Christianity; the emphasis of Jesus Christ's sacrifice on the cross

Evangelical Christianity- a broad term encompassing Protestant faith traditions (Institute for the Study of American Evangelicals) Hallmarks of evangelical Christianity: conversionism, activism, biblicism, and “crucicentrism” (Bebbington, 1989)

Existentialism- a philosophical and psychological movement which extends beyond physical understandings of nature and physics to explore human existence; seeks to answer questions such as Why do we exist? and Is life meaningful? (Prochaska \& Norcross, 2010)

Phenomenology- the study of human consciousness from the subjective first person perspective Religion-“a shared system of beliefs, principles or doctrines related to a belief in and worship of a supernatural power or powers regarded as creator(s) and governor(s) of the universe” (Love, 2001, p. 8); “an organized system of beliefs, practices, rituals, and symbols that serve (a) to facilitate individuals' closeness to the sacred or transcendent other (i.e., God, higher power, ultimate truth) and (b) to bring about an understanding of an individual's relationship and responsibility to others living together in community (Koenig, McCullough, and Larson, 2001p.18)

Spirituality- a mechanism by which individuals construct knowledge and meaning; defines how people create awareness of the interconnectedness of all things including unconscious and symbolic processes (Tisdell, 2003); a quest to understand the answers to ultimate questions about life, meaning, and about the sacred or transcendent and may or may not lead to or originate from religious engagement 


\section{Appendix B}

\section{Conversion to Evangelical Christianity during College: An Interpretative Phenomenological Analysis}

\section{Email to Group Leaders Requesting to Personally Visit their Organization and Recruit Participants}

Dear

My name is Meagan Brunson. I am a Counseling Psychology Ph.D. student at West Virginia University. I would like to request your permission to briefly speak at your next (name of organization or church) meeting and provide students information about an opportunity to participate in psychological research on the topic of converting to Christianity while in college.

The research project has been approved by the Appalachian State University and West Virginia University Institutional Review Boards. Participation in this study is completely voluntary. The research is being conducted by me under the leadership of my dissertation chairperson, Dr. Jeffrey Daniels. The purpose of the research is to describe individuals' experiences converting to evangelical Christianity during college, determine any factors within these conversion experiences that impact existential and psychological well-being or distress, and learn about how individuals coped with this transition. My hope is that the research will help psychologists better understand and support college students who are converting or who have already converted to the Christian faith. Potential personal gains from participating in the research project include increasing personal insight into one's conversion experience, a deeper appreciation for personal experiences, and the experience of sharing one's conversion experience with the researcher and with future research consumers

My presentation, at your meeting, would take approximately 5-10 minutes. Also, I would provide students a cover letter and information sheet to review should they be interested in participating. I have attached both of these to the email.

Please let me know if you will allow me to attend your meeting and inform students of this research opportunity. Also, please feel free to contact me with any questions at Meagan.Brunson@mail.wvu.edu or 828-545-7511. You may also contact my research advisor Dr. Jeff Daniels at Jeffrey.Daniels@mail.wvu.edu.

Thank you,

Meagan Brunson, M.A.

Counseling Psychology Doctoral Candidate

West Virginia University 


\section{Appendix C}

\section{Conversion to Evangelical Christianity during College: An Interpretative Phenomenological Analysis}

\section{Verbal Script for Direct Participant Recruitment}

Hello, my name is Meagan Brunson. I am a Counseling Psychology Ph.D. student at West Virginia University. I would like to provide you with information about an opportunity to participate in psychological research on the topic of converting to Christianity while in college. The research project has been approved by the Appalachian State University and West Virginia University Institutional Review Boards. Participation in this study is completely voluntary. The research is being conducted by me under the leadership of my dissertation chairperson, Dr. Jeffrey Daniels. The purpose of the research is to describe individuals' experiences converting to evangelical Christianity during college, determine any factors within these conversion experiences that impact existential and psychological well-being or distress, and learn about how individuals coped with this transition. My hope is that the research will help psychologists better understand and support college students who are converting or who have already converted to the Christian faith. Potential personal gains from participating in the research project include increasing personal insight into your conversion experience, a deeper appreciation for personal experiences, and the experience of sharing your conversion experience with the researcher and with future research consumers.

Participating in the research would involve completing an interview that will likely take 1.5 to 2 hours and will be audio recorded. Any information that is gathered as a result of participation in the study will be kept as confidential as legally possible. Audio recordings of interviews will be password-protected, stored in a locked container, and destroyed as soon as possible after the research is finished.

Your participation in this study is completely voluntary. If you are interested in participating in this study, please review the research study information sheet and the informed consent form, which I can provide you today. Then contact me, Meagan Brunson, at Meagan.Brunson@mail.wvu.edu or 828-545-7511 to discuss your interest. If you have any questions about the study, you can contact me using the contact information listed above. You can also contact my research advisor, Dr. Jeff Daniels, at Jeffrey.Daniels@mail.wvu.edu or 304293-2235. 


\section{Appendix D}

\section{Conversion to Evangelical Christianity during College: An Interpretative Phenomenological Analysis}

\section{INFORMED CONSENT FORM}

You, have been asked to participate in this research study, which has been explained to you by Meagan Brunson, M.A. This study is being conducted by Meagan Brunson, M.A., a Counseling Psychology Doctoral Candidate, in the Department of Counseling, Rehabilitation Counseling and Counseling Psychology at West Virginia University.

\section{Purpose of the Study}

The purpose of this study is to learn more about the experiences of individuals who converted to the Christian faith during college. Additionally, the researcher hopes to learn about the existential and psychological experiences of participants during this conversion and from what sources they sought support. A total of approximately 15 participants are expected to participate in this study.

\section{Description of Procedures}

This study involves an interview in which you will be asked to talk about your experience converting to the Christian faith. The interview will take approximately 1.5 to 2 hours for you to complete. You will also be asked to complete an informational form about yourself and your religious/spiritual experiences. You do not have to answer all of the questions. You will have the opportunity to see the questions you will be asked before signing this consent form. The interview will be audio recorded and transcribed. To ensure accuracy, you will be asked to review the researcher's analysis of your interview transcript.

\section{Risks and Discomforts}

There are no known or expected risks from participating in this study, except for possible mild frustration associated with answering questions about your personal conversion and change. Should you experience any emotional upset, a list of local mental health providers will be given to you.

\section{Alternatives to Participation}

You do not have to participate in this study. Your involvement is completely voluntary. If you choose to participate, you are allowed to stop at any time and ask that your information not be used until the formal analysis phase of the research project. You will be notified two weeks prior to the start of formal analysis phase.

\section{Benefits}

You may not receive any direct benefit from this study. The knowledge gained from this study may eventually benefit others. For example, the information from this study might help health care professionals improve treatment for people who are or have converted to faith during college. Some people might experience positive feelings that they participated in a study that 
may benefit others. You might benefit from being able to view results, which can be sent to you at your request.

\section{Financial Considerations}

There are no anticipated costs to you to participate in this study.

\section{Confidentiality}

Any information about you that is gathered as a result of your participation in this study will be kept as confidential as legally possible. Your research records, just like hospital records, may be subpoenaed by court order. They might be inspected by federal regulatory authorities without your additional consent. Exceptions to confidentiality include participant disclosures of, or the researcher learning about, suicidal or homicidal ideation, and ongoing or unreported child abuse or elder abuse.

Audio recordings of your interview will be password-protected and will be destroyed as soon as possible after the research is finished. The demographic form and audio recordings and written transcripts of your interview will be labeled with a number, not your name. The demographic form and all materials from your interview will be stored in a locked container. Your signed informed consent form will be stored in a separate locked container.

In any publications or presentations that result from this research, your name will not be used without your consent. Also, any information that might identify you will not be published or presented without your consent.

\section{Voluntary Participation}

Participation in this study is completely voluntary. You are free to withdraw your consent to participate in this study at any time prior to the formal analysis phase of the research project. Withdrawal or refusal to participate will not affect you, and you will not be penalized. If new information becomes available that may affect your willingness to participate in this study, this information will be given to you so that you can make an informed decision about whether or not to continue your participation. You have been given the opportunity to ask questions about the research, and you have received answers concerning areas you did not understand.

\section{Contact Persons}

In the event that you experience any negative effects related to this research, you should contact Meagan Brunson M.A., at Meagan.Brunson@mail.wvu.edu. If you have any questions, concerns, or complaints about this research, you can contact Ms. Brunson's research advisor and the department chair, Dr. Jeff Daniels, at 304-293-2235 or at Jeffrey.Daniels@mail.wvu.edu.

If you have any questions, concerns, or complaints about this research that are not answered by the researcher, you can contact the West Virginia University Institutional Review Board Office at 304293-7073. You can also call this number if you cannot talk to the researcher prefer to talk to someone else.

Participant's Signature

Participant's Name (please print)

\section{Date}




\section{Appendix E}

\section{Conversion to Evangelical Christianity during College: An Interpretative Phenomenological Analysis}

\section{Cover Letter to Participants}

\section{Dear Participant,}

This letter is a request for you to take part in a research project to assess how conversion to Evangelical Christianity during college affects students at Appalachian State University (ASU). This project is being conducted by Meagan Brunson, MA in the Department of Counseling, Rehabilitation Counseling, and Counseling Psychology with supervision of Dr. Jeffrey Daniels, an associate professor in the College of Education and Human Services at WVU, for a dissertation and partial requirements of a Doctor of Philosophy Degree in Counseling Psychology. Your participation in this project is greatly appreciated and will take approximately one to one and a half hours to complete a face-to-face interview which will be audio recorded.

Your involvement in this project will be kept as confidential as legally possible. All data will be reported in the aggregate. You must be 18 years of age or older to participate. Participant information and responses will be kept as confidential as legally possible. The audio and text documents will be kept in an encrypted and password protected document on a computer in a locked office of the researcher. After the study is completed, and the required duration for retaining data is expired, the electronic documents will be completely erased from the researcher's computer and paper documents and compact discs will be shredded. Your participation is completely voluntary. You may skip any question that you do not wish to answer and you may discontinue at any time. Your class standing will not be affected if you decide either not to participate or to withdraw. Discussing religious and spiritual issues may result in distress. Therefore, the researcher will provide each participant a list of local counseling resources for optional and voluntary follow-up. West Virginia University and Appalachian State University’s Institutional Review Boards acknowledgements of this project are on file.

I hope that you will participate in this research project, as it could be beneficial in understanding the impact conversion to Evangelical Christianity has on students. Thank you very much for your time. Should you have any questions about this letter or the research project, please feel free to contact Meagan Brunson at (828) 545-7511 or by e-mail at mbrunson@mix.wvu.edu or Dr. Jeffrey Daniels at (304) 293-2235 or Jeffrey.Daniels@mail.wvu.edu.

Thank you for your time and help with this project.

Sincerely,

Meagan Brunson, MA

Counseling Psychology Doctoral Candidate 


\section{Appendix F}

\section{Conversion to Evangelical Christianity during College: An Interpretative Phenomenological Analysis}

\section{Research Study Information Sheet}

Hello, my name is Meagan Brunson. I am a Counseling Psychology Ph.D. student at West Virginia University. I am conducting research on the topic of transitioning into Christianity while in college. The research project has been approved by the Appalachian State University and West Virginia University Institutional Review Boards. Participation in this study is completely voluntary.

The purpose of the research is to describe individuals' experiences converting to evangelical Christianity during college, determine any factors within these conversion experiences that impact existential and psychological well-being or distress, and learn about how individuals coped with this transition. My hope is that the research will help psychologists better understand and support college students who are converting or who have already converted to the Christian faith.

Participation involves engaging in an interview lasting approximately 1.5 to 2 hours which will be audio recorded. Any information that is gathered as a result of participation in the study will be kept as confidential as legally possible.

To participate in the study you must meet the following criteria:

1) You are a college student who converted to the Christian faith during college

2) You self-identify as evangelical Christian, to include:

a. You believe that lives need to be changed (e.g. People need to be saved or converted)

b. You work to behaviorally express the gospel

c. You have particular regard for the Bible

d. You emphasize Jesus Christ's sacrifice on the cross

3) You regularly attend an evangelical Christian church or organization (at least once per week)

4) You are 18 years old or older

5) You speaking English fluently

If you choose to participate in the study, you will be asked to complete a brief informational telephone conversation. At that time, I will provide you with more information about the study so you can make an informed decision about whether you want to participate. You can discontinue your participation at any time with no penalty for withdrawing.

If you are interested in participating in this study, please contact me, Meagan Brunson, at Meagan.Brunson@mail.wvu.edu or 828-545-7511 to discuss your interest. If you have any questions about the study, you can contact me using the contact information listed above. You can also contact my research advisor, Dr. Jeff Daniels, at Jeffrey.Daniels@mail.wvu.edu or 304-293-2235.

Thank you, Meagan Brunson, M.A.

Counseling Psychology Doctoral Candidate

West Virginia University

Department of Counseling, Rehabilitation Counseling and Counseling Psychology

502 Allen Hall

P.O. Box 6122

Morgantown, WV 26506 


\section{Appendix G \\ Conversion to Evangelical Christianity during College: An Interpretative Phenomenological Analysis}

\section{Demographic Form}

INSTRUCTIONS: Please complete each of the items to the best of your ability. If there is an item that you do not wish to answer, you are free to leave it blank. However, it is helpful to have the most complete information possible.

How old are you?

Sex (please check one):

Male

Female

Other (please explain):

\section{Current year in college:}

First year

Sophomore

Junior

Senior

Graduate Student

Law student

Medical student

\section{Marital/Relationship Status}

Current Marital/Relationship Status (please check one):

Single

Cohabiting

Married/Partnered

Separated/Divorced

Widowed

\section{Ethnicity/Race}

Ethnicity/Race (please check one):

African/African-American

American Indian or Alaska Native

Asian/Asian-American

Caucasian, non-Hispanic/non-Latino(a)

Caucasian, Hispanic/Latino(a)

Hispanic/Latino(a)

Middle Eastern

Native Hawaiian or Other Pacific Islander 
Multiracial (please indicate which ethnicities/races you identify with):

\section{Conversion to Christianity Information}

What was the date of your conversion to evangelical Christianity?

-

For the above date, please indicate if this is an approximation or a precise date:

Approximation

Precise

Were you attending spiritual or religious services around the time you converted to Christianity? Yes

No

If yes, how did the group that you attended identify itself?

Christian

Other (please describe):

\section{Current Spiritual and Religious Information}

Are you currently attending evangelical Christian spiritual or religious services?

Yes

No

If yes, how does the group that you attend identify itself?

Anglican

Baptist

Catholic

Lutheran

Methodist

Pentecostal

Presbyterian

Non-Denominational

Other (please describe):

How many religious group events (on average) do you engage in each week?

How many hours a week (on average) do you spend at formal or informal religious group events?

How many hours a week (on average) do you spend performing religious group-related activities or obligations (examples include prayer, meditation, reading scripture)?

How long have you been in the group? 


\section{Appendix $\mathbf{H}$}

\section{Conversion to Evangelical Christianity during College: An Interpretative Phenomenological Analysis}

\section{Interview Protocol}

\section{Introduction}

\section{a. Welcome}

“Hello. Thank you for your interest in helping me with my research. Again, I'm Meagan Brunson, the researcher for this interview project, which is approved by the West Virginia University Institutional Review Board.”

\section{b. Informed Consent}

i. Clarification/Questions (after reviewing the Informed Consent)

"Do you have any questions about the study?”

"Do you have any concerns about the study?"

\section{Interview}

\section{a. Review of Demographic Data and Conversion to Faith and Christian Group Involvement Information:}

\section{i. Clarification/Questions}

"Do you have any questions or concerns about the form?"

"Would you like to clarify or explain any response you gave on this form?”

\section{b. Open-Ended Questions}

i. Please tell me about your exposure to religion/spirituality before becoming a Christian.

ii. What do you think was a catalyst for your conversion to the Christian faith?

iii. Please tell me about your experience converting to the Christian faith.

iv. If you can remember back to this time in your life, what kind of thoughts and feelings did you experience during this time of conversion?

v. What were some of the positive experiences, if any, you had during your conversion?

vi. What were some of the most challenging experiences you had during your conversion?

vii. Did your conversion to faith impact you psychological or emotionally? If so in what ways? 
viii. Did your conversion to faith impact your thoughts about your future? If so in what ways?

ix. Was any part of your conversion distressing?

1. If so, what was distressing?

2. At the time, how did you cope with this distress?

x. Did you seek support or counsel at the time of your conversion?

1. If so, from whom?

2. And what about that person or persons lead you to seek their support?

xi. How did your friends and family react to your conversion?

xii. How do you think this conversion to the Christian faith was impacted by the fact that you were in college?

xiii. How does your conversion to the Christian faith affect you today?

1. What thoughts or feelings do you have when you think back to that time in your life?

xiv. Is there anything I did not ask you about your conversion to Christianity that you think might be beneficial for me to know?

\section{c. Closing}

\section{i. Further invitation}

"Is there anything else you would like to tell me about today's discussion?"

\section{ii. Debriefing}

"How did you feel discussing these topics?"

"What are your thoughts about today's discussion?"

\section{iii. Appreciation}

"Thank you for sharing your story with me. The information that you shared with me today will be very helpful for me to learn more about the experience of college students' conversion to the Christian faith during college.”

\section{iv. Invitation for the outcome and information for future contact}

"Is it okay for me to contact you if I need to clarify your responses or need further information?”

\section{v. Appreciation}

"Thanks again!” 


\section{Appendix I}

\section{Conversion to Evangelical Christianity during College: An Interpretative Phenomenological Analysis}

\section{Counseling Referral List}

Counseling and Psychological Services Center Appalachian State University 614 Howard Street or ASU Box 32044

Boone, NC 28608-2044

Phone: (828) 262-3180

Fax: (828) 262-3182

Blue Mountain Center for Integrative Health 1064 Meadowview Drive

Boone, NC 28607

Phone: 828/265.1455

Fax: 828/265.1535

Email: bluemountaincenternc@gmail.com

High Country Counseling

589 W. King Street (in the Vetro building)

Boone, NC 28607

Phone: 828-449-8049.

Email: info@highcountrycounseling.org

Psychotherapy Associates of Boone

895 State Farm Road, Building 100, Suite 104

Boone, NC 28607

In Oak Summit Office Park

Phone: 828-265-0190

180 Behavioral Health, PLLC

719-A Greenway Road

Boone, NC 28607

Phone: (828) 263-4480

http://www.180behavioralhealth.com 


\section{Appendix $\mathbf{J}$}

\section{Conversion to Evangelical Christianity during College: An Interpretative Phenomenological Analysis}

\section{Theme Directory Charts by Case}

\section{Case 1 Themes Directory}

\begin{tabular}{|c|c|c|}
\hline Superordinate Concepts & Themes & Quotes (with page and line numbers) \\
\hline \multirow[t]{5}{*}{$\begin{array}{l}\text { Previous Exposure to } \\
\text { Religion/Spirituality }\end{array}$} & Family Involvement & $\begin{array}{l}\text { "Um, I grew up Catholic. Um, so I came } \\
\text { to the United States when I was five } \\
\text { years old and my adoptive parents were } \\
\text { Catholic..." } 1.20\end{array}$ \\
\hline & Friend Involvement & $\begin{array}{l}\text { "And then with the Anglican Church um, } \\
\text { basically I was going for the wrong } \\
\text { reasons because my friend went...” } 2.9\end{array}$ \\
\hline & $\begin{array}{l}\text { Significant Influential } \\
\text { Persons }\end{array}$ & $\begin{array}{l}\text { "So he was the one that invited me to the } \\
\text { fall retreat and talked to me about my } \\
\text { adoption and just the things that I was } \\
\text { struggling with or like all the questions I } \\
\text { had about God um he was there to kind } \\
\text { of listen to me, so.” } 2.23 \\
\text { “... and there was a women who worked } \\
\text { with orphans in Uganda and she was } \\
\text { from the Netherlands and I had never met } \\
\text { somebody who... um, [crying] sorry... } \\
\text { I: It's okay... You can take your time. } \\
\text { P: Um, and actually understood...” } 8.24 \\
\text { “I did meet a mentor ... she is Christian } \\
\text { and so instead of being able to rely on } \\
\text { my mom since she’s not Christian and I } \\
\text { don't have a good relationship with her, } \\
\text { I've been able to rely on older women, } \\
\text { whether that's in the church or whether } \\
\text { that's certain mentors.” 13.2 }\end{array}$ \\
\hline & Lack of Exposure & \\
\hline & Negative Experiences & \\
\hline Unique to College & Independence & $\begin{array}{l}\text { "I think it helps that I was in college } \\
\text { because I was basically independent from } \\
\text { my parents and then I was able to kind of } \\
\text { make those decisions for myself." } 15.3\end{array}$ \\
\hline
\end{tabular}




\begin{tabular}{|c|c|c|}
\hline & & $\begin{array}{l}\text { "... and so I just think that that aspect of } \\
\text { that freedom or that independence helped } \\
\text { me to be able to pursue what I needed to } \\
\text { as an individual without their kind of } \\
\text { guidance or say as to what I should or } \\
\text { should not do." } 15.7\end{array}$ \\
\hline & $\begin{array}{l}\text { Parties are } \\
\text { Unsatisfactory }\end{array}$ & $\begin{array}{l}\text { “...before I became a Christian I went to } \\
\text { some clubs and partied and really did not } \\
\text { find satisfaction in that and realized that } \\
\text { there had to be something more than } \\
\text { doing that.” } 15.14\end{array}$ \\
\hline & & $\begin{array}{l}\text { “I think that was one of the things that I } \\
\text { really struggled with whenever I got } \\
\text { saved because even though I didn't want } \\
\text { to necessarily drink or party that was the } \\
\text { environment I was surrounded by and } \\
\text { I've always kind of struggled at night. I } \\
\text { don't really know why ever since I was a } \\
\text { child I've always been scared of the dark } \\
\text { and just kind of not liked that night time } \\
\text { and so I think that was difficult for me } \\
\text { because I felt, I feel more alone I guess at } \\
\text { night or if I'm not with people, if I'm not } \\
\text { going out and partying then what is there } \\
\text { for me to really do.” } 19.6\end{array}$ \\
\hline & Self-Exploration & \\
\hline Questioning God & Wrestling with Evil & $\begin{array}{l}\text { “...even in school, where I've learned } \\
\text { about wars or I've learned about things } \\
\text { such as sex trafficking or um just things } \\
\text { that are really kind of hard and dark and I } \\
\text { question God in that and questioned } \\
\text { whether he was real.” } 10.17\end{array}$ \\
\hline & & $\begin{array}{l}\text { "I just had been struggling I think a lot } \\
\text { with just sex trafficking and just the } \\
\text { darkness and kind of being overwhelmed } \\
\text { by it but to kind of have the breakthrough } \\
\text { that God has overcome and that he will } \\
\text { provide justice to his people." } 11.7\end{array}$ \\
\hline & Doubting God & $\begin{array}{l}\text { "So he was the one that invited me to the } \\
\text { fall retreat and talked to me about my } \\
\text { adoption and just the things that I was } \\
\text { struggling with or like all the questions I } \\
\text { had about God um he was there to kind } \\
\text { of listen to me, so." } 2.23\end{array}$ \\
\hline
\end{tabular}




\begin{tabular}{|c|c|c|}
\hline & & $\begin{array}{l}\text { “..I was like outside kind of questioning } \\
\text { God and wondering whether I really } \\
\text { wanted to do it...” } 3.5 \\
\text { “I guess the distress was more of me } \\
\text { being able to know that I could truly } \\
\text { believe in God without doubting him.” } \\
11.25 \\
\text { “Cause I was still, I guess, I was still } \\
\text { going to church then and I had a, a youth } \\
\text { group leader but I guess I was maybe } \\
\text { doubting the Lord or I wasn’t really } \\
\text { strong in my faith then.” } 17.7\end{array}$ \\
\hline & Doubting Allah & \\
\hline & Dismay with Islam & \\
\hline & $\begin{array}{l}\text { Reconciling Science } \\
\text { and Supernatural }\end{array}$ & \\
\hline & Resistant to Convert & $\begin{array}{l}\text { "...I was hesitant to get saved ...I think } \\
\text { my friend kind of volunteered me, or } \\
\text { something like that, "cause I was scared." } \\
5.16\end{array}$ \\
\hline \multirow[t]{2}{*}{$\begin{array}{l}\text { God is Omnipresent and } \\
\text { Sovereign }\end{array}$} & All Sufficient & $\begin{array}{l}\text { “...you just can’t rely on yourself, you } \\
\text { realize you can’t be your own savior um } \\
\text { and that the problems that you have you } \\
\text { can’t fix yourself or other people can’t } \\
\text { necessarily fix it for you.” } 3.20 \\
\text { “Yeah, I guess just realizing that I don’t } \\
\text { know what else I would have other than } \\
\text { being able to rely on Him.” } 12.8 \\
\text { “And so realizing that God has to be } \\
\text { number one in my life so I can’t put } \\
\text { people above him and I can’t put material } \\
\text { possessions above him and If I do than } \\
\text { He basically shows me that I, that I } \\
\text { should not.” } 16.11\end{array}$ \\
\hline & Evidence of God & $\begin{array}{l}\text { "So I think that God brings pain into our } \\
\text { lives at least nowadays to be able to } \\
\text { show, to show who He is and to show } \\
\text { that He is the savior and to show that the } \\
\text { pain that we do feel, if we can give that } \\
\text { to the Lord, that we can get joy in return } \\
8.11\end{array}$ \\
\hline
\end{tabular}




\begin{tabular}{|c|c|c|}
\hline & & $\begin{array}{l}\text { "But I think that everything happens } \\
\text { within its timing and that the Lord was, } \\
\text { was leading me to that conversion.” } \\
16.18 \\
\text { “...I was self-conscious of my height and } \\
\text { I guess that came from my sister too } \\
\text { because she would always dress up and } \\
\text { stuff. But, that was broken kind of my } \\
\text { sophomore year of high school when I } \\
\text { started being friends with Blair and so } \\
\text { seeing that the Lord was doing a work, I } \\
\text { guess, in that moment before I like truly } \\
\text { believed.” } 17.3 \\
\text { "So, I guess seeing how the Lord worked } \\
\text { even before I really surrendered my life } \\
\text { to Christ.” } 17.14 \\
\text { “... whenever I really felt like I needed } \\
\text { Him or when I was I think struggling } \\
\text { with my adoption or I guess like thanking } \\
\text { Him maybe for my adoption before I } \\
\text { became a Christian it wasn’t until I think } \\
\text { I realized until after I got saved that the } \\
\text { Lord had been there the whole time.” } \\
\text { 17.21 } \\
\text { "I realized that the Lord had been kind of } \\
\text { holding my hand even through, even } \\
\text { through the struggles, I guess, of my life } \\
\text { and feeling like I had been either } \\
\text { abandoned or alone.” } 18.2 \\
\end{array}$ \\
\hline & $\begin{array}{l}\text { Confidence in God's } \\
\text { Sovereign Plan }\end{array}$ & $\begin{array}{l}\text { "I know that the Lord has a plan for me." } \\
9.13\end{array}$ \\
\hline $\begin{array}{l}\text { Positive Emotional } \\
\text { Experiences }\end{array}$ & Peak Experiences & $\begin{array}{l}\text { "...I was on such as spiritual high from } \\
\text { that conversion that I felt like that any } \\
\text { problems that came my way that I would } \\
\text { be able to handle.” } 4.8 \\
\text { “...I guess it’s hard to explain, just like a } \\
\text { euphoria ...I felt awesome and that I felt } \\
\text { so great and that I had never felt that } \\
\text { way before...” } 4.13\end{array}$ \\
\hline
\end{tabular}




\begin{tabular}{|c|c|c|}
\hline & & $\begin{array}{l}\text { "I think, especially, cause if you go on } \\
\text { retreats or anything like that, I think } \\
\text { that's what I struggled with is, you get to } \\
\text { a spiritual high and, I mean I was saved } \\
\text { so that was a really big stepping stone } \\
\text { but, you go back into the real world..." } \\
4.23\end{array}$ \\
\hline & Newfound Hope & $\begin{array}{l}\text { "But just having the hope that since God } \\
\text { has done a work in my life and I realized } \\
\text { through my adoption that God has saved } \\
\text { me..." } 9.19 \\
\text { "So, I think it's just that surrendering of } \\
\text { your life and your will to, to a God that I } \\
\text { guess you have to have faith in but we } \\
\text { can I guess put our hope in." } 3.22\end{array}$ \\
\hline & Gratitude & $\begin{array}{l}\text { "I am thankful for my conversion and I } \\
\text { guess I never really thought about what } \\
\text { would happen if I hadn't been converted. } \\
\text { But I think that everything happens } \\
\text { within its timing and that the Lord was, } \\
\text { was leading me to that conversion. So I } \\
\text { guess I'm just thankful for it." } 16.17\end{array}$ \\
\hline & Healing & $\begin{array}{l}\text { "...I would still try to receive healing } \\
\text { form my adoption and the issues of } \\
\text { abandonment, and things like that, but it } \\
\text { never, the healing never really stayed I } \\
\text { guess.” } 7.25 \\
\text { "I knew that I was going through a } \\
\text { healing process and that it was healthy." } \\
8.15\end{array}$ \\
\hline & Relief & \\
\hline & Understanding & \\
\hline & Happiness & \\
\hline & Love & $\begin{array}{l}\text { "....it was that breakthrough I guess of... } \\
\text { the concept of Father Heart is I guess } \\
\text { being able to experience God's love, not } \\
\text { just knowing that God loves you but } \\
\text { feeling it your heart...” } 8.21\end{array}$ \\
\hline & $\begin{array}{l}\text { Freedom from } \\
\text { Legalism }\end{array}$ & \\
\hline Openness & Open to God & $\begin{array}{l}\text { "...even without somebody telling me, I } \\
\text { was able to open up my heart to God and } \\
\text { I had definitely been closing it to Him }\end{array}$ \\
\hline
\end{tabular}




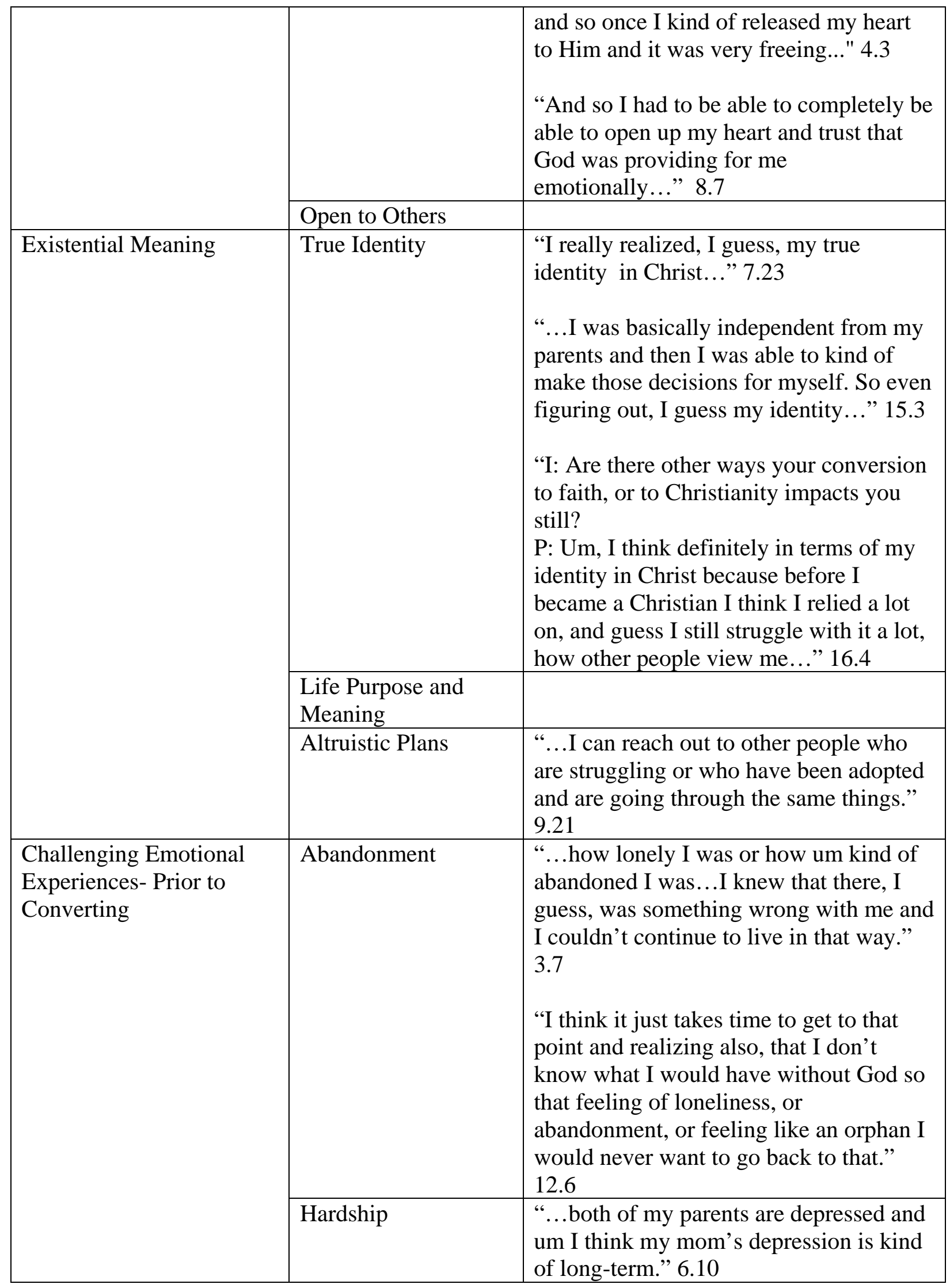




\begin{tabular}{|c|c|c|}
\hline & Confusion & $\begin{array}{l}\text { "Um and I think that's the realization and } \\
\text { the kind of um, I guess just realizing that } \\
\text { that feelings doesn't last and that's why } \\
\text { because we live in a world where there is } \\
\text { sin." } 5.3\end{array}$ \\
\hline \multirow[t]{4}{*}{$\begin{array}{l}\text { Challenging Emotional } \\
\text { Experiences -After } \\
\text { Converting }\end{array}$} & Spiritual Warfare & $\begin{array}{l}\text { "I think that the enemy has room to reign } \\
\text { in my household and I think that's what } \\
\text { is the most difficult, um, is experiencing } \\
\text { I guess like spiritual battle or even before } \\
\text { I could identify like spiritual warfare." } \\
6.15 \\
\text { "I guess before you described distressing, } \\
\text { I think the only thing that I really thought } \\
\text { about was like spiritual warfare so like } \\
\text { the opposite of, of God is the enemy. } \\
\text { And I think that was a difficult } \\
\text { process,..." } 10.13\end{array}$ \\
\hline & Discord with Others & $\begin{array}{l}\text { “...my parents grew up Catholic, going } \\
\text { back home and telling them that I was } \\
\text { Christian even interacting with my } \\
\text { brother and sister has always been } \\
\text { difficult. Um, and so I would say that's } \\
\text { probably the hardest thing, especially } \\
\text { whenever I go home.” } 5.22 \\
\text { "I was talking to my sister about baptism, } \\
\text { um, and so maybe it was after I got } \\
\text { saved, and she was like, basically saying } \\
\text { I was in a cult and um that I shouldn't } \\
\text { give into that...” } 7.7 \\
\text { "I think even recently, they maybe think } \\
\text { that, like I think that, that I'm better than } \\
\text { them. And that's not the case, I think } \\
\text { there’s been a lot of miscommunication } \\
\text { between us and it's hard for me to love } \\
\text { them as Christ loves them.” } 14.17\end{array}$ \\
\hline & Ongoing Hardship & $\begin{array}{l}\text { "Um and I think that's the realization and } \\
\text { the kind of um, I guess just realizing that } \\
\text { that feelings doesn't last and that's why } \\
\text { because we live in a world where there is } \\
\text { sin." } 5.3\end{array}$ \\
\hline & Guilt and Shame & $\begin{array}{l}\text { "it’s still a struggle because I give into } \\
\text { temptation and either I sin or I make } \\
\text { mistakes and it's I guess it's, I guess like }\end{array}$ \\
\hline
\end{tabular}




\begin{tabular}{|c|c|c|}
\hline & & $\begin{array}{l}\text { a daily or a weekly process of either } \\
\text { repenting or coming back to the Lord } \\
\text { and, and realizing my need for him.” } \\
15.25\end{array}$ \\
\hline \multirow[t]{2}{*}{ Supports } & Loss of Friends & $\begin{array}{l}\text { “...they didn’t, they never ostracized me } \\
\text { or anything like that or said that what I } \\
\text { was doing was wrong but it was just kind } \\
\text { of like a, I guess, a neutral separation um, } \\
\text { even if I didn't necessarily want that to } \\
\text { happen.” } 14.4 \\
\text { “... whenever I did convert and really } \\
\text { relied on Jesus for that support I think } \\
\text { they realized that either they could not } \\
\text { help me or that, that since I was relying } \\
\text { on my faith that, I guess, that they didn’t } \\
\text { necessarily need to be a support } \\
\text { anymore.” } 14.15\end{array}$ \\
\hline & $\begin{array}{l}\text { Current Critical } \\
\text { Evaluation }\end{array}$ & $\begin{array}{l}\text { "I think that the enemy has room to reign } \\
\text { in my household and I think that's what } \\
\text { is the most difficult, um, is experiencing } \\
\text { I guess like spiritual battle or even before } \\
\text { I could identify like spiritual warfare. } \\
\text { Um I think that is what's happening is } \\
\text { because I was following God and I was } \\
\text { changing and trying to glorify Him and } \\
\text { my parents haven't surrendered their } \\
\text { lives to Christ. Um and so, it's just that } \\
\text { spiritual aspect.” } 6.15 \\
\text { “Cause I guess we've struggled with, I } \\
\text { think my parents believe in God but in } \\
\text { terms of Catholicism, and the problems } \\
\text { that I've had with it, is that it's more I } \\
\text { guess traditional and it's more religious } \\
\text { and it's more about rules and law than } \\
\text { having a relationships with Christ . And } \\
\text { so I don’t think they necessarily } \\
\text { understand that they can have a } \\
\text { relationship with God...” 6.22 } \\
\text { “...based off of my experience with } \\
\text { Christianity and being saved I don’t think } \\
\text { that they’ve had that and I don't think } \\
\text { they are open to it because of maybe the } \\
\text { stigma behind it.” } 7.3\end{array}$ \\
\hline
\end{tabular}




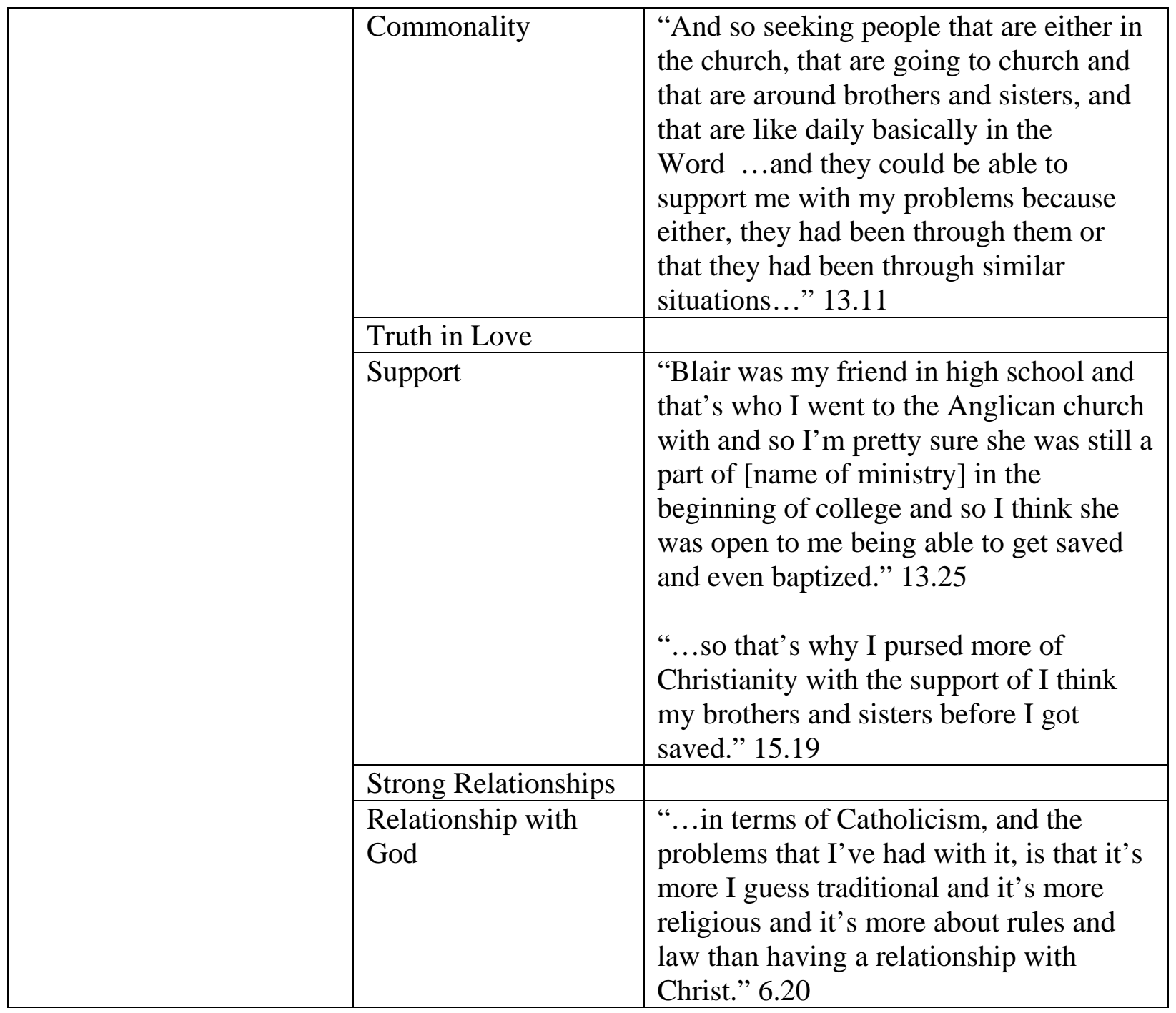




\section{Case 2 Themes Directory}

\begin{tabular}{|c|c|c|}
\hline Superordinate Concepts & Themes & Quotes (with page and line numbers) \\
\hline \multirow[t]{4}{*}{$\begin{array}{l}\text { Previous Exposure to } \\
\text { Religion/Spirituality }\end{array}$} & Family Involvement & $\begin{array}{l}\text { I could probably name off one hand how } \\
\text { many times I'd been to church growing } \\
\text { up. I don't know, I just didn’t really grow } \\
\text { up, and my mom is very spiritual, } \\
\text { spiritual person , my dad grew up going, } \\
\text { he went to a Catholic school and, but I } \\
\text { didn’t, I didn't go to Sunday school. And } \\
\text { I, I don't know, my parents are very } \\
\text { spiritual peopled well, my mom } \\
\text { specifically. } 4.4\end{array}$ \\
\hline & Friend Involvement & $\begin{array}{l}\text { "And then I started dating my girlfriend } \\
\text { and she grew up in a very Christian } \\
\text { household, her mom is a very devote } \\
\text { Christian. So she grew up going to } \\
\text { Sunday school and all that.” } 6.20 \\
\text { "I remember it was my girlfriend's, she } \\
\text { was in like the worship team, she did like } \\
\text { acappella school and, she's a good } \\
\text { singer, but they had a Christmas concert, } \\
\text { at, at her church and of course I feel the } \\
\text { need to go." } 7.9\end{array}$ \\
\hline & $\begin{array}{l}\text { Significant Influential } \\
\text { Persons }\end{array}$ & $\begin{array}{l}\text { "I was like, “They, they’re not bad } \\
\text { people,” the people at church they were } \\
\text { very nice to me... And I thought of my } \\
\text { girlfriend and her family, and I was like } \\
\text { their nice people, they’re not bad, "What } \\
\text { could be so bad about this?”... my aunt } \\
\text { and my mom took it really hard when I } \\
\text { told them I was agnostic . But I was like } \\
\text { you know what at least my loved ones } \\
\text { aren’t, aren’t so bad and they love this, } \\
\text { maybe I should give it a shot.” } 8.15 \\
\text { “...definitely my girlfriend, definitely my } \\
\text { pastor back home and uh my best friend } \\
\text { back home and my aunt. Yeah those are } \\
\text { the big ones.” } 14.16\end{array}$ \\
\hline & Lack of Exposure & $\begin{array}{l}\text { "I said basically that the people that I } \\
\text { surrounded myself with, basically the } \\
\text { way I was raised, not going to church no } \\
\text { friends or family that were really like } \\
\text { outgoing in their faith, or profound in }\end{array}$ \\
\hline
\end{tabular}




\begin{tabular}{|c|c|c|}
\hline & & $\begin{array}{l}\text { faith. My mom's very internal as far as } \\
\text { faith goes and like, I don’t know, my } \\
\text { dad, yeah he is spiritual, I don't know, } \\
\text { he’s a farmer, he works all the time so, } \\
\text { he never really has time to really go to } \\
\text { church.” } 5.19\end{array}$ \\
\hline & Negative Experiences & $\begin{array}{l}\text { "...then my mom told me growing up } \\
\text { that she never took me church because } \\
\text { that's where they all went; they all went } \\
\text { to that church. And if you have a bunch } \\
\text { of Christians quote on quote going to } \\
\text { church and being two faced my, she did } \\
\text { not want to raise me and my brother and } \\
\text { surround us, around people that were } \\
\text { going to be hypocrite." } 4.20\end{array}$ \\
\hline \multirow[t]{3}{*}{ Unique to College } & Independence & \\
\hline & $\begin{array}{l}\text { Parties are } \\
\text { Unsatisfactory }\end{array}$ & $\begin{array}{l}\text { "I had to distance myself with a few of } \\
\text { those friends. A lot of them are into } \\
\text { drinking and drugs, partying. They're in } \\
\text { like frats and sororities. I wasn’t, I mean } \\
\text { beforehand in high school, I really wasn’t } \\
\text { about any of that. Really and it's more } \\
\text { off putting even more so now...” } 11.19 \\
\text { “Uh, I have less foul of a mouth. I } \\
\text { certainly don't surround myself with } \\
\text { people I did before and associate myself } \\
\text { with the drinking and the partying.” } \\
12.15\end{array}$ \\
\hline & Self-Exploration & \\
\hline \multirow[t]{5}{*}{ Questioning God } & Wrestling with Evil & $\begin{array}{l}\text { "Just like a lot like that went wrong in } \\
\text { like my life and just in the world in } \\
\text { general, I thought, 'How could there be a } \\
\text { God?"” } 5.10\end{array}$ \\
\hline & Doubting God & $\begin{array}{l}\text { "I had doubts in God, of his existence all } \\
\text { through high school and then the very } \\
\text { beginning of my freshman year of } \\
\text { college I had doubts." } 5.8 \\
\text { "I just doubted creation and His } \\
\text { existence based on like what happened in } \\
\text { my life." } 6.2\end{array}$ \\
\hline & Doubting Allah & \\
\hline & Dismay with Islam & \\
\hline & $\begin{array}{l}\text { Reconciling Science } \\
\text { and Supernatural }\end{array}$ & $\begin{array}{l}\text { "I mean, of course I'd have that mindset } \\
\text { plus the fact that I love biology. I'm a }\end{array}$ \\
\hline
\end{tabular}




\begin{tabular}{|c|c|c|}
\hline & & $\begin{array}{l}\text { biology major and I want to be a } \\
\text { veterinarian so, like of course like the } \\
\text { whole science aspect that I surrounded } \\
\text { myself with. The one extreme, the whole } \\
\text { evolutionary, biggest extreme, the anti- } \\
\text { creationist. And that was me before } \\
\text { Christianity.” } 5.12 \\
\text { “And um, I would really clash, with a } \\
\text { religious side of me and a scientific side } \\
\text { of me. Because, ...if the earth was just a } \\
\text { little bit closer to the sun or a bit further } \\
\text { away, life would cease to exist. And } \\
\text { then, like you question God's existence } \\
\text { and all that and you, but you look up at } \\
\text { the stars and you see... the heavens.” } \\
\text { 7.22 } \\
\text { “...you can have a happy medium with } \\
\text { both science and religion regardless of } \\
\text { what people say. So that was, that meant } \\
\text { a lot to me. That was huge in my book.” } \\
\text { 9.20 } \\
\text { "I think was the biggest struggle, yeah } \\
\text { and especially with my girlfriend and her } \\
\text { family, I mean they don't believe in } \\
\text { evolution , and I, I to this day still do... I } \\
\text { believe that He created the Universe, the } \\
\text { sun the earth, all the beasts and man in a } \\
\text { way that's technically how evolution } \\
\text { occurred.” } 11.4 \\
\text { "P: As in, what was stressful? } \\
\text { I: Yeah. } \\
\text { P: Uh, the science without a doubt, } \\
\text { evolution versus religion thing, whether } \\
\text { or not God is real; that like you could not } \\
\text { see Him or prove His existence through } \\
\text { stuff like with hardcore facts or evidence } \\
\text { like science.” } 14.1\end{array}$ \\
\hline & Resistant to Convert & $\begin{array}{l}\text { "I was quiet at first, I didn’t sing the } \\
\text { hymns or the songs and I was hesitant to } \\
\text { stand or take communion...” } 7.15\end{array}$ \\
\hline $\begin{array}{l}\text { God is Omnipresent and } \\
\text { Sovereign }\end{array}$ & All Sufficient & $\begin{array}{l}\text { "I was just like praying, that all the bad } \\
\text { things I had done, feeling really bad for }\end{array}$ \\
\hline
\end{tabular}




\begin{tabular}{|c|c|c|}
\hline & & $\begin{array}{l}\text { myself and, I don't know, just wanting to } \\
\text { change who I was and I just, I just } \\
\text { wanted a savior, I wanted someone to } \\
\text { change that.” } 9.4\end{array}$ \\
\hline & Evidence of God & $\begin{array}{l}\text { "I don't know, I just, like going through } \\
\text { all the struggles but like, He helped guide } \\
\text { me and shape me into my own.” } 17.20 \\
\text { "And I remember the weeks and months } \\
\text { like, I don't know, proceeding that day, } \\
\text { and even to this day, like I remember the } \\
\text { other day, I have been finding coins at } \\
\text { random... So then I was like, "what is } \\
\text { going on?” I was like, "this is not a } \\
\text { coincidence, this has happened too often } \\
\text { for me to even,” I mean I know it’s } \\
\text { cheesy but, I don’t know. Something was } \\
\text { looking over me, I like to think.” } 6.12\end{array}$ \\
\hline & $\begin{array}{l}\text { Confidence in God's } \\
\text { Sovereign Plan }\end{array}$ & $\begin{array}{l}\text { “...there's more of a fulfillment in life, } \\
\text { knowing that you're saved. Knowing } \\
\text { that there’s something more; you find } \\
\text { restitution in something like that then just } \\
\text { nothingness.” } 10.11 \\
\text { "I mean He has a plan of everything and } \\
\text { He saw it fit then.” } 16.4 \\
\text { “And just awestruck by His timing. He’s } \\
\text { too good. I was, I don’t know, I'm still... } \\
\text { It just leaves me in awe.” } 17.16\end{array}$ \\
\hline \multirow[t]{5}{*}{$\begin{array}{l}\text { Positive Emotional } \\
\text { Experiences }\end{array}$} & Peak Experiences & $\begin{array}{l}\text { "So, that was one of the most profound } \\
\text { moments and to this day still just leaves } \\
\text { me breathless without words." } 8.9\end{array}$ \\
\hline & Newfound Hope & $\begin{array}{l}\text { "I: If you can remember back to this time } \\
\text { in your life, um what kind of thoughts } \\
\text { and feelings did you experience during } \\
\text { this time of conversion? ... } \\
\text { P: Uhm, hope for the future." } 9.15\end{array}$ \\
\hline & Gratitude & $\begin{array}{l}\text { "What thoughts or feelings do you have } \\
\text { when you think back to the time of } \\
\text { conversion? } \\
\text { P: Lucky. I feel really lucky in; well not } \\
\text { lucky, blessed is the word." } 17.14\end{array}$ \\
\hline & Healing & \\
\hline & Relief & $\begin{array}{l}\text { "I'm trying to find the right word. Um, I } \\
\text { guess relief and repentance." } 9.3\end{array}$ \\
\hline
\end{tabular}




\begin{tabular}{|c|c|c|}
\hline & & $\begin{array}{l}\text { “I don't know it’s like a huge weight was } \\
\text { lifted off your shoulders.” } 9.6 \\
\text { “I: And what were some of the positive } \\
\text { experiences... } \\
\text { P: Leading up it was a lot of wonder, a } \\
\text { lot of confusion. And then, yeah mostly } \\
\text { wonder especially when looking into the } \\
\text { stars. During: relief, joy, love. After: } \\
\text { belonging.” } 10.1\end{array}$ \\
\hline & Understanding & $\begin{array}{l}\text { "But, it's a lot of faith and just } \\
\text { coincidences like the coins [laughs] or } \\
\text { looking up at the sky and having prayers } \\
\text { answered and getting through hard } \\
\text { times.” } 14.5\end{array}$ \\
\hline & Happiness & $\begin{array}{l}\text { “During: relief, joy, love” } 10.4 \\
\text { "You find, I find myself happier, more } \\
\text { answered prayers, less difficulties in life } \\
\text { that's for sure." } 10.13\end{array}$ \\
\hline & Love & "During: relief , joy, love" 10.4 \\
\hline & $\begin{array}{l}\text { Freedom from } \\
\text { Legalism }\end{array}$ & \\
\hline Openness & Open to God & $\begin{array}{l}\text { "I was more open to it, to religion, to a } \\
\text { creationism, and like the middle gray } \\
\text { area that gets overlooked quite often } \\
\text { unfortunately. Um, so I guess my } \\
\text { openness, that timing was perfect." } 16.11\end{array}$ \\
\hline & Open to Others & $\begin{array}{l}\text { “And judgmental, I used to be very } \\
\text { judgmental and I try not, that's, that's } \\
\text { one that's a work in progress. But, I am } \\
\text { definitely getting better at that too. And, } \\
\text { just try to be more outgoing and genuine, } \\
\text { I don't know. I make it a goal of mine } \\
\text { each day to make at least one person } \\
\text { smile with one of my corny jokes, like } \\
\text { that.” } 12.17 \\
\text { It’s always good to hear people’s side of } \\
\text { things and their... It opens you up... } \\
\text { I: Um hum. } \\
\text { P: ...to new relationships and you know } \\
\text { common factors, and people’s } \\
\text { backgrounds and where you've come } \\
\text { from and it really opens up an }\end{array}$ \\
\hline
\end{tabular}




\begin{tabular}{|c|c|c|}
\hline & & $\begin{array}{l}\text { opportunity for you to just, to think twice } \\
\text { before you judge someone because you } \\
\text { don't know where they've been. You } \\
\text { don't know what it would be like to walk } \\
\text { in their shoes. } 18.16\end{array}$ \\
\hline \multirow[t]{5}{*}{ Existential Meaning } & True Identity & \\
\hline & $\begin{array}{l}\text { Life Purpose and } \\
\text { Meaning }\end{array}$ & $\begin{array}{l}\text { “...I don’t know, and you doubt yourself } \\
\text { and your place in this world, and you } \\
\text { look up at those stars and you think about } \\
\text { life, and that you're here, and everything } \\
\text { else is here, exists in its own perfect way. } \\
\text { You know that that's where you belong.” } \\
\text { 8.6 }\end{array}$ \\
\hline & & $\begin{array}{l}\text { "Well I meant I just said how I was } \\
\text { confused and wondered about my place } \\
\text { in the world and when I looked in the } \\
\text { night sky, looking up at them after } \\
\text { converting; it made me realize I have } \\
\text { place in this world." } 10.6\end{array}$ \\
\hline & & $\begin{array}{l}\text { “And just, I don't know, belonging in } \\
\text { this world. I mean we've had a lot of } \\
\text { issues with like suicide on this } \\
\text { campus...really just belonging. You have } \\
\text { a purpose here, you were given the } \\
\text { breath of life for a reason and you're } \\
\text { meant to do something with it. It's truly } \\
\text { profound.” } 10.15\end{array}$ \\
\hline & Altruistic Plans & $\begin{array}{l}\text { "To, in general, just to be a better person } \\
\text { and like to do good in this world and do } \\
\text { the little things to make someone’s day, } \\
\text { whether it be a compliment or a joke..." } \\
13.2\end{array}$ \\
\hline \multirow{2}{*}{$\begin{array}{l}\text { Challenging Emotional } \\
\text { Experiences- Prior to } \\
\text { Converting }\end{array}$} & Abandonment & \\
\hline & Hardship & $\begin{array}{l}\text { "So, after my grandfather passed away } \\
\text { when I was very young, my, my uncle } \\
\text { thought it was his right to basically, since } \\
\text { he was the older brother, that he deserved } \\
\text { more of the farm than my dad. ... So, } \\
\text { they basically screwed us for the farm. } \\
\text { My family went nearly bankrupt so my } \\
\text { dad had to sell the farm... And, I mean } \\
\text { we were basically driving ourselves into } \\
\text { the ground with like paying for lawyers } \\
\text { and all the court dates and all." } 4.11\end{array}$ \\
\hline
\end{tabular}




\begin{tabular}{|c|c|c|}
\hline & Confusion & $\begin{array}{l}\text { "Leading up it was a lot of wonder, a lot } \\
\text { of confusion." } 10.3\end{array}$ \\
\hline \multirow{4}{*}{$\begin{array}{l}\text { Challenging Emotional } \\
\text { Experiences -After } \\
\text { Converting }\end{array}$} & Spiritual Warfare & \\
\hline & Discord with Others & \\
\hline & Ongoing Hardship & \\
\hline & Guilt and Shame & $\begin{array}{l}\text { "I was guilty of like the things I had done } \\
\text { and doubting in God and betraying him } \\
\text { that way." } 9.18\end{array}$ \\
\hline \multirow[t]{5}{*}{ Supports } & Loss of Friends & $\begin{array}{l}\text { "Well at the time, friends would, 'Oh } \\
\text { you're a Christian now, you don't do this } \\
\text { and you don't do that' and being I guess } \\
\text { like ridiculed.” } 10.22 \\
\text { "I had to distance myself with a few of } \\
\text { those friends. A lot of them are into } \\
\text { drinking and drugs, partying.” } 11: 19 \\
\text { "But with the other ones, yeah it was a } \\
\text { little like surprising to them but they just } \\
\text { kind of went their own way.” } 15.21\end{array}$ \\
\hline & $\begin{array}{l}\text { Current Critical } \\
\text { Evaluation }\end{array}$ & \\
\hline & Commonality & $\begin{array}{l}\text { "My best friend is a lot like me. He’s a } \\
\text { biology major but he grew up with the } \\
\text { Church as well so he believes, he’s } \\
\text { already believed in both and still does, so } \\
\text { him and I have had plenty of deep } \\
\text { discussions about that, those sorts of } \\
\text { topics." } 15.1\end{array}$ \\
\hline & Truth in Love & \\
\hline & Support & $\begin{array}{l}\text { “...they were like, 'You're saved’ and } \\
\text { like my girlfriend was crying and, like } \\
\text { her mom was crying and, they were } \\
\text { telling other women who were crying } \\
\text { and smiling and hugging me...” 9.11 } \\
\text { “Um, my comfortability with them. To } \\
\text { know I wouldn’t receive judgment or a } \\
\text { smart remark or sarcasm I would get } \\
\text { someone who would listen and give } \\
\text { advice if need be, good advice. And, just } \\
\text { be there to love and support me, really } \\
\text { were the big ones.” } 14.19 \\
\text { And then my aunt, when I told her I was } \\
\text { agnostic, she was just devastated... we }\end{array}$ \\
\hline
\end{tabular}




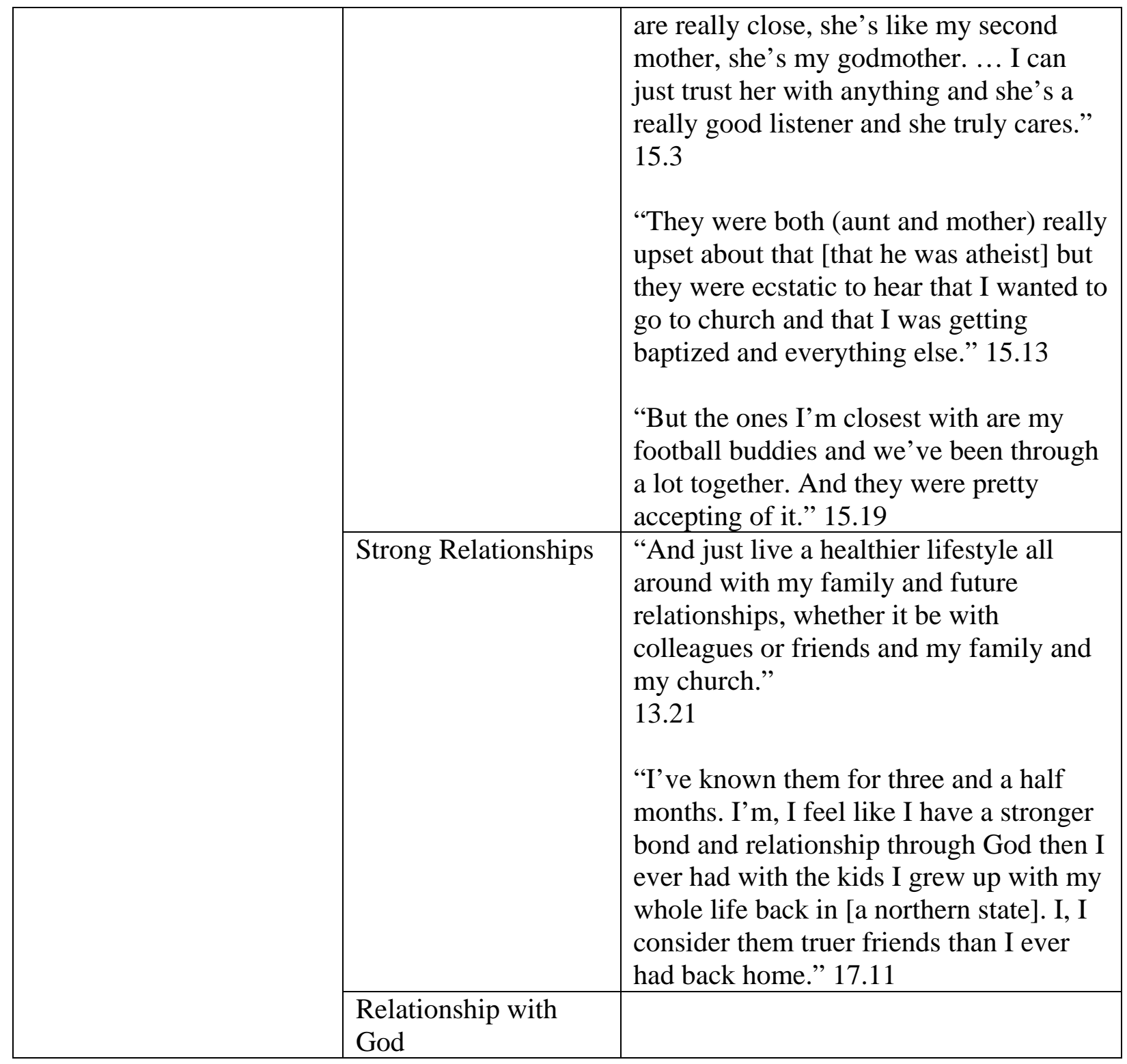




\section{Case 3 Themes Directory}

\begin{tabular}{|c|c|c|}
\hline Superordinate Concepts & Themes & Quotes (with page and line numbers) \\
\hline \multirow[t]{7}{*}{$\begin{array}{l}\text { Previous Exposure to } \\
\text { Religion/Spirituality }\end{array}$} & Family Involvement & $\begin{array}{l}\text { "Okay, well, I was raised Catholic, and } \\
\text { my parents were Catholic, and my whole } \\
\text { family is Catholic, and so I was raised } \\
\text { going to church every Sunday. } 1.14 \text { " }\end{array}$ \\
\hline & Friend Involvement & $\begin{array}{l}\text { "I had a couple friends were going to [a } \\
\text { Christian ministry] and they invited me } \\
\text { to come with them." } 2.4\end{array}$ \\
\hline & $\begin{array}{l}\text { Significant Influential } \\
\text { Persons }\end{array}$ & $\begin{array}{l}\text { “... and just not hanging out with the } \\
\text { people I had been hanging out with } \\
\text { anymore , besides one of my friends that } \\
\text { I’ve been friends with since my freshman } \\
\text { year of high school. Her name's Jessica } \\
\text { and she's an awesome super strong } \\
\text { Christian.” } 2.19\end{array}$ \\
\hline & & $\begin{array}{l}\text { I remember, I think Jessica is probably } \\
\text { the biggest instrument in my conversion } \\
\text { experience, I mean God used her it's not } \\
\text { her. } 15.21\end{array}$ \\
\hline & & $\begin{array}{l}\text { "So, she was pretty instrumental in just } \\
\text { like living with someone that was a } \\
\text { Christian and just seeing how the } \\
\text { Christian life worked. Um, and she's } \\
\text { wonderful. And then also with my } \\
\text { [campus ministry] intern, Sue, at the } \\
\text { time, just meeting with her and talking to } \\
\text { her about things was also really good for } \\
\text { me at the time.” } 16.15\end{array}$ \\
\hline & Lack of Exposure & \\
\hline & Negative Experiences & \\
\hline \multirow[t]{2}{*}{ Unique to College } & Independence & \\
\hline & $\begin{array}{l}\text { Parties are } \\
\text { Unsatisfactory }\end{array}$ & $\begin{array}{l}\text { “...I said like, “There has to be } \\
\text { something more.” And like I'm having } \\
\text { these conversations with one of my } \\
\text { friends that's a freshman now and she is } \\
\text { not a Christian and does a lot of drugs } \\
\text { and doesn't know why she coming to } \\
\text { [campus ministry] and she's like, 'I just } \\
\text { want something more and I'm tired of } \\
\text { what's happening.' I think that's where I } \\
\text { was.” } 21.1\end{array}$ \\
\hline
\end{tabular}




\begin{tabular}{|c|c|c|}
\hline & Self-Exploration & $\begin{array}{l}\text { “...I think it's a time of questioning, it's } \\
\text { this time of figuring out like who am I } \\
\text { apart from where I've been my whole } \\
\text { life...” } 20.19 \\
\text { "Like God had worn me down and I was } \\
\text { tired of trying to be good and screwing } \\
\text { up and not knowing who I was and not } \\
\text { knowing where my identity was, which I } \\
\text { feel like is such a big part of the college } \\
\text { experience is 'Where is your identity?' } \\
\text { and having to find the answer. So I think } \\
\text { that, or I think college provided that sort } \\
\text { of environment to prompt me to become } \\
\text { a Christian.” } 21.6\end{array}$ \\
\hline \multirow[t]{6}{*}{ Questioning God } & Wrestling with Evil & \\
\hline & Doubting God & $\begin{array}{l}\text { “... when I started attending [Christian } \\
\text { ministry] and that caused me to have like } \\
\text { a lot questions like, 'Why am I going to } \\
\text { Church every Sunday? I'm just doing } \\
\text { this out of habit. Does this mean } \\
\text { anything to me? Do I even believe what } \\
\text { they are saying? Do I believe in the } \\
\text { Bible?'” } 1.19 \\
\text { “And that basically led to a lot of } \\
\text { different conversations about like what I } \\
\text { believed like about theology and the } \\
\text { Catholic church and then broader things. } \\
\text { Like do I believe in the Bible...” } 3.1\end{array}$ \\
\hline & Doubting Allah & \\
\hline & Dismay with Islam & \\
\hline & $\begin{array}{l}\text { Reconciling Science } \\
\text { and Supernatural }\end{array}$ & \\
\hline & Resistant to Convert & \\
\hline $\begin{array}{l}\text { God is Omnipresent and } \\
\text { Sovereign }\end{array}$ & All Sufficient & $\begin{array}{l}\text { “... and like at the end towards closer to } \\
\text { me being a Christian or becoming a } \\
\text { Christian it was like my sinfulness and } \\
\text { my need for Him. I think I like hit an } \\
\text { end.” } 3.22 \\
\text { "I was like, 'This isn't in my hands' and } \\
\text { 'I'm just an instrument and I am very } \\
\text { small but God is very big, and He can do } \\
\text { big things and He can use me or He } \\
\text { can't, that's okay.' And just having hope }\end{array}$ \\
\hline
\end{tabular}




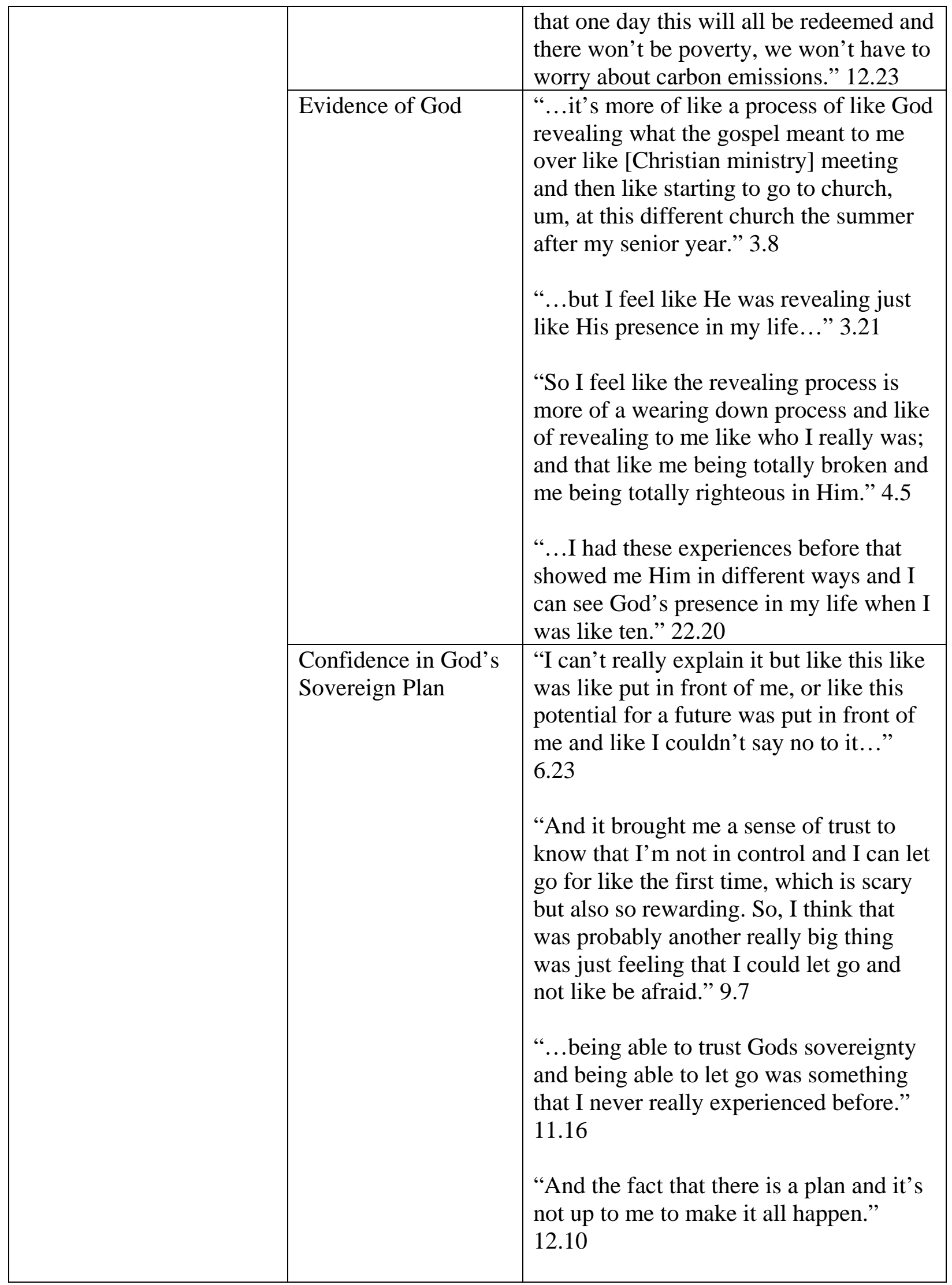




\begin{tabular}{|c|c|c|}
\hline & & $\begin{array}{l}\text { "I’m happy that it happened, I mean I } \\
\text { believe it would have happened } \\
\text { somehow, somewhere, not necessarily in } \\
\text { College but I mean that was God's plan } \\
\text { for me. It was not His plan for me to } \\
\text { become a Christian when I was seven. It } \\
\text { was his plan for me to become a } \\
\text { Christian when I was like 19.” } 22.16 \\
\text { “It also comes back to trust, like trusting } \\
\text { God and trusting that His word it true } \\
\text { and everyday I'm becoming more like } \\
\text { Jesus. And my struggles won’t look the } \\
\text { same as they do now next year.” } 24.7\end{array}$ \\
\hline \multirow[t]{5}{*}{$\begin{array}{l}\text { Positive Emotional } \\
\text { Experiences }\end{array}$} & Peak Experiences & $\begin{array}{l}\text { "Just being on this high of like, oh my } \\
\text { gosh this is amazing I feel so much peace } \\
\text { and love and grace and grace is } \\
\text { amazing." } 9.17 \\
\text { "But she was really good to help me sort } \\
\text { through like life coming down off of like } \\
\text { I'm-a-Christian-high.” } 18.5\end{array}$ \\
\hline & Newfound Hope & $\begin{array}{l}\text { "And like being, like struggling, or like } \\
\text { having this underlying theme of } \\
\text { struggling my whole life.... just not } \\
\text { feeling like peace about the decisions I } \\
\text { was making or the things going on } \\
\text { around me, like things that are happening } \\
\text { in the world, and having this new sense } \\
\text { of hope.” } 12.6\end{array}$ \\
\hline & Gratitude & $\begin{array}{l}\text { "So, when I look back I am thankful that } \\
\text { I did not become a Christina until I was } \\
19 \text { because I had these experiences } \\
\text { before that showed me Him in different } \\
\text { ways and I can look back and say I can } \\
\text { see God's presence in my life when I was } \\
\text { like ten." } 22.19 \\
\text { "So I think I look back and I am thankful } \\
\text { for my conversion experience and I am } \\
\text { thankful that I can look back and see so } \\
\text { much of His presence in that time..." } \\
22.21\end{array}$ \\
\hline & Healing & \\
\hline & Relief & $\begin{array}{l}\text { “...am I going to like lose this } \\
\text { relationship that’s really important to me }\end{array}$ \\
\hline
\end{tabular}




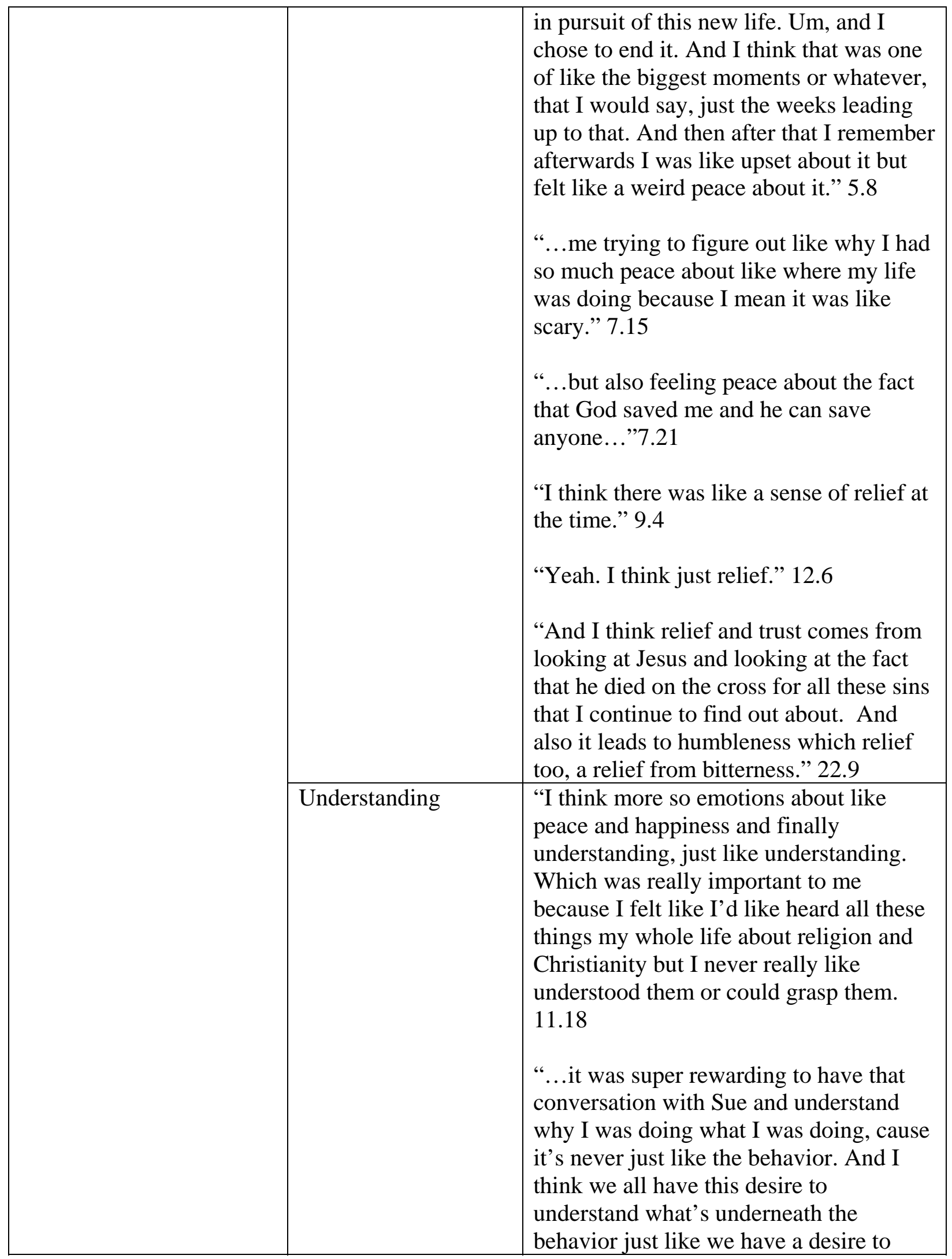




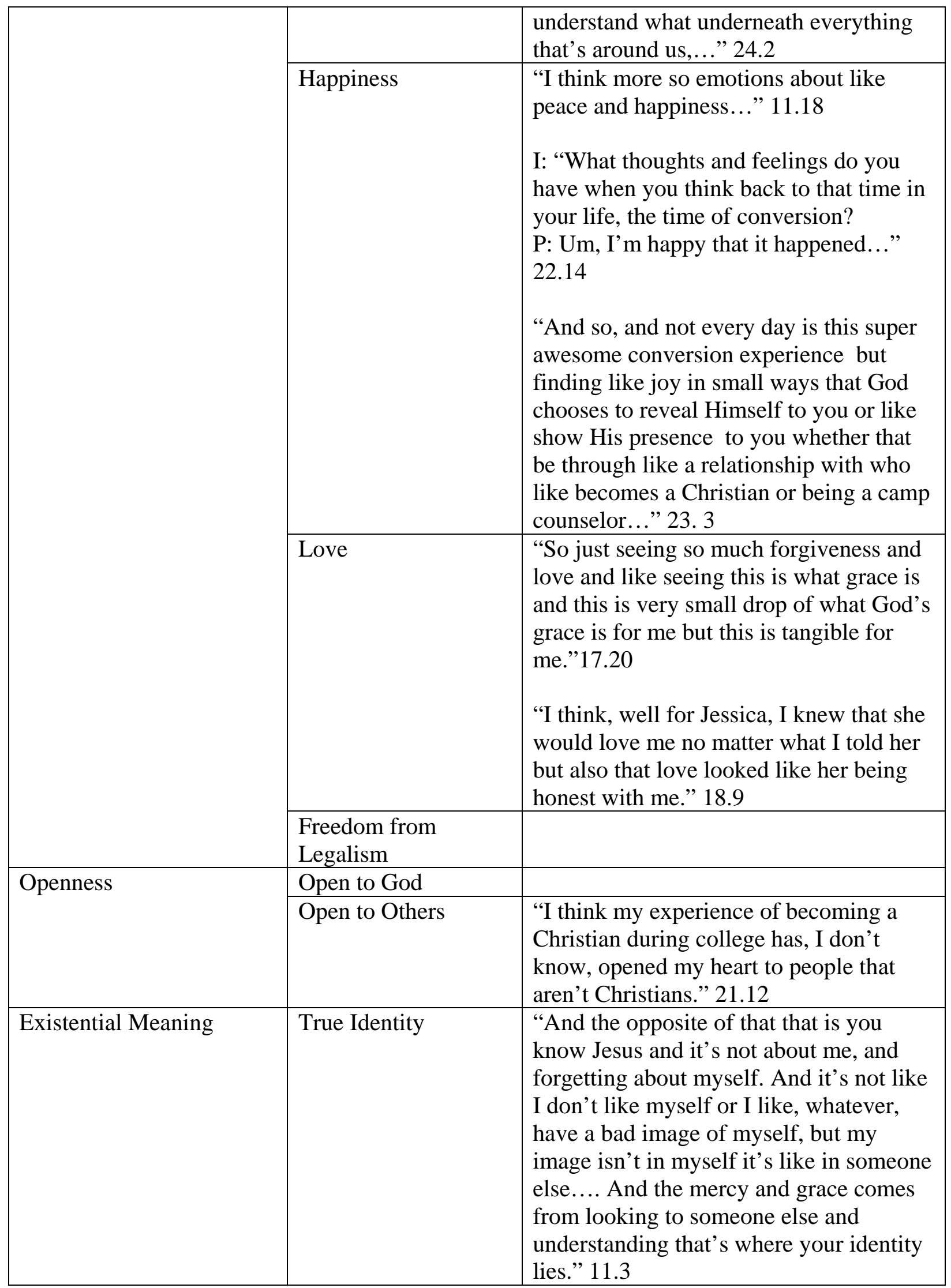




\begin{tabular}{|c|c|c|}
\hline & & $\begin{array}{l}\text { "So I feel like the revealing process is } \\
\text { more of a wearing down process and like } \\
\text { of revealing to me like who I really was; } \\
\text { and that like me being totally broken and } \\
\text { me being totally righteous in Him." } 4.5\end{array}$ \\
\hline & $\begin{array}{l}\text { Life Purpose and } \\
\text { Meaning }\end{array}$ & \\
\hline & Altruistic Plans & $\begin{array}{l}\text { "But understanding this is what I feel } \\
\text { passionate about and I feel passionate } \\
\text { about helping people. I think I felt } \\
\text { passionate about helping myself and I } \\
\text { still do, I am still just as sinful and } \\
\text { broken as I was before I became a } \\
\text { Christian, but I want to help other people } \\
\text { that have been struggling cause I struggle } \\
\text { too.” } 13.14 \\
\text { “... which led me to want to do } \\
\text { counseling whether that be with people } \\
\text { with mental health issues or addiction or } \\
\text { anything like that. " } 14.5\end{array}$ \\
\hline \multirow{3}{*}{$\begin{array}{l}\text { Challenging Emotional } \\
\text { Experiences- Prior to } \\
\text { Converting }\end{array}$} & Abandonment & \\
\hline & Hardship & $\begin{array}{l}\text { "I think, hum, well my senior year I } \\
\text { became really close to one of my } \\
\text { [Christian ministry] leaders and she had } \\
\text { to leave and so I may, She left and I felt } \\
\text { like I had kind of been betrayed or, I } \\
\text { don't know like left, I felt bad about } \\
\text { that." } 2.17\end{array}$ \\
\hline & Confusion & $\begin{array}{l}\text { “Um, I was upset because I didn’t want } \\
\text { to be put into a situation of having to like } \\
\text { end a relationship with someone but also } \\
\text { I felt a lot of peace ...” } 7.10\end{array}$ \\
\hline \multirow{2}{*}{$\begin{array}{l}\text { Challenging Emotional } \\
\text { Experiences -After } \\
\text { Converting }\end{array}$} & Spiritual Warfare & \\
\hline & Discord with Others & $\begin{array}{l}\text { “...so that summer I started going to a } \\
\text { different church which was really hard } \\
\text { because my family wasn't really } \\
\text { supportive of that. Um, they wanted me } \\
\text { to still go to mass with them...Um, so } \\
\text { that caused like some issues in my } \\
\text { family..." } 4.13 \\
\text { "I: ....Was any part of your conversion } \\
\text { distress and if so, what was distressing or } \\
\text { stressful? }\end{array}$ \\
\hline
\end{tabular}




\begin{tabular}{|c|c|c|}
\hline & & $\begin{array}{l}\text { P: I think the only part was probably my } \\
\text { relationship with my sister.” } 14.17 \\
\text { "Um, my sister wasn't supportive at the } \\
\text { beginning not in like a she didn’t want } \\
\text { me to be a Christian but she didn't } \\
\text { understand what was happening } \\
\text { really.... And then my parents not really } \\
\text { understanding why I left the Catholic } \\
\text { Church...” } 19.3\end{array}$ \\
\hline & Ongoing Hardship & $\begin{array}{l}\text { "Like I was able to let go but you're not } \\
\text { promised not having hardship in the } \\
\text { Christian life and I still did and so I think } \\
\text { it was really difficult for me to not resort } \\
\text { to shame and guilt when I messed up but } \\
\text { instead look at the gospel..." } 10.4 \\
\text { "So, I think it like helps me to continue } \\
\text { to live this Christian life which is hard, I } \\
\text { found that it was not easy becoming a } \\
\text { Christian and right after becoming a } \\
\text { Christian, it probably became harder." } \\
23.8\end{array}$ \\
\hline & Guilt and Shame & $\begin{array}{l}\text { “...like I couldn’t say no to like having } \\
\text { all of my guilt and shame whipped away } \\
\text { like from this past relationships I was } \\
\text { in.” } 7.2 \\
\text { “...I think it was really difficult for me to } \\
\text { not resort to shame and guilt when I } \\
\text { messed up but instead look at the gospel } \\
\text { so I think that was one of the most } \\
\text { difficult parts.” } 10.5 \\
\text { “... and being like, 'Why am I not there? } \\
\text { Why couldn’t I have been a Christian my } \\
\text { whole life?' And just becoming kind of } \\
\text { bitter about that and then like shaming } \\
\text { myself for not being that.” } 10.19\end{array}$ \\
\hline Supports & Loss of Friends & $\begin{array}{l}\text { “And so that conversation led to him } \\
\text { telling me that he liked seeing me started } \\
\text { going to [campus ministry], and like } \\
\text { started seeing me becoming a strong } \\
\text { Christian and he wanted to tell me that } \\
\text { like he's an atheist. And so I had to make } \\
\text { the decision, ... am I going to like lose }\end{array}$ \\
\hline
\end{tabular}




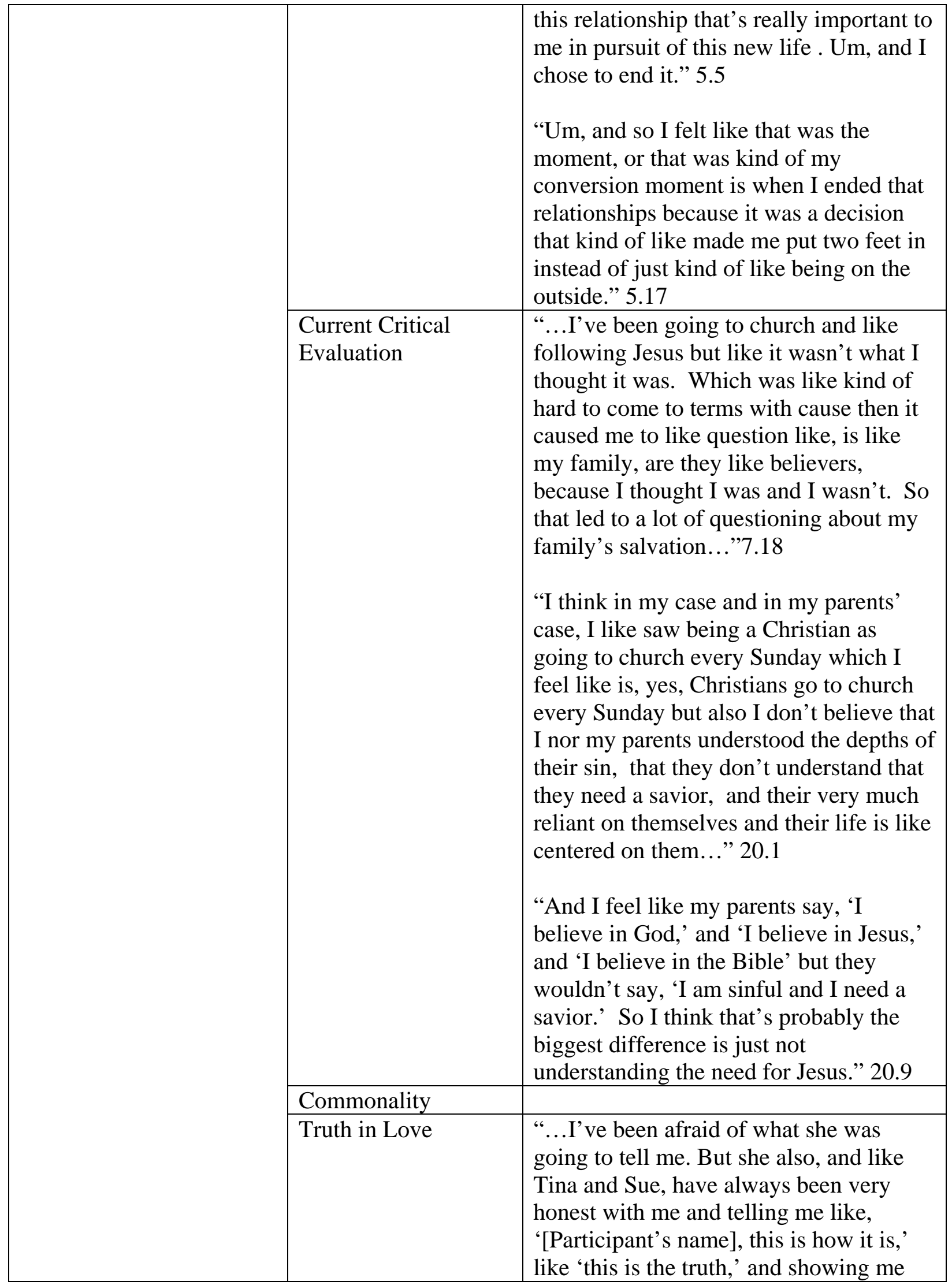




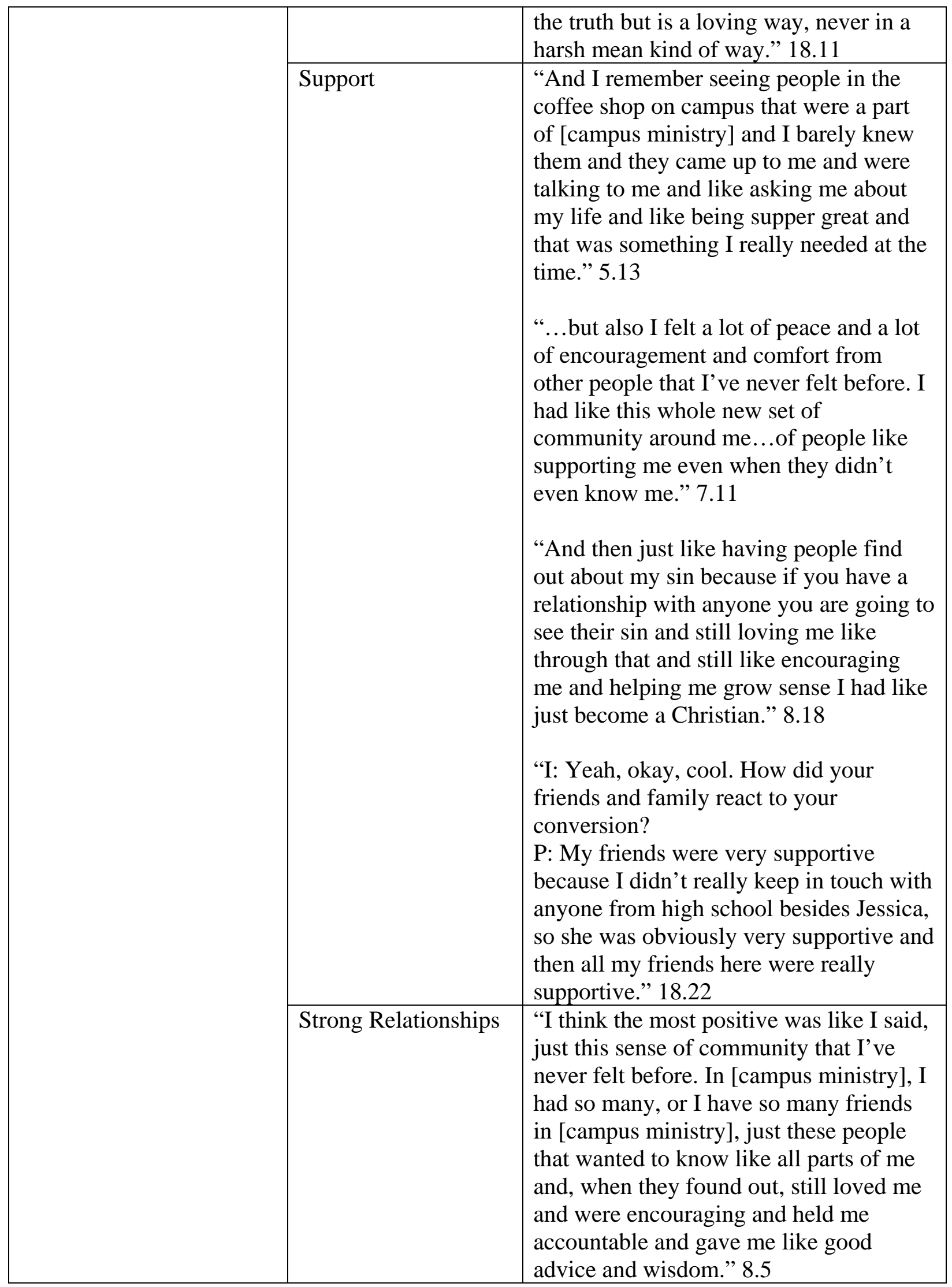




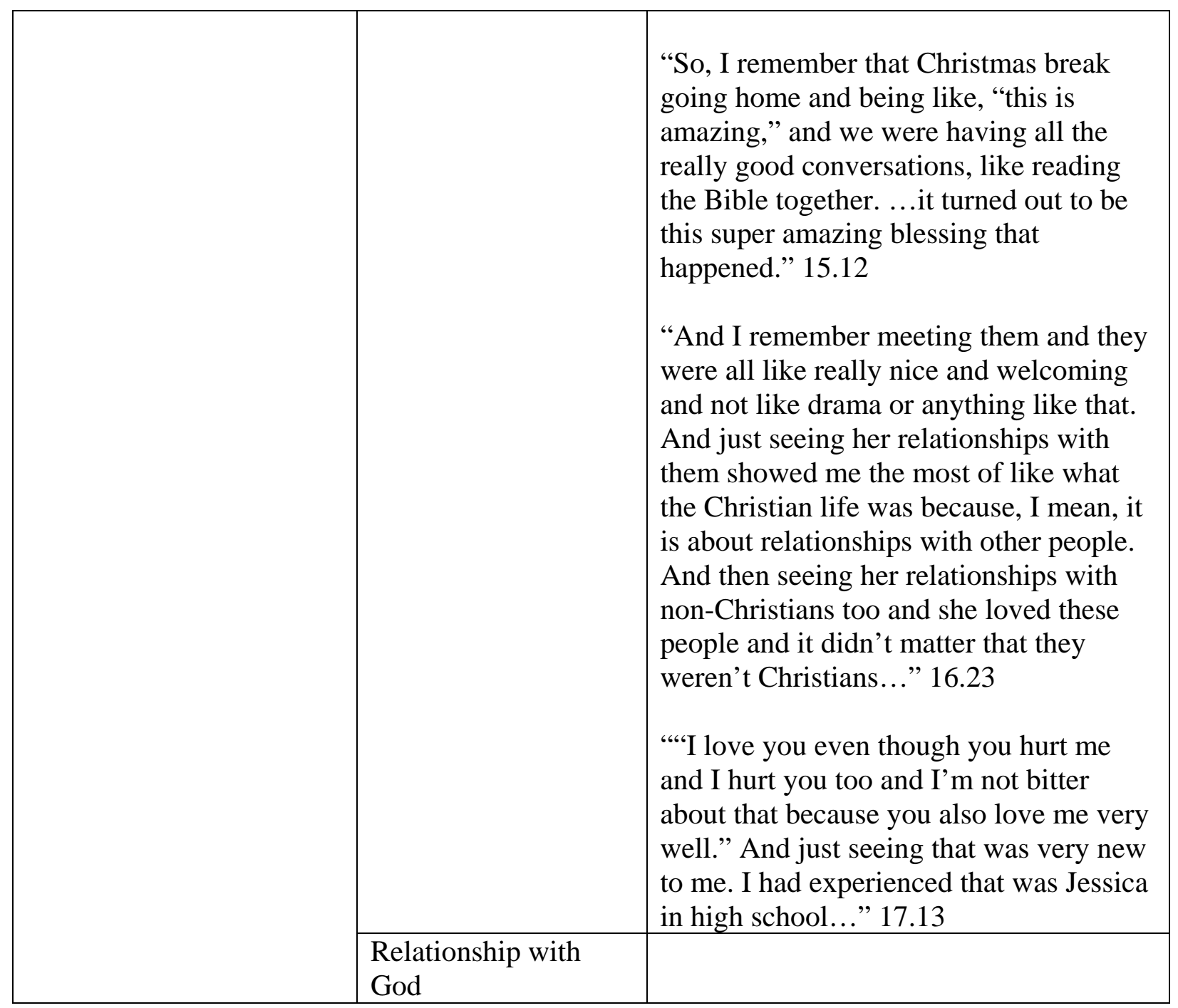




\section{Case 4 Themes Directory}

\begin{tabular}{|c|c|c|}
\hline Superordinate Concepts & Themes & Quotes (with page and line numbers) \\
\hline \multirow{7}{*}{$\begin{array}{l}\text { Previous Exposure to } \\
\text { Religion/Spirituality }\end{array}$} & Family Involvement & \\
\hline & Friend Involvement & $\begin{array}{l}\text { “..people looked at me like, "What, } \\
\text { you're not a Christian.” Throughout high } \\
\text { school the one questions I always had } \\
\text { asked.” } 1.15\end{array}$ \\
\hline & & $\begin{array}{l}\text { "Other than school, that was about it. I } \\
\text { mean football we'd have the Lord's } \\
\text { Prayer before every game that was about } \\
\text { it. } \\
\text { I: Okay. } \\
\text { P: It was just one of those rituals that } \\
\text { went, we had got, everyone does it.” } 2.9\end{array}$ \\
\hline & & $\begin{array}{l}\text { “...we just became friends, became } \\
\text { close, and just I mean I was never, I } \\
\text { don't know I never really thought of like } \\
\text { religion in the past but she would bring it } \\
\text { up every once in a while; never really } \\
\text { talked to me about it until the next } \\
\text { semester.” } 4.5\end{array}$ \\
\hline & & $\begin{array}{l}\text { “There was two of my good friends from } \\
\text { freshman year of college who were, have } \\
\text { always been in my, like they have been } \\
\text { in my life the entire time that I've been in } \\
\text { college and they've just been, they're } \\
\text { very religious and always talking to me, } \\
\text { every once in a while just bringing it } \\
\text { up,...” } 18.17\end{array}$ \\
\hline & $\begin{array}{l}\text { Significant Influential } \\
\text { Persons }\end{array}$ & $\begin{array}{l}\text { “... and was going through some hard } \\
\text { times. One of my good friends walked } \\
\text { up to me and said, 'Do you think that } \\
\text { believing in the Lord would give you } \\
\text { something to live for?' and I look at her } \\
\text { and am like, 'Maybe, I don't know."” } \\
2.18\end{array}$ \\
\hline & & $\begin{array}{l}\text { "But just, I mean I had a meeting with } \\
\text { [campus pastor] once a week just } \\
\text { learning, trying to understand it,..." } 5.18\end{array}$ \\
\hline
\end{tabular}




\begin{tabular}{|c|c|c|}
\hline & & $\begin{array}{l}\text { "But thankfully I had [campus pastor] he } \\
\text { could, to help me out with that who was } \\
\text { amazing. He showed me what I, what a } \\
\text { perfect Christian is pretty much.” } 8.18 \\
\text { "[Campus pastor] is one of the best } \\
\text { people ever. I think he has become one of } \\
\text { my best friends throughout this... he } \\
\text { came involved in my life and in my path } \\
\text { and became my mentor pretty much.” } \\
11.1 \\
\text { "Yeah. [Campus pastor] definitely was } \\
\text { the biggest one who whenever I needed } \\
\text { something, a question, he was there." } \\
16.20 \\
\text { "I joined a Bible study that semester; a } \\
\text { guy named Samuel who pretty much } \\
\text { became another mentor to me who } \\
\text { walked though Ephesians that semester } \\
\text { which has become my favorite book." } \\
17.3 \\
\text { "I mean there is always Lacey, because } \\
\text { she has been one of my closest friends } \\
\text { throughout this entire thing. And she } \\
\text { kind of the reason I became, how I } \\
\text { actually became a believer.” } 17.13\end{array}$ \\
\hline & Lack of Exposure & $\begin{array}{l}\text { "Well, growing up I was, my family has } \\
\text { never been very big into religion. My } \\
\text { mom is a pagan my dad is an atheist. I } \\
\text { was had very little exposure to it other } \\
\text { than people looked at me like, 'What, } \\
\text { you're not a Christian."” } 1.14\end{array}$ \\
\hline & Negative Experiences & $\begin{array}{l}\text { "Same kind of, every single interaction I } \\
\text { had someone that was a Christian they } \\
\text { would always ask me, 'Wait, you're } \\
\text { not?"” } 1.21\end{array}$ \\
\hline \multirow[t]{2}{*}{ Unique to College } & Independence & $\begin{array}{l}\text { "I went to high school living under my } \\
\text { parent's roof with what their rules were, } \\
\text { what they believed in, got to college and } \\
\text { I wanted to live my life my way..." } \\
19.20\end{array}$ \\
\hline & $\begin{array}{l}\text { Parties are } \\
\text { Unsatisfactory }\end{array}$ & \\
\hline
\end{tabular}




\begin{tabular}{|c|c|c|}
\hline & Self-Exploration & $\begin{array}{l}\text { “Like I was always searching, creating } \\
\text { myself, trying to find myself, and as it } \\
\text { happened after I converted...” } 14.4 \\
\text { “...I wanted to live my life my way and, } \\
\text { but I didn't know what that was so kind } \\
\text { of went to try everything kind of a deal. } \\
\text { So, I was open to anything really.” } 19.21\end{array}$ \\
\hline \multirow[t]{6}{*}{ Questioning God } & Wrestling with Evil & $\begin{array}{l}\text { "I guess it was the whole, contradiction } \\
\text { parts of the Bible, and the whole if He's } \\
\text { so omniscient, why does he know what's } \\
\text { going to happen to us sometimes stuff } \\
\text { like, why does he let bad things happen, } \\
\text { and just those things, everything that } \\
\text { atheists question about the Bible..." } 7.2\end{array}$ \\
\hline & Doubting God & $\begin{array}{l}\text { “...never been introduced to the Bible } \\
\text { before really, other than to use it as an } \\
\text { argument against it sort of thing.” } 5.19 \\
\text { “P: [laugh] Where am I? Why am I doing } \\
\text { this? } \\
\text { I: Yeah. 'Why am I...,' so even } \\
\text { questioning 'why do I keep going?' } \\
\text { P: Cause there was, I kept doubting every } \\
\text { single time, 'why, what, what is my } \\
\text { reasoning for going?’” } 7.22 \\
\text { "But at that point I was not an atheist, I } \\
\text { was an agnostic, and I was just wanted to } \\
\text { know.” } 12.9\end{array}$ \\
\hline & Doubting Allah & \\
\hline & Dismay with Islam & \\
\hline & $\begin{array}{l}\text { Reconciling Science } \\
\text { and Supernatural }\end{array}$ & \\
\hline & Resistant to Convert & $\begin{array}{l}\text { "'I'll try it' not really having any hopes, } \\
\text { or really plan to becoming a believer or } \\
\text { anything but.” } 2.22 \\
\text { "I didn't think I was fully going to accept } \\
\text { it until he said that, then something } \\
\text { moved me to just say, 'I have no more } \\
\text { reasons not to believe.”" } 5.12 \\
\text { "That was, like that thing where you sit } \\
\text { on the side of a waterfall and say well I } \\
\text { mine as well jump.” } 6.17\end{array}$ \\
\hline
\end{tabular}




\begin{tabular}{|c|c|c|}
\hline \multirow{3}{*}{$\begin{array}{l}\text { God is Omnipresent and } \\
\text { Sovereign }\end{array}$} & All Sufficient & \\
\hline & Evidence of God & $\begin{array}{l}\text { "And so, she asked me if I wanted to go } \\
\text { to her campus ministry...the Holy Spirit } \\
\text { was speaking to her.” } 2.20\end{array}$ \\
\hline & $\begin{array}{l}\text { Confidence in God's } \\
\text { Sovereign Plan }\end{array}$ & $\begin{array}{l}\text { "No matter what I'm going through I } \\
\text { know there is always a reason for it." } \\
20.18\end{array}$ \\
\hline \multirow[t]{5}{*}{$\begin{array}{l}\text { Positive Emotional } \\
\text { Experiences }\end{array}$} & Peak Experiences & $\begin{array}{l}\text { Where, I guess I had said I was a believer } \\
\text { but I never until I got baptized I guess it } \\
\text { was not technically official. So it was a } \\
\text { relief that I can, it's an outward show, a } \\
\text { sign that I do believe instead of just } \\
\text { saying it. } 9.1\end{array}$ \\
\hline & Newfound Hope & $\begin{array}{l}\text { "P: That probably helped with it } \\
\text { defiantly because I was more vulnerable } \\
\text { for just looking for something... } \\
\text { I: Yeah. } \\
\text { P: ...to give me hope.” } 5.1 \\
\text { "I was still depressed afterwards it's just } \\
\text { depression is not something that goes } \\
\text { away after a day. And, but it has gave me } \\
\text { something to, to hold on to, hope that } \\
\text { there's something better out there." } 13.8\end{array}$ \\
\hline & & $\begin{array}{l}\text { "Um, mainly happiness because it was } \\
\text { just the best, probably one of the best } \\
\text { parts of my life that feeling where I was } \\
\text { ecstatic because I finally found } \\
\text { something to live for instead of looking } \\
\text { for something to die to. } \\
\text { I: Wow } \\
\text { P: But, I guess that's the best word for it } \\
\text { is happiness. } \\
\text { I: Yeah. } \\
\text { P: Because everything before that was } \\
\text { just dark and now it's, there is a light.” } \\
21.1\end{array}$ \\
\hline & Gratitude & \\
\hline & Healing & $\begin{array}{l}\text { "And so, a couple months, almost maybe } \\
\text { a year, I don't know exactly, exactly how } \\
\text { long it was, it helped me get out of the } \\
\text { depression, fight it, and now I'm here.” } \\
13.13\end{array}$ \\
\hline
\end{tabular}




\begin{tabular}{|c|c|c|}
\hline & & $\begin{array}{l}\text { But I guess looking back then, I } \\
\text { definitely, makes it easier for me to go } \\
\text { through the day, makes it, because I am } \\
\text { not as depressed. It's easier to get out of } \\
\text { bed, easier to just do anything. } 20.9\end{array}$ \\
\hline & Relief & $\begin{array}{l}\text { "But, and during it, it was more like, or } \\
\text { at the moment it was a relief. It just, it } \\
\text { felt right." } 7.13 \\
\text { "So it [baptism] was a relief that I can, } \\
\text { it’s an outward show, a sign that I do } \\
\text { believe instead of just saying it.” } 9.2\end{array}$ \\
\hline & Understanding & $\begin{array}{l}\text { “...I had questions, and week after week, } \\
\text { those questions got shot down by either } \\
\text { [campus pastor], or the Holy Spirit, and } \\
\text { God Himself. And at that point, I started, } \\
\text { I looked and like well I have no reasons } \\
\text { anymore not to believe.” } 6.13 \\
\text { "I: Yeah. Okay. And you said, I had a lot } \\
\text { of, I did have a lot of questions but then } \\
\text { at some point, you just didn’t have any } \\
\text { more questions. } \\
\text { P: I just kept getting, kept getting } \\
\text { answers that I could believe in.” } 6.21 \\
\text { "And that helped me understand, and } \\
\text { understand the word of the Lord, and } \\
\text { understand the relationship that the Lord } \\
\text { has put there.” } 17.5\end{array}$ \\
\hline & Happiness & $\begin{array}{l}\text { "But, I guess that's the best word for it is } \\
\text { happiness." } 21.5\end{array}$ \\
\hline & Love & \\
\hline & $\begin{array}{l}\text { Freedom from } \\
\text { Legalism }\end{array}$ & \\
\hline Openness & Open to God & $\begin{array}{l}\text { "I just came into it just like 'Aw, I'll give } \\
\text { it a try and try and listen I am not going } \\
\text { to close my eyes and heart off away from } \\
\text { it.," } 12.11 \\
\text { "Being in college, I mean I guess I'm } \\
\text { more open in college, most people are." } \\
19.18\end{array}$ \\
\hline & Open to Others & \\
\hline Existential Meaning & True Identity & $\begin{array}{l}\text { "I mean I guess it kind of showed me } \\
\text { who I wanted to be. Become someone }\end{array}$ \\
\hline
\end{tabular}




\begin{tabular}{|c|c|c|}
\hline & & $\begin{array}{l}\text { who wanted to help people more, helped } \\
\text { me, that, that my life is not as important } \\
\text { as it was, as I always thought it was. And } \\
\text { that I, made me realize that my, the path I } \\
\text { was going on to be a cop was the right } \\
\text { path.” } 13.21 \\
\text { "I, hum, really just the Holy Spirit } \\
\text { opening my eyes to, this is who I am. } \\
\text { Like I was always searching, creating } \\
\text { myself, trying to find myself, and as it } \\
\text { happened after I converted it became } \\
\text { more clear. I was able to see through the } \\
\text { smoke more and realized that this is, I am } \\
\text { already dead pretty much and just keep } \\
\text { on, this is how I help others.” } 14.4\end{array}$ \\
\hline & $\begin{array}{l}\text { Life Purpose and } \\
\text { Meaning }\end{array}$ & $\begin{array}{l}\text { "I just don’t have that reluctant feeling } \\
\text { anymore it's like, “what's the point.” } \\
\text { Now there's, there's like a point to } \\
\text { everything. I have a reason to keep going } \\
\text { forward...” } 20.14 \\
\text { “...I was ecstatic because I finally found } \\
\text { something to live for...” } 21.2 \\
\text { "I have a path that I want to follow, I } \\
\text { have something to strive for which is } \\
\text { heaven. And, and a guideline to follow to } \\
\text { get there instead of just walking through } \\
\text { the darkness with, blind pretty much. } \\
\text { I: Um hum awesome. } \\
\text { P: Not knowing where I am, what I'm } \\
\text { doing, and what the reason is it for.” } 21.9\end{array}$ \\
\hline & Altruistic Plans & $\begin{array}{l}\text { "Become someone who wanted to help } \\
\text { people more, helped me, that, that my } \\
\text { life is not as important as it was, as I } \\
\text { always thought it was. And that I, made } \\
\text { me realize that my, the path I was going } \\
\text { on to be a cop was the right path. And } \\
\text { that, it helped me open my eyes that I } \\
\text { want to join the Navy so I can help save } \\
\text { people." } 13.21\end{array}$ \\
\hline \multirow{2}{*}{$\begin{array}{l}\text { Challenging Emotional } \\
\text { Experiences- Prior to } \\
\text { Converting }\end{array}$} & Abandonment & \\
\hline & Hardship & $\begin{array}{l}\text { "I: So what do you think was a catalyst } \\
\text { for your conversion to the Christian } \\
\text { faith? }\end{array}$ \\
\hline
\end{tabular}




\begin{tabular}{|c|c|c|}
\hline & & $\begin{array}{l}\text { P: Well it was my sophomore year, my } \\
\text { second semester, I was, had just been } \\
\text { fired from being an RA and it was going, } \\
\text { and lost my aunt to cancer, and was } \\
\text { going through some hard times.” } 2.15 \\
\text { “I didn't think I was struggling any more } \\
\text { than usual but, I guess the loss, my job } \\
\text { and my aunt, really had thrown me into } \\
\text { deeper depression and it was just, it was } \\
\text { a rough time.” 3.6 } \\
\text { "P: Freshman year I cut the tip of my } \\
\text { finger off. } \\
\text { I: Yowzer. } \\
\text { P: Yeah, it was not a fun time. I mean I } \\
\text { was depressed for, for about two months } \\
\text { and then got over it and now I love it. I } \\
\text { love my finger.” } 4.15 \\
\text { “...other than that I don’t know how } \\
\text { much exactly just me going through a } \\
\text { hard time and saying 'Okay' to } \\
\text { something, to a question.” } 19.15\end{array}$ \\
\hline & Confusion & $\begin{array}{l}\text { "I guess leading up to it, it was just wide } \\
\text { eyed confusion, just not knowing what I } \\
\text { was doing,...” } 7.10 \\
\text { "P: What is a Christian, the lifestyle? } \\
\text { Because I didn’t, I never knew, I never } \\
\text { had an example to follow other than... } \\
\text { I: Yeah. Wow. What did that feel like? } \\
\text { P: It was a little confusion there.” } 8.15 \\
\text { "I was just confused the entire time.” } \\
12.7\end{array}$ \\
\hline \multirow{2}{*}{$\begin{array}{l}\text { Challenging Emotional } \\
\text { Experiences -After } \\
\text { Converting }\end{array}$} & Spiritual Warfare & \\
\hline & Discord with Others & $\begin{array}{l}\text { “...knowing that my family would not } \\
\text { approve of it, and it was just kind of that } \\
\text { kind of stress there a little but not } \\
\text { much,..." } 7.11 \\
\text { "And then, the next couple months after } \\
\text { happening it was the stress dealing with } \\
\text { my family, explaining it to them,...” } 7.14\end{array}$ \\
\hline
\end{tabular}




\begin{tabular}{|c|c|c|}
\hline & & $\begin{array}{l}\text { "I was worried about what they would } \\
\text { think, what they would say, because } \\
\text { they're very, very, what's the word for it, } \\
\text { I guess judgmental is a good word for it. } \\
\text { If it’s not what they believe in it's not } \\
\text { right,...” } 8.6 \\
\text { “And then the day, that day, I get a phone } \\
\text { call from my mother screaming at me } \\
\text { cause, like asking me, "You got } \\
\text { baptized?” Which was a little bit } \\
\text { stressful, but not as much.” } 9.10 \\
\text { “...that was probably the most negative } \\
\text { experience I had. Just how is my family } \\
\text { going to react to this news?” } 11.13 \\
\text { "Like I say, all of it was dealing with my } \\
\text { family how they were going to react I } \\
\text { mean I knew my parents would, my } \\
\text { brothers I knew they would give me a } \\
\text { hard time cause they're my brothers but } \\
\text { they would really care.” } 15.5\end{array}$ \\
\hline & Ongoing Hardship & \\
\hline & Guilt and Shame & \\
\hline Supports & Loss of Friends & \\
\hline & $\begin{array}{l}\text { Current Critical } \\
\text { Evaluation }\end{array}$ & \\
\hline & Commonality & $\begin{array}{l}\text { “...me and two of the guys who are now } \\
\text { some of my closest friends um just like } \\
\text { found out that we play the same video } \\
\text { game and nerded out about that and they } \\
\text { invited me back to their place, it’s like } \\
\text { 11:00 o’clock at night, and we played } \\
\text { that for like four or five hours.” } 10.15 \\
\text { “[Campus pastor], it became a friendship } \\
\text { more than anything, I was just, we met } \\
\text { every Wednesday for coffee to talk about } \\
\text { the Bible and, and we'd find out we are } \\
\text { both [sports team] fans and we hung out } \\
\text { then a lot,...” } 17.22 \\
\text { "Showing common, common interests } \\
\text { and making friends with these people, }\end{array}$ \\
\hline
\end{tabular}




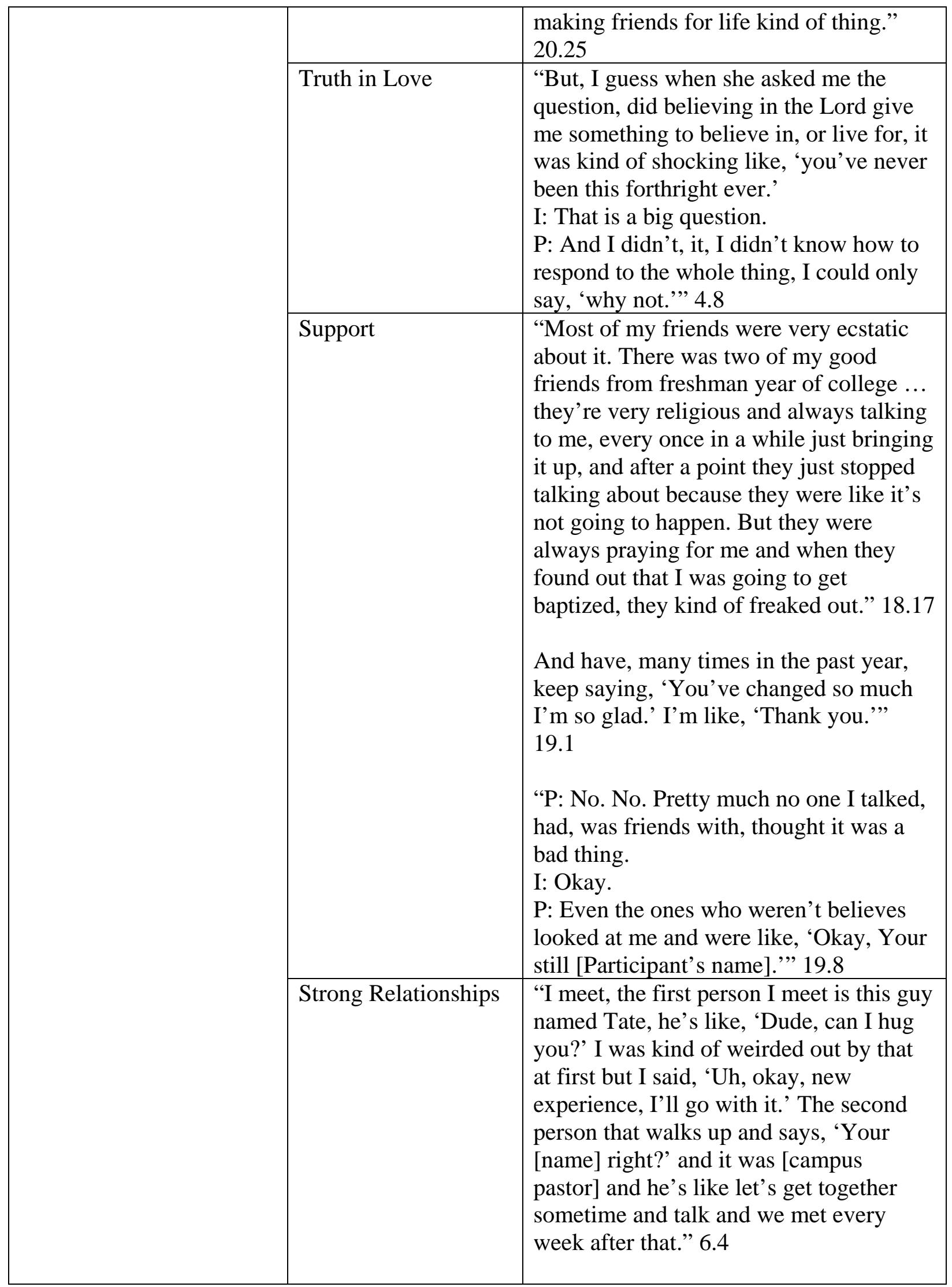




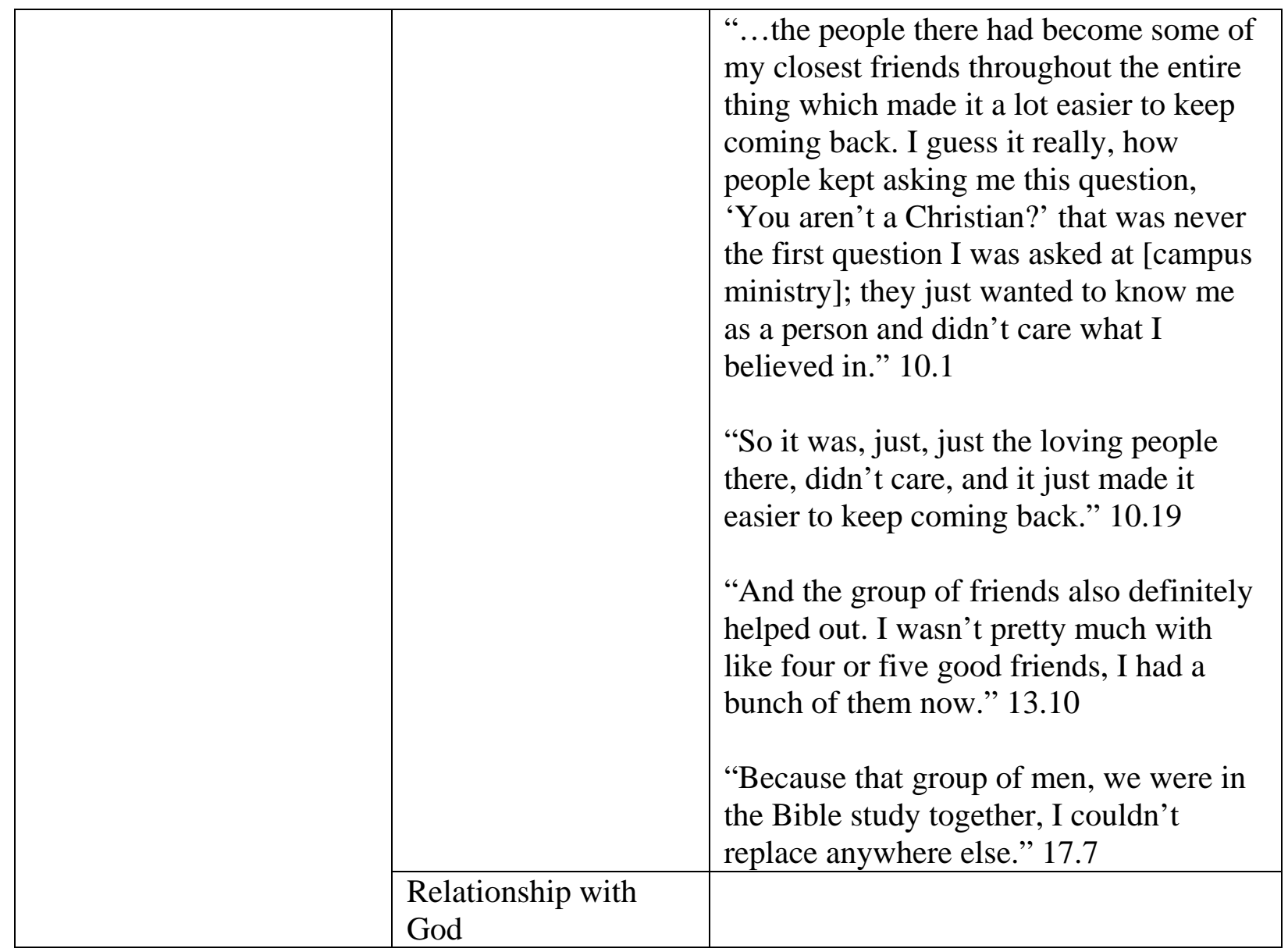




\section{Case 5 Themes Directory}

\begin{tabular}{|c|c|c|}
\hline Superordinate Concepts & Themes & Quotes (with page and line numbers) \\
\hline \multirow[t]{5}{*}{$\begin{array}{l}\text { Previous Exposure to } \\
\text { Religion/Spirituality }\end{array}$} & Family Involvement & $\begin{array}{l}\text { “...please tell me about your exposure to } \\
\text { religion and spirituality before becoming } \\
\text { a Christian. } \\
\text { P: I was Muslim. } \\
\text { I: Okay. So can you tell me just a little } \\
\text { bit about your background as a Muslim } \\
\text { person? } \\
\text { P: It was forced. It's forced on you when } \\
\text { you are young.” } 1.14 \\
\text { “This other one wasn't that bad but they } \\
\text { only teach you the good parts about } \\
\text { Islam. And there isn't very many good } \\
\text { parts, most of it is bad but they don't } \\
\text { teach you that.” } 3.15\end{array}$ \\
\hline & Friend Involvement & \\
\hline & $\begin{array}{l}\text { Significant Influential } \\
\text { Persons }\end{array}$ & $\begin{array}{l}\text { "I: ...What do you think was a catalyst } \\
\text { for your conversion to the Christian } \\
\text { faith? } \\
\text { P: That person inviting me to their } \\
\text { ministry.” } 5.15 \\
\text { "It also takes personal experiences to } \\
\text { believe like brother [campus minister's] } \\
\text { testimony. It was very inspiring and this } \\
\text { other girl she had like a supernatural } \\
\text { experience she told me about it; just } \\
\text { hearing other people's stories and } \\
\text { personal experiences.” } 18.4 \\
\text { "I: What do you think about the fact that } \\
\text { you were in college, did that kind of } \\
\text { make conversion possible or did being in } \\
\text { college...? } \\
\text { P: I guess running into that person who } \\
\text { invited me. I wish they would have came } \\
\text { into my life earlier.” } 21.19\end{array}$ \\
\hline & Lack of Exposure & \\
\hline & Negative Experiences & $\begin{array}{l}\text { "And one time they made us, we were all } \\
\text { being bad for one day because the } \\
\text { teacher wasn't there and we weren't } \\
\text { learning or anything, he made us hold } \\
\text { our ears and do sit ups for an hour.” } 3.4\end{array}$ \\
\hline
\end{tabular}




\begin{tabular}{|c|c|c|}
\hline & & $\begin{array}{l}\text { "Then you had to go and say whatever to } \\
\text { the main guy there and when you make } \\
\text { mistakes, he smacks you on the head." } \\
7.7 \\
\text { "I feel really bad when they are hitting } \\
\text { the kids." } 11.12 \\
\text { "Some people are very good they help } \\
\text { you without expecting anything in return } \\
\text { but other people always want, they only } \\
\text { help you as long as it benefits them; that } \\
\text { happened one time in a ministry." } 15.1\end{array}$ \\
\hline \multirow[t]{3}{*}{ Unique to College } & Independence & \\
\hline & $\begin{array}{l}\text { Parties are } \\
\text { Unsatisfactory }\end{array}$ & \\
\hline & Self-Exploration & \\
\hline \multirow[t]{3}{*}{ Questioning God } & Wrestling with Evil & \\
\hline & Doubting God & $\begin{array}{l}\text { "Someone invited me to their ministry } \\
\text { and I thought, "Why does this person } \\
\text { think their religion is right?” Then I did } \\
\text { research and found out Islam was } \\
\text { wrong.” } 4.14 \\
\text { "I didn't do research on theirs; I did } \\
\text { research on mine like, why don't they } \\
\text { believe Islam?” } 6.4 \\
\text { "I was about to stop reading, stop reading } \\
\text { after I found, read about Moses going } \\
\text { around killing everyone.” 9.13 } \\
\text { "I did question though one time when it } \\
\text { says women must remain silent.” } 17.5\end{array}$ \\
\hline & Doubting Allah & $\begin{array}{l}\text { “The only time I’ve realized I doubted } \\
\text { god was after I left I mean I had never } \\
\text { had doubts before.” } 1.20 \\
\text { “I: Okay. Yeah. So you said you didn’t } \\
\text { question the Muslim god until you... } \\
\text { P: I was always afraid to. } \\
\text { I: Uh huh. } \\
\text { P: Even like praying five times a day, I’d } \\
\text { always be afraid that he would hate me. } \\
\text { I: Who would hate you? }\end{array}$ \\
\hline
\end{tabular}




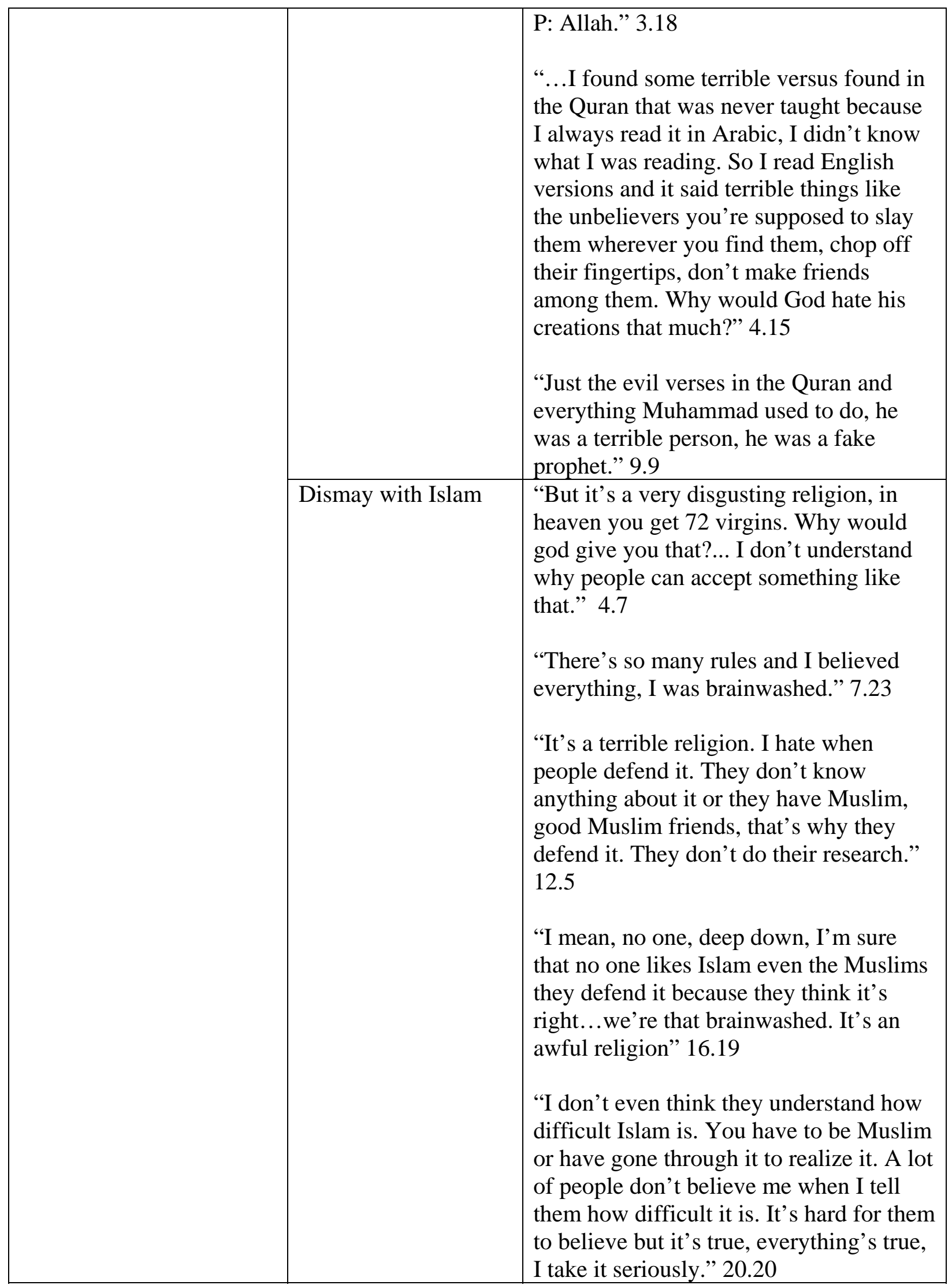




\begin{tabular}{|c|c|c|}
\hline & & $\begin{array}{l}\text { "I feel like terrorists would be true } \\
\text { Muslims. It says you're supposed to kill } \\
\text { non-Muslims. That's what they do they } \\
\text { follow it fully.” } 23.7\end{array}$ \\
\hline & $\begin{array}{l}\text { Reconciling Science } \\
\text { and Supernatural }\end{array}$ & $\begin{array}{l}\text { "I feel like evolution could have been } \\
\text { God driven. There's not enough proof for } \\
\text { it but the big bang doesn’t make much } \\
\text { sense. How did that start? And they } \\
\text { haven't been able to reproduce } \\
\text { abiogenesis in the lab: living things } \\
\text { coming from nonliving things.” } 17.11\end{array}$ \\
\hline & Resistant to Convert & \\
\hline \multirow{3}{*}{$\begin{array}{l}\text { God is Omnipresent and } \\
\text { Sovereign }\end{array}$} & All Sufficient & \\
\hline & Evidence of God & $\begin{array}{l}\text { "I noticed He sends people into your life } \\
\text { exactly when you need them, it's very } \\
\text { strange." } 18.6\end{array}$ \\
\hline & $\begin{array}{l}\text { Confidence in God's } \\
\text { Sovereign Plan }\end{array}$ & \\
\hline \multirow[t]{5}{*}{$\begin{array}{l}\text { Positive Emotional } \\
\text { Experiences }\end{array}$} & Peak Experiences & $\begin{array}{l}\text { "I've never experienced anything like } \\
\text { that. They were singing and dancing and } \\
\text { I never got that at mosque." } 7.4\end{array}$ \\
\hline & Newfound Hope & \\
\hline & Gratitude & \\
\hline & Healing & \\
\hline & Relief & $\begin{array}{l}\text { "I went to this place to learn more about } \\
\text { Islam. Yeah it’s really bad. Churches are } \\
\text { so peaceful.” } 2.11 \\
\text { "I: ... Okay, great. So tell me about your } \\
\text { experience converting to the Christian } \\
\text { faith. } \\
\text { P: It’s a relief, I am glad I got out of } \\
\text { Islam; it’s the best thing that's ever } \\
\text { happened to me.” } 7.20 \\
\text { "It’s a really big relief, I feel like if any } \\
\text { Muslim left, they would be really, really } \\
\text { happy.” } 8.9 \\
\text { “It was in November. Yeah I felt happy, } \\
\text { relieved actually. That’s what it was } \\
\text { like.” } 8.21 \\
\text { “Just happiness, relief. Glad I got out.” } \\
9.20\end{array}$ \\
\hline
\end{tabular}




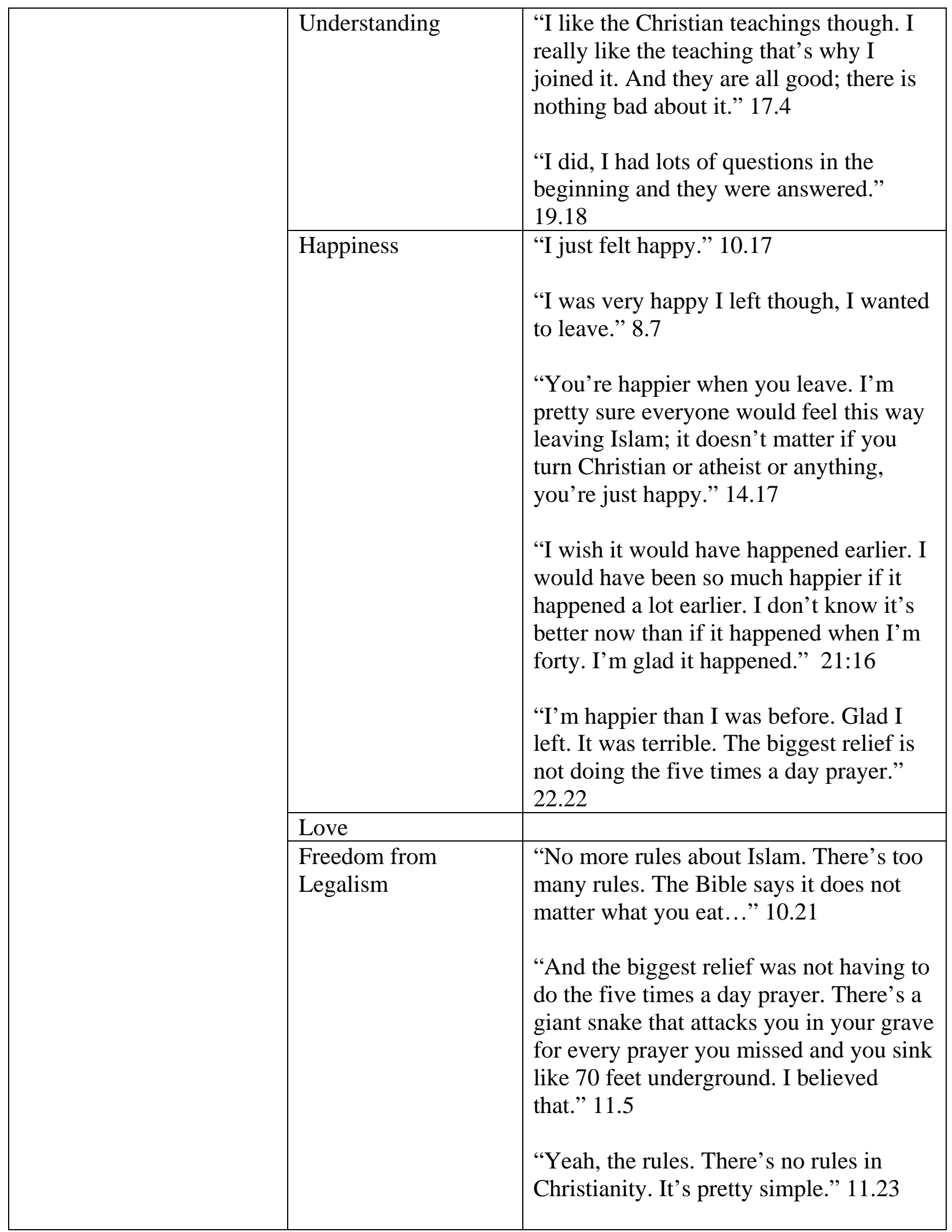




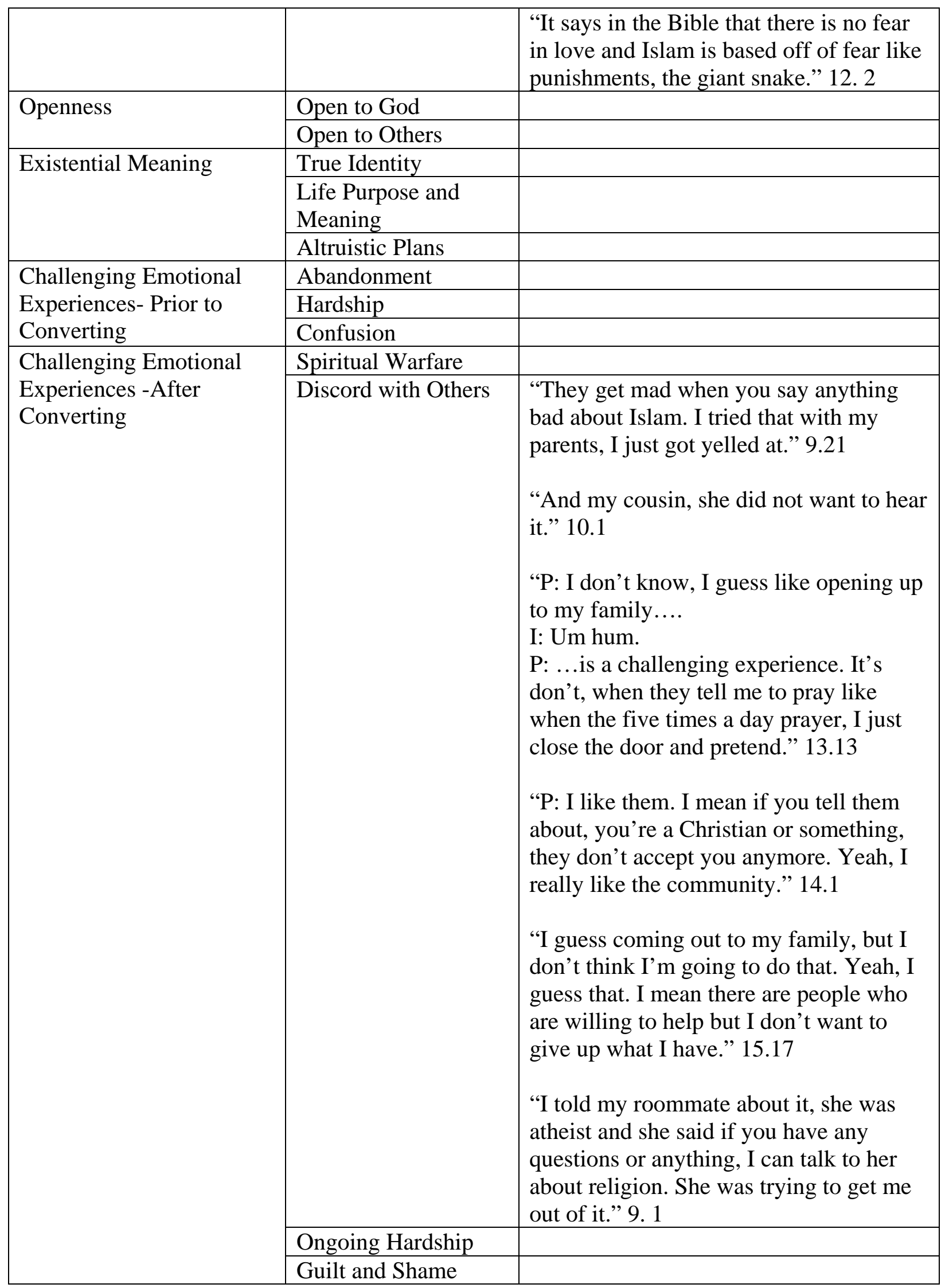




\begin{tabular}{|c|c|c|}
\hline \multirow[t]{7}{*}{ Supports } & \multicolumn{2}{|l|}{ Loss of Friends } \\
\hline & $\begin{array}{l}\text { Current Critical } \\
\text { Evaluation }\end{array}$ & $\begin{array}{l}\text { “...your parents brainwash you, and } \\
\text { going there just, and just the other } \\
\text { Muslims, they all believe it. You say } \\
\text { something bad about Muhammad they } \\
\text { get really mad. I used to be like that.” } 4.4\end{array}$ \\
\hline & Commonality & \\
\hline & Truth in Love & \\
\hline & Support & $\begin{array}{l}\text { "I told one girl, we, she was my friend } \\
\text { since when I was young, I told her but } \\
\text { she supports me. She said, 'It's your life } \\
\text { do whatever you want.' She had secrets } \\
\text { too.” } 21.9\end{array}$ \\
\hline & Strong Relationships & $\begin{array}{l}\text { "I: ... what other positive experiences did } \\
\text { you have when you converted? } \\
\text { P: I guess just Christian fellowship, like } \\
\text { [campus ministry] I really like those } \\
\text { groups." } 12.12 \\
\text { "Yeah. I like the people. They're really } \\
\text { friendly and nice, willing to help." } 13.9\end{array}$ \\
\hline & $\begin{array}{l}\text { Relationship with } \\
\text { God }\end{array}$ & \\
\hline
\end{tabular}




\section{Case 6 Themes Directory}

\begin{tabular}{|c|c|c|}
\hline Superordinate Concepts & Themes & Quotes (with page and line numbers) \\
\hline \multirow[t]{5}{*}{$\begin{array}{l}\text { Previous Exposure to } \\
\text { Religion/Spirituality }\end{array}$} & Family Involvement & $\begin{array}{l}\text { "Well, I was raised in a very traditional } \\
\text { Christian home. I was raised Baptist for } \\
\text { the most part um from the beginning of } \\
\text { my life. And then we started going to this } \\
\text { very large non-denominational church } \\
\text { whenever I was in about third } \\
\text { grade..."1.16 }\end{array}$ \\
\hline & Friend Involvement & \\
\hline & $\begin{array}{l}\text { Significant Influential } \\
\text { Persons }\end{array}$ & $\begin{array}{l}\text { "I told Jackson while I was drunk, I said, } \\
\text { "you know Jackson the only way that I } \\
\text { would ever believe in a God again is } \\
\text { because I see people like you who show } \\
\text { love and who care for people and who } \\
\text { are completely, you know, accepting of } \\
\text { people despite what they have done in } \\
\text { the past, that kind of thing.” } 4.21 \\
\text { "He (God) said, 'Jackie and Jackson, } \\
\text { those two, the people that, you know, } \\
\text { took care of you when no one else did } \\
\text { and have been there for you even } \\
\text { whenever you pretty much spat in their } \\
\text { face, that kind of thing; they’ve been } \\
\text { there. And I want to show you love } \\
\text { through people and I want you to love } \\
\text { people the way that I love people.” } 6.1 \\
\text { “And um it was from my friends and } \\
\text { from him (campus minister). That would } \\
\text { be I guess who I got counsel from.” } 15 . \\
20\end{array}$ \\
\hline & Lack of Exposure & \\
\hline & Negative Experiences & $\begin{array}{l}\text { “...whenever I was raised in the church I } \\
\text { was raised in, you know a lot of people } \\
\text { pushed a lot of people, you know, pushed } \\
\text { people away not because of the way they } \\
\text { dress but because of who they were. I } \\
\text { guess they don't like the fact that they } \\
\text { were not like everyone else.” } 8.9 \\
\text { “...the side that he and I had been raised } \\
\text { in with you know the loving God with a } \\
\text { hateful hand...” } 17.3\end{array}$ \\
\hline
\end{tabular}




\begin{tabular}{|c|c|c|}
\hline \multirow[t]{3}{*}{ Unique to College } & Independence & $\begin{array}{l}\text { It's the place where most young people } \\
\text { first become independent." } 17.14\end{array}$ \\
\hline & $\begin{array}{l}\text { Parties are } \\
\text { Unsatisfactory }\end{array}$ & $\begin{array}{l}\text { "I honestly think it was a desperation for } \\
\text { meaning to my life because out of } \\
\text { everything that happened whenever I first } \\
\text { came to [this university], you know, I did } \\
\text { a lot of partying and I did a lot of } \\
\text { drinking and that kind of thing and I saw } \\
\text { in no way that my life was going forward } \\
\text { and I didn’t know what I was doing.” } 3.2 \\
\text { “...well I was able to break myself out of } \\
\text { drinking so that was a positive, that's } \\
\text { definitely positive because I would, I } \\
\text { wouldn’t drink just to casually you know } \\
\text { enjoy it, I would drink to forget and that, } \\
\text { that was turning me into, you know it } \\
\text { was kind of ruining me as a person.” 9.4 } \\
\text { “I think was just seeing people not, not } \\
\text { knowing that there is something better } \\
\text { than just getting high and you know } \\
\text { forgetting all the time, so.” 15.1 }\end{array}$ \\
\hline & Self-Exploration & $\begin{array}{l}\text { "College is a place of exploring. It's a } \\
\text { place of trying things both good and bad } \\
\text { that you haven't done before.” } 17.13\end{array}$ \\
\hline \multirow[t]{2}{*}{ Questioning God } & Wrestling with Evil & \\
\hline & Doubting God & $\begin{array}{l}\text { I asked him a lot of particular questions } \\
\text { just about just about various social issues } \\
\text { today, like you know, I'm liberal so it } \\
\text { was, it was kind of like, you know does } \\
\text { God you know love homosexual } \\
\text { people. ... So I asked him, 'What does } \\
\text { God think of this?'” 5.6 } \\
\text { “I felt a lot of curiosity and I guess } \\
\text { questioning and you know all that kind of } \\
\text { stuff, um I was also a bit anxious because } \\
\text { of the fact that I didn't know and I wasn't } \\
\text { used to not knowing things.” 7.8 } \\
\text { "I heard that message and then I was like, } \\
\text { 'That sounds too good to be true, I'm } \\
\text { going to, I'm going, I'm going to run. I } \\
\text { can't deal with this because there is no } \\
\text { way that this is; this is too good to be }\end{array}$ \\
\hline
\end{tabular}




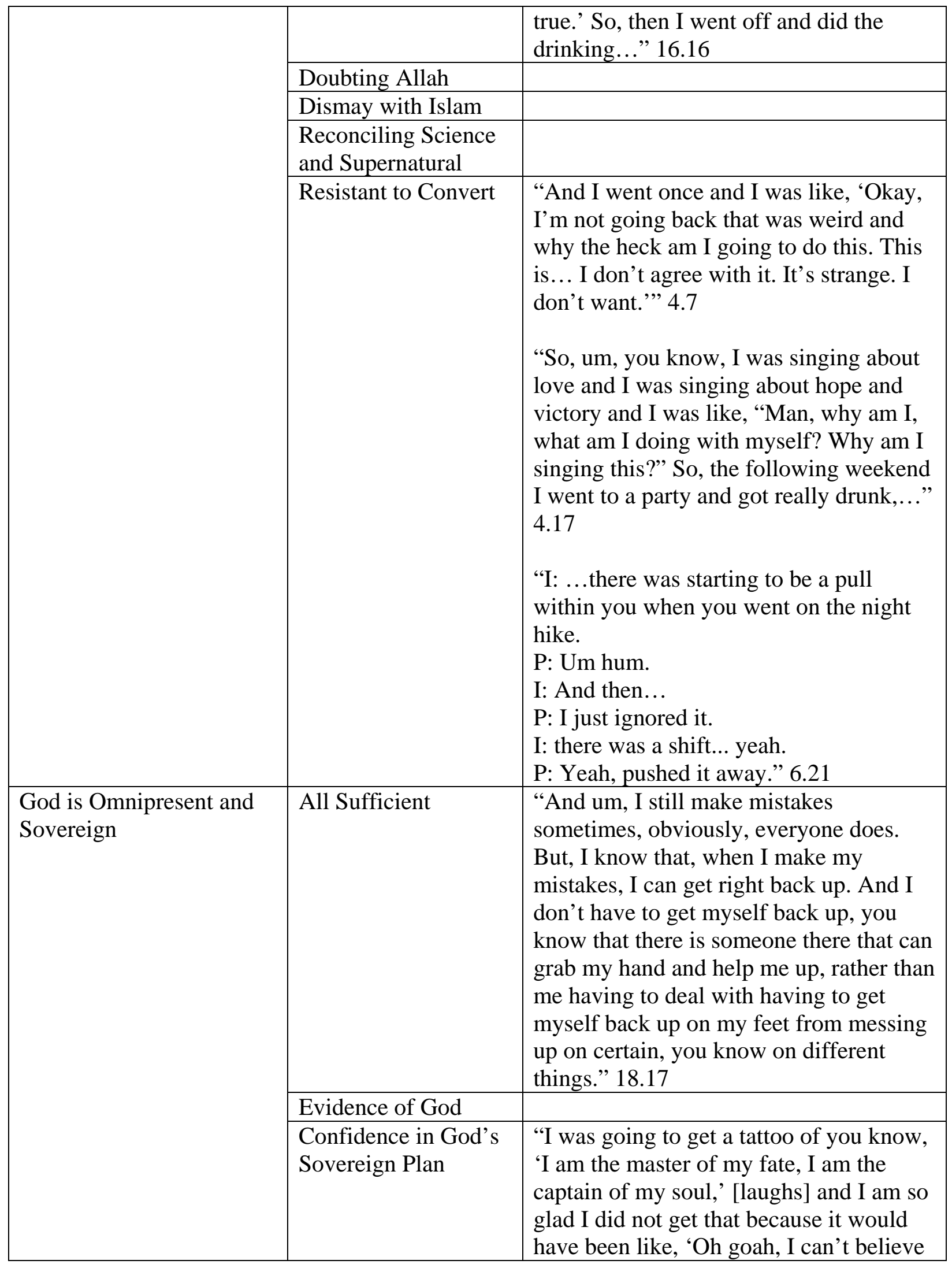




\begin{tabular}{|c|c|c|}
\hline & & $\begin{array}{l}\text { I just got that and now I believe in God } \\
\text { and gave my fate to Him.”” } 18.2 \\
\text { "Giving up on my future is the hardest } \\
\text { thing I've ever done. But, it's, it's good } \\
\text { because I know that God's got it. And } \\
\text { thankfully, I don't because if I did I'd be, } \\
\text { you know, there's no telling where I'd be } \\
\text { going right now, so.” } 13.14\end{array}$ \\
\hline \multirow[t]{2}{*}{$\begin{array}{l}\text { Positive Emotional } \\
\text { Experiences }\end{array}$} & Peak Experiences & $\begin{array}{l}\text { "I had a really big experience with God } \\
\text { there. Like, I just started singing worship } \\
\text { songs that I hadn’t sang in a long time } \\
\text { and it felt different this time around } \\
\text { because it wasn't just words it was, I was } \\
\text { actually meaning what I was saying.” } \\
4.15 \\
\text { “And I had this, this just, this moment } \\
\text { where God showed himself to me.” } 5.22 \\
\text { "And I heard, I heard the message that he } \\
\text { spoke that night was about the love of the } \\
\text { Father and that completely was just like } \\
\text { wow this guy really hears something } \\
\text { even, it's either that or he is completely } \\
\text { nuts I'm not sure which one it is } \\
\text { honestly, so, yeah.” } 16.9\end{array}$ \\
\hline & Newfound Hope & $\begin{array}{l}\text { "And um, emotionally, I, I was not } \\
\text { negative, which was a big one for me } \\
\text { because, I'm, I've always been a very } \\
\text { pessimistic, glass half-empty, negative } \\
\text { person. And the fact that life was } \\
\text { beautiful for once and I just saw the } \\
\text { beauty, and there was a lot of darkness, } \\
\text { but that the beauty still can take over the } \\
\text { darkness if I would just help it, if I would } \\
\text { just be willing for that to happen.” } 11.20 \\
\text { So, emotionally, I would definitely say } \\
\text { the negativity truly was uprooted out of } \\
\text { my life.” } 12.5 \\
\text { "That I had not tried to show them that } \\
\text { there was hope that I was with them } \\
\text { when I didn't think there was hope.” } \\
14.17\end{array}$ \\
\hline
\end{tabular}




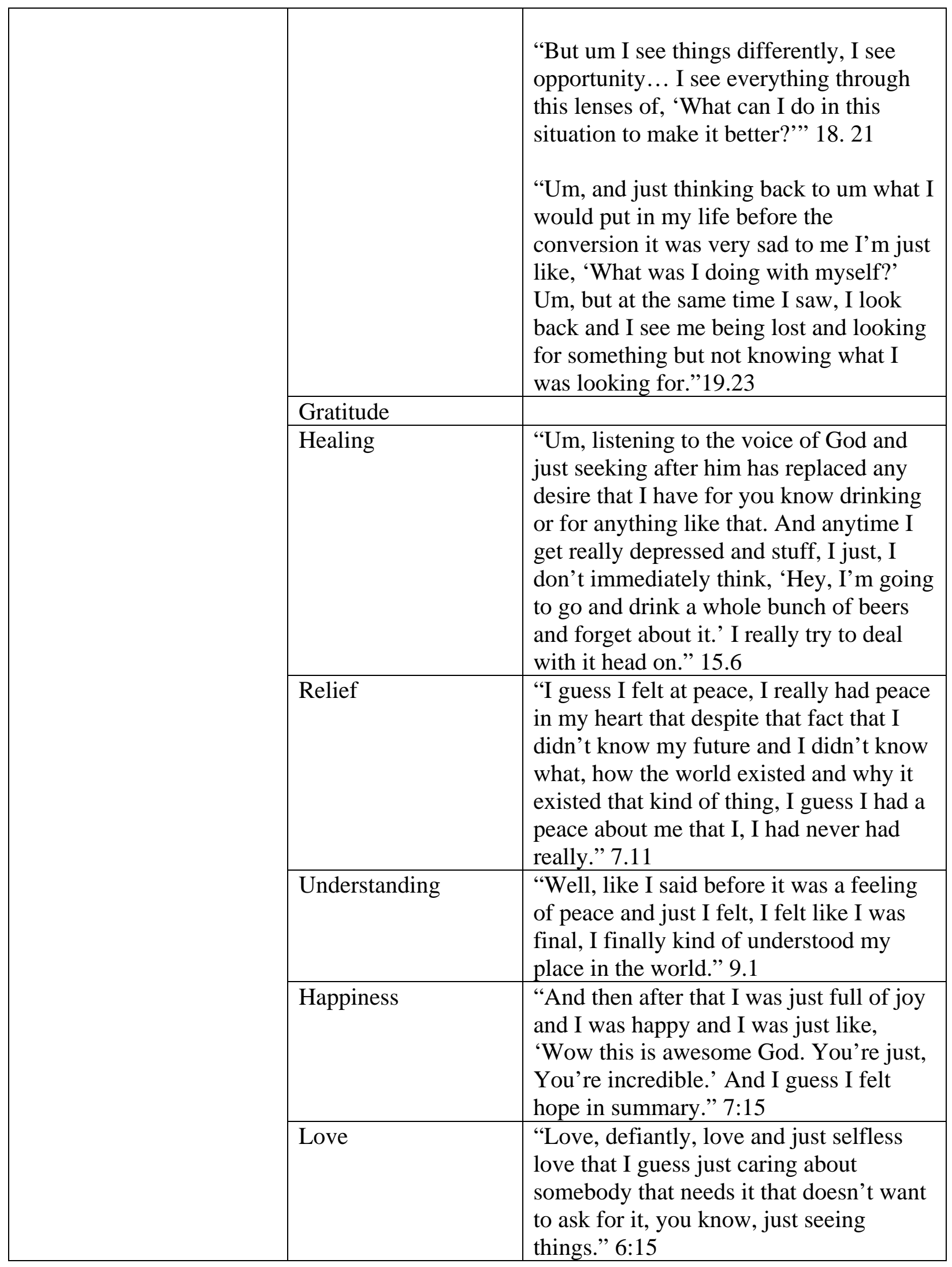




\begin{tabular}{|c|c|c|}
\hline & $\begin{array}{l}\text { Freedom from } \\
\text { Legalism }\end{array}$ & \\
\hline \multirow[t]{2}{*}{ Openness } & Open to God & $\begin{array}{l}\text { "Following that, I, I was really thinking } \\
\text { about things and I was, you know, } \\
\text { seeking after God,...” } 5.4 \\
\text { "I asked him a lot of those questions and } \\
\text { then finally at the end I said, 'So, how do } \\
\text { I get, you know this God?’” 5.14 } \\
\text { ““'All right God, well I guess I’m not } \\
\text { getting distracted with anything tonight. } \\
\text { So what exactly...' I said, 'If you're } \\
\text { really there you know show yourself to } \\
\text { me,”” } 5.20\end{array}$ \\
\hline & Open to Others & $\begin{array}{l}\text { “...I broke barriers that I guess that I had } \\
\text { inside of, inside of me. Like just barriers } \\
\text { of talking to certain people, like, like um } \\
\text { I was very judgmental... Just it broke a } \\
\text { lot of my judgmental barriers toward } \\
\text { people whenever I did, you know, } \\
\text { convert to Christianity.” } 11.9\end{array}$ \\
\hline \multirow[t]{2}{*}{ Existential Meaning } & True Identity & $\begin{array}{l}\text { “...but it’s really brought me out of } \\
\text { where I was and it’s brought me into who } \\
\text { I am, so.” } 15.12 \\
\text { "Well, um, [laughs] I’m a completely } \\
\text { different person.” } 18.16\end{array}$ \\
\hline & $\begin{array}{l}\text { Life Purpose and } \\
\text { Meaning }\end{array}$ & $\begin{array}{l}\text { "So I guess that the real thing was that I } \\
\text { wanted a real meaning to my life, I } \\
\text { wanted like an authentic love that was, } \\
\text { you know, something that did not } \\
\text { disappear, like if I did something, } \\
\text { honestly, so.” } 3.5 \\
\text { "I wanted meaning... every single day } \\
\text { inside of me, and I just, I was like, "Man, } \\
\text { I'm just tired of thinking like this. Is } \\
\text { there not anything that is constant in the } \\
\text { world; so, anything that gives meaning to } \\
\text { people?” 3.11 } \\
\text { "I guess that I'm supposed, that I realized } \\
\text { that I'm supposed to take care of the } \\
\text { world and that I'm supposed to you know }\end{array}$ \\
\hline
\end{tabular}




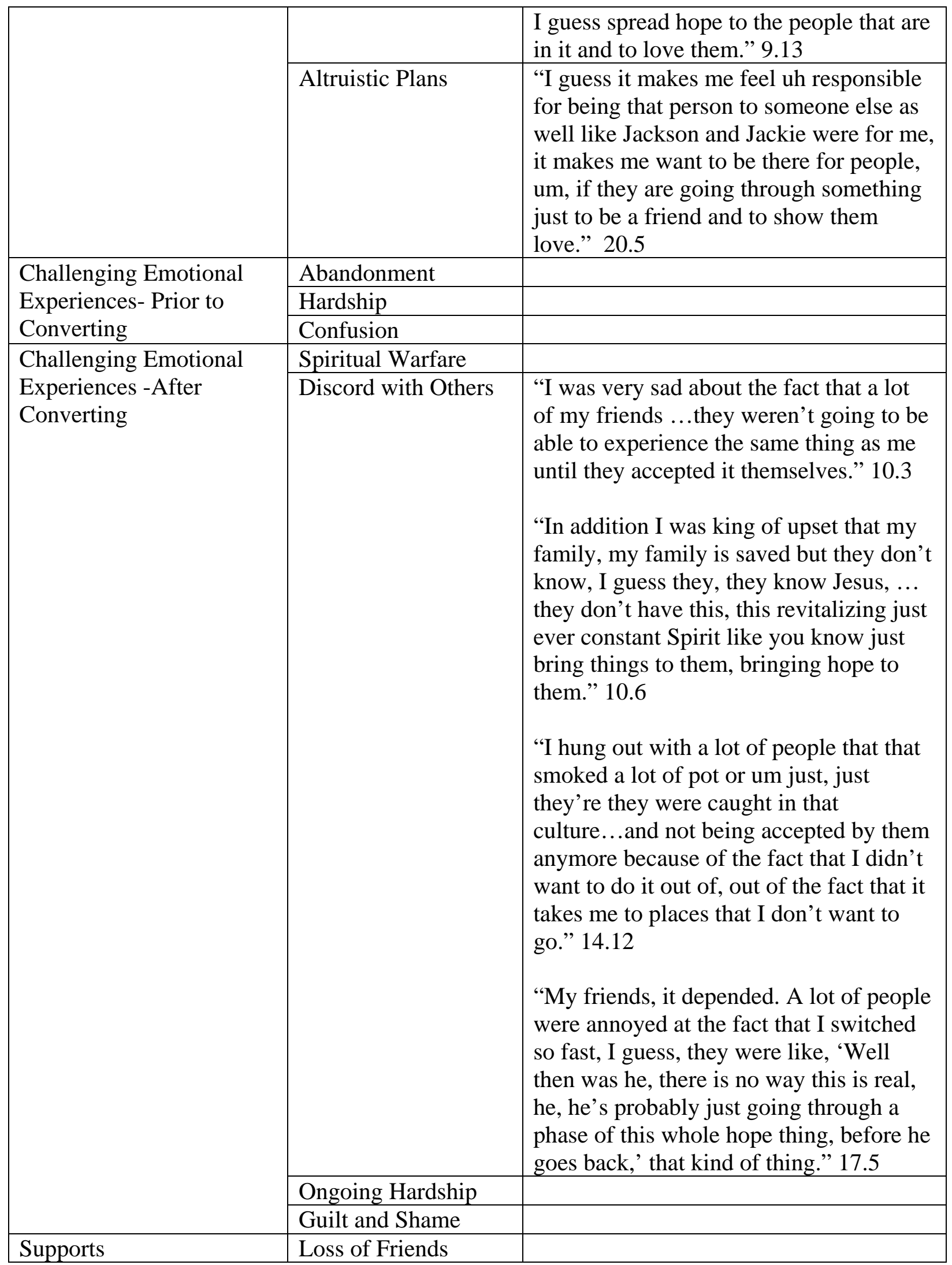




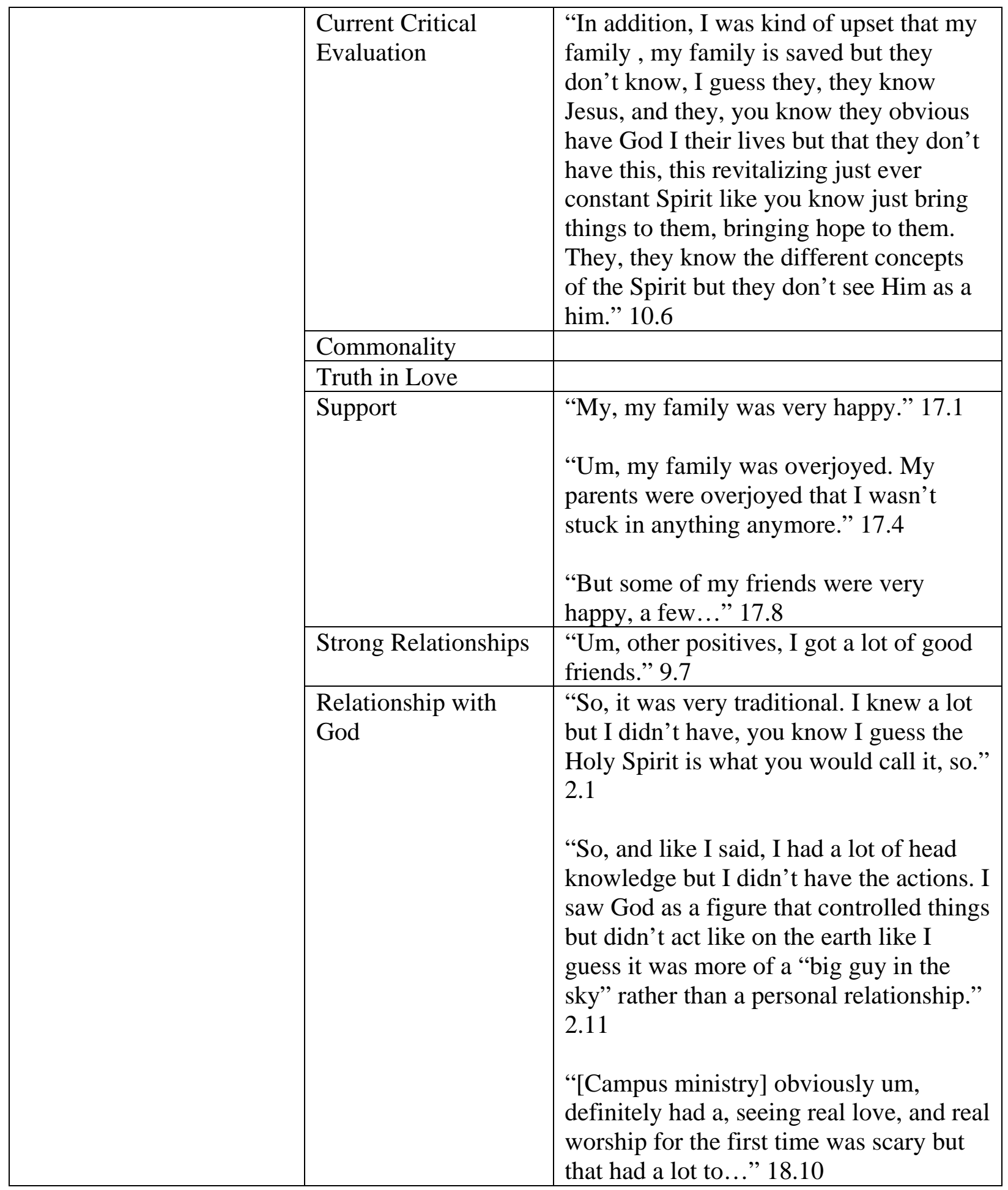




\section{Case 7 Themes Directory}

\begin{tabular}{|c|c|c|}
\hline Superordinate Concepts & Themes & Quotes (with page and line numbers) \\
\hline \multirow[t]{5}{*}{$\begin{array}{l}\text { Previous Exposure to } \\
\text { Religion/Spirituality }\end{array}$} & Family Involvement & $\begin{array}{l}\text { "I grew up in the church, um, not like } \\
\text { others would say necessarily. We went to } \\
\text { church on Sundays, it was sort of a, 'We } \\
\text { just go to church because it's what we } \\
\text { are supposed to do."” 1:20 }\end{array}$ \\
\hline & Friend Involvement & $\begin{array}{l}\text { "Yeah, so one of the first girls I met at } \\
\text { [this University] was really involved in } \\
\text { the [campus ministry] community..." } \\
3.11\end{array}$ \\
\hline & $\begin{array}{l}\text { Significant Influential } \\
\text { Persons }\end{array}$ & $\begin{array}{l}\text { "I: ... What do you think was a catalyst } \\
\text { for your conversion to the Christian } \\
\text { faith? } \\
\text { P: Um, probably people that didn't talk } \\
\text { about Christian... augh, they, they didn’t, } \\
\text { they showed me Jesus through their } \\
\text { actions more than speaking it at me } \\
\text { because I wasn’t willing to really listen } \\
\text { to it after a while.” } 2.11 \\
\text { "I will hold those people dear to my } \\
\text { heart, because I don't know how big of a } \\
\text { role I played in their life, but yeah, they } \\
\text { played a big role in mine.” } 18.2\end{array}$ \\
\hline & Lack of Exposure & \\
\hline & Negative Experiences & $\begin{array}{l}\text { "Yeah, people in the church before } \\
\text { seemed very judgmental and I thought } \\
\text { that if they actually knew what was going } \\
\text { on in my head or the part that I was } \\
\text { playing that I was completely fake that } \\
\text { they would just completely just disregard } \\
\text { me.” } 4.2 \\
\text { P: Um, I, I don't know, I dressed like a } \\
\text { hippy, I had a couple of dreads in my } \\
\text { hair, and I was still smoking cigarettes on } \\
\text { campus and people were like, "She came } \\
\text { to church on Sunday, but she is weird } \\
\text { and she is smoking on campus.”... but } \\
\text { people were like, 'She doesn't look like a } \\
\text { Christian so she shouldn't be one,' so.” } \\
7.12\end{array}$ \\
\hline Unique to College & Independence & $\begin{array}{l}\text { "Um, yeah and so I came to college and } \\
\text { was like, 'I'm going to do my own thing, }\end{array}$ \\
\hline
\end{tabular}




\begin{tabular}{|c|c|c|}
\hline & & $\begin{array}{l}\text { I don't need this lifestyle because I am } \\
\text { my own person now, I don't have to } \\
\text { listen to my parents and I don't have to } \\
\text { do these things, I can do whatever I want } \\
\text { to.'” } 3.4\end{array}$ \\
\hline & $\begin{array}{l}\text { Parties are } \\
\text { Unsatisfactory }\end{array}$ & \\
\hline & Self-Exploration & $\begin{array}{l}\text { "I think people are trying to figure out } \\
\text { who they are, who they want to be, } \\
\text { where they're supposed to be, who their } \\
\text { friends are, just all those questions." } \\
16.20\end{array}$ \\
\hline \multirow[t]{6}{*}{ Questioning God } & Wrestling with Evil & \\
\hline & Doubting God & $\begin{array}{l}\text { “..so I came in surprisingly majoring in } \\
\text { religious studies mainly because I think it } \\
\text { made my parents happy; they were like, } \\
\text { "Oh, our Christian daughter.” And } \\
\text { because, it’s like I secretly wanted } \\
\text { something to officially prove Christianity } \\
\text { wrong.” } 10.16\end{array}$ \\
\hline & Doubting Allah & \\
\hline & Dismay with Islam & \\
\hline & $\begin{array}{l}\text { Reconciling Science } \\
\text { and Supernatural }\end{array}$ & \\
\hline & Resistant to Convert & $\begin{array}{l}\text { “And so then, and then especially the } \\
\text { summer coming into college I, I just } \\
\text { didn't want anything to do with } \\
\text { Christianity really.” } 3.3 \\
\text { "But, I don't, I think I knew the truth in } \\
\text { high school but I had just run from it for } \\
\text { so long.” } 4.12 \\
\text { "Oh gosh [laugh], I didn't want to be a } \\
\text { Christian. I laugh at that because, I could } \\
\text { get into so many theological jokes but I } \\
\text { didn’t want to be a Christian.” } 5.16\end{array}$ \\
\hline \multirow{3}{*}{$\begin{array}{l}\text { God is Omnipresent and } \\
\text { Sovereign }\end{array}$} & All Sufficient & \\
\hline & Evidence of God & $\begin{array}{l}\text { "I'm not defined by the things I've done, } \\
\text { I guess, like I'm not, I'm not } \\
\text { [participant's name] who was once bad } \\
\text { but now she's good. I'm Charlotte } \\
\text { because I had a plan set before me before } \\
\text { I was born.” } 17.20\end{array}$ \\
\hline & $\begin{array}{l}\text { Confidence in God's } \\
\text { Sovereign Plan }\end{array}$ & $\begin{array}{l}\text { "Um, I don’t know, I feel like I have a } \\
\text { purpose for my life, I am excited to }\end{array}$ \\
\hline
\end{tabular}




\begin{tabular}{|c|c|c|}
\hline & & $\begin{array}{l}\text { graduate [laughs] like get into the real } \\
\text { world because I'm like not that worried } \\
\text { about what my plan for my life because I } \\
\text { know it is taken care of.” } 9.1 \\
\text { "But, I don't know, like I’m taken care of } \\
\text { no matter how bad my depression gets.” } \\
10.4 \\
\text { “...but I'm zero percent worried about } \\
\text { my future at this point; um, and I would } \\
\text { have never said that about a year or two } \\
\text { ago.” } 11.2\end{array}$ \\
\hline \multirow{9}{*}{$\begin{array}{l}\text { Positive Emotional } \\
\text { Experiences }\end{array}$} & Peak Experiences & \\
\hline & Newfound Hope & \\
\hline & Gratitude & $\begin{array}{l}\text { "I, my conversion, I love it, honestly...” } \\
17.23\end{array}$ \\
\hline & Healing & $\begin{array}{l}\text { “..because my conversion experience } \\
\text { my first year was me kind of getting, like } \\
\text { planted in a sober life...” } 13.16\end{array}$ \\
\hline & Relief & \\
\hline & Understanding & $\begin{array}{l}\text { "So, I think it was sort of turning back } \\
\text { around and seeing the truth again but } \\
\text { finally accepting it for what it was and } \\
\text { not letting myself be so hard to it." } 4.13\end{array}$ \\
\hline & Happiness & $\begin{array}{l}\text { "I don't think I have ever been more } \\
\text { satisfied or more fulfilled.” } 8.21\end{array}$ \\
\hline & Love & \\
\hline & $\begin{array}{l}\text { Freedom from } \\
\text { Legalism }\end{array}$ & \\
\hline \multirow[t]{2}{*}{ Openness } & Open to God & \\
\hline & Open to Others & $\begin{array}{l}\text { “Um, I guess, um, I was finally telling } \\
\text { people what I was feeling. I, well } \\
\text { actually, I didn’t even do that until } \\
\text { probably at least a year after I } \\
\text { converted.” } 6.15 \\
\text { “I finally um trusted people enough to } \\
\text { talk about things that I’ve experienced.” } \\
7.1 \\
\text { “I think my family got a little closer or, } \\
\text { not closer but I think that I became less } \\
\text { judgmental of my parents and of my } \\
\text { family and so; I am still working on that } \\
\text { of course.” } 7.4\end{array}$ \\
\hline
\end{tabular}




\begin{tabular}{|c|c|c|}
\hline & & $\begin{array}{l}\text { "Um, I think that it is easy for me to } \\
\text { understand people on the other side; I'd } \\
\text { like to say so. Um, I know that it’s easy } \\
\text { for me to talk to people who are non- } \\
\text { Christian; it's easier for me to talk to } \\
\text { people who are non-Christian than it is } \\
\text { Christian..." } 17.4 \\
\text { "But, I love it because it makes me relate } \\
\text { to people, there's not a lot of people in } \\
\text { the Christian community that feel } \\
\text { comfortable like going up to like some } \\
\text { weird people on [name of university]'s } \\
\text { campus and being like, "Yeah, I'm a } \\
\text { Christian.” And, I'm not saying I'm } \\
\text { completely comfortable with that either } \\
\text { but I'm saying that I understand that } \\
\text { people aren't going to become a } \\
\text { Christian because you tell them they } \\
\text { should be; you have to, you need to show } \\
\text { them a reason they should be, so.” } 18.13\end{array}$ \\
\hline \multirow[t]{3}{*}{ Existential Meaning } & True Identity & $\begin{array}{l}\text { "But, yeah, I guess now a days, it’s more } \\
\text { of like, “Okay, I’m prideful,” I am, I get } \\
\text { obsessed with being someone rather than } \\
\text { finding my identity in Christ.” } 17.9\end{array}$ \\
\hline & $\begin{array}{l}\text { Life Purpose and } \\
\text { Meaning }\end{array}$ & $\begin{array}{l}\text { "Um, I don't know, I feel like I have a } \\
\text { purpose for my life, I am excited to } \\
\text { graduate [laughs] like get into the real } \\
\text { world because I'm like not that worried } \\
\text { about what my plan for my life because I } \\
\text { know it is taken care of.” } 9.1 \\
\text { "Yeah, before, yeah I did not know what } \\
\text { I was going to do when I came to } \\
\text { college, I didn't know what my purpose } \\
\text { was or even if the stuff I liked even had a } \\
\text { purpose..." } 10.15\end{array}$ \\
\hline & Altruistic Plans & \\
\hline \multirow{3}{*}{$\begin{array}{l}\text { Challenging Emotional } \\
\text { Experiences- Prior to } \\
\text { Converting }\end{array}$} & Abandonment & \\
\hline & Hardship & \\
\hline & Confusion & \\
\hline \multirow{3}{*}{$\begin{array}{l}\text { Challenging Emotional } \\
\text { Experiences -After } \\
\text { Converting }\end{array}$} & Spiritual Warfare & \\
\hline & Discord with Others & \\
\hline & Ongoing Hardship & $\begin{array}{l}\text { "And so I know, like well, once I stopped } \\
\text { doing all that stuff, I was diagnosed with }\end{array}$ \\
\hline
\end{tabular}




\begin{tabular}{|c|c|c|}
\hline & & $\begin{array}{l}\text { depression, which is like, ah that sucks } \\
\text { but it's I'm good because I have Jesus } \\
\text { um so that was something,...” } 8.16 \\
\text { “Um, [laughs] I mean, of course there's a } \\
\text { lot of times where I don't think that I } \\
\text { have a purpose and I don't think that life } \\
\text { is, or I'm satisfied.” 9.17 } \\
\text { “But I am constantly, I mean I still have } \\
\text { to battle to not going back to my, what is } \\
\text { it, like alcohol or anything, I think that } \\
\text { those are always going to be struggle, } \\
\text { they’re just going to slowly fade as I get } \\
\text { older.” } 17.7\end{array}$ \\
\hline & Guilt and Shame & $\begin{array}{l}\text { "Oh gosh the thoughts, I was frustrated, } \\
\text { there was a lot of frustration because I } \\
\text { was not only was I judgmental toward } \\
\text { myself but I felt judged a little bit by } \\
\text { others because I was a Christian and I } \\
\text { was being upfront and honest that I was } \\
\text { like trying not to party or trying not to do } \\
\text { these things and other people were like, } \\
\text { 'Whoa, who is this girl because we don't } \\
\text { talk about that?”" } 5.20 \\
\text { "But, but it was, I just felt judged and it } \\
\text { was a hard transition um, yeah, there was } \\
\text { a lot going on.” } 6.6 \\
\text { "I had to tell them what, well, some of } \\
\text { what I had been doing um and then they } \\
\text { sort of found out what I had been doing } \\
\text { in college, especially via looking at my } \\
\text { grades and that was also distressing. But } \\
\text { yeah just talking to my parents and } \\
\text { having to be honest for like the first time } \\
\text { in my life.” } 11.17\end{array}$ \\
\hline Supports & Loss of Friends & $\begin{array}{l}\text { "My friends back home, [laughs] yeah, } \\
\text { they, none of them are really Christians } \\
\text { so I don't really have that many friends } \\
\text { back home anymore.”15.1 } \\
\text { “... we all just have different } \\
\text { backgrounds which is like, I love them to } \\
\text { death but they don't, yeah they don't get }\end{array}$ \\
\hline
\end{tabular}




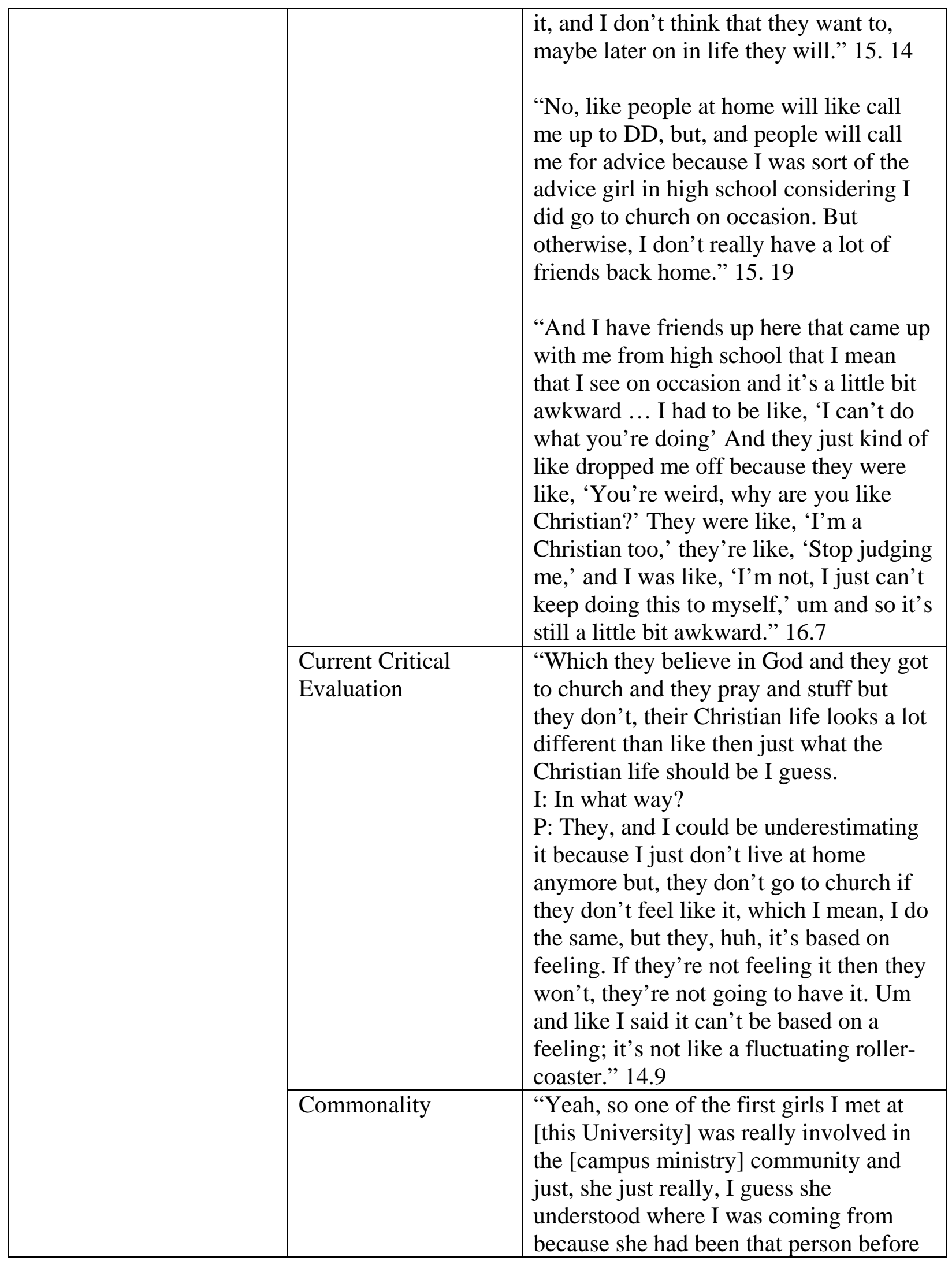




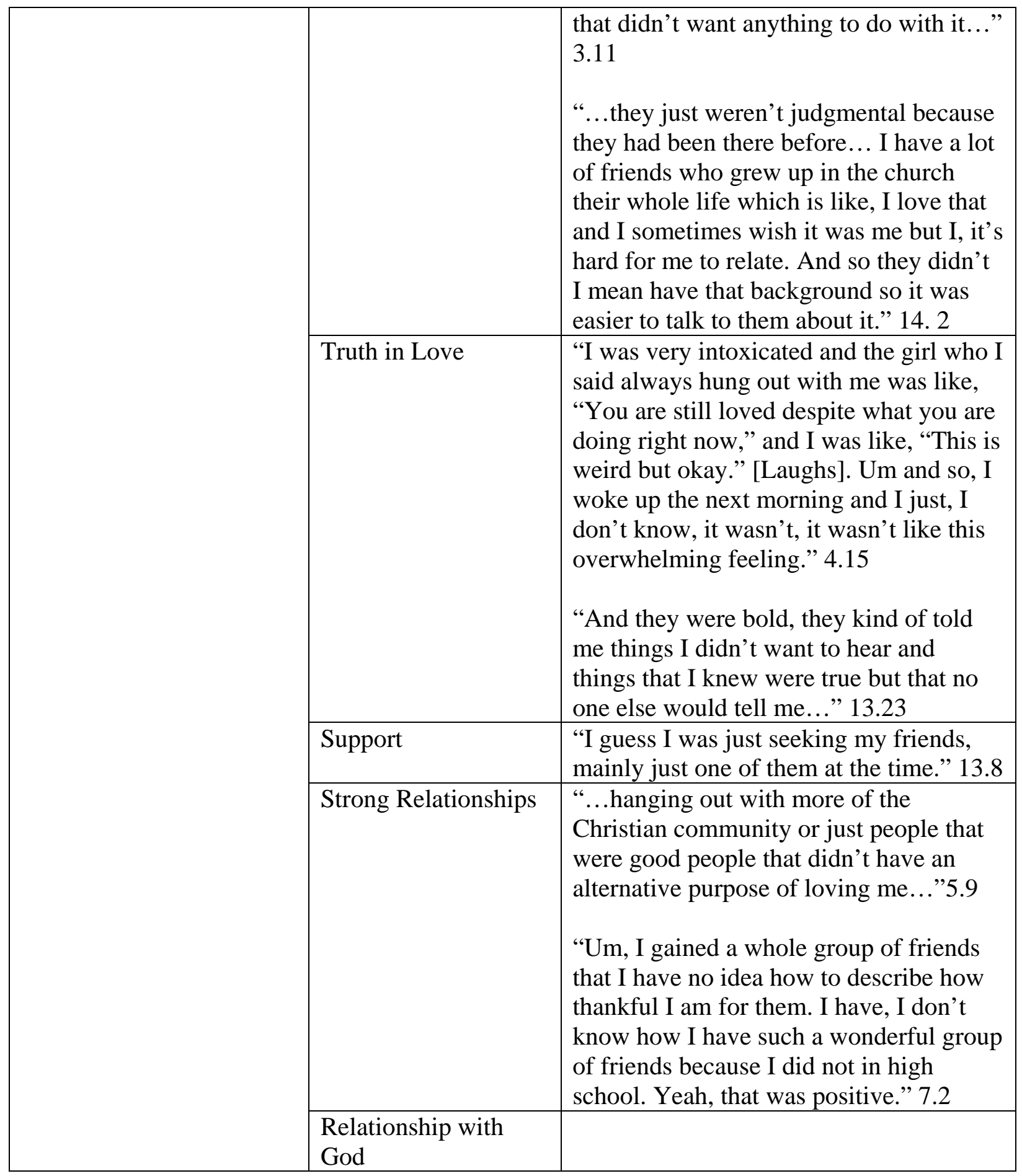




\section{Case 8 Themes Directory}

\begin{tabular}{|c|c|c|}
\hline Superordinate Concepts & Themes & Quotes (with page and line numbers) \\
\hline \multirow[t]{4}{*}{$\begin{array}{l}\text { Previous Exposure to } \\
\text { Religion/Spirituality }\end{array}$} & Family Involvement & $\begin{array}{l}\text { “Okay, I grew up, like my parents raised } \\
\text { me to believe in God but not necessarily } \\
\text { give your life away, complete sacrifice, } \\
\text { and um I just don’t think that's their } \\
\text { relationship with God so they just didn’t } \\
\text { necessarily know to expose me to that.” } \\
2.1 \\
\text { “What was your exposure to religion and } \\
\text { spirituality at that point, if at all? } \\
\text { P: Still just like, like, I don’t know, I } \\
\text { don’t want to say nothing because it } \\
\text { wasn’t nothing, like my mom, we would } \\
\text { pray together at night before bed. But } \\
\text { that's about all.” } 4.12\end{array}$ \\
\hline & Friend Involvement & $\begin{array}{l}\text { "And then one of my friends, decided to } \\
\text { have a small group at her house over the } \\
\text { summer. Like completely random, she } \\
\text { had actually was just a new Christian, so } \\
\text { she was like, "Oh I'll just have small } \\
\text { group at my house, all our friends can } \\
\text { come.” And I just thought it would be a } \\
\text { social event. And it, I, it just changed my } \\
\text { life, I don’t know, I can’t think of a } \\
\text { specific thing that happened.” } 4.20\end{array}$ \\
\hline & $\begin{array}{l}\text { Significant Influential } \\
\text { Persons }\end{array}$ & $\begin{array}{l}\text { "I guess before she went to college, so } \\
\text { like a year before I converted, she } \\
\text { became a Christian, became very, I } \\
\text { guess, active and she decided that if she } \\
\text { was going to be home all summer she } \\
\text { wanted to do something, and so she was } \\
\text { like, “okay I'll have food, I'll have } \\
\text { whatever, like let's just...” and we would } \\
\text { do Bible study every Wednesday...” } 6 . \\
11 \\
\text { "Well [campus minister] at [campus } \\
\text { ministry], she's basically my therapist } \\
\text { slash mother slash sister like. I would sit } \\
\text { in her office for hours.” 20. } 6\end{array}$ \\
\hline & Lack of Exposure & $\begin{array}{l}\text { “...then we moved to [another southern } \\
\text { state] and we had some bad experiences } \\
\text { with churches. Anyway and so we just }\end{array}$ \\
\hline
\end{tabular}




\begin{tabular}{|c|c|c|}
\hline & & $\begin{array}{l}\text { stopped going to church altogether and } \\
\text { so I, my family has not gone to a church } \\
\text { in, since I was 11; so anyway, I guess I } \\
\text { just wasn't, it just wasn’t a big part of } \\
\text { life.” } 2.11\end{array}$ \\
\hline & Negative Experiences & $\begin{array}{l}\text { “...and then we moved to [another } \\
\text { southern state] and we had some bad } \\
\text { experiences with churches.” } 2.11 \\
\text { "So, and then the pastor was caught } \\
\text { watching child pornography on the } \\
\text { church computers and had to leave the } \\
\text { church. And so then we left the church } \\
\text { as well...”3.3 } \\
\text { “...but my parents were trying to go to } \\
\text { small group...So my mom brought her } \\
\text { little pigs in a blanket and was ready to } \\
\text { go to small group and when she got there } \\
\text { it was a like swingers thing were you } \\
\text { dropped your keys in. } \\
\text { I: Oh my. } \\
\text { P: [Laughing] And so my parents just } \\
\text { took their pigs in a blanket and left. So } \\
\text { then, we just stopped going to church.” } \\
\text { 3.6 }\end{array}$ \\
\hline \multirow[t]{3}{*}{ Unique to College } & Independence & \\
\hline & $\begin{array}{l}\text { Parties are } \\
\text { Unsatisfactory }\end{array}$ & \\
\hline & Self-Exploration & $\begin{array}{l}\text { "It's just a time, where you kind of get to } \\
\text { decide what you're going to do with your } \\
\text { life in general like your career but also } \\
\text { like what kind of person you are going to } \\
\text { be and it just all seems to happen in } \\
\text { college I feel like." 23. } 10\end{array}$ \\
\hline \multirow[t]{6}{*}{ Questioning God } & Wrestling with Evil & \\
\hline & Doubting God & \\
\hline & Doubting Allah & \\
\hline & Dismay with Islam & \\
\hline & $\begin{array}{l}\text { Reconciling Science } \\
\text { and Supernatural }\end{array}$ & \\
\hline & Resistant to Convert & $\begin{array}{l}\text { "I was on the treadmill on campus at the } \\
\text { gym and I decided that I was going to, no } \\
\text { really give it all to God, but you know } \\
\text { add a little seasoning to life of God. So, } \\
\text { looking back that's, like I can laugh at }\end{array}$ \\
\hline
\end{tabular}




\begin{tabular}{|c|c|c|}
\hline & & $\begin{array}{l}\text { that, so I decided that I would add a little } \\
\text { God and keep mostly [participant's } \\
\text { name], so.” } 9.12\end{array}$ \\
\hline \multirow{3}{*}{$\begin{array}{l}\text { God is Omnipresent and } \\
\text { Sovereign }\end{array}$} & All Sufficient & \\
\hline & Evidence of God & $\begin{array}{l}\text { “Um, I really, looking back, God was } \\
\text { just coming after me, my whole, I mean } \\
\text { my whole life.” } 4.16 \\
\text { “I know that I had a bad break up at the } \\
\text { end of my of my freshman year in } \\
\text { college. And, I don’t know if it was like, } \\
\text { God was all I had, kind of a thing, it } \\
\text { doesn’t really feel like that’s how it was. } \\
\text { God was just coming after me.” } 4.17 \\
\text { “...I just had a very active prayer life } \\
\text { when I was so young that... And my } \\
\text { parents hadn’t really taught me that so I } \\
\text { really just feel like God drew me to him } \\
\text { my whole life and it, it was really just a } \\
\text { few years ago that I was like, “Okay, I } \\
\text { accept” or whatever.” 5. } 17 \\
\text { “...everyone had such a different, one of } \\
\text { our friends, she now has two children. } \\
\text { She had just given birth to her first child } \\
\text { and she was sixteen. She’d had like I } \\
\text { mean a very hard childhood and she } \\
\text { came to know Christ then. She’s now } \\
\text { married. Anyway, so it, I mean God was } \\
\text { all up in that.” 6. } 21\end{array}$ \\
\hline & $\begin{array}{l}\text { Confidence in God's } \\
\text { Sovereign Plan }\end{array}$ & $\begin{array}{l}\text { “...but I just knew that God was taking } \\
\text { care of her even though I was pretty } \\
\text { apathetic towards God , I was just like, } \\
\text { "Oh, he’s got this” kind of a thing, like } \\
\text { which is weird for someone who isn’t, I } \\
\text { just guess, God gave me peace about it.” } \\
5.10 \\
\text { “Cause like I know, my roommates freak } \\
\text { out about it but like we'll be watching a } \\
\text { movie and they'll be like, “I mean what } \\
\text { do you even do” if there's like a } \\
\text { murderer and I'm like, "I'd just tell them } \\
\text { to take me,” and their like, “you're so } \\
\text { ready to die,” and I'm like, "I kind of }\end{array}$ \\
\hline
\end{tabular}




\begin{tabular}{|c|c|c|}
\hline & & $\begin{array}{l}\text { am,” not like in a morbid way but I just } \\
\text { don't, it doesn't bother me, like I know } \\
\text { where I'm going it's not like a big } \\
\text { deal...” } 16.13 \\
\text { "Like agendas are my best friend and so } \\
\text { that's something I struggle with in } \\
\text { general because God shows me every } \\
\text { day that it's not going to go how I plan , } \\
\text { it's going to go how He plans it which } \\
\text { for that I'm appreciative because my } \\
\text { plans suck.” } 18.4 \\
\text { "I guess it's affected my future plans in } \\
\text { the opposite way; I feel like I'm okay not } \\
\text { having a plan where I am such a } \\
\text { planner.” } 18.10 \\
\text { Well, like I said, I think that God's been } \\
\text { chasing me my whole life, so I think that } \\
\text { this was an inevitable thing to happen...” } \\
22.18\end{array}$ \\
\hline \multirow[t]{2}{*}{$\begin{array}{l}\text { Positive Emotional } \\
\text { Experiences }\end{array}$} & Peak Experiences & $\begin{array}{l}\text { "P: Just like coming to know Christ, } \\
\text { giving my life to Christ. That's just I } \\
\text { mean it's the thing, you know, that's just } \\
\text { it. } \\
\text { I: Yeah. } \\
\text { P: But um, yeah, I mean it's the best } \\
\text { thing that's ever happened to me and I } \\
\text { feel like that's belittling it to even say } \\
\text { that, you know." } 14.6\end{array}$ \\
\hline & Newfound Hope & $\begin{array}{l}\text { “And um I'm a lot more calm I actually } \\
\text { have a severe panic disorder that I'm } \\
\text { medicated for so I'm sure the medication } \\
\text { helps but I'm a lot more calm now. I, I } \\
\text { know where my hope is and that just } \\
\text { makes a person calm, you know.” } 17.6\end{array}$ \\
\hline
\end{tabular}




\begin{tabular}{|c|c|c|}
\hline & Gratitude & $\begin{array}{l}\text { "Yeah, I guess like, now I'm very } \\
\text { grateful for that time in my life.” } 25.1 \\
\text { "But um, I don't know I think I'm more, } \\
\text { I think I'm more thankful than I used to } \\
\text { be...” 24. } 7\end{array}$ \\
\hline & Healing & \\
\hline & Relief & $\begin{array}{l}\text { "I guess like during the time it was like } \\
\text { kind of turmoil but now it’s peaceful." } \\
24.15\end{array}$ \\
\hline & Understanding & $\begin{array}{l}\text { "But um yeah, it's nice to like be able to, } \\
\text { if, if I'm upset about something, it's nice } \\
\text { to able to have a scripture telling me } \\
\text { what to do... I mean it doesn't tell you } \\
\text { like, “Okay, turn right," it doesn't tell } \\
\text { you everything but it tells you, well it } \\
\text { usually just says to put your faith in God } \\
\text { but that works, so, I guess it just tells you } \\
\text { that.” } 17.8\end{array}$ \\
\hline & Happiness & "Um, I'm more joyful..." 24 \\
\hline & Love & $\begin{array}{l}\text { "And I don’t know we just, we just love } \\
\text { each other, and it’s not like, 'Love you } \\
\text { girl, bye.' It’s like we love each other." } \\
13.22\end{array}$ \\
\hline & $\begin{array}{l}\text { Freedom from } \\
\text { Legalism }\end{array}$ & \\
\hline \begin{tabular}{|l} 
Openness \\
\end{tabular} & Open to God & \\
\hline & Open to Others & $\begin{array}{l}\text { "I'm trying to be more gentle and God's } \\
\text { helping me with that. I'm not like a harsh } \\
\text { person but I'm a very straightforward } \\
\text { person and I'd rather be more gentle." } \\
\text { 17. } 18\end{array}$ \\
\hline Existential Meaning & True Identity & $\begin{array}{l}\text { "I: How does your conversion to the } \\
\text { Christian faith affect you today? } \\
\text { P: Um, it, that's kind of a hard question, } \\
\text { it's just who I am now. It just, how does } \\
\text { it affect who I am? I just feel like it is } \\
\text { who I am, I can't really, um, I mean it’s } \\
\text { part of everyday life now.” 23. } 17\end{array}$ \\
\hline & $\begin{array}{l}\text { Life Purpose and } \\
\text { Meaning }\end{array}$ & \\
\hline & Altruistic Plans & $\begin{array}{l}\text { "I do know that I want to get my C’s } \\
\text { which is Certified Clinically Competent } \\
\text { so that I can go and travel and help } \\
\text { people. My dream of all dreams is I } \\
\text { really want to go to a place where, in }\end{array}$ \\
\hline
\end{tabular}




\begin{tabular}{|c|c|c|}
\hline & & $\begin{array}{l}\text { Africa a lot of the places don't have sign } \\
\text { language so the deaf people have no way } \\
\text { to communicate, they won't } \\
\text { communicate their whole lives... } \\
\text { I: Wow. } \\
\text { P: at all. They never can communicate. } \\
\text { So I want to go teach sign language.” } \\
\text { 18.11 }\end{array}$ \\
\hline \multirow{5}{*}{$\begin{array}{l}\text { Challenging Emotional } \\
\text { Experiences- Prior to } \\
\text { Converting }\end{array}$} & Abandonment & \\
\hline & Hardship & $\begin{array}{l}\text { And uh, okay, okay this is probably } \\
\text { significant, my mom has had cancer } \\
\text { twice and almost died.... but I just knew } \\
\text { that God was taking care of her even } \\
\text { though I was pretty apathetic towards } \\
\text { God, I was just like, “Oh, he’s got this” } \\
\text { kind of a thing, like which is weird for } \\
\text { someone who isn’t, I just guess, God } \\
\text { gave me peace about it. } 5.8\end{array}$ \\
\hline & & $\begin{array}{l}\text { “Okay, well, my freshman year was, I } \\
\text { would say, the darkest point in my life. I } \\
\text { was like partying a lot and I don't know I } \\
\text { was very on and off with the boyfriend } \\
\text { that I had had all through high school.” } \\
9.1\end{array}$ \\
\hline & & $\begin{array}{l}\text { “Oh yeah so I would say I was probably } \\
\text { like the most broken, I've ever been, I } \\
\text { was just very low. And, I had surrounded } \\
\text { myself with people who were also very } \\
\text { broken. And went home that summer and } \\
\text { I, I needed Jesus and he found me so.” } \\
\text { 9.17 }\end{array}$ \\
\hline & Confusion & $\begin{array}{l}\text { "I, like thinking about it like this seems } \\
\text { confusing, but when it was happening I } \\
\text { never identified it as being confusing. } \\
\text { But now it seems like I was being pulled } \\
\text { in all these different directions, but I } \\
\text { don't think I thought of it that way when } \\
\text { it was happening. But now, it seems } \\
\text { confusing.” } 24.12 \\
\text { "But I think that while it was happening } \\
\text { it was probably, I mean confusing } \\
\text { because it’s not what I knew, it was like } \\
\text { unknown territory and I was also }\end{array}$ \\
\hline
\end{tabular}




\begin{tabular}{|c|c|c|}
\hline & & $\begin{array}{l}\text { changing so much, I was, I mean, just so } \\
\text { many things about me were changing...” } \\
25.2\end{array}$ \\
\hline \multirow{5}{*}{$\begin{array}{l}\text { Challenging Emotional } \\
\text { Experiences -After } \\
\text { Converting }\end{array}$} & Spiritual Warfare & \\
\hline & Discord with Others & $\begin{array}{l}\text { "But in the middle of the store, which she } \\
\text { says I yelled, I would beg to differ, but I } \\
\text { said, "What are you doing to grow } \\
\text { toward God?" So I pretty much called } \\
\text { her out in the middle of the store which I } \\
\text { shouldn't have done; However, I'd been } \\
\text { a Christian for a whole month and I } \\
\text { didn't know." } 15.19\end{array}$ \\
\hline & & $\begin{array}{l}\text { "And I never fight with my mom and so } \\
\text { that has been and a few other times she } \\
\text { be like, "I think you're being } \\
\text { judgmental”... I would never mean to } \\
\text { come off that way. But she has thought } \\
\text { that a few times and it really hurts my } \\
\text { feelings when she thinks that way so we } \\
\text { fought multiple times about I guess } \\
\text { multiple times about my attitude toward } \\
\text { Christianity so that's hard.”16.6 }\end{array}$ \\
\hline & Ongoing Hardship & \\
\hline & Guilt and Shame & $\begin{array}{l}\text { “...one time she was arguing with me } \\
\text { and she said, 'You're the worst Christian } \\
\text { I've ever met.' And it was kind of like } \\
\text { that moment that my friend had in } \\
\text { English class where, and I was like, 'Oh } \\
\text { my gosh, this is awful, I need to do } \\
\text { something.” } 9.9\end{array}$ \\
\hline Supports & Loss of Friends & $\begin{array}{l}\text { I lost all my, I mean not all my friends; I } \\
\text { have one friend from freshman year that } \\
\text { is still friends with me... But anyway, } \\
\text { they all thought I was trying to be holy } \\
\text { then thou. And so I lost most of my } \\
\text { friends. It was really hard, I actually } \\
\text { looked into transferring schools cause I } \\
\text { thought I couldn't find Christians up here } \\
\text { and I needed someone to relate to. 9. } 22 \\
\text { "It was just like, I guess it, I felt more } \\
\text { distant from her because of that, where } \\
\text { like we bonded over drinking before, } \\
\text { [laughing] a strong connection. Anyway, }\end{array}$ \\
\hline
\end{tabular}




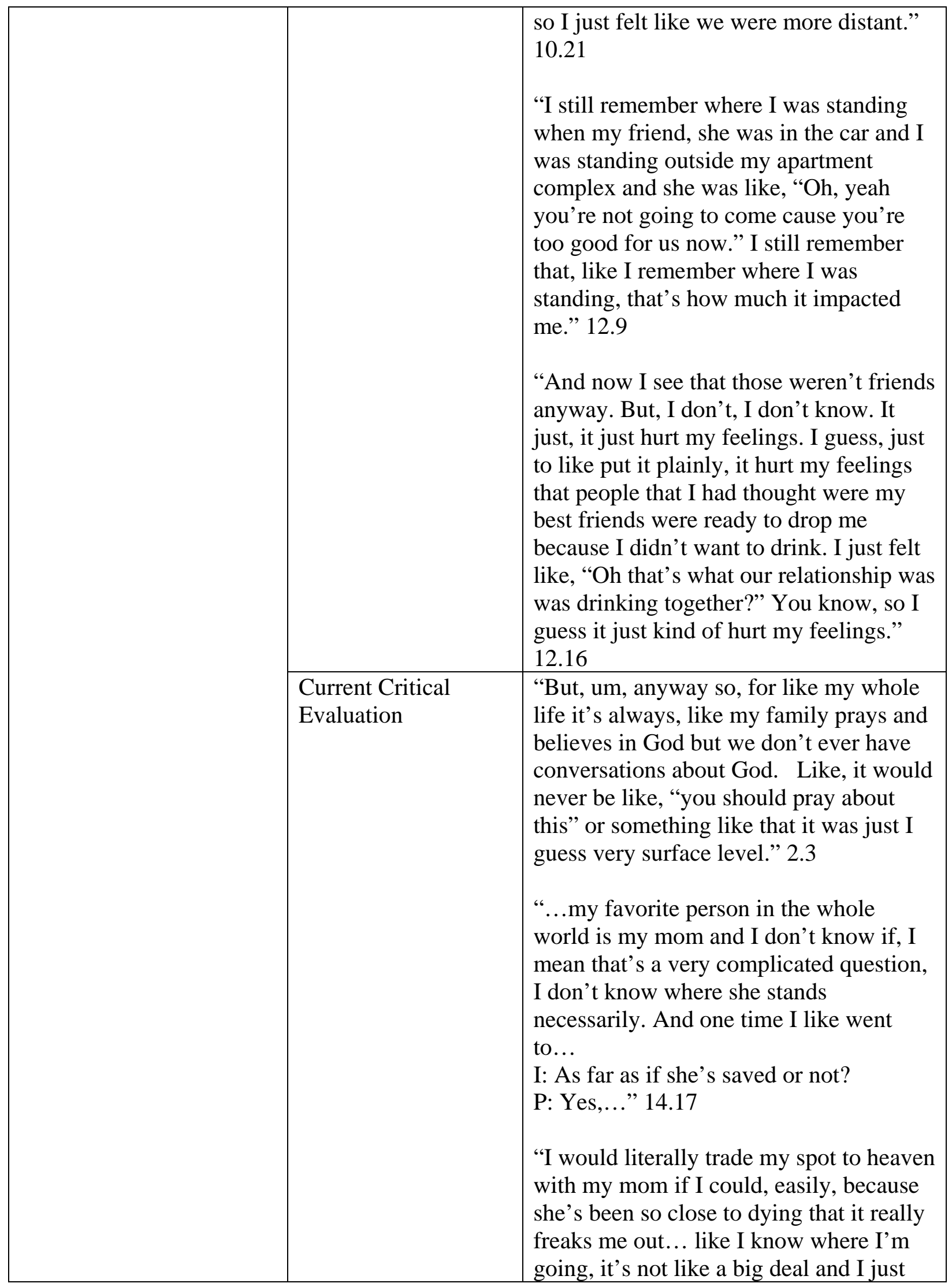




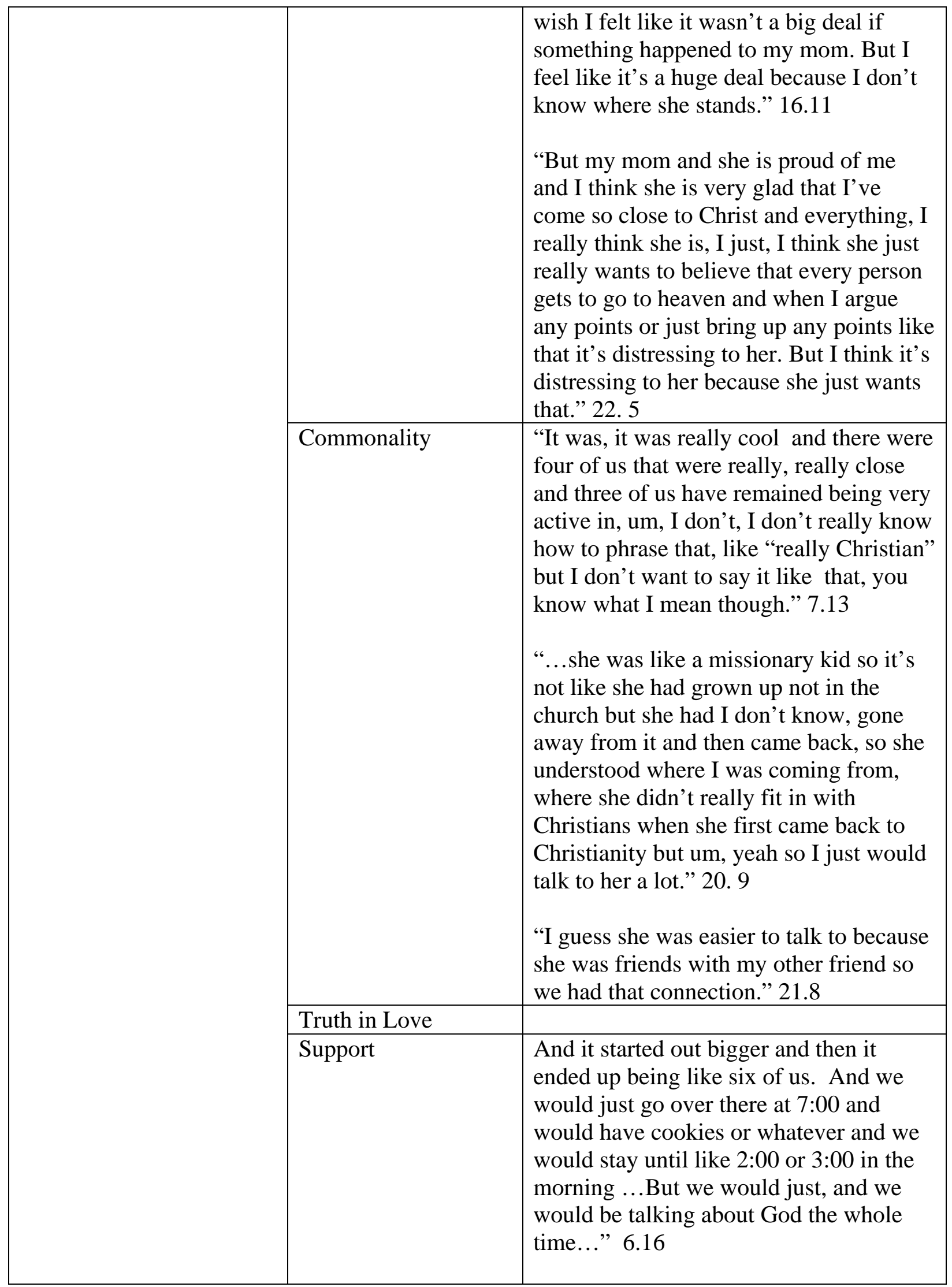




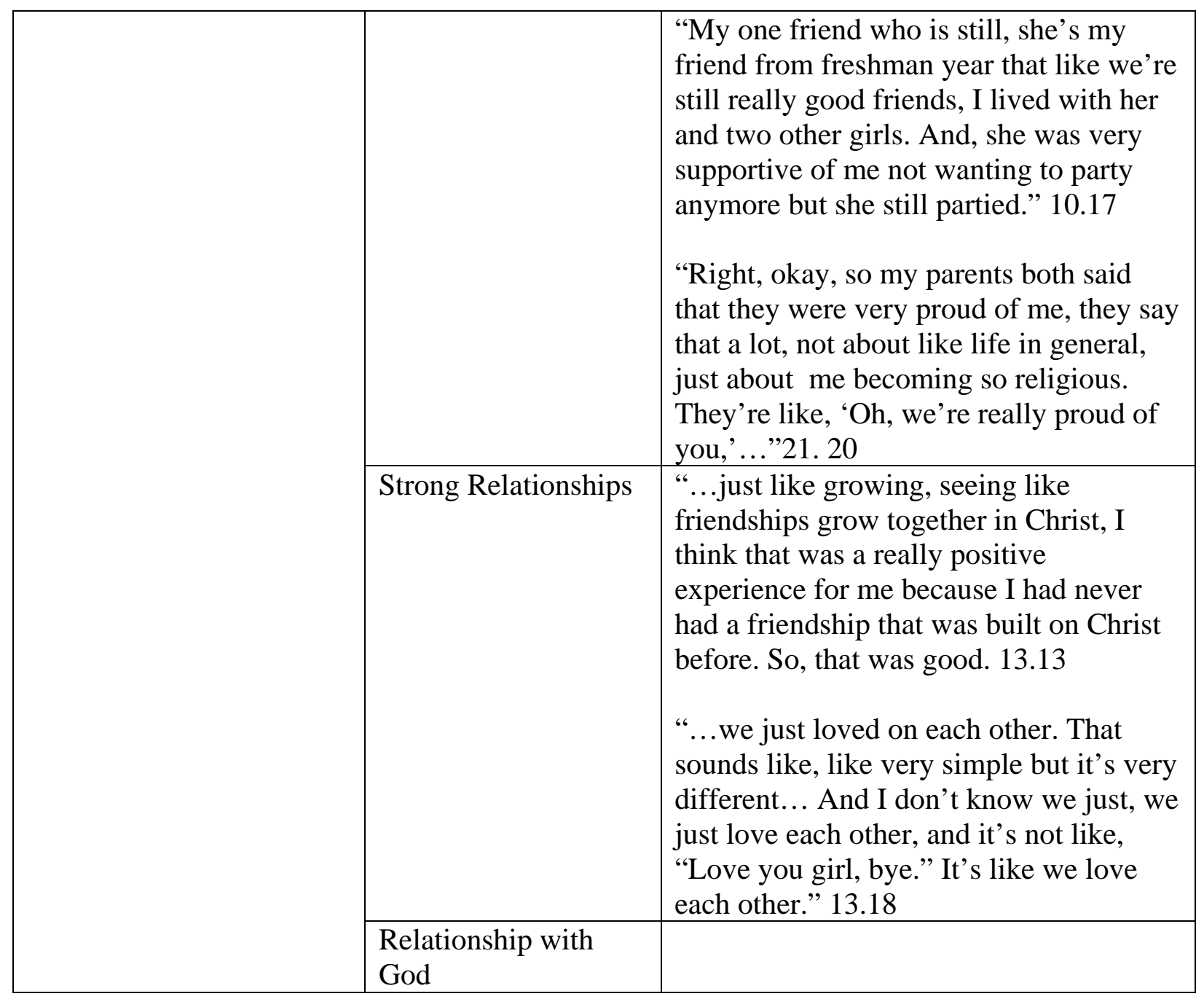




\section{Case 9 Themes Directory}

\begin{tabular}{|c|c|c|}
\hline Superordinate Concepts & Themes & Quotes (with page and line numbers) \\
\hline \multirow[t]{5}{*}{$\begin{array}{l}\text { Previous Exposure to } \\
\text { Religion/Spirituality }\end{array}$} & Family Involvement & $\begin{array}{l}\text { "Uh, when I grew up my parents } \\
\text { identified as Christian, and I grew up } \\
\text { until I was } 11 \text { going to church.” } 1.16 \\
\text { “...my parents stopped going to church. } \\
\text { They only went during holidays so it } \\
\text { wasn't really a big part of my life } \\
\text { anymore.” } 1.20\end{array}$ \\
\hline & Friend Involvement & \\
\hline & $\begin{array}{l}\text { Significant Influential } \\
\text { Persons }\end{array}$ & $\begin{array}{l}\text { "I: Yeah, okay. So, what do you think } \\
\text { was the catalyst for your conversion to } \\
\text { the Christian faith? } \\
\text { P: I'd have to say it would be my fiancé.” } \\
2.21 \\
\text { "And so the next year he, and I don't } \\
\text { even know how to explain how he did it, } \\
\text { but it was like him and his family, just } \\
\text { showed me God's love in the most } \\
\text { amazing way.” } 3.3 \\
\text { "I think that's how God used my fiancé } \\
\text { first because He overcame those walls } \\
\text { with him so that He could be let in...” } \\
10.17\end{array}$ \\
\hline & Lack of Exposure & $\begin{array}{l}\text { "So I always grew with an excitement } \\
\text { and an excitement to talk about God but I } \\
\text { guess I got, it just kind of died off when } \\
\text { we stopped going to church." } 2.7\end{array}$ \\
\hline & Negative Experiences & $\begin{array}{l}\text { "And then when I went to youth groups, } \\
\text { it seemed like a lot of people would just } \\
\text { pick and choose who they hung out with } \\
\text { and wouldn’t really care about anyone } \\
\text { else or they’d gossip. So, I had a } \\
\text { hypocrite, I had a hypocritical and } \\
\text { skeptical view of the church.” } 3.19\end{array}$ \\
\hline Unique to College & Independence & $\begin{array}{l}\text { “...even though they (her parents) were } \\
30 \text { minutes away was like I was on my } \\
\text { own, I had to make my own decisions, I } \\
\text { chose when to eat, I chose when to sleep } \\
\text { like all that and I had to work hard for } \\
\text { everything.” } 20.17\end{array}$ \\
\hline
\end{tabular}




\begin{tabular}{|c|c|c|}
\hline & & $\begin{array}{l}\text { "I think it was a time to where I could } \\
\text { say I could think for myself to where I } \\
\text { wasn't around my parents all the time..." } \\
20.11\end{array}$ \\
\hline & $\begin{array}{l}\text { Parties are } \\
\text { Unsatisfactory }\end{array}$ & \\
\hline & Self-Exploration & $\begin{array}{l}\text { "And it was just a time for me to actually } \\
\text { explore God on my own time and I had } \\
\text { to make my own schedule and explore } \\
\text { who I was and I ended up finding it. And } \\
\text { so I think college offered the freedom I } \\
\text { needed to be freed in a way.” } 21.1\end{array}$ \\
\hline \multirow[t]{6}{*}{ Questioning God } & Wrestling with Evil & \\
\hline & Doubting God & $\begin{array}{l}\text { "And they kind of all just built on top of } \\
\text { each other until I kind of declared in my } \\
\text { own mind that there was no god.” } 2.14 \\
\text { "I just was mad because I’d pray and I } \\
\text { felt like my prayers weren’t answered } \\
\text { and that if there was anyone that he } \\
\text { would have cared about me and it } \\
\text { seemed like every time I prayed things } \\
\text { just got worse. So, I just kind of decided } \\
\text { to figure it out on my own.” 2.18 } \\
\text { “...I guess you could say that I viewed } \\
\text { God in a very negative light for a lot, } \\
\text { before I became a Christian...” 9.23 } \\
\text { "Um but there was just a lot of factors } \\
\text { that cause that anger and I was like } \\
\text { blaming God for like all of it, which } \\
\text { caused even more anger because I } \\
\text { thought He should have done } \\
\text { something.” } 13.14\end{array}$ \\
\hline & Doubting Allah & \\
\hline & Dismay with Islam & \\
\hline & $\begin{array}{l}\text { Reconciling Science } \\
\text { and Supernatural }\end{array}$ & \\
\hline & Resistant to Convert & \\
\hline $\begin{array}{l}\text { God is Omnipresent and } \\
\text { Sovereign }\end{array}$ & All Sufficient & $\begin{array}{l}\text { "I felt like anything could come my way, } \\
\text { even if I had a bad day, or like the world } \\
\text { um came crumbling and I didn't know } \\
\text { what to do like God would have my } \\
\text { back." } 14.8\end{array}$ \\
\hline
\end{tabular}




\begin{tabular}{|c|c|c|}
\hline & Evidence of God & $\begin{array}{l}\text { "Um, and she just mocked me for that } \\
\text { and I just had a problem....and so I left } \\
\text { that situation. And I got told that there } \\
\text { was no way I was going to get another } \\
\text { room at all... Well, they found out that } \\
\text { day that there was one room left in the } \\
\text { entire building that had only one bed } \\
\text { because the person never showed up and } \\
\text { then I went there. The roommate I got } \\
\text { ended up being, becoming my friend and } \\
\text { she was a really like strong Christian and } \\
\text { everything and found, I'm like there's no } \\
\text { way God's hand was not in that.” } 17.4 \\
\text { “...but I can only see God's hand in it } \\
\text { and so even at the moments I would say I } \\
\text { was at my lowest, absolute lowest, and } \\
\text { darkest moments in my life I can see how } \\
\text { God was present. And I think that gives } \\
\text { me joy and peace to know that even if } \\
\text { like right now for example if I was in a } \\
\text { really dark place even if I don't see or } \\
\text { hear or feel God's presence, I know he is } \\
\text { there and I know He’s orchestrating } \\
\text { something for His good and I just want to } \\
\text { be used to expand His kingdom in } \\
\text { whatever way possible.” } 22.13\end{array}$ \\
\hline & $\begin{array}{l}\text { Confidence in God's } \\
\text { Sovereign Plan }\end{array}$ & $\begin{array}{l}\text { "He’s, it’s kind of been, that's been an } \\
\text { even slower process, cause it's been over } \\
\text { the past, I would say two years that He’s } \\
\text { been shaping, and he's going to be } \\
\text { shaping it [her calling and future plans] } \\
\text { for the rest of my life for my future.” } \\
15.12 \\
\text { "I feel like he changed my perspective on } \\
\text { my future because he gave me hope in it. } \\
\text { And even if I didn't know what I was } \\
\text { doing, I knew that he was in control, } \\
\text { that's all I needed to know." } 15.15\end{array}$ \\
\hline $\begin{array}{l}\text { Positive Emotional } \\
\text { Experiences }\end{array}$ & Peak Experiences & $\begin{array}{l}\text { "Um, but one day I was just having a bad } \\
\text { day and I remember sitting at my desk, } \\
\text { nothing really special, and it's like the } \\
\text { sun came through my window and hit my } \\
\text { desk and then I had this overwhelming }\end{array}$ \\
\hline
\end{tabular}




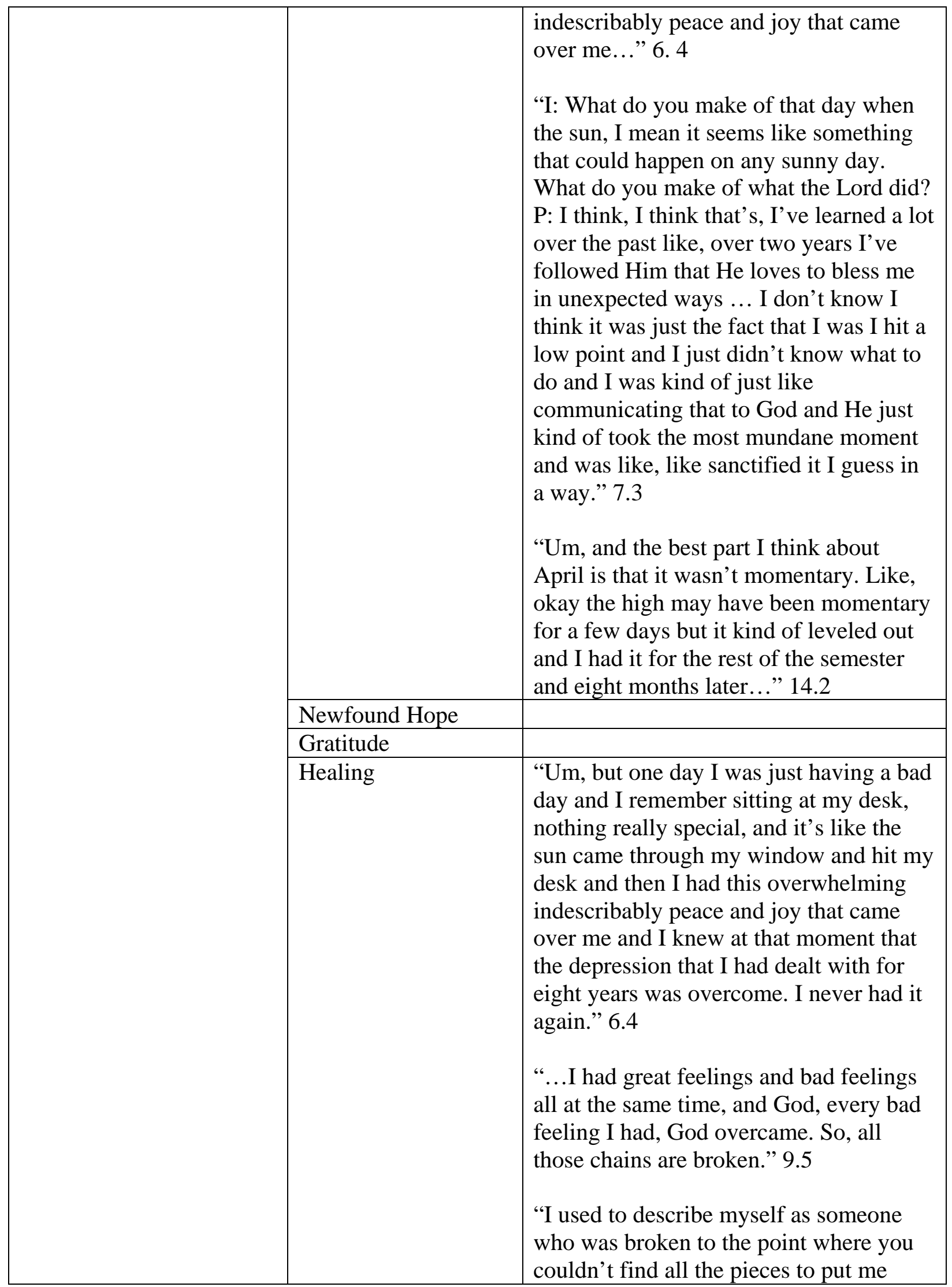




\begin{tabular}{|c|c|c|}
\hline & & $\begin{array}{l}\text { back together and he says that only God } \\
\text { could and when God does he doesn't put } \\
\text { you back together the way you were first } \\
\text { formed he puts you together the way he } \\
\text { sees you into a beautiful mosaic...” } \\
11.18\end{array}$ \\
\hline & Relief & \\
\hline & Understanding & $\begin{array}{l}\text { "So I can find comfort in knowing that } \\
\text { He’s present even if I don’t in my senses } \\
\text { recognize that He’s there.” } 22.18\end{array}$ \\
\hline & Happiness & $\begin{array}{l}\text { “...I can’t put into words the joy I had in } \\
\text { April, it’s just like this indescribable } \\
\text { overflow to where you just want to give } \\
\text { it to everybody, you can’t shut up about } \\
\text { God...” 9.3 } \\
\text { “I: Okay. And how did you feel } \\
\text { discussing these topics today? } \\
\text { P: Joyful, I love talking about God and } \\
\text { what He’s done.” } 23.2 \\
\text { “...some days I’m just naturally happy } \\
\text { and joy, joyful about God, but I would } \\
\text { say like, it’s like taking a pitcher of water } \\
\text { and an empty glass and just dumping the } \\
\text { whole thing at once not slowly filling it } \\
\text { up and it just overflows everywhere.” } \\
9.12\end{array}$ \\
\hline & Love & $\begin{array}{l}\text { "I think as soon as you have a } \\
\text { perspective that He is love, everything } \\
\text { changes. So I think that's like the } \\
\text { underlying foundation for every small } \\
\text { and big moment that was positive." } 10.2\end{array}$ \\
\hline & $\begin{array}{l}\text { Freedom from } \\
\text { Legalism }\end{array}$ & \\
\hline Openness & Open to God & $\begin{array}{l}\text { "I was going to get to know God for } \\
\text { myself cause I'm not going to listen to } \\
\text { really right now what anyone else has to } \\
\text { say about God, I need to know who this } \\
\text { God is, on a personal level, through His } \\
\text { word." } 5.1 \\
\text { "Um, I would say overcoming my own } \\
\text { walls I had against others and against, } \\
\text { even like my walls against God, and let, } \\
\text { against letting people in. Um, so I think }\end{array}$ \\
\hline
\end{tabular}




\begin{tabular}{|c|c|c|}
\hline & & $\begin{array}{l}\text { that's how God used my fiancé first } \\
\text { because He overcame those walls with } \\
\text { him so that He could be let in...” } 10.15\end{array}$ \\
\hline & Open to Others & $\begin{array}{l}\text { "Um, I would say overcoming my own } \\
\text { walls I had against others and against, } \\
\text { even like my walls against God, and let, } \\
\text { against letting people in. Um, so I think } \\
\text { that's how God used my fiancé first } \\
\text { because He overcame those walls with } \\
\text { him so that He could be let in...”10.15 }\end{array}$ \\
\hline \multirow[t]{3}{*}{ Existential Meaning } & True Identity & $\begin{array}{l}\text { "He was like changing my perspective on } \\
\text { my identity before He changed my } \\
\text { perspective on my future because I don't } \\
\text { think anyone's ready for the calling God } \\
\text { has for them until they know who they } \\
\text { are in Christ." } 15.6\end{array}$ \\
\hline & $\begin{array}{l}\text { Life Purpose and } \\
\text { Meaning }\end{array}$ & \\
\hline & Altruistic Plans & \\
\hline \multirow{2}{*}{$\begin{array}{l}\text { Challenging Emotional } \\
\text { Experiences- Prior to } \\
\text { Converting }\end{array}$} & Abandonment & \\
\hline & Hardship & $\begin{array}{l}\text { "I: Yeah you said you I think you used } \\
\text { the word drifted or you grew away from } \\
\text { it. What do you think, what do you } \\
\text { attribute to that? } \\
\text { P: Um, well, my dad lost his job when I } \\
\text { started high school um for nearly four } \\
\text { years. So my entire high school } \\
\text { experience and so there was a lot of } \\
\text { financial and family hardship and I had } \\
\text { just, I was bullied in high school, and } \\
\text { there was just a lot, I had a lot of bad } \\
\text { experiences with some people and } \\
\text { friends betrayed me and I was in a } \\
\text { relationship that wasn’t really healthy." } \\
\text { 2.9 } \\
\text { "I also dealt with depression so at that } \\
\text { same time like everything was building } \\
\text { on time of it so I as getting to a climax in } \\
\text { my depression and a climax in my peak } \\
\text { of interest in God... } \\
\text { I: Yeah. } \\
\text { P: ... so when I finally had enough of } \\
\text { things that's when everything kind of } \\
\text { came together.” } 3.7\end{array}$ \\
\hline
\end{tabular}




\begin{tabular}{|c|c|c|}
\hline & & $\begin{array}{l}\text { "I was highly stressed cause since } 16 \text { I } \\
\text { was going on the premed path and it was } \\
\text { like half way through my first year in } \\
\text { college and I just felt miserable I felt like } \\
\text { that's not where I'm supposed to go but I } \\
\text { didn’t know for sure. So, I about had } \\
\text { enough of not knowing answers and } \\
\text { feeling bad about myself and my } \\
\text { situation...” } 4.19 \\
\text { “...I used to be suicidal and um I hated } \\
\text { everyone and everything, I was really } \\
\text { bad, like I would say I was a very angry } \\
\text { person and I was angry at God } \\
\text { originally...” } 7.23 \\
\text { “...then my uncle died and this was a } \\
\text { few months before I became a Christian } \\
\text { and I was really close to him and so me } \\
\text { trying to be really strong for my mother } \\
\text { because that was her brother um was } \\
\text { really hard, and that kind of plummeted } \\
\text { everything that happened and so that } \\
\text { would be an underlying cause why I was } \\
\text { at a peak of depression in January.” } 8.18 \\
\text { "Well a lot of those walls were caused } \\
\text { because I was bullied or um some family } \\
\text { stuff so I was just, I used to be this really } \\
\text { outgoing person and then I became } \\
\text { introverted and didn’t want to talk to } \\
\text { anybody, I was afraid they would judge } \\
\text { me for everything.” } 11.15\end{array}$ \\
\hline & Confusion & \\
\hline \multirow[t]{2}{*}{$\begin{array}{l}\text { Challenging Emotional } \\
\text { Experiences -After } \\
\text { Converting }\end{array}$} & Spiritual Warfare & $\begin{array}{l}\text { "Like I'd hit a high and then I'd hit a } \\
\text { really low point um so I think it was just } \\
\text { hard because the enemy had it out for me } \\
\text { in a way. Um, I'm talking about the } \\
\text { spiritual enemy." } 10.22\end{array}$ \\
\hline & Discord with Others & $\begin{array}{l}\text { "Um, but my parents did not react well. } \\
\text { Like you would think they would } \\
\text { because they identify as Christians but } \\
\text { they viewed how I was following God } \\
\text { and how passionate I was, and how } \\
\text { passionate I was in following the law and } \\
\text { everything and they called me a zealot... }\end{array}$ \\
\hline
\end{tabular}




\begin{tabular}{|c|c|c|}
\hline & & $\begin{array}{l}\text { I: Wow. } \\
\text { P: ... in terms, so. I mean Jesus said you } \\
\text { will be rejected by your own family..." } \\
19.8 \\
\text { "Um, they did like, they didn't like it to } \\
\text { the point they almost cut me off because } \\
\text { I wanted to go into youth ministry and } \\
\text { they thought that that was the worst } \\
\text { decision and they weren’t really } \\
\text { supportive.” } 19.15 \\
\text { “...but my parents and I had a lot tension } \\
\text { because how I viewed God was not how } \\
\text { they viewed God...my dad was shocked } \\
\text { that I said that if God called me to it I'd } \\
\text { be willing to die for my faith because He } \\
\text { is more important, they just don’t } \\
\text { understand it.” } 19.20\end{array}$ \\
\hline & Ongoing Hardship & $\begin{array}{l}\text { “And but I can’t remember the day, um, } \\
\text { and then in April it's kind of like, I still } \\
\text { sort of dealt with depression it not like it } \\
\text { went away as soon as I slammed down } \\
\text { the Bible everything changed.” } 5.22 \\
\text { “...I still dealt with them and even now } \\
\text { I'll deal with insecurities just not that } \\
\text { awful anymore.” 9. } 1 \\
\text { "But, it was really hard to overcome } \\
\text { some of the experiences like I had had } \\
\text { previously and the thoughts that were } \\
\text { tied to those things, like they always } \\
\text { would knock me down. Like I’d hit a } \\
\text { high and then I'd hit a really low } \\
\text { point...” } 10.20\end{array}$ \\
\hline & Guilt and Shame & \\
\hline Supports & Loss of Friends & $\begin{array}{l}\text { “...of course the ones I knew that were } \\
\text { not Christians obviously given, not very } \\
\text { happy. } \\
\text { I: Okay. } \\
\text { P: They didn't like explicitly express it } \\
\text { but like a lot of them, I lost a lot of } \\
\text { friends... } \\
\text { I: Okay. }\end{array}$ \\
\hline
\end{tabular}




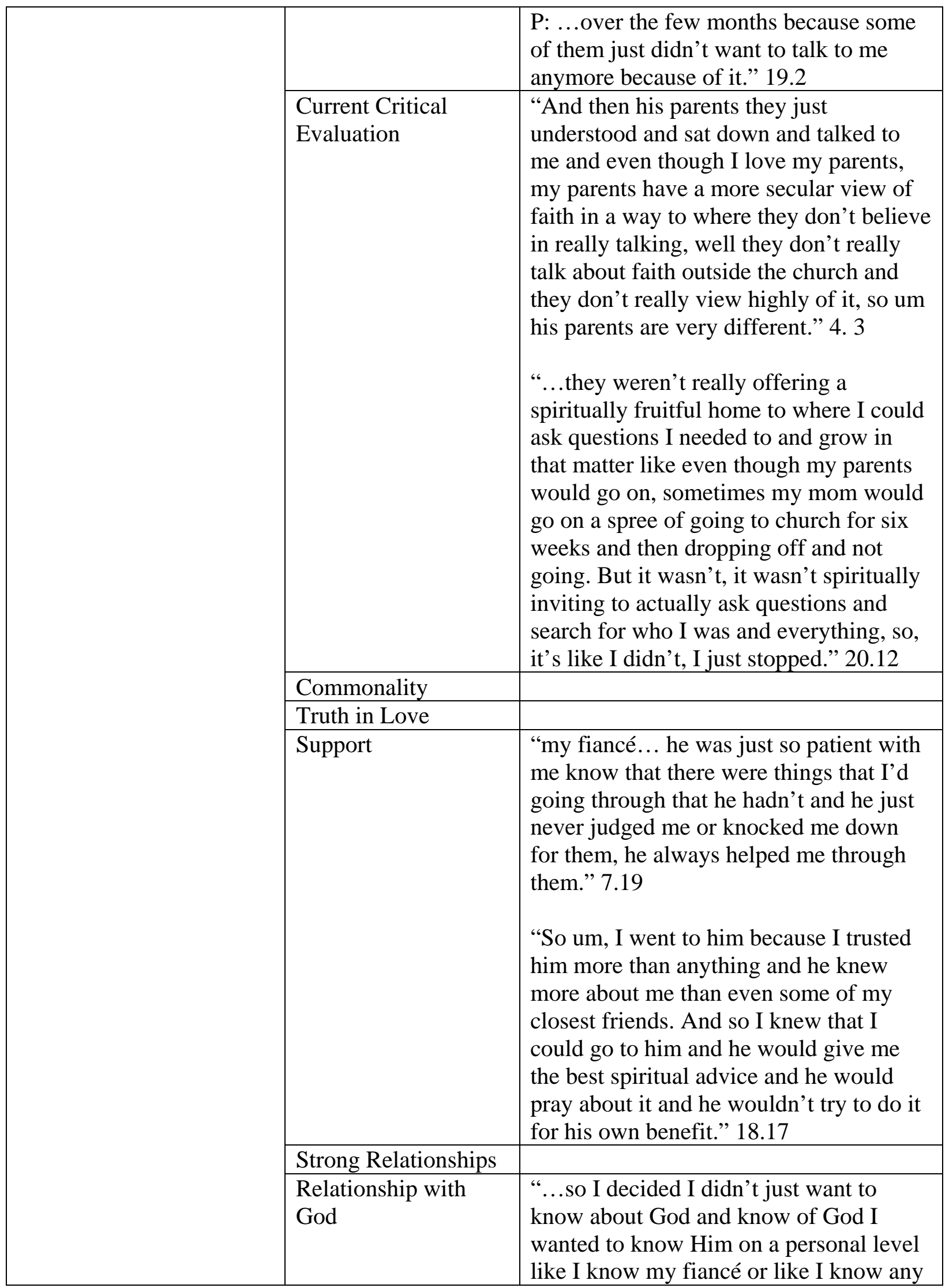




\begin{tabular}{|l|l|}
\hline \multirow{1}{|l|}{} & $\begin{array}{l}\text { of my best friends. And like even now I } \\
\text { could say I probably I know Him a lot } \\
\text { better than I did then but I still don't } \\
\text { know him enough so, I think it's just, I } \\
\text { decided I was going to get to know Him } \\
\text { as a relationship...” 5.13 }\end{array}$ \\
$\begin{array}{l}\text { "Um like I think it did emotionally from } \\
\text { the standpoint of um my perspective on, } \\
\text { "I'm going to pursue Him as a } \\
\text { relationship" versus as someone } \\
\text { watching over you kind of thing." } 12.9\end{array}$ \\
\hline
\end{tabular}

